\author{
Mon og r a p h \\ urn:1sid:zoobank.org:pub:7BA0D937-437E-4252-8EF4-4F35E6B59445
}

\title{
A revision of the genus Mesoconius Enderlein (Diptera, Micropezidae, Taeniapterinae)
}

\author{
Stephen A. MARSHALL \\ School of Environmental Sciences, University of Guelph, Guelph, Ontario, N1G 2W1 Canada. \\ E-mail: samarsha@uoguelph.ca
}

urn:1sid:zoobank.org:author:0BBC95DD-0E89-49DC-80BE-E40261E9F5FE

\begin{abstract}
The Neotropical genus Mesoconius Enderlein, 1922 is revised with the redescription or diagnosis of 20 previously described South American species, the description of one new species of the $M$. infestus group (M. triunfo sp. nov.) from Mexico and the description of 32 new species in four species groups from Andean South America (M. eques group: M. albiseta sp. nov., M. albitergum sp. nov., M. anchitarsus sp. nov., M. cosanga sp. nov., M. epandribarba sp. nov., M. hirsutimamma sp. nov., M. nigripleuron sp. nov., M. noteques sp. nov., M. pasachoa sp. nov., M. rufipleuron sp. nov. and M. suzukii sp. nov.; $M$. infestus group: $M$. acca sp. nov., M. albipedis sp. nov., M. nigricephala sp. nov. and $M$. notacca sp. nov.; M. nono group: M. aurantium sp. nov., M. bipleuron sp. nov., M. garyi sp. nov., M. nono sp. nov., M. reinai sp. nov., M. uchumachi sp. nov., M. woytkowskii sp. nov. and M. zorro sp. nov.; M. oblitus group: M. apa sp. nov., M. apicalis sp. nov., M. gelbifacies sp. nov., M. keili sp. nov., M. lobopoda sp. nov., M. nigra sp. nov., M. quadritheca sp. nov., M. rex sp. nov. and M. ruficrus sp. nov.). Calobata eques Schiner, 1868 is transferred from Cliobata Enderlein, 1923 to Mesoconius and all South American species previously treated as Zelatractodes Enderlein, 1922 are transferred to Mesoconius. Mesoconius aeripennis Enderlein, 1922 is synonymized with M. eques, M. enderleini Frey, 1927 is synonymized with M. infestus Enderlein, 1922 and Aristobata melini Frey, 1927 is synonymized with M. filipes (Enderlein, 1922). Mesoconius garleppi (Enderlein, 1922) is newly recognized as a subjective junior homonym and given the replacement name Mesoconius ottoi nom. nov. A maximum likelihood tree is provided for 29 species of Mesoconius sequenced for the barcode region of $\mathrm{CO} 1$ and a key is provided for all South American species of Mesoconius.
\end{abstract}

Keywords. South America, Mexico, Andes, cloud forest, Zelatractodes.

Marshall S.A. 2019. A revision of the genus Mesoconius Enderlein (Diptera, Micropezidae, Taeniapterinae). European Journal of Taxonomy 548: 1-126. https://doi.org/10.5852/ejt.2019.548

\section{Introduction}

The 60 species in the Neotropical genus Mesoconius Enderlein, 1922 form a distinctive clade of relatively large (usually 16-20 mm long) micropezids characterized by the absence of a genital fork, which is otherwise a prominent feature of sternite 5 in all New World taeniapterine males. Approximately half the species in the genus also have a strongly swollen, apically pointed or nipple-like katatergite. 
Species of Mesoconius that lack the conspicuously swollen katatergite have in the past been treated as Zelatractodes Enderlein, 1922, a paraphyletic group synonymized with Mesoconius by Marshall (2015). Almost all species of Mesoconius are characteristic of higher elevation Neotropical forests and several of them seem to have highly restricted ranges that reflect the fragmented nature of Neotropical alpine habitats. Most species of Mesoconius are rare in collections and many are currently known from only one or a few specimens, although some appear to be locally abundant. The six Central American species of Mesoconius were revised by Marshall (2015). The South American species are revised here, and a new species is added from Mexico. No species of Mesoconius are known from both South and Central America; however, the two well-defined species groups (M. infestus and M. eques groups) recognized in the South American fauna are also found in Central America. The Mexican species and most Central American species belong to the M. infestus group.

Most species of Mesoconius occur in Andean South America, from Bolivia to Venezuela, where they are characteristic of high elevation cloud forests and elfin forests. Relatively few specimens have been collected below $1000 \mathrm{~m}$ and several Andean species are known only from 2500-3000 m. Most of the specimens used in this study were collected on small dung baits or taken in Malaise traps. Larvae and larval habitats remain unknown for the genus. Many species of Mesoconius are remarkable mimics of sympatric ichneumonid wasps, often with elaborate and bright colours almost exactly matching apparent models. This apparent mimicry extends to structural characters such as the petiolate abdomen, antenna-like fore legs and even the prominent katatergite that closely matches a similar structure on sympatric ichneumonid wasps (Marshall 2015). The closest relatives to Mesoconius are probably within the large paraphyletic group currently treated as Calosphen Hennig, 1935, but the generic classification of Taenipterinae Cresson, 1930 is presently unstable and the great majority of related species remain undescribed. Mesoconius is one of the few easily diagnosable and adequately defined genera in the subfamily.

\section{Material and methods}

Approximately 400 specimens were examined, either borrowed from or deposited in the following collections:

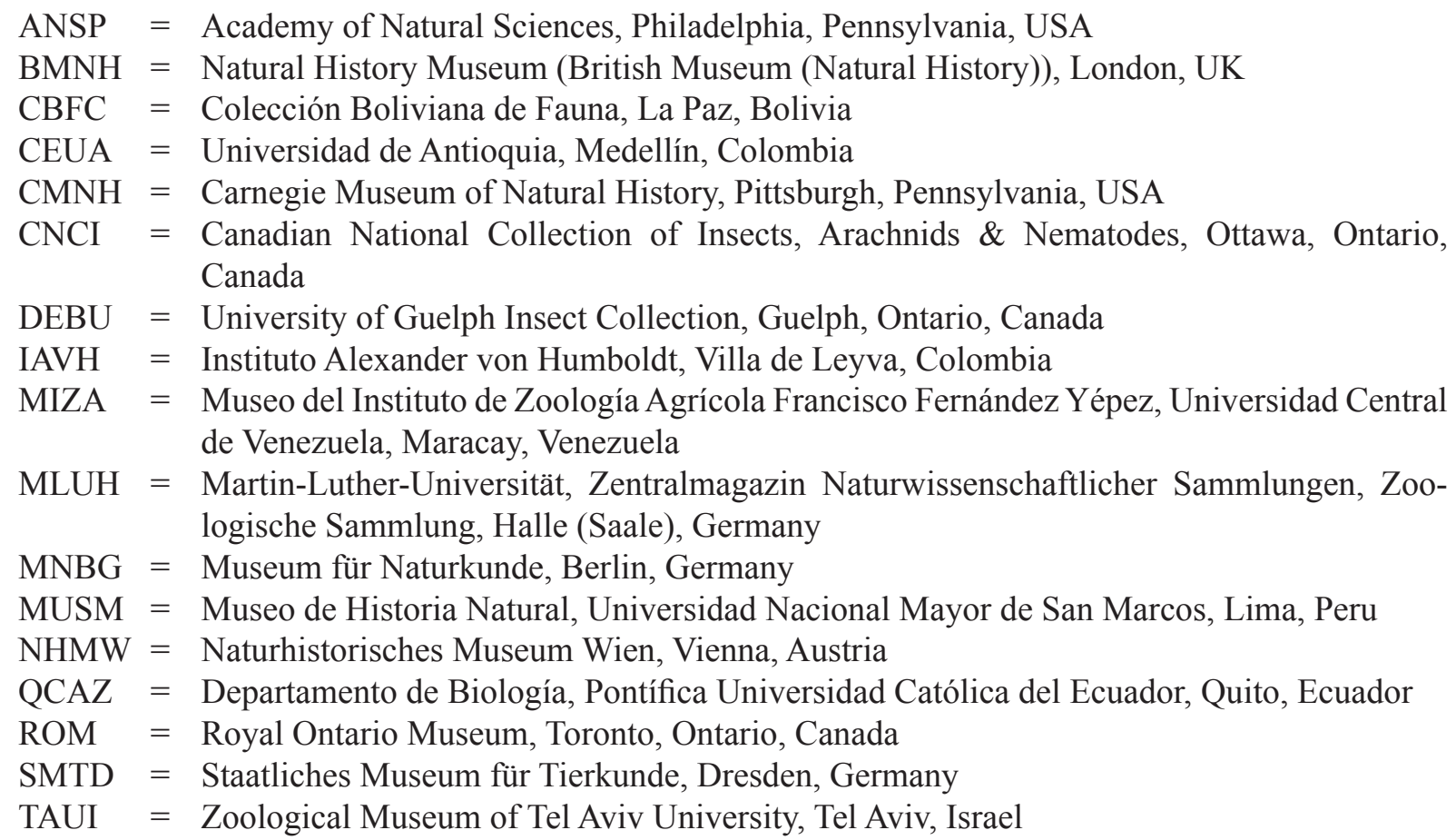


UNCB = Museo de Historia Natural, Instituto de Ciencias Naturales, Universidad Nacional de Colombia, Sante Fe de Bogotá, Colombia

USNM = United States National Museum (National Museum of Natural History), Washington DC, USA

ZMUH $=$ Zoological Museum, University of Helsinki, Helsinki, Finland

Diagnoses of species known only from types in MNBG are based on notes and photographs taken by the author during a visit to Berlin in 2001.

Morphological terms and procedures follow Marshall $(2011,2015)$. Areas of microtrichia are refered to as microtrichose although they may appear as pruinose or tomentose in some lights. The abbreviations ' $\mathrm{T}$ ', ' $\mathrm{P}$ ' and ' $\mathrm{S}$ ' are used for tergite, pleuron and sternite, respectively. The epicephalon and paracephalon are not clearly differentiated in most Mesoconius (but see M. anchitarsus sp. nov.), together forming a plate (usually shiny, sometimes densely microtrichose) that usually tapers to a point anterior to the level of the anterior ocellus and mesal to the posterior extension of the fronto-orbital plate. The three pairs of bristles on the upper back of the head are useful in differentiating the species groups of Mesoconius: the outermost and posteriormost bristle, on the paracephalon, is the outer vertical bristle (often absent); the middle bristle, beside the postocellar extension of the frontal vitta, is the postocellar (sometimes absent); the bristle invariably present on the epicephalon more or less midway between the postocellar and outer vertical bristles is treated as the inner vertical. The bristles between the frontal vitta and the eye are treated as fronto-orbitals; a posterior (upper) fronto-orbital is often present on the epicephalon posterior to the level of the ocellar triangle (but still far anterior to the inner vertical bristle); an anterior fronto-orbital is usually present near the anterior point of the epicephalon. The base of the abdomen is petiolate, with the petiole made up of all or part of abdominal segment one, segments one and two, or segment one along with the basal part of segment two. Segments are considered petiolate if the pleural membrane is reduced and all that is visible is a narrow tergite.

In other New World taeniapterine males, the ventral pregenital area is dominated by a large S5 mostly made up of a prominent forked posteromedial process (genital fork or copulatory fork) that conceals or mostly conceals a relatively small S6; in these species, the genital fork clasps the apex of the female oviscape during mating. In Mesoconius the reduction of S5 and its associated posteromedial genital fork usually leaves S6 as the conspicuous pregenital sternite, although both S6 and S5 are greatly reduced in some lineages of Mesoconius (virtually absent in the M. infestus group, see Fig. 27D; greatly modified in M. suzukii sp. nov., see Fig. 18E). Like most taeniapterines, species of Mesoconius usually have the distiphallus divided into a broad basal distiphallus and a slender distal distiphallus, with a broad phallic bulb in between. The ejaculatory duct runs through the basal distiphallus and usually expands into a swollen lower chamber as it enters the phallic bulb. The upper chamber of the phallic bulb varies widely; it is usually bulbous, but can be hood-like as in M. infestus Enderlein, 1922, in which it forms a saddlelike piece perforated by a characteristic 'window' (Fig. 25G). The phallic bulb probably serves as a joint or hinge between the relatively short and broad basal distiphallus and the typically long and slender distal distiphallus; it might also serve as a pump to help unfold the elongate distal distiphallus within the female, as has been described for some Tephritidae (Eberhard 2005). Observations and photographs of M. dianthus Marshall, 2015 (a Central American member of the M. infestus group) in copula show that the male epandrium rotates forward to clamp the female's oviscape against S6, a position that puts the tip of the female's abdomen close to the position of the phallic bulb, near the anteroventral margin of the epandrium. This suggests that, at least in the M. infestus group, the distal distiphallus must hinge forward almost $180^{\circ}$ at the phallic bulb. The distal distiphallus can be slender and whip-like, slender and straight, wiry and twisted, apically expanded, short or greatly reduced. A few species of Mesoconius have a vestigial distal distiphallus, as do some related genera. 
Internal structures of the female abdomen are important in the taxonomy of Mesoconius. The bursa copulatrix (the anterior part of the vagina; hereafter abbreviated to 'bursa') varies in size and structure, as does the associated ventral receptacle. Of more use in defining species or species groups of Mesoconius are the structures of the two spermathecal ducts, which either arise separately from the apex of the bursa or share a characteristically structured common base (common duct). Although some species (M. nigra sp. nov., M. quadritheca sp. nov.) have two ducts that each lead to a pair of spermathecae, most species have a main duct going to a pair of spermathecae and a smaller duct going to a single, variously reduced spermatheca. The main duct, which is often subdivided into differently structured sections, ultimately splits into two stems that each run to a large spermatheca. The stems differ widely in structure, with some groups characterized by straight stems with simple swellings and others characterized by elaborately twisted or studded stems.

The phallic bulb and other male genitalic characters were studied using routine clearing with lactic acid or potassium hydroxide. The more delicate structures of the female terminalia were examined by clearing the abdomen with potassium hydroxide before making an incision in the side of the oviscape through which to tease out the bursa and spermathecae (see Fig. 14B). The spermathecal ducts are easily damaged, but characters of the bursa, ducts and spermathecae are often useful diagnostic features at the species or species group level. Spermathecae and associated structures were stained with lignin pink when necessary to highlight lightly sclerotized structures.

Internal genitalia were photographed using a $35 \mathrm{~mm}$ Nikon DSLR mounted on a compound microscope. External structures were photographed using a Canon DSLR mounted on a Stackshot motorized rail. Field photographs were taken with Nikon DSLR cameras equipped with $60 \mathrm{~mm}$ or $105 \mathrm{~mm}$ macro lenses and remote flash units. Most specimen or character images were stacked using Helicon Focus software. Lengths are given as head tip to wing tip (antennal socket to wing base + wing length) and do not include abdominal dimensions because of the variable shrinkage and twisting of the abdomen in dried specimens.

Specimens were sequenced for the 'barcode' region of cytochrome oxidase I (CO1) whenever possible. Forty-five specimens of Mesoconius (29 species) were among several hundred micropezids submitted to the Biodiversity Institute of Ontario for barcoding, with the results summarized here as a maximum likelihood tree (Fig. 50).

Label data are generally repeated verbatim with original abbreviations, including: SFF (Santuario de Fauna y Flora) and PNN (Parque Nacional Natural). Some common terms (such as "trap" and "valley") on foreign language labels are translated into English for the material examined lists.

New species names, unless otherwise specified, are to be treated as arbitrary combinations of letters and are given as nouns in apposition in keeping with ICZN Code article 31.2.2.

\section{Results}

Class Hexapoda Blainville, 1816

Order Diptera Linnaeus, 1758

Superfamily Nerioidea Hendel, 1916

Family Micropezidae Loew, 1861

Subfamily Taeniapterinae Cresson, 1930

Mesoconius Enderlein, 1922

Mesoconius Enderlein, 1922: 176 (type species: Mesoconius infestus Enderlein, 1922). 
Zelatractodes Enderlein, 1922: 169 (type species: Zelatractodes filipes Enderlein, 1922) (synonymized in Marshall 2015).

Aristobata Frey, 1927: 69 (type species: Aristobata melini Frey, 1927 = Zelatractodes filipes Enderlein, 1922) (synonymized in Steyskal 1968).

\section{Description}

Length 11-21 mm. Colour variable between, and often within, species.

HEAD. Arista bare. Fronto-orbital bristles weak to strong, in one-two pairs with upper pair (if present) at or above level of upper ocelli, lower pair below level of lower ocellus near overlap between epicephalon and orbital plate. Postocellar and outer vertical bristles present or absent, inner vertical bristles always present, although sometimes very small. Lower frons usually elevated, forming a transverse, slightly scooped band in front of frontal vitta; frontal vitta usually broad and diamond- or teardrop-shaped and slightly elevated in front of ocelli but shape, elevation and extent variable. Face pale and weakly sclerotized on ventral third to half, broadly elevated to narrowly carinate dorsally; frons usually separated from antennal socket, exposing a suprantennal shelf or antennal base between antenna and lower margin of frontal plate. Clypeus shiny medially, microtrichose laterally or posterolaterally, normally slightly angled forward on pinned specimens. Palpus parallel-sided or nearly so, usually broad.

THorax. Cervical sclerite usually with a swollen microtrichose posterior section sometimes (females only) with a whitish or dull posterior patch of sensillae; anterior section depressed, flat, bare and sometimes divided by a carina. Prosternum on two planes, anterior part depressed and narrow, posterior (main) part usually broad (narrow in M. bipleuron sp. nov.), usually microtrichose, often setose, rarely bare. Pronotum microtrichose, except for narrow anterolateral lobe. Scutum with two notopleural bristles and one posterior (prescutellar) dorsocentral bristle (rarely absent); scutellum usually with a few discal setulae and a single pair of long apical bristles (absent in $M$. garyi sp. nov. only). One or more fore tarsomeres of one or both sexes sometimes enlarged and flattened. Fore tibia longitudinally grooved, often inconspicuously so but sometimes strongly flattened and conspicuously sulcate on posterior face. Mid and hind femora densely microtrichose distally, bare or almost bare and shiny basally; hind femur usually at least slightly swollen distally. Katatergite usually at least slightly swollen, often very prominent with a nipple-like central process. Dorsocentral bristles in a single posterior pair, often reduced, rarely absent. Wing variable in colour, but usually darkened at least in distal half and often with an indistinct preapical clear area that is partially or completely divided into patches; some species with clear, uniformly pigmented or distinctly banded wing. Third costal sector (between $R_{2+3}$ and $R_{4+5}$ ) short, much less than half as long as second costal sector. Anal cell short, with a strong longitudinal crease or false vein in basal third. Costagial bristle relatively short, extending approximately to humeral crossvein.

ABDOMEN. Usually distinctly petiolate, with syntergite $1+2$ elongate and pleuron of at least segment one reduced, rendering the base of the abdomen conspicuously slender (the closely related M. nigra sp. nov., $M$. quadritheca sp. nov. and M. ruficrus sp. nov. are exceptions, with only the basal portion of segment 1 constricted).

FEMALE ABDOMEN. Oviscape short and stout, with upper and lower surfaces fused to form a cylinder, usually directed posteriorly or ventrally, rather than strongly deflexed anteriorly as in many Taeniapterinae. Spermathecae $(1+2$, rarely $2+2)$ and associated ducts typically complex and often species-specific, usually with a distinct ventral receptacle on a broad bursa. In most species a relatively thick duct (paired spermathecal duct) leads to paired spermathecae, each of which is on a frequently elaborately sculptured or swollen stem; a smaller duct (single spermathecal duct) leads to a single (or rarely a pair of) small 
spermatheca(e). Spermathecal ducts either arise independently from apex of bursa or from a short or long common duct before splitting into paired and single ducts.

Male abdomen. Male S5 small to entirely reduced, S6 elongate to greatly reduced, often expanded posteriorly; S8 usually large and often different in colour and texture from preceding tergites and from epandrium; epandrium small to very small; ejaculatory apodeme variable in size. Hypandrium forming a short to long loop anteriorly (anterior margin either belt-like, scoop-like, or broad and twisted), posteriorly articulating with long anteroventral epandrial extensions and extending medially into a robust and microtrichose phallic plate. Postgonite small and inconspicuous, but apically broad, with small apical or preapical setae, basiphallus usually small and frame-like, but sometimes extended well beyond base of distiphallus; distiphallus divided into a broad basal part, a prominent phallic bulb, and (usually) a variously developed distal part.

\section{Keys to the South American species of Mesoconius Enderlein, 1922}

Some species of Mesoconius are sexually dimorphic for colour, and most show intraspecific variation in the conspicuous colour characters traditionally used to distinguish species. This infraspecific colour variation, combined with a very high level of local endemism, often made it difficult to match the limited fresh material to older names. Many species remain known only from single specimens taken at type localities that have not been practical to re-sample, such as Thiele's collection localities in the Colombian Andes and the infamous late $19^{\text {th }}$ century Peruvian collection locality of "Callanga" (Woytkowski 1974). For several of the species known only from older type specimens, genitalic characters are unavailable and chaetotaxy can only be inferred. Inclusion of these species in the keys demands the use of colour as a key character, despite intraspecific variability in pigmentation patterns.

\section{Key one: general key and key to species of the Mesoconius infestus group}

1. Katatergite almost always swollen (Fig. 5E), usually conspicuously swollen with a nipple-like apex (Fig. 9E); exceptions (three species of the M. eques group with an indistinctly swollen katatergite) lack postocellar bristles (Fig. 5B). Outer vertical bristle absent (Fig. 5B) ..................2

- Katatergite weakly swollen and gently rounded, without a nipple-like apex (Fig. 38D); postocellar bristle always present. Outer vertical bristle present or absent

Key three

2. Mid and hind legs uniformly orange, without bands; body entirely black to very dark brown, notum with indistinct silvery vitta (Fig. 23A). Wing brown, with three small clear spots distally Mesoconius flavipes Enderlein, 1922 (Colombia)

- If legs uniformly orange, then body also entirely or partly orange. Wing and notum variable ....3

3. Postocellar bristle absent, upper back of head thus with only inner vertical bristle (Fig. 3F). Stems of paired spermathecae conspicuously multi-branched and/or spermathecal ducts sharing a common stem well beyond apex of bursa (Fig. 3C). Hypandrium anteriorly narrow and ribbon-like (Fig. 6D) ............................esoconius eques group ............................. ey two

- Postocellar and inner vertical bristles present. Stems of paired spermathecae sometimes swollen but not branched or tuberculate. Spermathecal ducts arising separately from a short distal extension of bursa (Fig. 27C). Hypandrium anteriorly very broad and conspicuously twisted (Fig. 21B) ......................................esoconius infestus group ...................................4

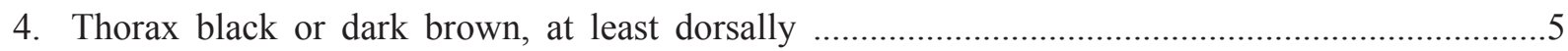

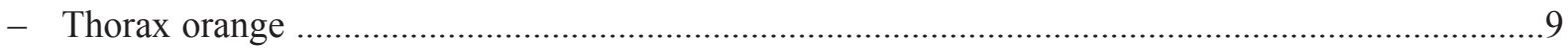

5. Hind tibia black and posteroventral part of pleuron, mid coxa and hind coxa orange .........6

- Hind tibia yellow or orange. Pleuron and coxae black ......................................................... 
6. Katepisternum and part of abdominal T1 orange or red (Fig. 22H). Oviscape bare, shiny Mesoconius albimanus Enderlein, 1922 (Peru, Colombia, Bolivia)

- Katepisternum and abdominal T1 black (Fig. 22G). Oviscape largely setulose

Mesoconius albipedis sp. nov. (Colombia)

7. Fore tarsus white, contrasting with bright yellow hind tarsomeres 1 and 2 (Fig. 27A). Hind femur black, except for orange apex Mesoconius notacca sp. nov. (Peru)

- Fore tarsus yellow, similar in colour to hind tarsomeres 1 and 2. Hind femur orange with black bands

8. Sternite 8 of male (the dorsal sclerite immediately anterior to the epandrium) mostly microtrichose, shiny only on anterior quarter (Fig. 21A). Frontal vitta more or less diamond-shaped (Fig. 20B). Length about $20 \mathrm{~mm}$ Mesoconius acca sp. nov. (Peru)

- Sternite 8 of male entirely bare and shiny (Fig. 24B). Frontal vitta teardrop-shaped (Fig. 24E). Length less than $19 \mathrm{~mm}$ Mesoconius infestus Enderlein, 1922 (Bolivia, Colombia, Ecuador) (possibly a species complex; highly variable in leg colour)

9. Head black Mesoconius nigricephala sp. nov. (Ecuador, Colombia)

- Head orange 10

10. Mid and hind femora entirely orange (Fig. 23C) .......Mesoconius fulvus Enderlein, 1922 (Ecuador)

- Mid and hind femora with broad black bands at midlength (Fig. 23D) 11

11. Fore tibia black, except for extreme apex. Frontal vitta rounded anteriorly, not sharply demarcated from lower frons (Fig. 29D) ............Mesoconius ujhelyianus Enderlein, 1922 (Colombia, Ecuador)

- Fore tibia yellow-brown. Frontal vitta distinctly triangular, upper margin tapered, and lower margin straight and forming a sharp line of demarcation between the black frontal vitta and the yellow lower frons (Fig. 23F) Mesoconius garleppi Enderlein, 1922 (Peru)

Key two: the Mesoconius eques group (outer vertical and postocellar bristles absent)

1. Katatergite conspicuously swollen, with a prominent nipple-like apex (Fig. 16B) ....................2

- Katatergite at most slightly swollen, without a prominent nipple-like apex (Fig. 18D) ............14

2. Mid and hind leg entirely or almost entirely black, femora sometimes with narrow pale rings or with narrow reddish basal and distal parts. Body colour black or blue-black; hind tarsus never white

- No leg entirely or almost entirely black. Body colour variable, if black then hind tarsus white ......5

3. Fore tarsus mostly white, first tarsomere not enlarged (Fig. 15A)

- Fore tarsus black, first tarsomere sometimes enlarged

.Mesoconius pasachoa sp. nov. (Ecuador)

4. First tarsomere of fore leg of both sexes enlarged, broad and flat (Fig. 9B). Mid coxa with comb of black anteroventral bristles. White bands on hind femur usually distinct

Mesoconius eques (Schiner, 1868) (Ecuador, Venezuela)

- First tarsomere of females slender (Fig. 13C), males unknown. Mid coxa with comb of golden anteroventral bristles. Bands on mid and hind femora indistict to obsolete

Mesoconius noteques sp. nov. (Peru)

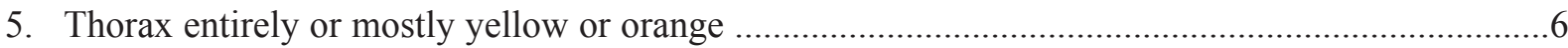

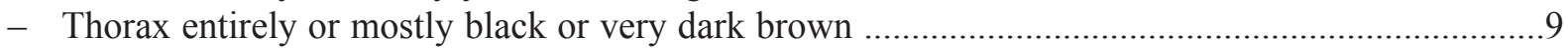


6. Thorax, base of abdomen and basal third of mid and hind femora orange to red, without vittae. Abdominal pleuron with black vertical stripes; tergites black (Fig. 17A)

Mesoconius rufithorax Enderlein, 1922 (Peru and Bolivia)

- Thorax colour not totally orange to red, notum distinctly vittate. Abdominal pleuron unmarked; tergites 3-6 usually pale or desclerotized

7. Fore tarsus (of females and known males) unmodified. Abdomen of males white, tergites pale and lightly sclerotized (males of $M$. cosanga sp. nov. unknown) .................8

- Fore tarsomere 1 of female greatly enlarged, wider and longer than remainder of tarsus (Fig. 4C). Abdomen of male dark, tergites sclerotized

Mesoconius anchitarsus sp. nov. (Venezuela)

8. Fore tarsus black. Notum with broad black vittae. Ocellar triangle elevated, orange (Fig. 3F) ..

Mesoconius albitergum sp. nov. (Colombia)

- Fore tarsus white. Notum orange, with narrow golden vittae interrupted by suture (Fig. 7C). Ocellar triangle not elevated, mostly black (Fig. 7A) ...........Mesoconius cosanga sp. nov. (Ecuador)

9. Mid and hind femora with a pale yellow or orange band at middle, sometimes margined with darker bands

- Mid and hind femora without a pale band, instead either bicoloured, concolourous reddish or with darker bands

10. Fore tarsus mostly yellow (base of basal tarsomere black). Mid and hind femora reddish brown, with an inconspicuous pale middle band. Abdominal pleuron pink, tergites and oviscape mostly orange (Fig. 16E)

Mesoconius rufipleuron sp. nov. (Ecuador)

- Fore tarsus entirely black. Mid and hind femora orange or yellow, with a pale yellow band at middle. Abdomen darker, differently pigmented, usually part black and part yellow . .11

11. Males with cercus tapered and simple (Fig. 6A). Notum with two presutural and four postsutural narrow golden longitudinal vittae; katatergite prominent and orange, in contrast with otherwise mostly dark mesopleuron (Fig. 5E). Black preapical bands on mid and hind femora weak and narrow (Fig. 5A) ... Mesoconius auristrigatus Enderlein, 1922 (Ecuador, Colombia)

- Males with cercus bilobed (Fig. 12E). Notum with a broad median black strip flanked by broad lateral golden vittae; katatergite not contrasting with surrounding mesopleuron. Black preapical bands on mid and hind femora broad and strong (Fig. 11D)

Mesoconius nigripleuron sp. nov., in part (Peru, Bolivia)

12. Katatergite orange. Mid and hind femora entirely red-orange exept for a narrow black base. Mid and hind tibiae orange (Fig. 10A)

Mesoconius hirsutimamma sp. nov. (Colombia)

- Katatergite dark. Mid and hind femora yellow-red at least distally, usually with black rings or black base. Tibiae yellow to brown

13. Frontal vitta with a tapered point reaching anterior margin of frons and with lateral extensions almost reaching eye. Epandrium with a pointed tuft of densely packed setae at posteroventral corner (Fig. 8C). Female abdominal pleuron pale ......Mesoconius epandribarba sp. nov. (Colombia)

- Frontal vitta broadly rounded anteriorly, widely separated from both frons margin and eye. Epandrium without a pointed tuft of densely packed setae at posteroventral corner (Fig. 12A). Female abdominal pleuron darkly pigmented (Fig. 11A) ...Mesoconius nigripleuron sp. nov., in part (Peru) 
14. Hind femur orange on basal half and black on distal third, with a yellow or white ring between black and orange parts; mid femur basally orange, distally black (Fig. 14F). Tergites 1-3 orange, distal tergites black. Males unknown ....Mesoconius obtusiconus Enderlein, 1922 (Peru, Colombia)

- Mid and hind femora black with orange apices and a white central band, or femora orange with a black band near middle. Tergites uniformly coloured or darkest near base of abdomen

15. Mid and hind femora black with orange apices and a white central band. Male fore tarsus black, distal tarsomeres greatly enlarged (Fig. 1B). Female fore tarsus white basally and black distally (Fig. 1C). Body mostly black. Male S5 and S6 elongate, well developed. Wing uniformly pigmented

Mesoconius albiseta sp. nov. (Ecuador)

- Mid and hind femora orange with brown rings (Fig. 19), basal two thirds of hind femur sometimes more extensively pigmented. Fore tarsus entirely white, male fore tarsus with apex of tarsomere 1 curved to meet an enlarged tarsomere two Fig. 19D). Body usually mostly orange. Sternite 5 of male greatly reduced, S6 reduced to two widely separated sclerites (Fig. 18E). Males with wing clear, except for a dark apical spot (Fig. 19D), female wing uniformly yellowishclear Mesoconius suzukii sp. nov. (Colombia)

\section{Key three: the Mesoconius oblitus and nono groups}

Species with a postocellar bristle but without a swollen katepisternum will key out here. These species are divided into the 'M. nono group' (with an outer vertical bristle) and the 'M. oblitus group' (without an outer vertical bristle), but the vertical bristles are often broken and can be difficult to assess. Both groups are infrequently collected, and most species are known from either a single sex, a single specimen, or from inadequate older type specimens.

1. Thorax orange to reddish brown; head entirely black

- Thorax usually dark brown or black, but if orange then head similarly coloured at least on posterior half

2. Wing mostly clear, with a broad and distinct but incomplete dark discal band (Fig. 36A). Anterior spiracle black

Mesoconius uchumachi sp. nov. (Bolivia)

- Wing either uniformly pigmented, uniformly clear, or infuscated with one-three clear areas distally. Anterior spiracle orange to reddish brown .....

3. Mid and hind femora with a white ring near the middle

- Mid and hind femora uniformly pigmented or black distally, without a white ring ....................5

4. Basal half of mid and hind femora orange to brown, darker adjacent to white distomedian ring; distal part beyond white ring black, broad and sulcate (Fig. 30E)

Mesoconius scurrus (Hennig, 1935) (Bolivia)

- Mid and hind femora brown, except for broad white ring near middle; distal part of hind femora neither strongly swollen nor sulcate (Fig. 40G)

Mesoconius versicolorus (Enderlein, 1922) (Colombia, Venezuela)

5. Prothorax black. Hind femur sharply bicoloured, distal half black (Fig. 40E)

Mesoconius filipes (Enderlein, 1922) (Peru)

- Prothorax brown, similar to mesothorax. Hind femur uniformly brown in typical specimens (Fig. 40C) Mesoconius cyclops (Hennig, 1935) (Bolivia)

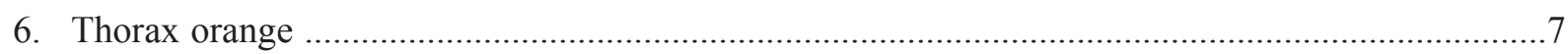

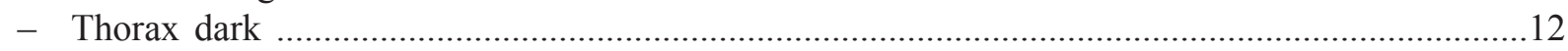


7. Mid and/or hind femora with basal or distomedian black rings (Figs 33A, 38A). Frontal vitta black (Fig. 38C). Outer vertical bristle present or absent

- Mid and hind femora uniformly pigmented. Frontal vitta orange (Fig. 31A). Outer vertical bristle present (Fig. 31A)

8. Scutellum with a pair of long apical bristles (Fig. 38B). Postpronotal lobe orange. Frontal vitta black, but not extending to anterior margin of frons, or entire lower frons black; flat to strongly convex

- Scutellum without apical or other bristles. Thorax with a distinct black spot over postpronotal lobe (Fig. 33A). Frontal vitta flat, black, elongate-triangular and reaching or almost reaching anterior margin of an otherwise reddish frons (Fig. 33F)

Mesoconius garyi sp. nov. (Peru)

9. Mid and hind femora with distomedian rings. Fore tarsomere 1 mostly black. Frontal vitta strongly convex or lower frons black

- Hind femur with basal black ring, mid femur uniformly orange. Fore tarsus entirely yellow. Frontal vitta almost flat, black, widely separated from anterior margin of frons, lower frons orange (Fig. 30C)

Mesoconius ottoi (new replacement name for M. garleppi (Enderlein, 1922); Bolivia and perhaps Colombia)

10. Outer vertical bristle present (Fig. 38C). Wing uniformly infuscated. Lower frons entirely black, concolourous with frontal vitta and contrasting with yellow face and antennal bases (Fig. 38C). Fore tarsus black distally. Hind femur with two black rings ......Mesoconius zorro sp. nov. (Peru)

- Outer vertical bristle absent. Wing with distal clear areas (Fig. 40B). Anterior margin of frontal vitta separated from frons margin by pale area. Fore tarsus white distally. Hind femur with a single incomplete ring Mesoconius braueri (Hennig, 1935) (Venezuela)

11. Mid and hind femora uniformly brown (Fig. 30A). Fore tarsus and tibia similarly pale brown ... Mesoconius hoffmannsi (Enderlein, 1922) (Peru)

- Mid and hind femora uniformly orange (Fig. 31A). Fore tarsomeres 2-5 white, contrasting with black fore tibia and base of tarsomere 1 Mesoconius aurantium sp. nov. (Peru)

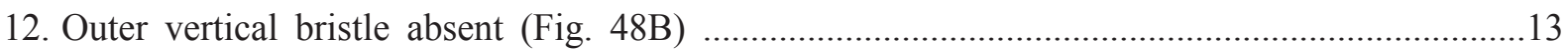

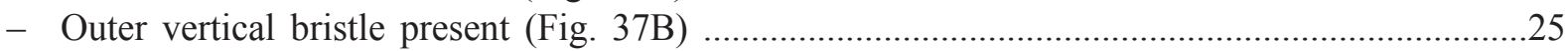

13. Frons sharply bicoloured: lower frons, face and antennae orange to yellow, remainder of head black. Fore tarsomere 1 expanded, strongly and conspicuously so in male (Fig. 43C). Hind femur dark, with a reddish distomedian ring Mesoconius lobopoda sp. nov. (Colombia)

- Lower frons dark, not sharply contrasting with upper frons. Fore tarsomere 1 similar in diameter to tibia, not strongly flattened in either sex. Hind femur without a reddish distomedian ring .........14

14. Face and lunule yellow (Fig. 42A). Frontal vitta broadly reaching frontal margin. Mid and hind femora with broad basal and distal black bands, similar in length to intervening middle orange band (Fig. 41D) .15

- Face and lunule at least partially dark. Frontal vitta tapered, reaching frontal margin at most as a point. Femoral colour variable

15. Mid and hind femoral apices orange (Fig. 41D). Postocellar portion of frontal vitta tapered to a narrow point; parafacial orange (Fig. 41E). Oviscape orange

Mesoconius apicalis sp. nov. (Ecuador)

- Mid and hind femoral apices black (Fig. 42B). Postocellar portion of frontal vitta broad; parafacial black (Fig. 42A). Oviscape black .Mesoconius gelbifacies sp. nov. (Ecuador) 
16. Hind femur with a broad distomedian pale ring (Fig. 45B) ..................................................18

- Hind femur with at most a narrow distomedian pale ring .............................................................

18. Frontal vitta strongly convex and dome-like (Fig. 45E). Epicephalon microtrichose

Mesoconius oblitus (Hennig, 1935) species complex (Venezuela, Colombia)

- Frontal vitta at most slightly convex, not dome-like. Epicephalon shiny

19. Body dark metallic blue (Fig. 48A). Mid and hind femora black with white bases and white distomedian rings. Fore and hind tarsi black Mesoconius rex sp. nov. (Colombia)

- Body black to dark brown. Femora without white basal rings. Fore and/or hind tarsi all or mostly white

20. Hind femur with pale ring between basal yellow half and distal brown third; mid femur darkened in distal third but without pale ring (Fig. 40A)

Mesoconius afurcatus (Hennig, 1935) (Venezuela)

- Mid and hind femur dark basally and distally and with a broad pale ring at middle (Fig. 42E) .. Mesoconius keili sp. nov. (Ecuador)

21. Abdomen all or mostly reddish or orange. Mid and hind femora orange, with or without darker rings .22

- Abdomen all or mostly black or metallic blue-black. Mid and hind femora mostly black, sometimes with paler rings

22. Mid and hind femora orange with indistinct distomedian rings. Scutellum brown. Wing lightly infuscated, with clear distal areas (Fig. 40F) ..Mesoconius rufiventris (Enderlein, 1922) (Colombia)

- Mid and hind femora orange, without distomedian rings. Scutellum orange. Wing heavily and evenly infuscated, yellow, without clear distal areas (Fig. 49D) .......Mesoconius ruficrus sp. nov. (Peru)

23. Hind femur with an indistinct reddish mediodistal ring, femora otherwise black. Wing with clear distal patches (Fig. 41A) Mesoconius apa sp. nov. (Bolivia)

- Mid and hind femur with white distomedian ring. Wing darkly infuscated, without clear patches

24. Inner vertical and postocellar bristles greatly reduced, barely distinguishable from surrounding setulae (Fig. 47A)

Mesoconius quadritheca sp. nov. (Peru)

- Inner vertical and postocellar bristles large, distinct (Fig. 44A)

Mesoconius nigra sp. nov. (Bolivia)

25. Thorax sharply bicoloured: notum black, balance of thorax entirely yellow (Fig. 37A). First abdominal tergite and base of $\mathrm{T} 2$ entirely yellow to orange, abdomen otherwise black

Mesoconius wytkowskii sp. nov. (Peru)

- Neither thorax nor abdomen sharply bicoloured 26

26. Thorax and abdomen entirely black or metallic blue 27

- Thorax partially black, but with orange or reddish-brown patches at least on pleuron; abdominal tergites orange (females) or brown (males) (Fig. 32) ....Mesoconius bipleuron sp. nov. (Colombia) 
27. Thorax and abdomen black, notum silvery microtrichose, except for broad central strip (Fig. 34A). Legs variable in colour, but hind femora either uniform in colour or with basal half dark. Abdominal pleuron dark Mesoconius nono sp. nov. (Ecuador)

- Thorax and abdominal tergites metallic blue with light pruinosity. Mid and hind femora black, with broad white distomedian bands (Fig. 35A). Abdominal pleuron white, except for upper part of $\mathrm{P} 2$ Mesoconius reinai sp. nov. (Colombia)

\section{Species descriptions}

The species treatments below are in alphabetical order within each of four groups: the M. eques group, the M. infestus group, the M. nono group and the M. oblitus group. The latter two, loosely equivalent to 'Zelatractodes' of previous authors, are weakly supported groups diagnosed on the presence (M. nono group) or absence (M. oblitus group) of outer vertical bristles. Species descriptions are prefaced with a brief summary of readily visible colour characters, followed by descriptions of the head, thorax and abdomen. Previously described species known only from undissected type material are briefly diagnosed rather than redescribed. Previously described species known from undissected type material as well as dissected non-type material are redescribed based in part on the dissected non-type material.

\section{Mesoconius eques group}

\section{Diagnosis}

The Mesoconius eques group is recognizable by the absence of postocellar and outer vertical bristles (thus with only inner vertical bristles on the upper back of the head) and, with a few exceptions (M. obtusiconus, M. albiseta sp. nov., M. suzukii sp. nov.), the presence of a greatly enlarged, pointed katatergite.

\section{Description}

Upper fronto-orbital bristle usually absent (minute in M. suzukii sp. nov., well developed only in M. obtusiconus); lower fronto-orbital strong or weak, usually inserted in a patch of microtrichia near lower point of epicephalon. Prosternum usually microtrichose and with at least a few fine setulae anteriorly, bare in M. suzukii sp. nov. Wing usually evenly infuscated but sometimes with clear or dark areas; one species (M. rufithorax) has dark wings with clear discal spots similar to those in species of the M. infestus group.

FEMALE ABDOMEN. Stems of paired spermathecae usually characteristically folded with multiple processes (except M. suzukii sp. nov. and M. rufithorax); paired spermathecal duct divided into basal and distal sections (except M. rufithorax) and arising from apex of narrowed distal part (common duct) of bursa; in almost all species the single spermathecal duct arises from side of the common duct, widely separated from the paired duct.

Male abdomen. Tergite and sternite 6 well developed, S6 very large (except in M. suzukii sp. nov.). Anterior hypandrial loop narrow and ribbon-like, in contrast to broad scoop-like anterior hypandrium of other species groups. Distal distiphallus usually very long and slender, much longer than basal distiphallus (shorter in M. suzukii sp. nov.).

\section{Distribution}

Other than the Central American species M. tigrinus Marshall, 2015, members of this species group occur only in Andean South America. 


\section{Remarks}

Mesoconius suzukii sp. nov. is included in the M. eques group because of its head chaetotaxy, even though it lacks the many other putative synapomorphies found in the remainder of the species group. Sequence data (Fig. 50) suggest that M. suzukii sp. nov. does not belong with the rest of the group. The placement of M. rufithorax also needs re-assessment on the basis of more and better specimens. With the exception of these two problematic species, the $M$. eques group is strongly supported as monophyletic on the basis of the elaborate spermathecal stems, the large and elongate male S6 and the elongate distal distiphallus.

Mesoconius albiseta sp. nov.

urn:1sid:zoobank.org:act:65BD76B7-22D2-49B1-B76C-78265FE647D7

Figs 1-2

\section{Etymology}

The specific name is a noun referring to the white anterior notopleural bristle, which stands out in contrast to the black posterior notopleural bristle.

\section{Material examined}

Holotype

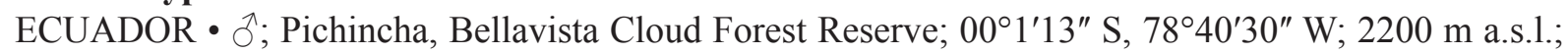
9-13 May 2009; S.A. Marshall leg.; QCAZ.

\section{Paratypes}

ECUADOR • 2 $q+$; same collecting data as for holotype; one $q$ in alcohol; MYCRO336-18 sequenced for CO1; DEBU.

\section{Description}

LENGTH. $16-17 \mathrm{~mm}$.

CoLour. Mostly black, but abdominal pleuron with a prominent pattern of black and white vertical bands. Body otherwise with areas of pruinosity or colour as follows: middle of face pale microtrichose, contrasting with shiny black lunule and bright silver microtrichose gena, postgena, and parafacial; inner margin of subantennal area with a narrow shiny strip; clypeus orange-brown, with setulosity restricted to posterior corners, palpus yellow-orange; frontal vitta velvety black. Propleuron with orange central area sharply contrasting with ventral and posterior margins. Mesopleuron with vertical patterns of dense golden pruinosity, katepisternum entirely microtrichose but only posterior third of anepisternum microtrichose; postpronotal lobe and notopleuron also strongly microtrichose, scutum with very short, dense microtrichia forming three longitudinal bands (a central band dark and lateral golden microtrichose bands); golden bands extending on to sides of scutellum. Female with fore tarsomeres 1 and 2 white, except for small black ventral patch at base, tarsomere 3 brown with black setulae, tarsomeres 4 and 5 black; male fore tarsus strongly modified, with tarsomere 1 bicoloured and the strongly swollen, tarsomeres $2-5$ black. Fore femur orange on basal half, black distally; mid and hind femora black, except for a narrow orange base, a white ring at middle and brown apex. Tibiae brown. Wing lightly infuscated, slightly darker on apical third. Abdomen brown at base of T1-2, tergites otherwise black; pleuron in both sexes boldly patterned, with tapered black bands extending ventrally from margins of T2-6

HEAD. Epicephalon and paracephalon shiny, indistinctly striate, bare except for patch of setulae around inner vertical bristle; frontal vitta broad anterior to ocelli $(0.44 \times$ frontal width), tapered to anterior margin of frons, sharply tapered behind ocelli. One strong fronto-orbital bristle inserted near junction 


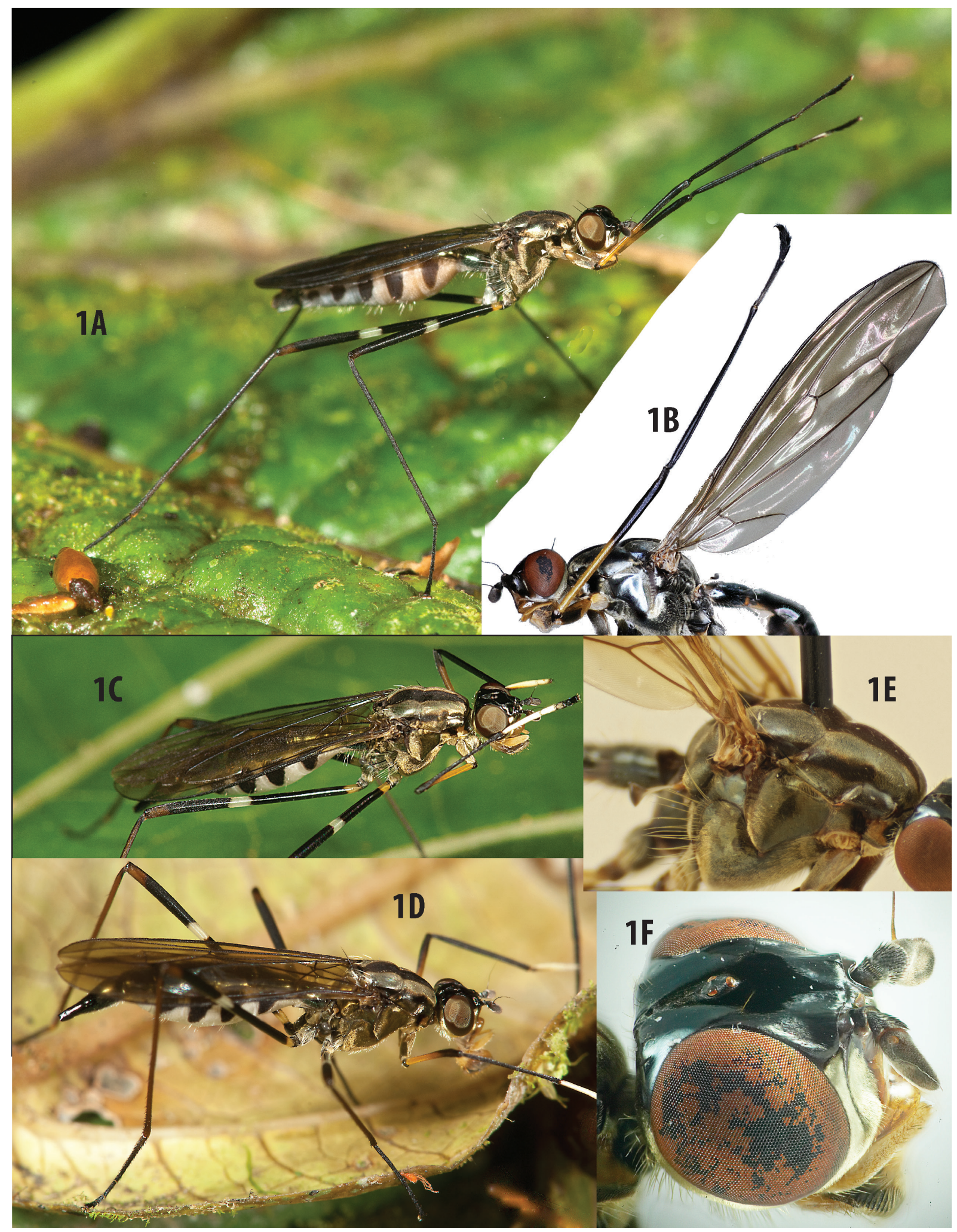

Fig. 1. Mesoconius albiseta sp. nov., external characters. A. Holotype prior to capture, ô, QCAZ. B. $\widehat{\partial}$, showing swollen fore tarsomeres. C-D. Paratype prior to capture, $q$, DEBU. E. Pleuron and base of abdomen to show katatergite. F. Head, ${ }^{\lambda}$. 
of epicephalon and orbital strip. Upper face with a broad, parallel-sided, weakly convex, microtrichose central ridge separated from broad microtrichose parts of subantennal areas by small, shiny, blackbrown area. Postgena with long white setae.

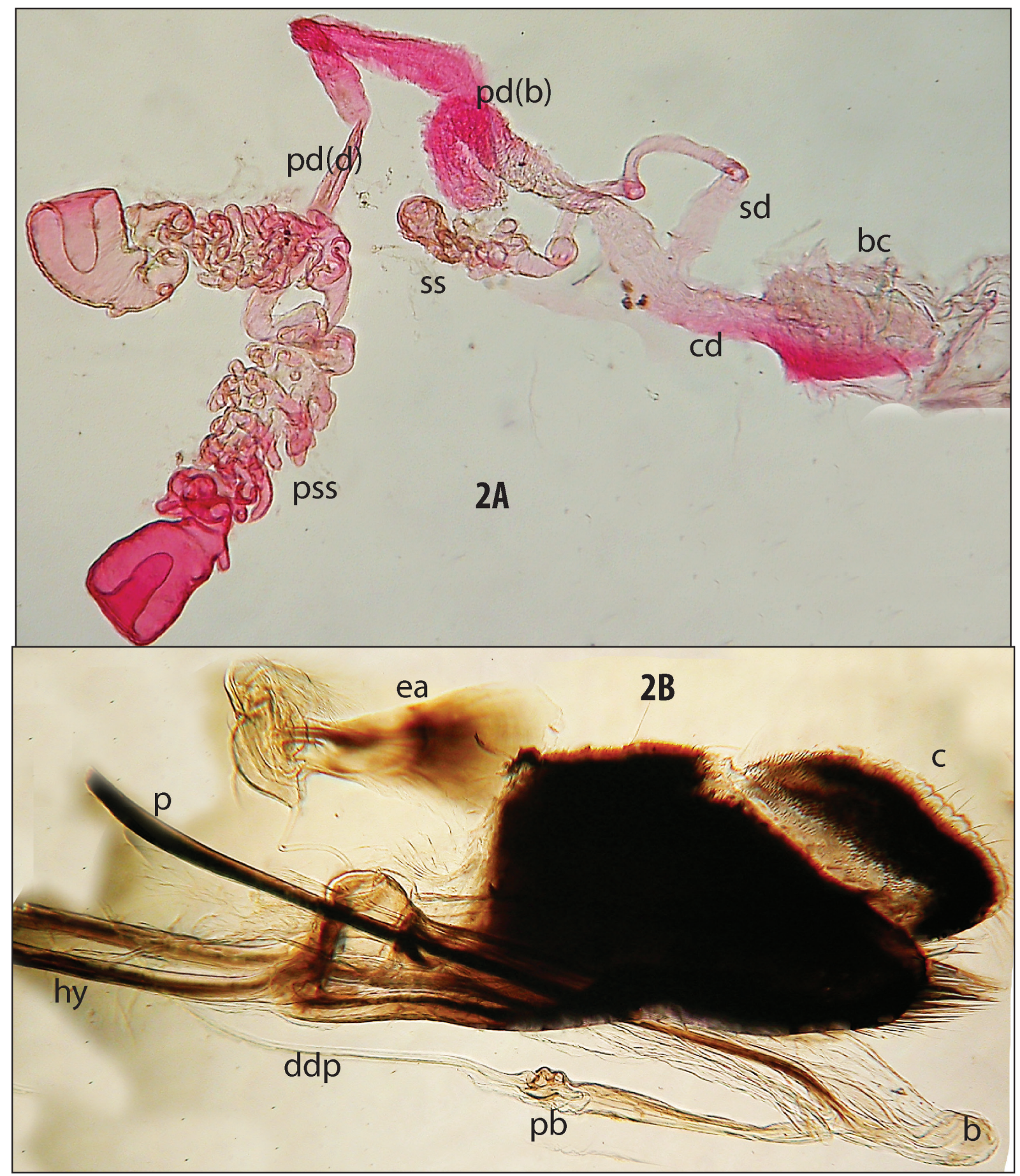

Fig. 2. Mesoconius albiseta sp. nov., internal characters. A. Spermatheca and associated structures. B. Male terminalia, left lateral. Abbreviations: $\mathrm{b}=$ basiphallus; $\mathrm{bc}=$ bursa copulatrix; $\mathrm{c}=$ cercus; $\mathrm{cd}=$ common duct; $\mathrm{ddp}=$ distal distiphallus; $\mathrm{ea}=$ ejaculatory apodeme; hyp = hypandrium; $\mathrm{p}=$ phallapodeme; $\mathrm{pb}=$ phallic bulb; $\mathrm{pd}(\mathrm{b})=$ paired spermathecal duct (basal section); $\mathrm{pd}(\mathrm{d})=$ paired spermathecal duct (distal section); pss = paired spermathecal stem; sd = single spermathecal duct; ss = single spermatheca. 
THORAX. Cervical sclerite with a vertical groove separating a subquadrate, convex, partially microtrichose posterior portion from a smaller, pale, mostly bare anterior portion. Scutum with silvery areas as noted above, otherwise finely microtrichose, with scattered small acrostichal setulae near middle and with small dorsocentral setulae forming a distinct row along border between dark central area and microtrichose longitudinal band; postpronotal lobe microtrichose except for shiny anterior face, some small setulae posteroventrally. Notopleuron with a white anterior bristle and a black posterior bristle. Supra-alar bristle white. Dorsocentral bristle strong, white and longer than scutellum in female, black and shorter in male. Apical scutellar bristle very long. Katatergite moderately swollen, entirely setulose, without a point or prominent apex. Vertical row of katepisternal bristles white. Coxae with white anteroventral setae.

ABdomen. Abdominal petiole including segment one only, P2 as deep as P3; length of T1+2 double length of T3. Tergites shiny, sparsely microtrichose, with white setulae.

Female ABDOMEn. Oviscape black. Bursa and ventral receptacle small, bursa distally extending as a broad common spermathecal duct. Single spermathecal duct arising laterally at mid point of common spermathecal duct, broad near base then uniformly smooth and parallel-sided before expanding into a convoluted stem leading to a small oval spermatheca. Paired spermathecal duct arising at apex of common duct, broad and rugose from apex of common duct until transforming into a narrower, smooth distal half that ultimately splits into two long, broad, convoluted stems, each ending in a flat-topped smooth spermatheca.

Male abdomen. Sternites 5 and 6 elongate, tapered anteriorly and notched posteromedially. S7 narrow ventrally, fused with S8 laterally. S8 black, entirely microtrichose, posterior third sparsely setulose. Epandrium elongate, longer than S8, with prominent, tapered, setose posteroventral angles; cercus large, simple and distinct. Basiphallus projecting far posterior to base of distiphallus, basiphallus thus forming a large, lobate epiphallus; distiphallus unusually small, basal part narrowly tubular, apically expanded as a small phallic bulb; distal part of distiphallus narrow and whip-like. Ejaculatory apodeme small, narrow, barely twice as large as sperm pump and much smaller than epandrium.

\section{Remarks}

Mesoconius albiseta sp. nov. is externally distinctive for its mostly bright silvery subantennal areas and pale upper face, its several white thoracic bristles, the strongly swollen male tarsus and the colour pattern, with vertical thoracic and abdominal bands. Internally, the very large posterior basiphallus extension (epiphallus) of the male is unique in the genus but the elongate, conspicuously convoluted paired spermathecal stems of the female suggest a relationship to other species of the M. eques group.

Mesoconius albitergum sp. nov. urn:1sid:zoobank.org:act:AD7675B2-46CD-4AA0-B4AE-6F041FB80DD8

Fig. 3

\section{Etymology}

The specific name refers to the pale and lightly sclerotized T3-6, which contrast with the fully sclerotized orange T1-2.

\section{Material examined}

\section{Holotype}

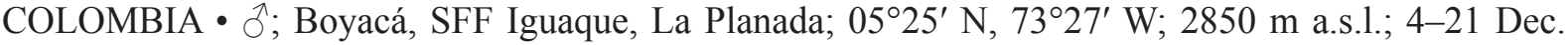
2001; P. Reina leg.; IAVH.

\section{Paratypes}

COLOMBIA • 3 우; same collecting data as for holotype; IAVH • 2 + $q$; Boyacá, SFF Iguaque, La

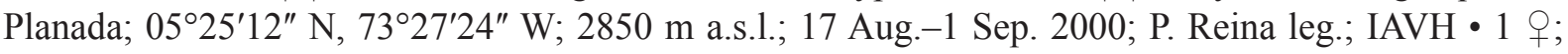


Boyacá, SFF Iguaque, La Planada; $05^{\circ} 25^{\prime}$ N, 732ㄱ' W; 2850 m a.s.1.; 6-23 Oct. 2000; P. Reina leg.; Malaise trap; UGIC 178-15/MYCRO079-15 sequenced for CO1; IAVH • 2 q ; ; Boyacá, SFF Iguaque, La Planada; 05 2512" N, 7327'24" W; 2850 m a.s.1.; 25 Jun.-13 Jul. 2000; P. Reina leg.; Malaise trap;

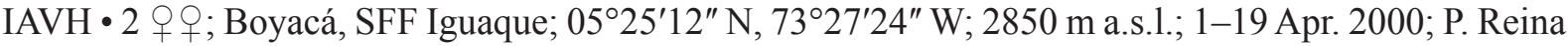

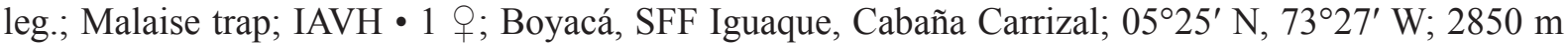
a.s.1.; 27 Mar.-16 Apr. 2001; P. Reina leg.; Malaise trap; IAVH • 1 क ; Boyacá, SFF Iguaque, Quebrada Carrizal; 05 $25^{\prime} \mathrm{N}, 7^{\circ} 27^{\prime} \mathrm{W}$; $3350 \mathrm{~m}$ a.s.l.; 7-21 Jan. 2001; P. Reina leg.; IAVH • 2 우; Boyacá, SFF Iguaque, Cerro Pan de Azucar; 05 $25^{\prime} \mathrm{N}, 7^{\circ} 27^{\prime} \mathrm{W}$; 3300 m a.s.l.; 10-28 Jun. 2001; P. Reina leg.; Malaise trap; IAVH • 2 우; Boyacá, SFF Iguaque, Cerro Pan de Azucar; $05^{\circ} 25^{\prime} \mathrm{N}, 7^{\circ} 27^{\prime} \mathrm{W} ; 3300 \mathrm{~m}$ a.s.l.; 12 Sep.-13 Oct. 2001; P. Reina leg.; Malaise trap; IAVH • 1 \&; Boyacá, SFF Iguaque, La Planada; $05^{\circ} 25^{\prime} \mathrm{N}, 73^{\circ} 27^{\prime} \mathrm{W} ; 2856 \mathrm{~m}$ a.s.1.; 13-30 Jul. 2001; P. Reina leg.; IAVH • 1 ; Boyacá, SFF Iguaque, La Planada; $05^{\circ} 25^{\prime} \mathrm{N}, 7^{\circ} 27^{\prime} \mathrm{W}$; $2850 \mathrm{~m}$ a.s.1.; 30 Jul.-17 Aug. 2000; P. Reina leg.; IAVH • 1 O; Boyacá, SFF Iguaque, La Planada; $05^{\circ} 25^{\prime} \mathrm{N}, 7^{\circ} 27^{\prime} \mathrm{W}$; $2850 \mathrm{~m}$ a.s.l.; 23 Sep.-11 Oct. 2000; P. Reina leg.;

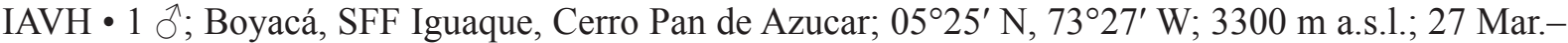
16 Apr. 2001; P. Reina leg.; Malaise trap; IAVH • 1 đ̇; Boyacá, SFF Iguaque, La Planada; $05^{\circ} 25^{\prime} 12^{\prime \prime}$ N, 73²7'24" W; 2850 m a.s.1.; 2-19 Aug. 2000; P. Reina leg.; IAVH • 1 O; Nariño, RP Planada Via Hondon; $01^{\circ} 15^{\prime}$ N, 78¹5’ W; 1930 m a.s.l.; G. Oliva leg.; Malaise trap; IAVH.

\section{Description}

LENGTH. 17-19 mm.

Colour. Burnt orange, except as follows: parafacial, postgena and most of gena silvery microtrichose, middle part of gena shiny brown ventrally; palpus and clypeus yellow; lower face white; frontal vitta anterior to ocelli velvety black striate, frons with black transverse area at lower margin of vitta, which is widely separated from anterior frons margin; upper frons paler than lower frons. Cervical sclerite entirely orange and subshining. Katepisternum and anepisternum with black patches ventrally; scutum with two narrow central black vittae on anterior $2 / 3$ and broader sublateral black bands broken by deep transverse suture and ending well before scutellum. Fore tibia and all tarsi dark brown to black, mid femur with a white band before middle and hind femur with a white band at middle (band sometimes indistinct on mid femur). Wing evenly and lightly infuscated. Abdomen white or very pale and lightly sclerotized between darker, fully sclerotized syntergite $1+2$ and oviscape (female) or S8 (male); posterior corners of tergite 2 black.

HEAD. Epicephalon and paracephalon very finely striate, dull; lower margin of epicephalon and upper parafacial microtrichose, forming a pruinose patch visible at some angles. Frontal vitta not visibly extending posterior to ocelli; ocellar triangle distinctly elevated. Lower fronto-orbital bristle strong, inserted well anterior to ocellar triangle in microtrichose patch near lower margin of epicephalon. Upper face broadly raised, flat or very weakly convex at middle, subantennal areas shiny.

THORAX. Cervical sclerite with a vertical groove separating a large subquadrate posterior portion from a small anterior portion. Notum with central area almost bare; acrostichal and dorsocentral setulae sparse and minute, but in distinct rows. Postpronotal lobe subshining, very sparsely microtrichose, with some scattered small pale bristles, anterior margin bare and almost vertical, posterior margin setulose and only slightly less vertical than anterior margin. Dorsocentral bristle very small, similar in size to discal scutellar setulae and $1 / 3$ as long as supra-alar bristle. Scutellum with four small discal setulae and long, closely spaced apical bristles (longer than scutellum). Katatergite very prominent, with a long, nipplelike, microtrichose pointed process. Notopleuron with two (rarely three) widely spaced black bristles. Vertical row of katepisternal bristles black. Fore coxa with black anteroventral setae, mid and hind coxae with golden anteroventral setae. 

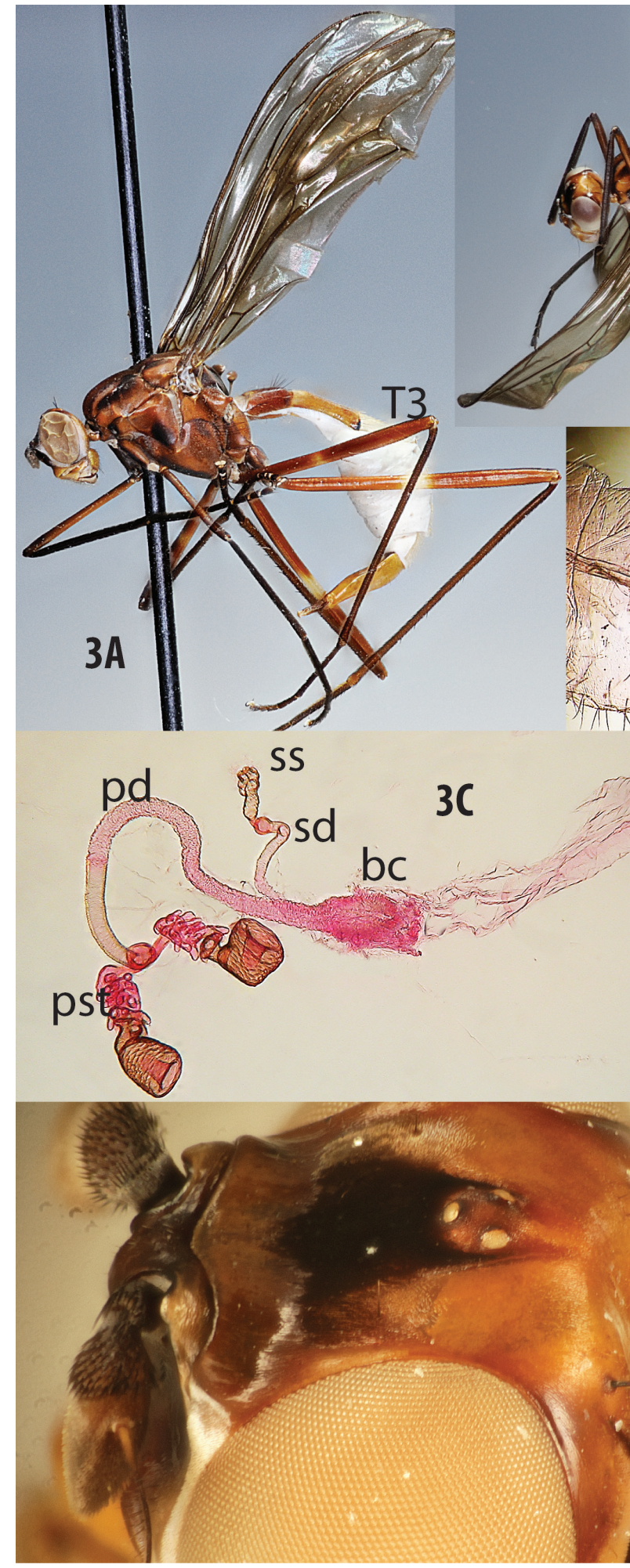

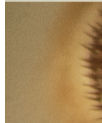

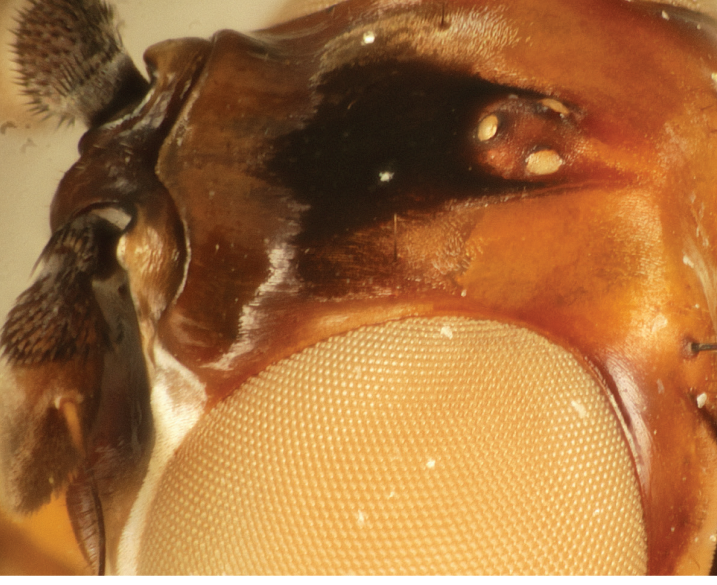

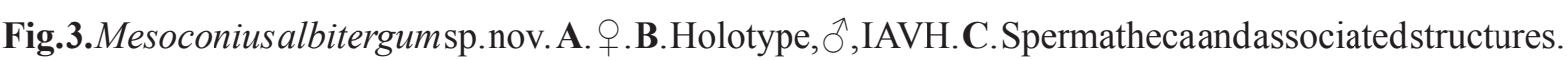
D. Abdominal apex, ${ }^{\lambda}$, lateral view. E. Male terminalia, lateral view but with phallus twisted (basiphallus $90^{\circ}$ left, distiphallus $180^{\circ}$ ). F. Head and thorax, ${ }^{\circ}$. Abbreviations: $b=$ basiphallus; $b c=$ bursa copulatrix; $\mathrm{bdp}=$ basal distiphallus; $\mathrm{c}=$ cercus; $\mathrm{dd}=$ distal distiphallus; $\mathrm{e}=$ epandrium; iv = inner vertical bristle; $\mathrm{pb}=$ phallic bulb; $\mathrm{pd}=$ paired spermathecal duct; $\mathrm{pst}=$ paired spermathecal duct; $\mathrm{sd}=$ single spermathecal duct; ss $=$ single spermatheca. 
ABDomen. Abdominal segment 1 and base of segment 2 petiolate; $1+2$ slightly more than twice as long as tergite 3 . T1 with a ring of long thin preapical setae.

Female abdomen. Oviscape pale brown, darker at apex, bare except for scattered setulae. Bursa only slightly swollen, twice the diameter of common spermathecal duct at base; ventral receptacle small and inconspicuous. Single spermathecal duct branching off a very short common duct that tapers slightly to the much longer, paired spermathecal duct, which is divided into distinct parts, including a long rugose basal $2 / 3$ that abruptly transforms into a slightly narrower, relatively smooth (indistinctly striate) distal third. Paired spermathecae expanded distally, apex invaginated, surface reticulate, stem (beyond division of paired duct) broad and conspicuously coiled and tuberculate. Single spermathecal duct similar in texture to distal part of paired spermathecal duct, but much smaller; single spermatheca vestigial, very small and tuberculate, on a long, thick stem separated from main part of duct by a constriction.

MaLe ABDOMEn. Sternite 5 small; S6 large, pale, lightly sclerotized, with evenly spaced equal small setae, broadest posteriorly. Sternite 7 ventrally broad; S7 and S8 sparsely microtrichose with few setulae, contrasting with pale, setulose T3-6. Sternite 8 marginally larger than epandrium, pale and bare; epandrium with stout dark setae on dorsal half, but with only a few scattered setae ventrally; cercus large and strongly projecting posteriorly, in contrast with most congeners. Hypandrium elongate and slender, forming an anterior loop extending beyond anterior margin of T6, anterior apex small and thin. Basiphallus well developed, broad, extending laterally and posteriorly to base of distiphallus. Basal part of distiphallus very broad, but strongly flattened, distally abruptly expanding to enclose a phallic bulb, which sperm duct enters through a distinct, condyle-like basal process flanked by a similar lobe; distal distiphallus tapered and whip-like. Ejaculatory apodeme very small, smaller than attached sperm pump.

\section{Remarks}

This species shares many distinctive features with the Ecuadorian $M$. cosanga sp. nov., including the unusual pale T3-6 and pale femoral bands. Mesoconius cosanga sp. nov., however, has white fore tarsi, lacks black notal and pleural markings, and lacks the raised ocellar triangle. These two species make up a single branch on the $\mathrm{CO} 1$ tree (Fig. 50), but they are widely separated on that branch. Mesoconius albitergum sp. nov. is apparently characterized by a number of characters in the male genitalia, such as the unusual distiphallus, projecting cercus and extremely elongate hypandrium, but males of the closely related $M$. cosanga sp. nov. remain unknown and only 3 of the 31 examined specimens of M. albitergum sp. nov. are males. The Venezuelan species M. anchitarsus sp. nov. is closely related, but easily distinguished by its greatly swollen female fore tarsomere 1 and its darkly pigmented and sclerotized male T3-6.

Mesoconius anchitarsus sp. nov.

urn:lsid:zoobank.org:act:D73E5CA8-A4A6-4658-AF62-F33D00158249

Fig. 4

\section{Etymology}

The species name refers to the broad female fore tarsomere 1 .

\section{Material examined}

Holotype

VENEZUELA • P; Mérida, Tabay, La Mucuy, Laguna Suero trail; 2700 m a.s.l.; 19 Jun.- 24 Jul. 1989; S. and J. Peck leg.; cloud forest; Malaise trap; MIZA. 
Paratypes

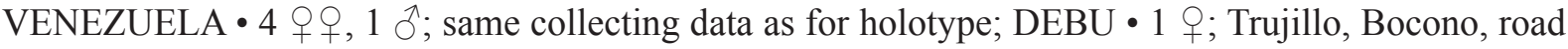
to Guaracamal; 2130 m a.s.l.; 2 Mar. 1995; S.A. Marshall leg.; DEBU • 1 o ; Merida, Rio Albarregas; 2200 m a.s.1.; 24 Apr. 1988; S.A. Marshall leg.; cloud forest; DEBU.

\section{Description}

\section{LENGTH. $17 \mathrm{~mm}$.}

Colour. Head mostly orange-brown, darker anteriorly; frontal vitta velvety dark brown anterior to ocellus, ocellar triangle and posterior part of vitta orange; antennae blackish microtrichose; clypeus, all of face below lunule and palpus yellow to orange; parafacial, gena (except small shiny midventral strip) and part of postocciput silver-microtrichose. Notum mostly orange, with two pairs of black vittae, outer vitta broader and interrupted by suture (vittae indistinct in male). Fore leg of male dark brown, except pale basal half of femur and pale distal part of tarsomere 1 and all of tarsomeres $2-5$. Fore femur of female orange, fore tibia and tarsus black, tarsus with expanded and enlarged black tarsomere 1. Mid and hind femora of male dark brown to black, except for a broad and contrasting white band flanked by narrow reddish-brown zones and a reddish apex; female with brown mid and hind femora, broken by a white band at middle. Wing uniformly yellowish infuscated. Abdominal T3-6 pale and lightly sclerotized in females, sclerotized and brown like $\mathrm{T} 1+2$ in male; pleuron white.

HEAD. Epicephalon dull, contrasting with shiny paracephalon and orbital strips; frontal vitta slightly depressed, slightly tapered posterior to ocelli, slightly expanded anterior to ocelli with a narrow anteromedial point usually touching anterior margin of frons. One small fronto-orbital bristle inserted at level of anterior ocellus (on border between epicephalon and orbital strip). Upper face broadly raised, lunule prominent and setulose. Clypeus mostly bare, microtrichosity restricted to back corner. Subantennal area microtrichose.

THORAX. Cervical sclerite subshining, with a vertical groove separating a large subquadrate microtrichose posterior portion from a small bare anterior portion. Notum finely and densely microtrichose, acrostichal and dorsocentral setulae in indistinct rows. Postpronotal lobe sparsely microtrichose, with several scattered small pale setae, anterior and posterior margins flat. Dorsocentral bristle thin, longer than scutellar length. Scutellum with four small discal setulae and a pair of long, closely spaced apical bristles. Katatergite moderately prominent, with a small pointed apex. Notopleuron with two widely spaced black bristles. Vertical row of katepisternal bristles golden. Fore coxa with black anteroventral setae, mid and hind coxae with golden anteroventral setae. Fore tarsus of female with expanded and enlarged black tarsomere 1, twice as thick and as long as remaining tarsomeres. Male tarsomere 1 elongate, but no thicker than other tarsomeres. Mid and hind femora almost bare basal to white band, microtrichose and distinctly swollen distally.

ABdomen. Abdominal segments $1+2$ petiolate, with almost no pleuron visible in male; female with $\mathrm{T} 2$ less petiolate. $\mathrm{T} 1+2$ about twice as long as T3; T1 setose, with preapical long, thin lateral setae; constricted area between $\mathrm{T} 1$ and $\mathrm{T} 2$ bare.

Female ABDomen. Single spermatheca and duct vestigial, arising from side of a short, broad common duct shared with much broader and longer paired spermathecal duct, paired duct with a membranous basal $2 / 3$ and a narrow, smooth distal third; stems of paired spermathecae convoluted, paired spermathecae pipe-shaped.

Male abdomen. Sternite 5 small; S6 large, unmodifed, broadest posteriorly. Synsternite 7-8 sparsely microtrichose, shiny, contrasting with dull, microtrichose preceding sclerites and microtrichose epandrium; S7 with a broad ventral part. Sternite 8 much smaller than epandrium; epandrium elongate, subquadrate, sparsely setose except densely long-setose produced posteroventral corner; cercus elongate 


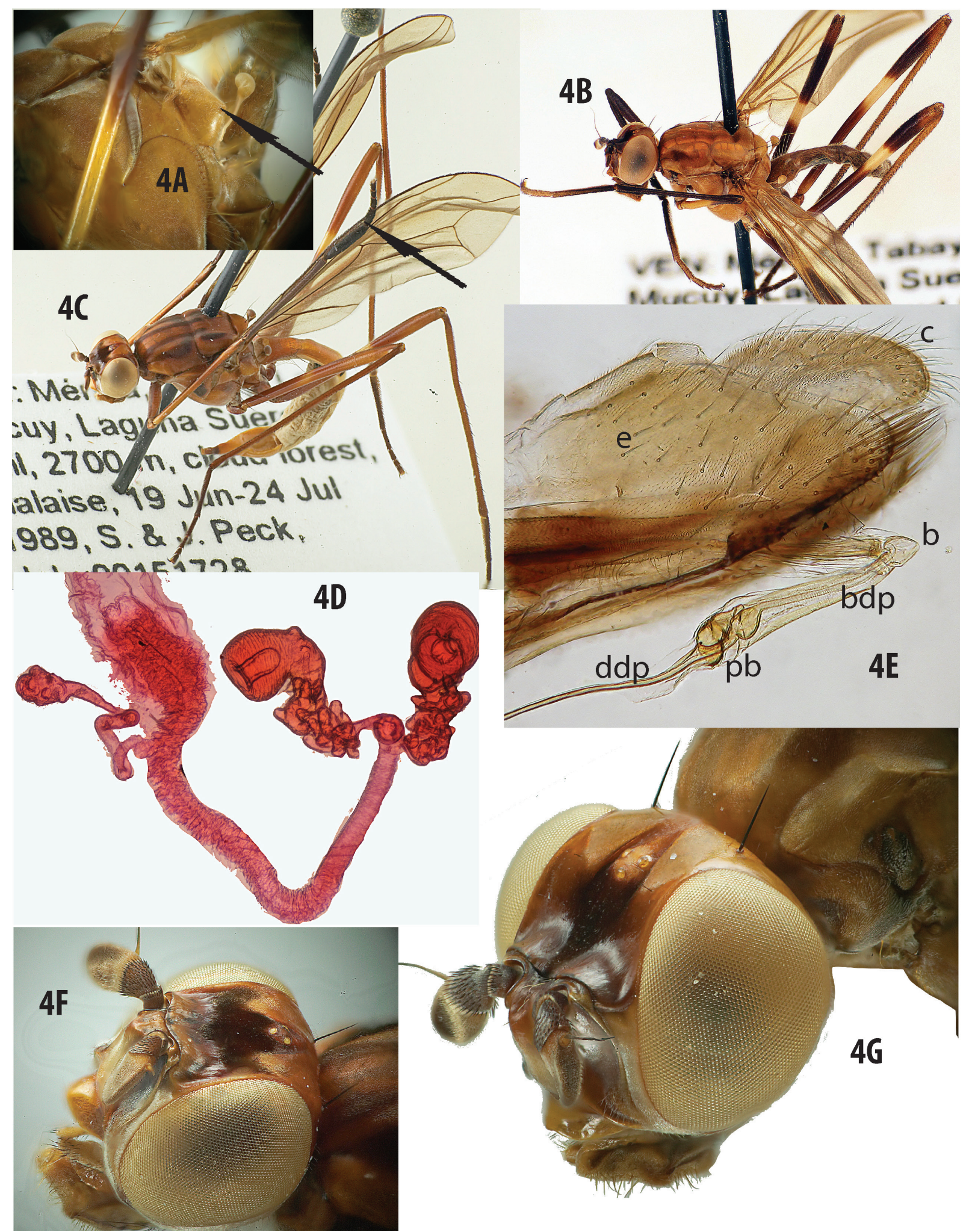

Fig. 4. Mesoconius anchitarsus sp. nov. A. Thorax-abdomen junction to show prominent katatergite (indicated by arrow). B. Paratype $\delta$. C. .. D. Spermatheca and associated structures. E. Male terminalia. F. Head,, . G. Head, $\widehat{\partial}$. Abbreviations: $\mathrm{b}=$ basiphallus; $\mathrm{bdp}=$ basal distiphallus; $\mathrm{c}=$ cercus; $\mathrm{ddp}=\mathrm{distal}$ distiphallus; $\mathrm{e}=$ epandrium; $\mathrm{pb}=$ phallic bulb. 
oval, ventral part projecting. Basiphallus extending slightly beyond base of distiphallus. Basal part of distiphallus very short, narrow basally, gradually expanding to a broad, truncate and somewhat flattened apex enclosing base of phallic bulb; distal part of distiphallus very long and whip-like, extending beyond narrow anterior hypandrial margin. Ejaculatory apodeme greatly reduced, smaller than associated sperm pump.

\section{Remarks}

Mesoconius anchitarsus sp. nov. is very similar to M. albitergum sp. nov. (Colombia) and M. cosanga sp. nov. (Ecuador), with almost the same thoracic and leg pigmentation and very similar internal genitalia. The females of $M$. anchitarsus sp. nov., however, are strikingly different because of their greatly enlarged and flattened first fore tarsomere. The only available male specimen of M. anchitarsus sp. nov. differs from males of M. albitergum sp. nov. in having darkly pigmented and sclerotized T3-6.

Mesoconius auristrigatus Enderlein, 1922

Figs 5-6

Mesoconius auristrigatus Enderlein, 1922: 178.

\section{Material examined}

Holotype

COLOMBIA • + ; v. Nolcken leg.; MNBG.

The collector was presumably J.H. Wilhelm Baron (von) Nolcken, who collected in the mountains of Colombia during 1870-71 (Papavero 1973).

\section{Other material}

COLOMBIA • 1 q; Huila, PNN Cueva de los Guácharos Mirador; $01^{\circ} 38^{\prime}$ N, 7606' W; 1980 m a.s.l.; 2-5 Dec. 2001; D. Campos leg.; Malaise trap 4; MYCRO325-18 sequenced for CO1; IAVH.

ECUADOR • 1 गे; Napo, SierrAzul Lodge, 14 km W of Cosanga; 2200 m a.s.1.; 8-11 May 2002; S.M. Paiero leg.; dung on leaf; MYCRO455-18 sequenced for CO1; DEBU • 2 q 9 ; Pichincha, $15 \mathrm{~km} \mathrm{NW}$ of Nono, road to Mindo; 2000 m a.s.1.; 25 Oct. 1999; S.A. Marshall leg.; on log; DEBU • 1 क; Pichincha, Bellavista Reserve; 2200 m a.s.l.; 28 Oct. 1999; S.A. Marshall leg.; DEBU • 2 q o ; Pichincha, Mindo, trail to Bellavista Reserve; $00^{\circ} 03^{\prime 2} 29^{\prime \prime}$ S, $78^{\circ} 46^{\prime} 06^{\prime \prime}$ W; 1 May 2011; S.A. Marshall leg.; DEBU • 4 우; Pichincha, Bellavista Cloud Forest Reserve; 0001'13" S, 7840'30" W; 2200 m a.s.1.; 9-13 May 2009; S.A. Marshall leg.; MYCRO080-15 sequenced for CO1; DEBU.

\section{Redescription}

LENGTH. 17-18 mm.

Colour. Head black, except as follows: parafacial, postgena and most of gena silvery microtrichose, middle part of gena shiny brown ventrally; palpus yellow-orange; lower face pale, face and clypeus otherwise brown. Thorax mostly dark brown to black, with reddish patches, notum dull brown, except for indistinct subshining black patch above postpronotal lobe, prominent narrow golden dorsocentral vitta and a wider postsutural vitta running over supra-alar area to side of scutellum; posterior notopleural bristle arising from a microtrichose patch; pleuron with large silvery patches posteroventrally on katepisternum and posteriorly on anepisternum; most of propleuron, cervical sclerite and prominent katatergite orange. Fore leg orange basally, apex of femur, tibiae and tarsus black, mid and hind femora orange, except for a variably brown- or black-margined middle white band (in some specimens white band only margined distally). Wing uniformly infuscated, without clear spots or bands. Abdomen with 
tergites reddish and pleuron pale on segments 1-3; tergites brown and pleuron darkened on segments 4-6. Oviscape pale brown, darker at apex.

HEAD. Epicephalon and paracephalon very finely striate, dull; frontal vitta sharply tapered posterior to ocelli, broad anterior to ocelli, with an inconspicuous anteromedial point, widely separated from anterior margin of frons; inner vertical bristle strong, with four-five setulae near base. One strong fronto-orbital bristle inserted in a discrete patch of thick white microtrichia near lower margin of epicephalon. Upper face broadly raised, microtrichosity of lower face extending dorsally as a parallel-sided band almost to lunule, subantennal areas mostly shiny, lower corner microtrichose.

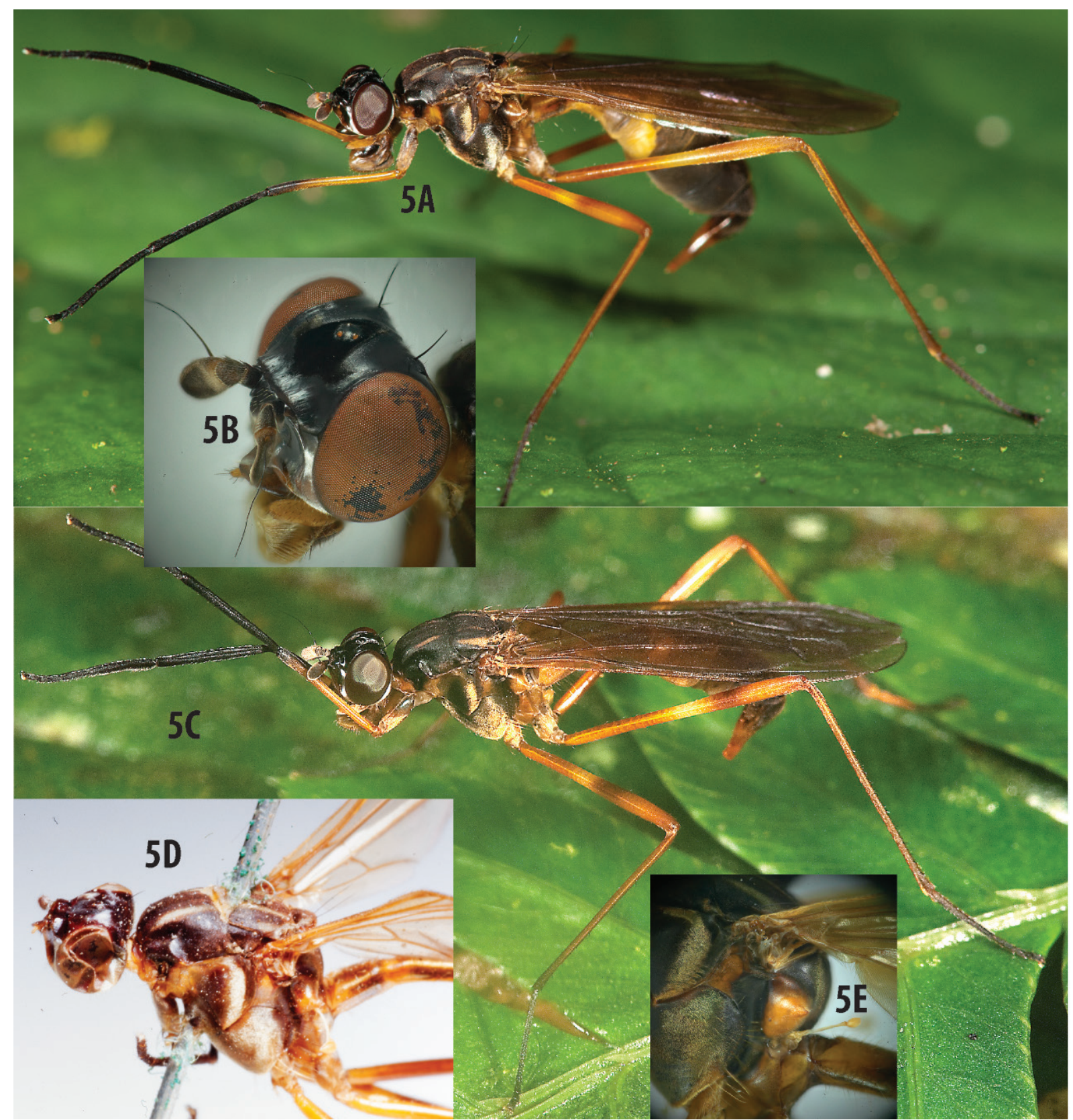

Fig. 5. Mesoconius auristrigatus Enderlein, 1922, external characters. A, C. Living $q q$, Ecuador. B. Head, + . D. Holotype,, , MNBG. E. Pleuron and base of abdomen to show orange katatergite. 
THORAX. Cervical sclerite with a vertical groove separating a large subquadrate posterior portion from a small anterior portion. Notum finely and densely microtrichose, acrostichal and dorsocentral setulae in distinct rows, scattered setulae also present anterolaterally. Postpronotal lobe dull, densely microtrichose with several scattered small pale setae, anterior margin bare, shiny and almost vertical, posterior margin bare and sloped. Notopleuron with two widely spaced bristles, posterior bristle darker and thicker than

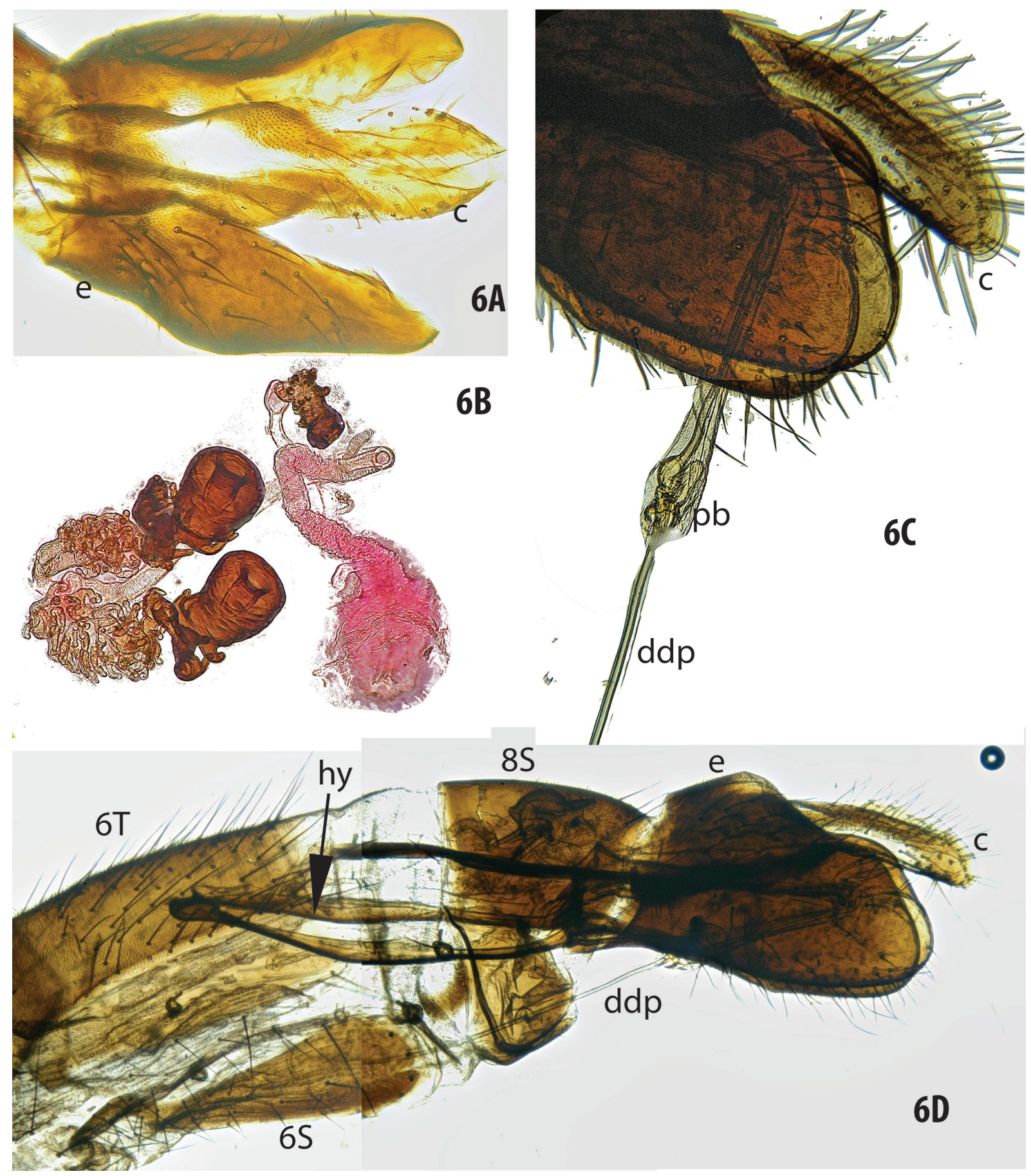

Fig. 6. Mesoconius auristrigatus Enderlein, 1922, internal characters. A. Male epandrium and cerci, posterodorsal view. B. Spermathecae and associated structures. C. Male terminalia with phallus teased out, directed ventrally. D. Apex of abdomen, $\widehat{O}$, lateral view. Abbreviations: $\mathrm{c}=$ cercus; $\mathrm{ddp}=\mathrm{distal}$ distiphallus; $\mathrm{e}=$ epandrium; hy = hypandrium; $\mathrm{pb}=$ phallic bulb. 
anterior. Dorsocentral bristle very small, golden, shorter than scutellar length and about $1 / 3$ as long as golden supra-alar. Scutellum with four small discal setulae and a pair of long, closely spaced black apical bristles (longer than scutellum). Katatergite very prominent, with a long, nipple-like microtrichose pointed process. Vertical row of katepisternal bristles golden. All coxae with golden anteroventral setae.

ABDOMEN. Abdominal segment 1 and basal half of segment 2 petiolate; length of $1+2$ slightly less than double length of tergite 3 . T1 setose, with preapical long, thin lateral setae.

Female ABDomen. Oviscape bare, except for scattered setulae. Bursa small, suboval, ventral receptacle small and inconspicuous. Single spermathecal duct constricted at base, branching off a very short common duct that then tapers slightly to much longer paired spermathecal duct, which is divided into distinct parts including a short rugose basal $1 / 3$ that abruptly transforms into a slightly narrower, relatively smooth (indistinctly striate) distal $2 / 3$. Paired spermathecae expanded distally, apex invaginated, surface reticulate, stem (beyond division of paired duct) broad, conspicuously coiled and finely tuberculate on basal half, distal half dark, thick and very strongly tuberculate. Single spermathecal duct similar in texture to distal part of paired spermathecal duct but much smaller, single spermatheca small, on a thick tuberculate stem as thick as spermatheca, separated from main part of duct by a constriction.

MALE ABDOMEN (tentative association; see Remarks). Sternites 5 and 6 large, tapered anteriorly and notched posteromedially. Synsternite 7-8 sparsely microtrichose, shiny, contrasting with dull, microtrichose preceding sclerites and pale microtrichose epandrium; S7 with a very broad but unmodified ventral part. Sternite 8 much smaller than epandrium, epandrium elongate, sparsely setose except for a dense patch of setae posteroventrally; cercus prominent, large, elongate and slightly curved, strongly projecting posteroventrally. Hypandrium elongate and slender, extending to anterior margin of T6. Basiphallus small, not extending beyond base of distiphallus. Basal part of distiphallus narrow basally, distally abruptly expanding to enclose a small phallic bulb; distal part of distiphallus tapered and whip-like. Ejaculatory apodeme very small, smaller than attached sperm pump.

\section{Remarks}

Mesoconius auristrigatus seems to be very closely related to M. nigripleuron sp. nov. (from Peru). Male specimens assigned to these two species are similar, but those of $M$. nigripleuron sp. nov. have apically concave or bilobed cerci, in contrast to the tapered cerci of the one male treated as M. auristrigatus. These species also differ in leg colour and spermathecal structure, and they are widely separated (p-distance ca 10\%) on the CO1 tree (Fig. 50). Ecuadorian and Colombian female specimens treated here as M. auristrigatus have distinct $\mathrm{CO} 1$ sequences and differ slightly in the colour of the margins of the bands on mid and hind tibia. Examination of more extensive collections might justify recognition of the Ecuadorian populations as a separate species and might show that the Ecuadorian populations on the eastern side of the Central Valley (now known from one male) and western side of the Central Valley (now known only from females) differ. See also Remarks under M. noteques sp. nov.

Mesoconius cosanga sp. nov. urn:1sid:zoobank.org:act:58017DCD-03F4-4131-99EA-9D7ADA383EA2

Fig. 7

\section{Etymology}

The specific name of this species is a noun in apposition taken from the name of the type locality.

\section{Material examined}

\section{Holotype}

ECUADOR • + ; Napo, 4.2 km S of Cosanga, pipeline trail; 2150 m a.s.1.; 7 Nov. 1999; S.A. Marshall leg.; UGIC176-15/MYCRO077-15, sequenced for CO1; QCAZ. 

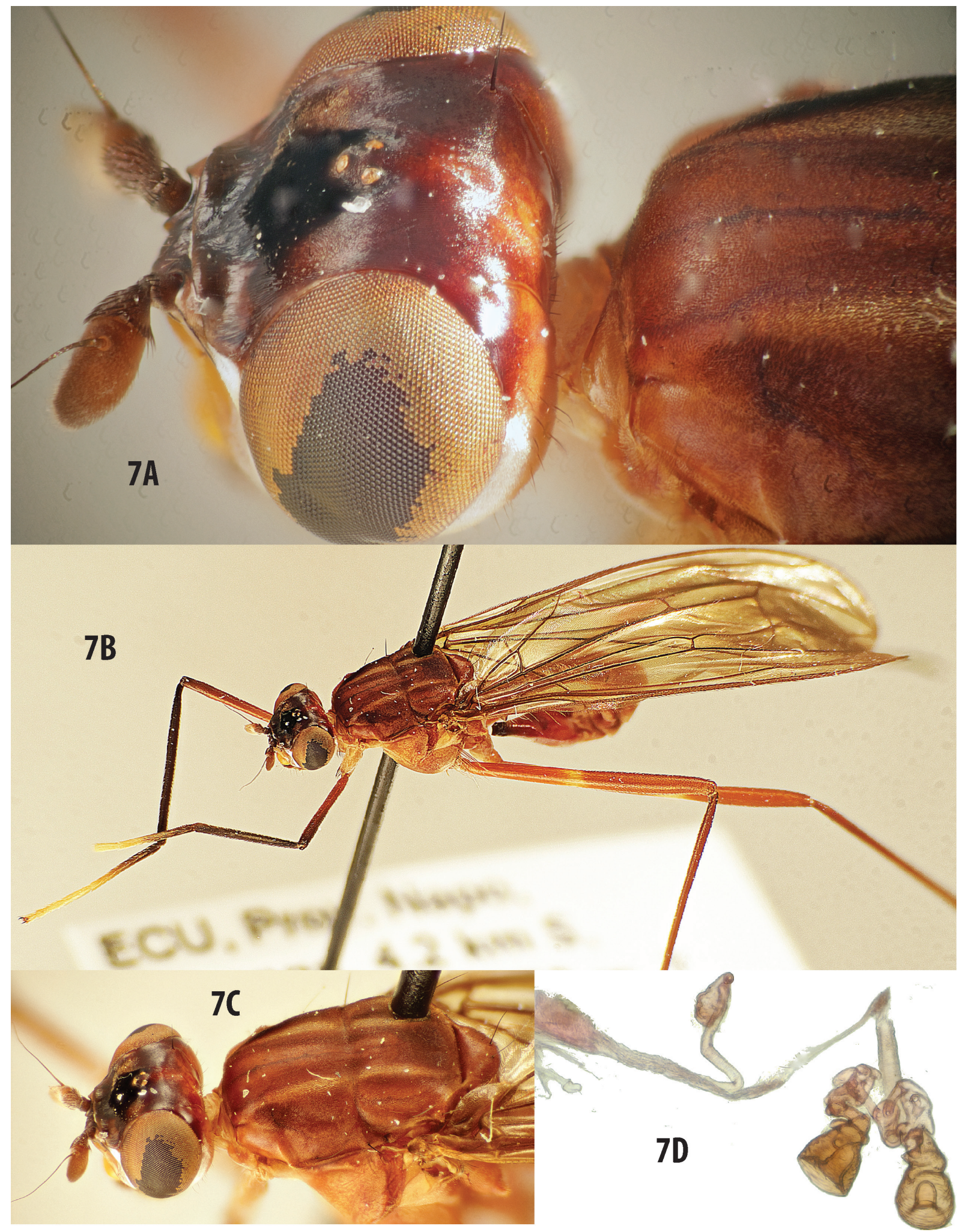

Fig. 7. Mesoconius cosanga sp. nov., holotype,, , QCAZ. A. Head and notum. B. Habitus. C. Head and thorax. D. Spermatheca and associated structures. 
Description (female holotype only)

LENGTH. $15 \mathrm{~mm}$.

Colour. Burnt orange, except as follows: parafacial, postgena and most of gena silvery microtrichose, palpus and clypeus yellow; lower face white; frontal vitta anterior to ocelli velvety black, lower frons dark reddish brown. Cervical sclerite entirely pale yellow and subshining. Scutum with two narrow, sublateral golden vittae (lines of golden microtrichia) broken by deep transverse suture and ending well before scutellum; area between postpronotal lobe and narrow golden vittae darkened by black microtrichia; middle of scutum with a very narrow, indistinct black vitta. Fore tibia dark brown to black, fore tarsus white, except at base; mid and hind femora with a narrow and indistinct white band, before middle on mid femur and at middle on hind femur. Wing uniformly brownish-yellow infuscated. Abdomen pale and lightly sclerotized between darker, fully sclerotized syntergite $1+2$ and oviscape.

HEAD. Epicephalon very finely striate, dull; paracephalon smooth and shiny; frontal vitta not visibly extending posterior to ocelli. Fronto-orbital bristle small, inserted on lower, microtrichose part of epicephalon well anterior to ocellar triangle. Upper face broadly raised, convex at middle, subantennal areas mostly shiny, silvery microtrichose in lower quarter.

Thorax. Cervical sclerite not distinctly divided into anterior and posterior portions. Acrostichal and dorsocentral setulae sparse and minute, but in distinct rows. Postpronotal lobe subshining, very sparsely microtrichose, with some scattered small pale setae, anterior margin bare and almost vertical, posterior margin setulose and only slightly less vertical than anterior margin. Dorsocentral bristle very small, similar in size to scutellar setulae and about $1 / 3$ as long as supra-alar. Scutellum with four small discal setulae and pair of long, closely spaced apical bristles (longer than scutellum). Katatergite very prominent, with a long, nipple-like, microtrichose pointed process. Notopleuron with two widely spaced black bristles. Vertical row of katepisternal bristles golden. Fore coxa with black anteroventral setae, mid and hind coxae with anteroventral golden setae.

Female abdomen. As described for M. albitergum sp. nov.

\section{Remarks}

Mesoconius cosanga sp. nov. is very closely related to the Colombian species M. albitergum sp. nov., with which it shares the distinctive desclerotization of the middle abdominal segments. It differs from M. albitergum sp. nov. in having white fore tarsi, a pale anterior spiracle and a mostly orange notum without broad black vittae. Mesoconius cosanga sp. nov. and M. albitergum sp. nov. were recovered as a single branch on the $\mathrm{CO} 1$ tree, but with a deep split between the species.

Mesoconius epandribarba sp. nov.

urn:1sid:zoobank.org:act:39ECDB1C-D9C9-48E7-B339-5095F1CB0A48

Fig. 8

\section{Etymology}

The specific name is a noun referring to the beard-like posteroventral corner of the epandrium.

\section{Material examined}

\section{Holotype}

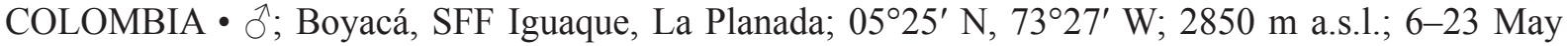
2000; P. Reina leg.; Malaise trap; IAVH.

Paratypes

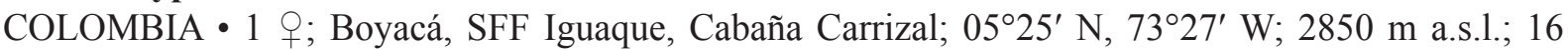
Apr.-2 May 2001; P. Reina leg.; IAVH • 1 O; Boyacá, SFF Iguaque, Quebrada Los Francos; $05^{\circ} 25^{\prime} \mathrm{N}$, 
73²7’ W; 2860 m a.s.1.; 7-24 Feb. 2001; P. Reina leg.; IAVH • 1 đ’; Boyacá, SFF Iguaque, La Planada; $05^{\circ} 25^{\prime}$ N, 7327' W; 2850 m a.s.1.; 19 Apr.-6 May 2000; P. Reina leg.; Malaise trap; MYCRO328-18

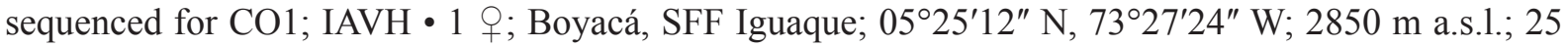
Jun.-13 Jul. 2000; P. Reina leg.; Malaise trap; IAVH • $1{ }^{\top}$; Boyacá, SFF Iguaque, La Planada; $05^{\circ} 25^{\prime} \mathrm{N}$, $73^{\circ} 27^{\prime}$ W; 2850 m a.s.1.; 13-30 Jul. 2000; P. Reina leg.; Malaise trap; IAVH.

\section{Description}

LENGTH. 17-20 mm.

Colour. Head black, except as follows: parafacial, postgena and most of gena silvery microtrichose, middle part of gena shiny brown ventrally; palpus pale dull yellow, darker basally; lower face pale, face and clypeus otherwise brown to black. Cervical sclerite reddish brown and subshining. Thorax mostly black, notum with dull silvery longitudinal lateral vittae continuous with broader postsutural vittae running over supra-alar area to side of scutellum; scutellum reddish brown; dorsocentral bristle inserted in reddish prescutellar patches. Fore coxa black, fore femur yellow except for brown apex, mid and hind femora black on basal quarter to half, otherwise bright yellow; mid and hind tibiae yellowish brown, tarsi brown but densely black setose. Wing uniformly and conspicuously yellow, without clear spots or bands. Abdomen with tergites black and pleuron pale; oviscape shiny reddish brown, except for dark apex.

HEAD. Epicephalon and paracephalon finely striate, dull; frontal vitta sharply tapered posterior to ocelli, broad anterior to ocelli, with an anteromedial point reaching anterior margin of frons; inner vertical bristle strong, with four-five setulae near base. One strong fronto-orbital bristle inserted in a discrete patch of thick white microtrichia near lower margin of epicephalon. Upper face broadly raised, white microtrichosity of lower face extending dorsally almost to lunule, subantennal areas microtrichose on outer half.

THORAX. Cervical sclerite with a vertical groove separating a large subquadrate posterior portion from a small anterior portion. Notum finely and densely microtrichose, acrostichal and dorsocentral setulae in distinct rows, scattered setulae also present anterolaterally. Postpronotal lobe densely microtrichose, with several scattered small pale bristles, anterior margin bare, shiny and almost vertical, posterior margin bare and sloped. Dorsocentral bristle golden, longer than scutellar length (right dorsocentral black on one female paratype). Scutellum with four small discal setulae and long, closely spaced golden apical bristles (longer than scutellum). Katatergite very prominent, with a long, nipple-like, microtrichose pointed process. Anterior notopleural bristle golden; posterior bristle black, on a microtrichose patch. Vertical row of katepisternal bristles brown. All coxae with black anteroventral setae, mid coxae with some golden setae.

ABDomen. Abdominal segment 1 and base of segment 2 petiolate, length of $1+2$ slightly more than double length of T3. T1 setose, with preapical long, thin lateral setae.

Female ABDomen. Oviscape bare except for scattered setulae, microtrichose apex and a narrow preapical band of microtrichia. Bursa broad, ventral receptacle small and inconspicuous; single spermathecal duct short and branching off side of a broad and parallel-sided common duct that continues unmodified as proximal half of paired spermathecal duct, distal half slightly narrower, relatively smooth (indistinctly striate). Paired spermathecae pipe-shaped, expanded distally to invaginated apex, surface transverse striate, stem (beyond division of paired duct) broad and conspicuously coiled and tuberculate, darker at base of spermatheca. Single spermathecal duct similar in texture to distal part of paired spermathecal duct but much smaller, single spermatheca elongate and tubercle-studded, separated from stem by a small spherical swelling. 


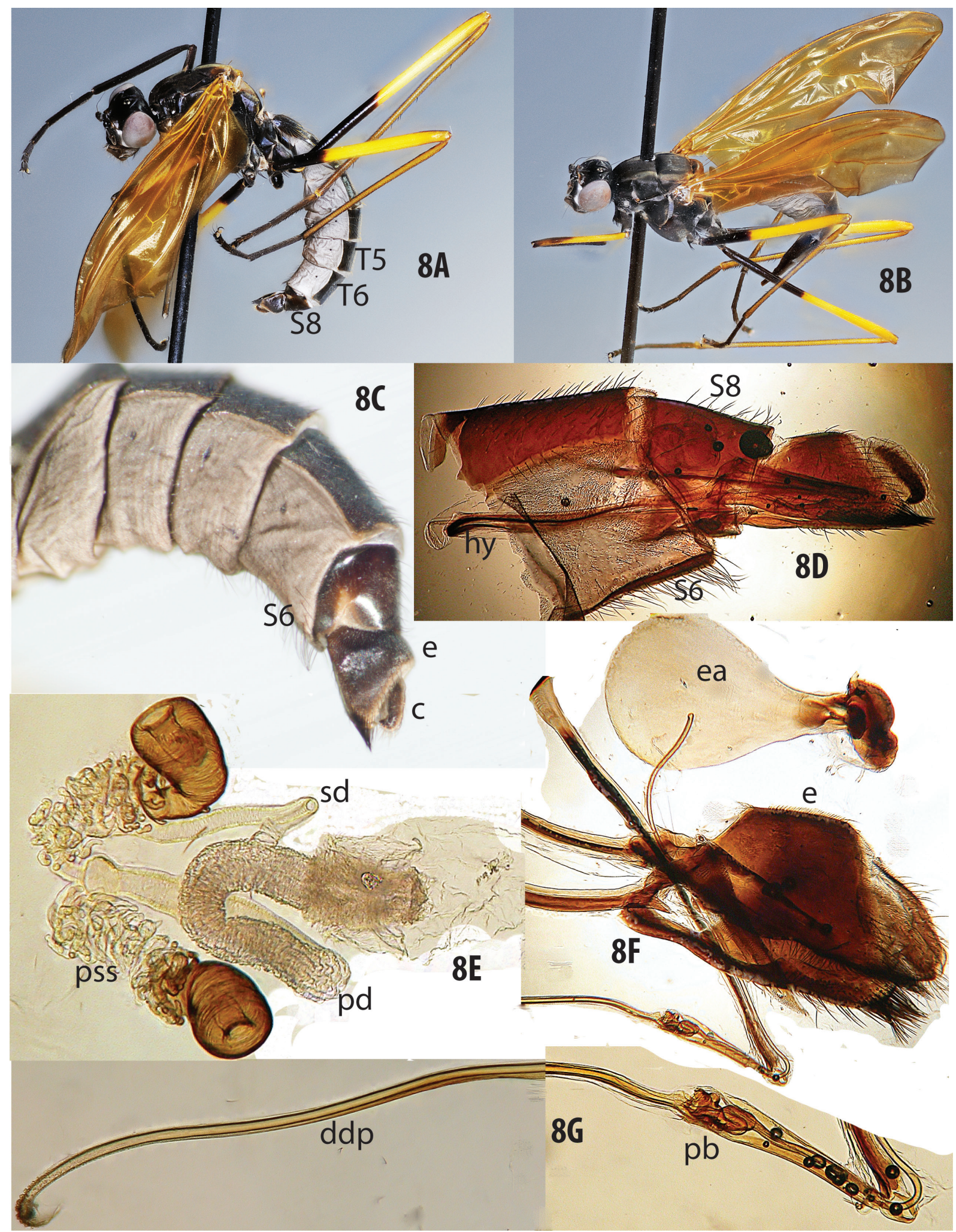

Fig. 8. Mesoconius epandribarba sp. nov. A. Holotype, ô, IAVH. B. Paratype, $q$. C. Abdomen in lateral view, $\widehat{\jmath}$. D. Male terminalia and abdominal segments 5-8. E. Spermathecae and associated structures. F. Male terminalia, left lateral view. G. Phallus, left lateral view. Abbreviations: $\mathrm{c}=$ cercus; $\mathrm{ddp}=\mathrm{distal}$ distiphallus; $\mathrm{e}=$ epandrium; $\mathrm{ea}=$ ejaculatory apodeme; hy = hypandrium; $\mathrm{pb}=$ phallic bulb; $\mathrm{pd}=$ paired spermathecal duct; pss = paired spermathecal stem; $s d=$ single spermathecal duct. 
Male abdomen. Sternite 5 long and thin, similar to S4; S6 large, tapered anteriorly, expanded and notched posteromedially. Synsternite 7-8 mostly microtrichose, shiny and bare on anterior third of S8, contrasting with dull, microtrichose preceding sclerites and microtrichose epandrium; S7 with a very broad but unmodified ventral part. Sternite 8 larger than epandrium, epandrium short dorsally and elongate ventrally, microtrichose but sparsely setose, except for a dense and prominent patch of setae posteroventrally; cercus small but distinct. Hypandrium elongate and slender, extending to anterior margin of T6, anterior apex not expanded. Basiphallus small, not extending beyond base of distiphallus. Basal part of distiphallus very short, narrow basally, distally abruptly expanding to enclose a small phallic bulb; distal part of distiphallus slender, parallel-sided, more than twice as long as basal distiphallus. Ejaculatory apodeme similar in size to epandrium.

\section{Remarks}

Mesoconius epandribarba sp. nov., M. nigripleuron sp. nov. and M. auristrigatus are closely related and very similar.

Mesoconius eques (Schiner, 1868) comb. nov.

Fig. 9A-C, D (in part), E-I

Calobata eques Schiner, 1868: 251.

Mesoconius aeripennis Enderlein, 1922: 180. syn. nov.

Cliobata eques - Steyskal 1968: 48.6

\section{Material examined}

Type material of Calobata eques Schiner, 1868

VENEZUELA • $\widehat{~}$ (probable type); "eques, Alta Sammlung"; "Venezuela"; "Mesoconius End. F. Hendel det."; NHMW.

Holotype of Mesoconius aeripennis Enderlein, 1922

ECUADOR • + ; Baños; R. Haensch leg.; MNBG.

Other material

ECUADOR - 4 ऊิô, 8 우; Napo, SierrAzul Reserve, $14 \mathrm{~km}$ W of Cosanga; $2200 \mathrm{~m}$ a.s.l.;

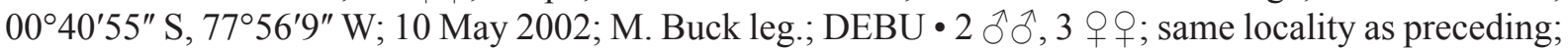

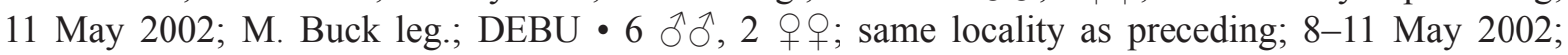

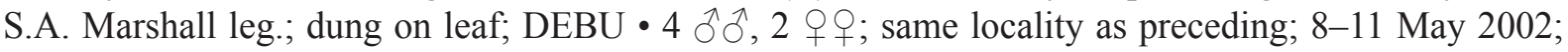
S.M. Paiero leg.; MYCRO074-15 sequenced for CO1; DEBU • 1 \%; same locality as preceding; 8-11 May 2002; P. Careless leg.; DEBU • 1 đ̊; same locality as preceding; 5 Nov. 1999; S.A. Marshall leg.; dung ball; DEBU • 1 क ; Napo, Yanayacu; 23-28 Jul. 2008; W.K. Reeves leg.; DEBU • 1 đ̃; Napo, $4.2 \mathrm{~km}$ S of Cosanga, pipeline trail; 2150 m a.s.1.; 7 Nov. 1999; S.A. Marshall leg.; QCAZ.

\section{Description}

LENGTH. $16-18 \mathrm{~mm}$.

CoLour. Black, including wing membrane, except as follows: parafacials, gena and face strongly silvery microtrichose, inner and outer margins of subantennal areas shiny brown; mid and hind femur usually with white bands near or just beyond middle, bands vary from wide to obsolete. Notum with postsutural area silvery microtrichose, except at middle, pruinosity extending presuturally as two broad longitudinal vittae and sometimes a narrow median vitta. Abdominal pleuron dirty white. 
HEAD. Epicephalon and paracephalon finely striate, subshining; frontal vitta velvety, posteriorly tapered to a broad, densely microtrichose patch extending to level of inner vertical bristles, broad and broadly tapered anteriorly, extending $2 / 3$ of distance from ocellus to frons margin. One large fronto-orbital bristle, inserted at junction of epicephalon and orbital strip. Antennae separated by width of antennal socket, upper quarter of face strongly and broadly carinate, lower face flat. Clypeus mostly bare. Lower back of head densely short-setose.

THORAX. Cervical sclerite with a microtrichose, subquadrate posterior portion and a small bare anterior portion. Fore tibia narrow, sulcate on outer face. Tarsomere 1 of fore leg expanded and flat, much wider than and longer than other tarsomeres combined, very broad and cultriform in male, less conspicuously broadened in female. Mid and hind femora shiny and almost bare basal to pale band near midpoint, setulose and slightly swollen distally. Notum microtrichose, with rows of small acrostichal and dorsocentral setulae; postpronotal lobe microtrichose, with some scattered small setulae, anterior margin forming a vertical, shiny face. Dorsocentral bristle slightly longer than scutellar length. Scutellum with two-four small discal setulae and a pair of long apical bristles (longer than scutellum). Katatergite very prominent, with a long, tapered microtrichose nipple-like process. Notopleuron with two widely spaced black bristles. Vertical row of katepisternal bristles black. Coxae with anteroventral black setae.

AвDomen. Abdominal segment 1 and base of segment 2 petiolate; length of $1+2$ twice as long as that of tergite 3 .

FEMALE ABDOMEN. Bursa small, inconspicuous; ventral receptacle reduced; single spermatheca small, tuberculate, on a short duct arising from side of a long common duct that becomes basal part of paired spermathecal duct; paired spermathecae with a very long, broad duct divided into two parts: basal $2 / 3$ broader, more membranous and accordian-like, distal part more sclerotized and with weak transverse striations and slightly swollen before splitting into strongly tuberculate stems leading to each spermatheca. Paired spermathecae cup-like, invaginated apically, with transverse striations.

MALE ABDOMEN. S5 small, unmodified. S6 tapered anteriorly, broad posteriorly, posterior margin with a deep V-shaped emargination. S7 broad, extending along hind margin of S6. S7-8 black, shiny except for dull, microtrichose posterior margin. Epandrium with large, quadrate, setose posteroventral angles, cercus large and in a more or less dorsal position. Hypandrium anteriorly forming a simple loop with a small and narrow anterior process. Basiphallus very small, frame-like; not extending beyond base of distiphallus. Basal part of distiphallus short, narrowly tubular, gradually expanding to a large phallic bulb; distal part of distiphallus $3 \times$ as long, terminating in a barb-like apex. Ejaculatory apodeme slightly smaller than epandrium.

\section{Remarks}

The unusual appearance of this species, which is almost entirely black including the wing membrane and abdominal pleuron, is matched by an undescribed species of Poecilotylus Hennig, 1934 (Fig. 9D, in part) from the same locality in Ecuador where most of the specimens of Mesoconius eques examined here were collected. Mesoconius noteques sp. nov., from Peru, also resembles M. eques in external features other than the fore tarsi (slender in M. noteques sp. nov.), but is very different in the structure of the spermathecal ducts. The other almost entirely black species in the Mesoconius eques group, M. pasachoa sp. nov., has more extensive pale pigmentation on the tibiae and tarsi. The most remarkable external feature of $M$. eques is the expanded, paddle-like tarsomere 1, which is especially broad in the male but also conspicuously expanded in the female. The only congener with a similarly expanded male tarsomere is $M$. lobopoda sp. nov., in which the expanded tarsomere of males is brown on the outer surface and brilliantly white on the inner surface. Mesoconius lobopoda sp. nov. differs widely in other characters and does not belong to this species group. The type specimens of M. eques (described from 


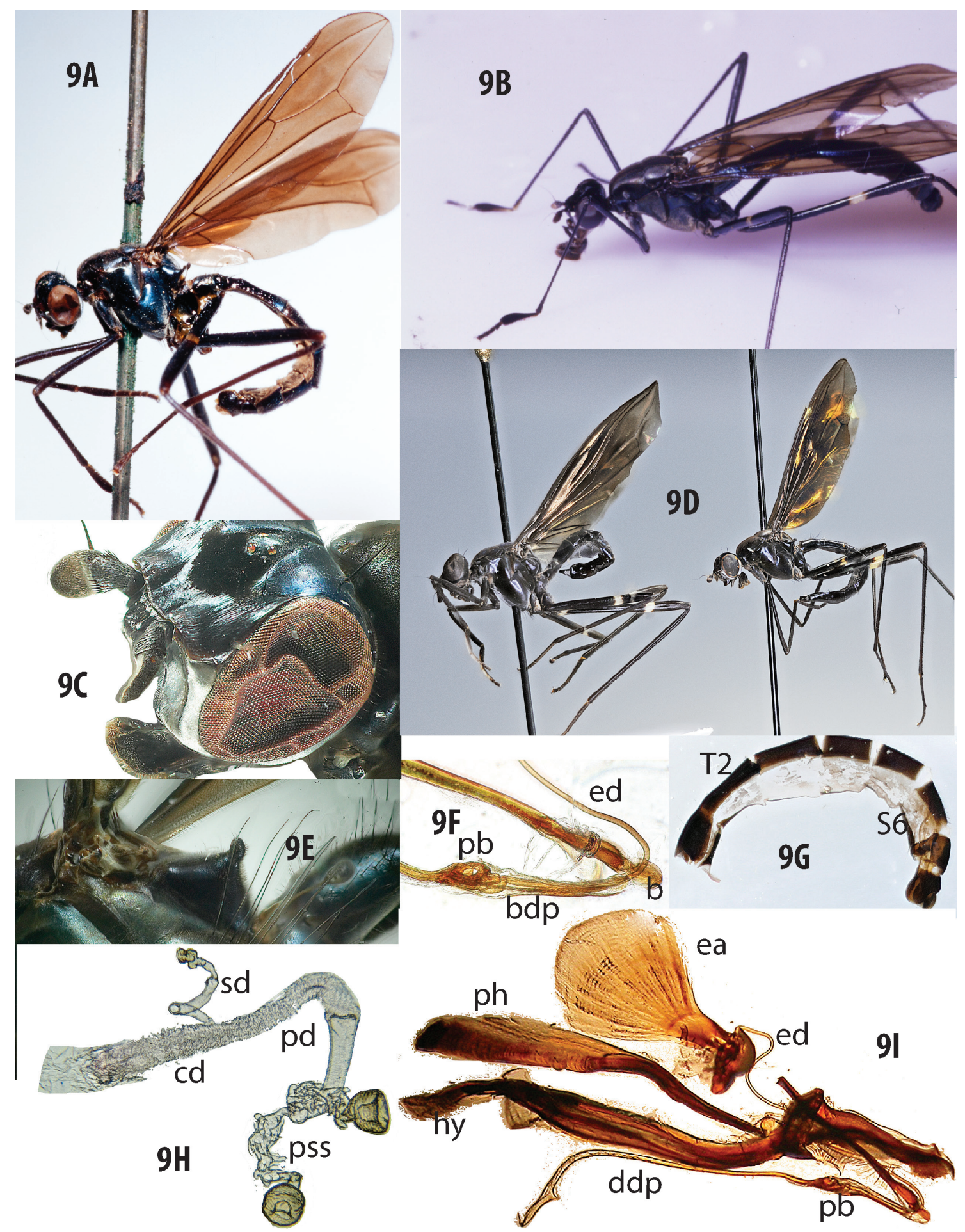

Fig. 9. Mesoconius eques (Schiner, 1868). A. Presumed holotype, $\hat{\partial}$, NHMW, Venezuela. B. Live $\widehat{\partial}$, Ecuador. C. Head. D. $\odot$ (right) and a sympatric undescribed species of Poecilotylus Hennig, 1934 (left), Ecuador. E. Thorax-abdomen junction to show prominent katatergite. F. Base of phallus and distal part of phallapodeme, Ecuador. G. Abdomen, ô, lateral view, Ecuador. H. Spermatheca and associated structures, Ecuador. I. Male aedeagus and associated structures, Ecuador. Abbreviations: bdp = basal distiphallus; $\mathrm{cd}=$ common spermathecal duct/distal bursa; $\mathrm{ddp}=$ distal distiphallus; ea $=$ ejaculatory apodeme; ed = ejaculatory duct; hy = hypandrium; $\mathrm{pb}=$ phallic bulb; $\mathrm{pd}=$ paired spermathecal duct; $\mathrm{ph}=$ phallapodeme; $\mathrm{pss}=$ paired spermathecal stem; $\mathrm{sd}=$ single spermathecal duct. 
Venezuela) and M. aeripennis (described from Ecuador) differ slightly, as the hind femur of the former has a white band and the hind femur of the latter appears to be immaculate. Most of the new material reported here (from Ecuador) seems identical to the type of M. eques (from Venezuela) but the band on the hind femur is reduced on some specimens. I see no other character that might justify recognizing M. aeripennis and M. eques as different species.

\section{Mesoconius hirsutimamma sp. nov. urn:lsid:zoobank.org:act:2DA4B03F-AC09-4DB1-88BF-5BC39E0A19DF}

Fig. 10

\section{Etymology}

The specific name is a noun in apposition that translates loosely to 'hairy nipple', referring to the distinctive katatergite.

\section{Material examined}

\section{Holotype}

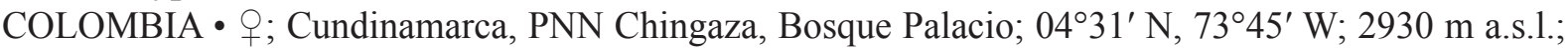
13-31 Oct. 2000; E. Raigoso leg.; MYCRO329-18 sequenced for CO1; IAVH.

Description (females only)

LENGTH. $19 \mathrm{~mm}$.

Colour. Head black anterior to ocelli, except for golden setulose first flagellomere, upper back of head reddish, clypeus orange medially, lower face and parafacial strips pale. Thorax mostly black, but with distinct orange areas including katatergite and surrounding area, postpronotal lobe and scutellum apex. Fore leg black, except for mostly orange coxa and yellow tarsomeres; base of tarsomere 1 apparently black because of dense black setulae. Mid and hind femora narrowly black at base, but otherwise reddish orange, mid and hind tibae orange, tarsi mostly black. Wing uniformly dark yellowish, without clear spots or bands. Abdominal tergites black, extreme apex of oviscape orange; pleuron white.

HEAD. Frontal vitta elongate, broadly reaching anterior and posterior head margins, middle weakly delineated from fronto-orbital strip. One strong fronto-orbital bristle inserted in fronto-orbital strip near lower margin of epicephalon. Upper face broad, distinctly elevated, face otherwise pale, membranous and microtrichose, subantennal areas shiny. Clypeus shiny, bare, distinctly striate.

THORAX. Cervical sclerite with a small, bare anterior portion, with a carina separating it from a middle portion that is depressed far below large, convex microtrichose posterior portion. Notum finely and densely microtrichose, acrostichal and dorsocentral setulae long and in distinct rows. Postpronotal lobe densely microtrichose, with several setae on ventral half only; anterior margin almost vertical, bare and shiny dorsally; posterior margin microtrichose and sloped. Dorsocentral bristle golden, twice as long as scutellum. Scutellum with four small discal setulae and long, closely spaced golden apical bristles (longer than scutellum). Katatergite very prominent, with a long, nipple-like setulose pointed process. Notopleuron with two widely spaced black bristles. Vertical row of katepisternal bristles black. All coxae with golden anteroventral setae.

ABDOMEN. Abdominal segment 1 and base of segment 2 petiolate; length of $1+2$ slightly less than double length of tergite 3 . T1 setose, with preapical long, thin lateral setae. Oviscape bulbous basally, somewhat flattened distally; bare except for scattered setulae. Bursa elongate, ventral receptacle prominent, with a distinct head. Single spermathecal duct branching off a long, broad common duct; single spermatheca 
greatly reduced, single duct very short. Paired spermathecal duct divided into distinct parts including a rugose basal $2 / 3$ that abruptly transforms into a relatively smooth distal $1 / 3$. Paired spermathecae expanded distally to deeply invaginated apex, surface ringed with transverse striae, stem (beyond division of paired duct) elongate and conspicuously tuberculate.

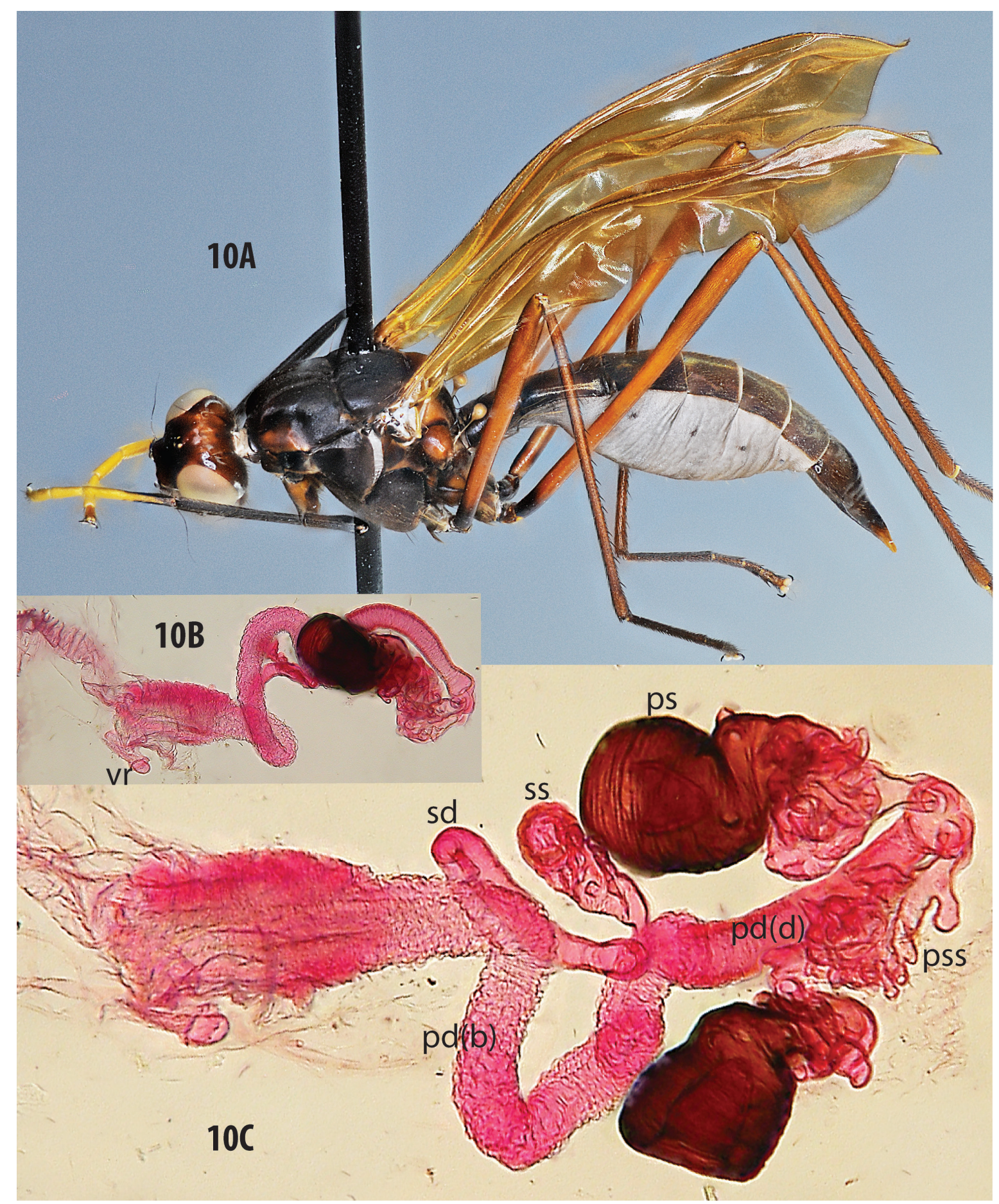

Fig. 10. Mesoconius hirsutimamma sp. nov. A. Holotype,, , IAVH. B-C. Spermathecae and associated structures. Abbreviations: $\mathrm{pd}(\mathrm{b})=$ paired spermathecal duct (basal section); $\mathrm{pd}(\mathrm{d})=$ paired spermathecal duct (distal section); $p s$ = paired spermatheca; $p s s=$ paired spermathecal stem; sd = single spermathecal duct; ss $=$ single spermatheca; $v r=$ ventral receptacle. 


\section{Remarks}

The broad, yellow-brown wings, the prominent orange katatergite, red mid and hind femora with a narrow black base, and the orange tibiae are diagnostic for M. hirsutimamma sp. nov.

Mesoconius nigripleuron sp. nov.

urn:1sid:zoobank.org:act:E0C3E8FB-3EAF-4AE2-969D-6E6A271C81ED

Figs $11-12$

\section{Etymology}

This species is named for the darkly pigmented abdominal pleuron.

\section{Material examined}

\section{Holotype}

PERU • P; Cusco, Wayqecha Biological Station, $9 \mathrm{~km} \mathrm{NE}$ of Challabamba; $13^{\circ} 10^{\prime} 20^{\prime \prime} \mathrm{S}, 71^{\circ} 35^{\prime} 00^{\prime \prime} \mathrm{W}$; 2600-2700 m a.s.1.; 1-6 Dec. 2011; S.A. Marshall leg.; MUSM.

\section{Paratypes}

PERU • 7 우, 3 $\hat{o}$; same collecting data as for holotype; three specimens sequenced for CO1: MYCRO075-15, MYCRO078-15, MYCRO327-18; DEBU • 3 우; same collecting data as for holotype; MUSM • 1 क; same locality as holotype; 16-18 Jul. 2014; M. Zhang and B. Sharanowski leg.; Malaise trap; DEBU.

\section{Other material}

BOLIVIA • 1 क; La Paz, Coroico, Cerro Uchumachi; 2550 m a.s.1.; 16 ${ }^{\circ} 12^{\prime} 43^{\prime \prime}$ S, 67 $67^{\circ} 42^{\prime} 49^{\prime \prime}$ W; 16 Apr. 2001; S.A. Marshall leg.; cloud forest; MYCRO324-15 sequenced for CO1; DEBU.

\section{Description}

LENGTH. 17-19 mm.

CoLour. Head black, except for first flagellomere, which is reddish basally and dark brown distally, and reddish palpus and clypeus. Thorax mostly dark brown to black, apex of scutellum, pleural suture and supra-alar area orange; notum with two broad silvery-golden microtrichose lateral vittae and a weak central vitta (at least presuturally); postsutural part of notum with broad lateral vittae only. Legs of females sharply bicoloured, fore leg black except for mostly orange femur, mid femur narrowly orange at base but otherwise black on basal half and orange distally, hind femur black on basal half and orange distally, mid and hind tibae orange, tarsi mostly black but tarsomere 1 of mid and hind leg pale basally and ventrally. Legs of males variably coloured, mid and hind femora orange basally and with a central white band, with black areas on both sides of white band or with one distinct black band distal to white band. Wing uniformly dark yellowish, without clear spots or bands. Abdomen mostly black, bases of $\mathrm{T} 2$ and T3 brown, T2 with an orange posterior corner; T1 of male orange, pleuron uniformly and darkly pigmented.

HEAD. Orbital strip and epicephalon microtrichose, paracephalon shiny, finely striate; frontal vitta weakly delineated, broad anterior to ocelli, with a broad and inconspicuous anteromedial margin widely separated from anterior margin of frons, narrow and sulcate posterior to ocelli; inner vertical bristle strong, with four-five setulae near base; outer vertical bristle and postocellar bristle absent. One strong fronto-orbital bristle inserted in a discrete patch of microtrichia near lower margin of epicephalon. Upper face broad and slightly elevated, face otherwise membranous and microtrichose, subantennal areas shiny, parafacials microtrichose. Clypeus shiny, mostly bare, distinctly striate, microtrichosity restricted to dorsal part of posterolateral corner. 
THORAX. Cervical sclerite with a small, bare anterior anterior portion, with a carina separating it from a middle portion that is in turn separated from large posterior, setulose portion by another carina. Notum finely and densely microtrichose, acrostichal and dorsocentral setulae long and in distinct rows, scattered

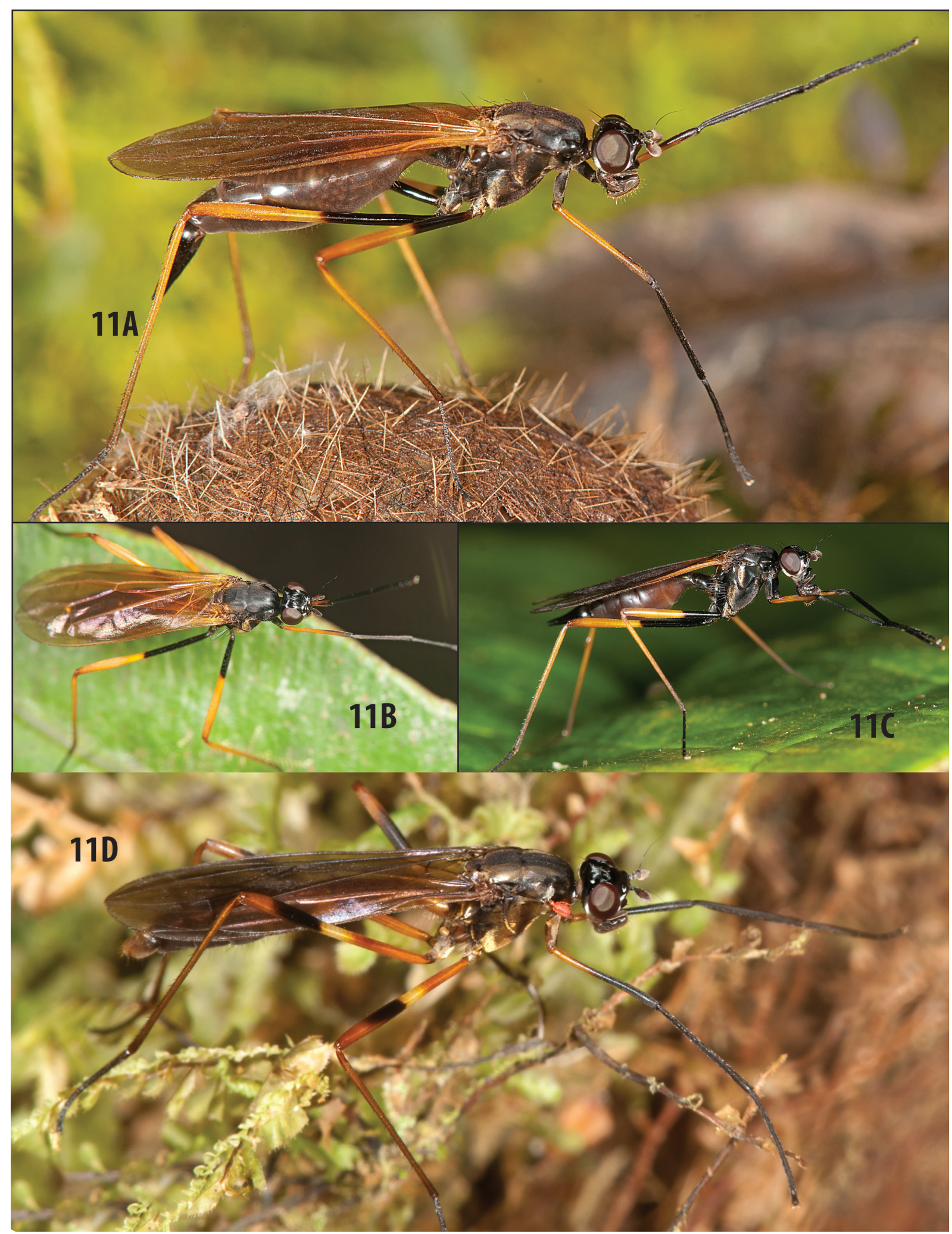

Fig. 11. Mesoconius nigripleuron sp. nov., living specimens, Peru. A-C. $q q$. D. §̂. 
setulae anterolaterally. Postpronotal lobe dull, densely microtrichose, with several scattered small pale setae, anterior margin almost vertical, bare and shiny dorsally; posterior margin microtrichose and steeply sloped. Dorsocentral bristle black, slightly shorter than length of scutellum. Scutellum with four small discal setulae and long, closely spaced black apical bristles (longer than scutellum). Katatergite very prominent, with a long, nipple-like microtrichose pointed process. Notopleuron with two widely spaced black bristles. Vertical row of katepisternal bristles golden. All coxae with golden anteroventral setae.

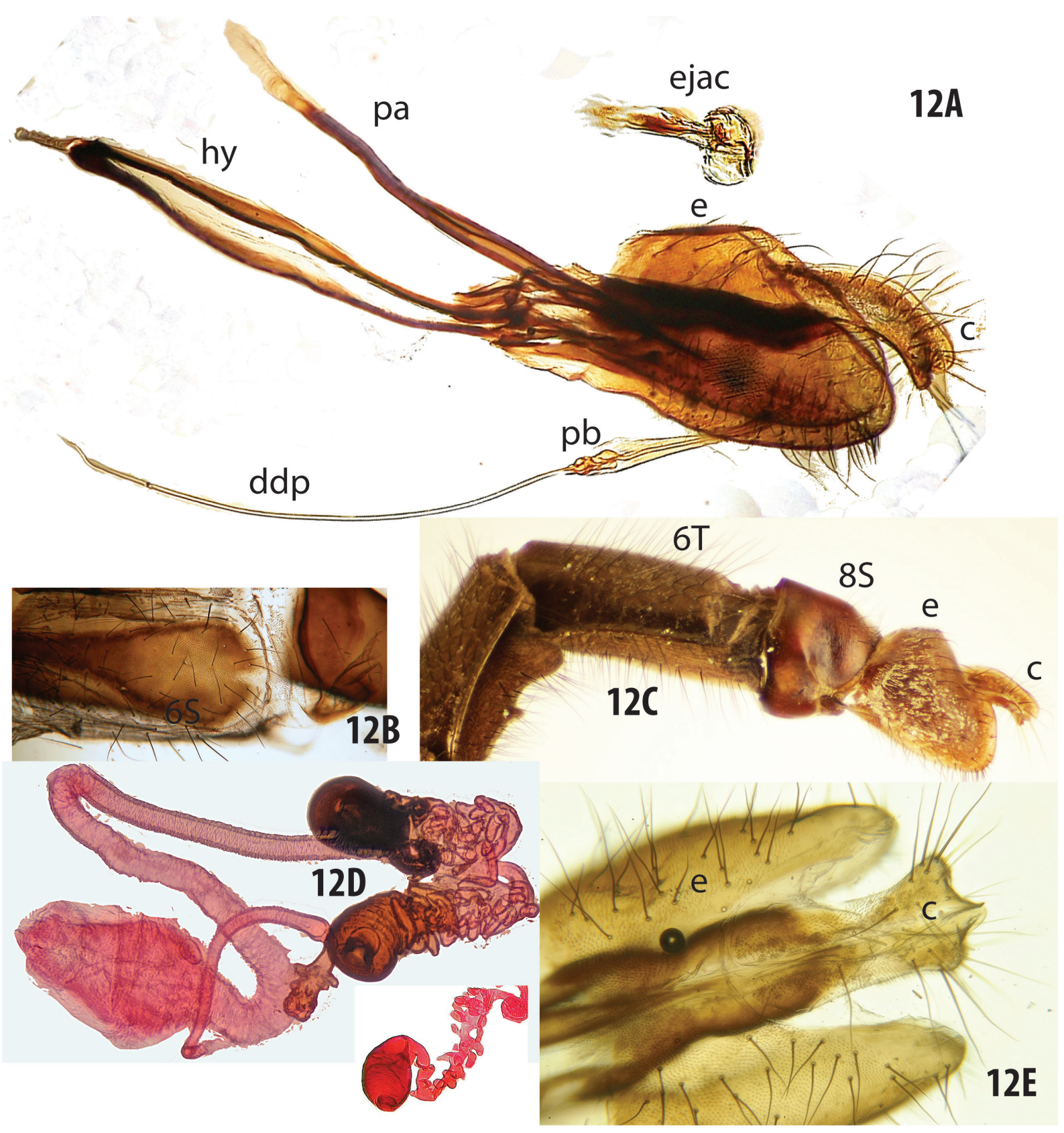

Fig. 12. Mesoconius nigripleuron sp. nov., internal characters, Peru. A. Male terminalia, lateral view. B. S6 to S8, O. C. Abdomen, O. D. Spermathecae and associated structures (inset: one of the paired spermathecae with a partially uncoiled stem). E. Male epandrium and cerci, posterodorsal view. Abbreviations: $\mathrm{c}=$ cercus; $\mathrm{ddp}=$ distal distiphallus; $\mathrm{e}=$ epandrium; ejac $=$ ejaculatory apodeme; $\mathrm{hy}=$ hypandrium; $\mathrm{pa}=$ phallapodeme; $\mathrm{pb}=$ phallic bulb. 
AвDOMEN. Abdominal segment 1 and base of segment 2 petiolate; $1+2$ slightly less than twice as long as tergite 3 . T1 setose, with preapical long, thin lateral setae.

FemAle ABDOMEn. Oviscape bare except for scattered setulae. Bursa elongate, ventral receptacle small and inconspicuous. Single spermathecal duct branching laterally off a short, broad common duct; single spermatheca greatly reduced, single duct almost as long as paired duct, but less than $1 / 4$ as wide. Paired spermathecal duct divided into distinct parts, including a rugose basal half that abruptly transforms into a slightly narrower, relatively smooth (indistinctly striate) distal half. Paired spermathecae expanded distally to invaginated apex, surface reticulate, stem (beyond division of paired duct) elongate and conspicuously coiled and tuberculate.

MALE ABDOMEN. Sternite 5 small and narrow; S6 large, tapered anteriorly and notched posteromedially; T6 densely golden microtrichose. Synsternite $7-8$ sparsely microtrichose, forming a shiny ring contrasting with dull, microtrichose preceding sclerites and pale microtrichose epandrium; S7 with a very broad but unmodified ventral part. Sternite 8 similar in size to epandrium (longer dorsally, shorter ventrally), epandrium elongate, sparsely setose except for a dense patch of setae posteroventrally; cerci prominent, large, elongate and apically bilobed, together forming a medially keeled tripartite distal shield strongly projecting posteroventrally. Hypandrium elongate and slender, extending to anterior margin of T6. Basiphallus small, not extending beyond base of distiphallus. Basal part of distiphallus narrow basally, distally abruptly expanding to enclose a small phallic bulb with a small ventral sac and an elongate dorsal sac; distal part of distiphallus slender, twice as long as basal part. Ejaculatory apodeme very small, smaller than attached sperm pump.

\section{Remarks}

The distinctive black, yellow-winged females of this species usually differ from those of other black species by their sharply bicoloured mid and hind femora with dark bases and yellow-orange distal halves, although the one female specimen from Bolivia has leg colour like males from Peru. Males, which can be strikingly different in colour but are identical in $\mathrm{CO} 1$ sequence to the females (sequences 078 and 327 are male and female, respectively), key out with M. auristrigatus Enderlein, 1922, although they are generally darker, with a darker katatergite, dark thoracic bristles, a dark reddish brown palpus and much darker femoral banding (compare Figs 5A and 11D). One of the males has only one distinct black band distal to the white band on both mid and hind femora (Fig. 11D); the other two have black areas on both sides of the white band. Many distinctive features (elongate and curved cercus, characteristic epandrium, elongate and posteriorly expanded sternite 6 , darkly pigmented female abdominal pleuron) suggest that $M$. nigripleuron sp. nov. and $M$. auristrigatus are closely related, despite the strikingly different females and the distinct male cerci.

Mesoconius noteques sp. nov.

urn:1sid:zoobank.org:act:F10BDA67-7B09-4796-80F3-97C10C598F7F

Fig. 13

\section{Etymology}

This species was named by adding a prefix to the name of the superficially similar M. eques (Schiner, 1868).

\section{Material examined}

Holotype

PERU • +; Cusco, Wayqecha Biological Station, $9 \mathrm{~km} \mathrm{NE}$ of Challabamba; $13^{\circ} 10^{\prime} 20^{\prime \prime} \mathrm{S}, 71^{\circ} 35^{\prime} 00^{\prime \prime} \mathrm{W}$; 2600-2700 m a.s.1.; 1-6 Dec. 2011; S.A. Marshall leg.; MUSM.

Paratype

PERU • 19; same collecting data as for holotype; MYCRO454-18; DEBU. 
Description (female only)

\section{LENGTH. $18 \mathrm{~mm}$.}

Colour. Almost entirely black, including wing membrane and abdominal pleuron, except as follows: parafacial, gena and face strongly silvery microtrichose, inner margins of subantennal areas shiny brown;

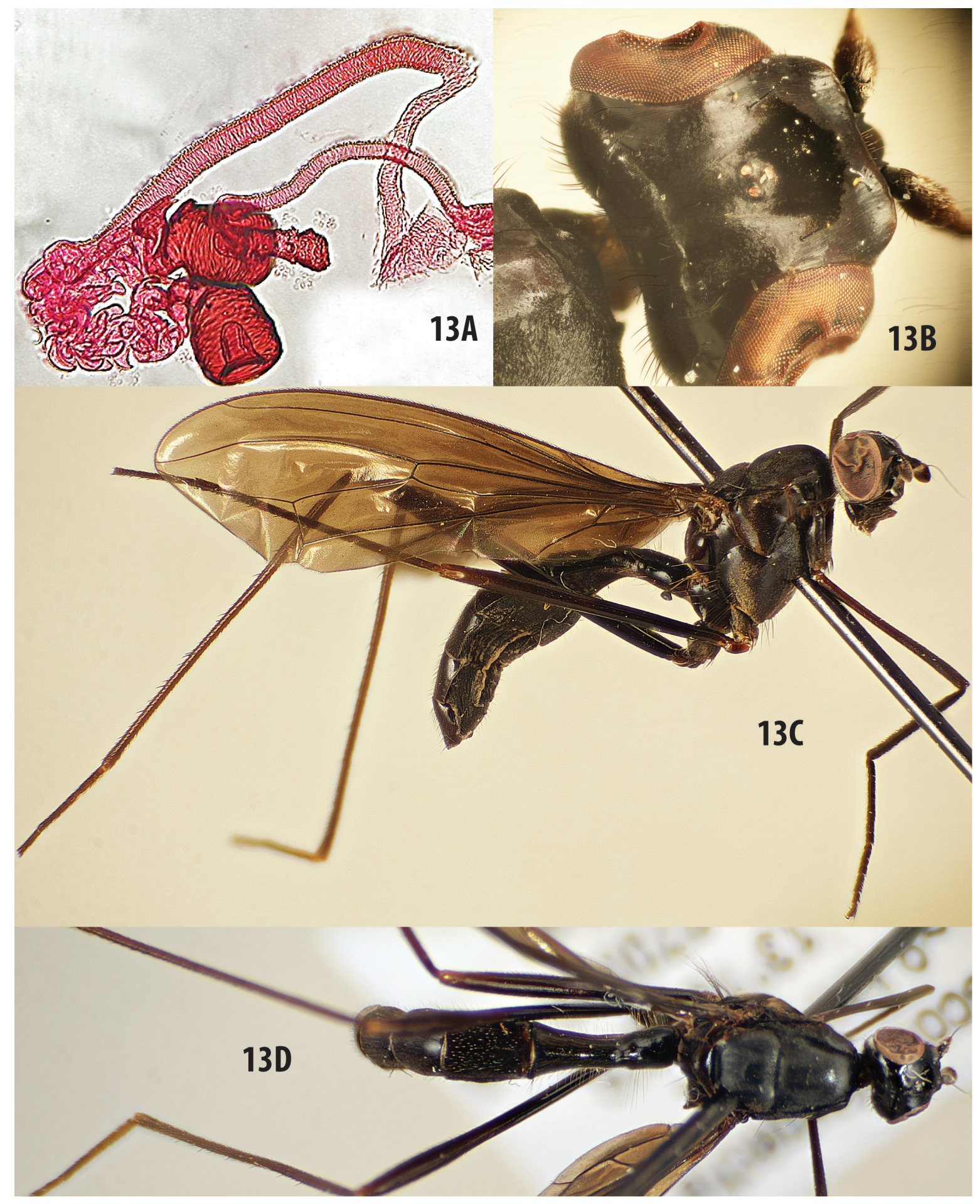

Fig. 13. Mesoconius noteques sp. nov., 우. A. Spermathecae and associated structures. B. Head. C. Habitus, lateral view. D. Body, dorsal view. 
base of first flagellomere reddish. Mid and hind femora with indistinct (barely discernable) yellow bands near or just beyond middle, somewhat reddish distal to bands. Notum with dense microtrichosity forming three very indistinct longitudinal silvery vittae. Katatergite reddish brown.

HEAD. Epicephalon and paracephalon finely striate, subshining; frontal vitta posteriorly broadly tapered, almost to level of inner vertical bristles without surrounding microtrichosity, broad and broadly rounded anteriorly, extending $2 / 3$ of distance from ocellus to frons margin. One large fronto-orbital bristle inserted at junction between epicephalon and orbital strip. Antennae separated by more than width of antennal socket, upper quarter of face strongly and broadly carinate, lower face flat. Clypeus mostly bare. Lower back of head densely short-setose.

THORAX. Cervical sclerite with a microtrichose, subquadrate posterior portion and a small, bare anterior portion. Fore tibia flat, sulcate on outer face. Tarsomere 1 of fore leg narrow. Mid and hind femora shiny and almost bare basal to pale band near midpoint, setulose and slightly swollen distally. Notum microtrichose, with rows of small acrostichal and dorsocentral setulae; postpronotal lobe microtrichose with some scattered small setulae, anterior margin forming a vertical face, shiny on upper half. Dorsocentral bristle slightly longer than scutellum. Scutellum with two-four small discal setulae and a pair of long apical bristles (longer than scutellum). Katatergite very prominent, with a long, tapered microtrichose, nipple-like process. Notopleuron with two widely spaced black bristles. Vertical row of katepisternal bristles black. Fore coxa with anteroventral black setae, mid coxa with row of golden anteroventral setae.

ABdomen. Abdominal segment 1 and base of segment 2 petiolate; length of $1+2$ double that of tergite 3. Bursa small, smooth; ventral receptacle inconspicuous; single spermatheca small but elongate, with several tuberculate processes, on a short duct arising near apex of bursa independently of paired duct. Paired spermathecae with a very long, broad duct divided into two parts: basal third more membranous and wrinkled, distal part more sclerotized, with weak transverse striations and slightly swollen before splitting into strongly convluted stems leading to each spermatheca. Paired spermathecae large and elongate, almost cylindrical, but slightly expanded and invaginated apically.

\section{Remarks}

This species looks much like Mesoconius eques and was initially misidentified as such, but it differs in having an unmodified fore tarsomere 1 , golden mid-coxal setae and both spermathecal ducts arising independently from the small bursa (on a long common duct in M. eques). Mesoconius noteques sp. nov. is one of several sympatric and remarkably similar black Micropezidae, and the material described here was collected at the same time and place as the superficially similar M. quadritheca sp. nov. and a very similar undescribed black species of Cliobata Enderlein, 1922. The paratype was sequenced for the barcode region of $\mathrm{CO} 1$ and recovered in the middle of a cluster of M. nigripleuron sp. nov. on the maximum likelihood tree (Fig. 50), apparently sharing the same haplotype as three of the sequenced M. nigripleuron sp. nov., a differently coloured species with orange wings and banded legs. Since $M$. noteques sp. nov. is known only from females, and since females of the M. eques group are mostly very similar, it is possible that $M$. noteques sp. nov. is an extreme colour variant of $M$. nigripleuron sp. nov. However, this is unlikely, as wing colour is not known to vary intraspecifically in the genus and other colour characters are extremely different, well outside the normal range of variation.

Mesoconius obtusiconus Enderlein, 1922

Fig. 14

Mesoconius obtusiconus Enderlein, 1922: 179. 


\section{Material examined}

Holotype

PERU • †; Cusco, Callanga, Piñipiñi Valley; 1500 m a.s.l.; O. Garlepp leg.; MNBG.

\section{Other material}

COLOMBIA • O; Nariño, La Planada Nature Reserve Parcela Permanente; $01^{\circ} 15^{\prime} \mathrm{N}, 78^{\circ} 15^{\prime} \mathrm{W} ; 1885 \mathrm{~m}$ a.s.l.; 2-16 Jun. 2001; G. Oliva leg.; Malaise trap; M2382; IAVH.

\section{Description}

Described based on Colombian non-type specimen (female) except as noted.

\section{LENGTH. $17 \mathrm{~mm}$.}

Colour. Abdomen orange at base (T1-2 or T1-3), otherwise black; thorax mostly black, metapleuron and scutellum orange on Colombian specimen but not on type. Head black, except as follows: gena, extreme anteroventral corner of face and parafacial silvery microtrichose, palpus orange-brown, margin and postocellar part of frontal vitta silvery microtrichose, scutum with a silvery longitudinal vitta on each side, presutural part of silver strip narrow and tapered anteriorly, postsutural part broader and split to create a diffuse, central dark patch. Fore tarsus white (type with base of tarsomere 1 and all of tarsomeres 4-5 darkened), hind tarsus white, with mostly white setae on tarsomeres $1-4$, dark setae on tarsomere 5 (hind tarsus missing on Colombian specimen); fore femur orange basally, black distally; mid femur sharply divided into orange basal and black distal half; hind femur similarly divided, but with a white band near base of distal black part. Tibiae black. Wing clear except for indistinct broad discal and apical bands. Oviscape black. Pleuron pale except for slightly darkened upper halves of pleura 3-6.

HEAD. Epicephalon and paracephalon bare and shiny, indistinctly striate, sharply contrasting with dull striate orbits and lower frons; frontal vitta broad anterior to ocelli $(0.44 \times$ frontal width), constricted behind ocelli to form a broad, microtrichose, parallel-sided band. Fronto-orbital bristles (2) widely separated, upper fronto-orbital bristle very large, inserted on epicephalon well above orbital strip, lower fronto-orbital minute. Upper face flat, except for a narrow central carina, subantennal areas shiny.

Thorax. Cervical sclerite with a vertical groove separating a microtrichose, subquadrate, dark and convex posterior portion from a small, bare, pale anterior portion. Scutum with microtrichose pattern of silvery areas as noted above, otherwise unevenly microtrichose, broad central vitta with a narrow long-microtrichose vitta flanked by scattered small acrostichal setulae near middle; dorsocentral setulae minute, but forming a row; postpronotal lobe microtrichose, except for shiny anterior fifth, which has many small setulae. Dorsocentral bristle strong, longer than scutellum. Katatergite slightly swollen, entirely setulose, without a point or prominent apex. Vertical row of katepisternal bristles yellow. Coxae with black anteroventral setae.

ABdomen. Abdominal segments 1 and 2 petiolate; length of $1+22.4 \times$ that of tergite 3 . Bursa with a small oval body bearing a finger-like ventral receptacle, distally extending as a broad common spermathecal duct. Single spermathecal duct arising just before apex of common spermathecal duct, uniformly smooth and parallel-sided until a constriction just before basally swollen and distally tapered single spermatheca. Paired spermathecal duct arising at apex of long common duct, entirely smooth and uniform from apex of striated common duct to constriction, before splitting into paired spermathecae and their stems. Paired spermathecae oval, distinctly striate, each stem with a large oval swelling and a distal section with an S-bend putting spermatheca at right angle to duct. Single spermathecal duct only slightly smaller than paired duct, spermatheca narrow but well developed. 


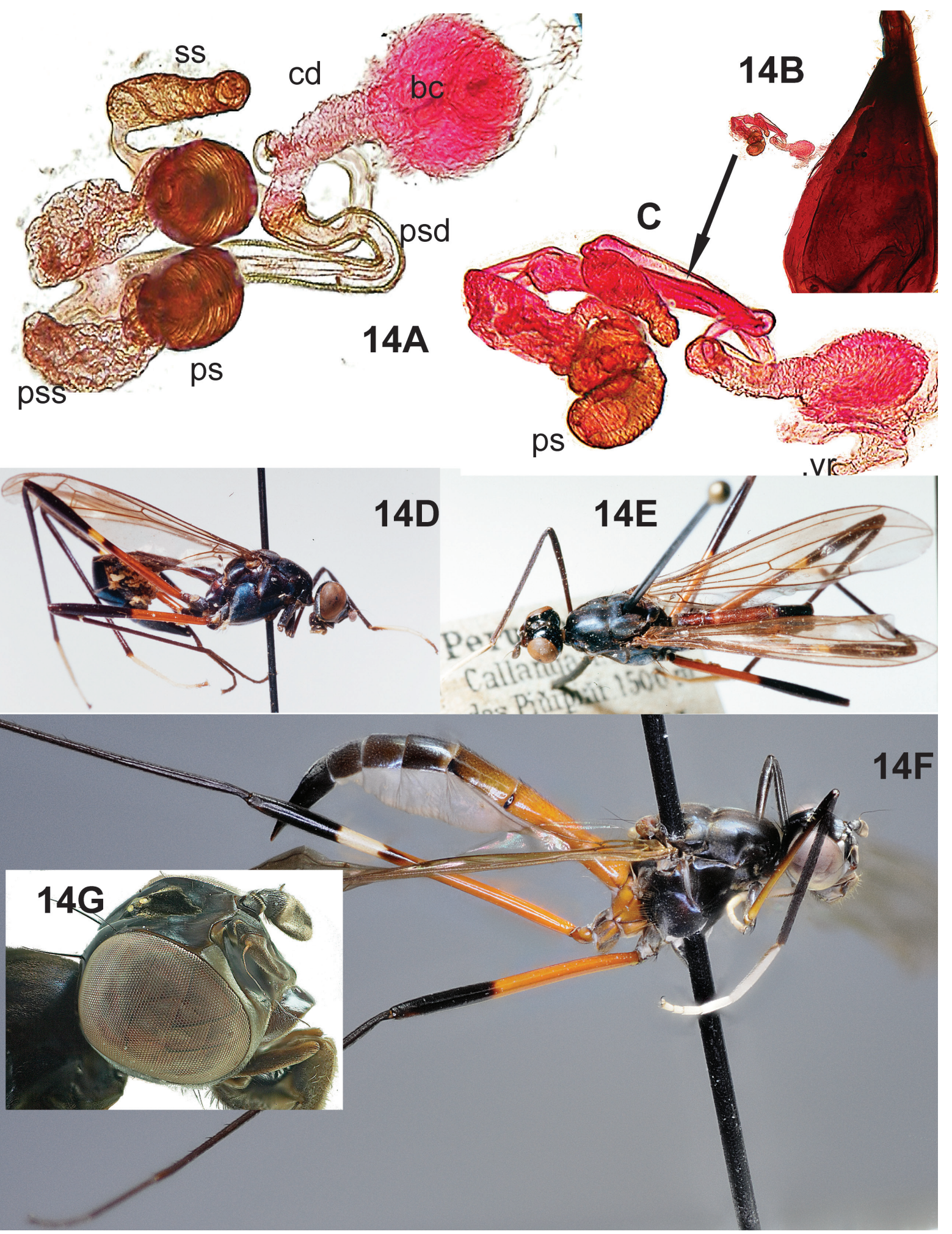

Fig. 14. Mesoconius obtusiconus Enderlein, 1922, 우.A. Spermathecae and associated structures, dorsal view, Colombia. B. Oviscape with spermathecae teased out, Colombia. C. Spermathecae and associated structures, lateral view, Colombia. D-E. Holotype, MNBG, Peru. F. Entire specimen, Colombia. G. Head, Colombia. Abbreviations: $\mathrm{bc}=$ bursa copulatrix; $\mathrm{cd}=$ common duct; $\mathrm{ps}=$ paired spermatheca; psd = paired spermathecal duct; pss = paired spermathecal stem; ss = single spermatheca; $v r$ = ventral receptacle. 


\section{Remarks}

The holotype of M. obtusiconus, from Peru, and the specimen from Colombia differ in a number of details, including the distal fore tarsomeres (white in the Colombian specimen, dark in the type) and the colour of the metapleuron and hind coxa (red in the Colombian specimen, black in the type). Both specimens, however, share several distinctive characters, such as the colour of the mid and hind femora, the broad postocellar part of the frontal vitta, a similar pattern of silvery pruinosity on the scutum and a similarly reddish abdominal base. Furthermore, they easily key out together because of the distinctive femoral colour. More specimens of this species (or species group) are needed to clarify what variation is intraspecific and what is interspecific.

This is one of the five species originally described in Mesoconius solely on the basis of specimens from Callanga, Peru. Two remain known only from the types. The other three, M. obtusiconus, M. albimanus Enderlein, 1922 and M. infestus Enderlein, 1922 present similar problems because of differences between the Callanga material and putatively conspecific material from Colombia.

Mesoconius obtusiconus is unusual because the absence of a postocellar bristle places it in the M. eques group, but the relatively flat katatergite and the spermathecal complex resemble those of the M. oblitus group.

\section{Mesoconius pasachoa sp. nov. urn:Isid:zoobank.org:act:BE206484-2EBE-442A-AD70-3AA5E440DD7F}

Fig. 15

\section{Etymology}

The name of the species is a noun in apposition taken from the name of the type locality.

\section{Material examined}

Holotype

ECUADOR • + ; Pichincha, Pasachoa Reserve; 00²5'28" S, 78³0'58” W; 2800 m a.s.1.; 14 Jun. 2011; S.A. Marshall leg.; MYCRO 330-18 sequenced for CO1; QCAZ.

Description (holotype female only)

LENGTH. $18 \mathrm{~mm}$.

CoLOuR. Uniformly black to dark brown, including wing membrane and abdominal pleuron but excluding white fore tarsomeres $2-4$, white distal half of fore tarsomere 1 and ventral side of tarsomere 5 , white parafacial and postocular strips, and brown first flagellomere.

HEAD. Epicephalon and paracephalon finely striate, subshining; frontal vitta weakly differentiated, posteriorly tapered to a broad, densely microtrichose patch extending to level of inner vertical bristles; broad and broadly tapered anteriorly, reaching frons margin. One large fronto-orbital bristle at point of overlap between epicephalon and orbital strip. Antennae separated by double width of antennal socket, upper quarter of face strongly and broadly carinate, lower face flat. Clypeus mostly bare. Lower back of head densely short-setose.

THORAX. Cervical sclerite with a microtrichose, subquadrate posterior portion and a small bare anterior portion. Fore tibia narrow and strongly flattened on basal $3 / 4$, outer face with a bare central vitta on basal $3 / 4$, distal $1 / 4$ expanded. Tarsomere 1 of fore leg shorter than other tarsomeres combined. Mid and hind femora shiny and almost bare basal to pale band near midpoint, setulose and slightly swollen distally. 
Notum almost bare, minutely microtrichose, with rows of indistinct acrostichal and dorsocentral setulae; postpronotal lobe microtrichose. Dorsocentral bristle strong, twice as long as scutellum. Scutellum with two-four small discal setulae and long apical bristles (longer than scutellum). Katatergite very prominent, with a long, tapered, microtrichose nipple-like process. Notopleuron with two long, widely spaced bristles. Vertical row of katepisternal bristles black. Coxae with anteroventral black setae.

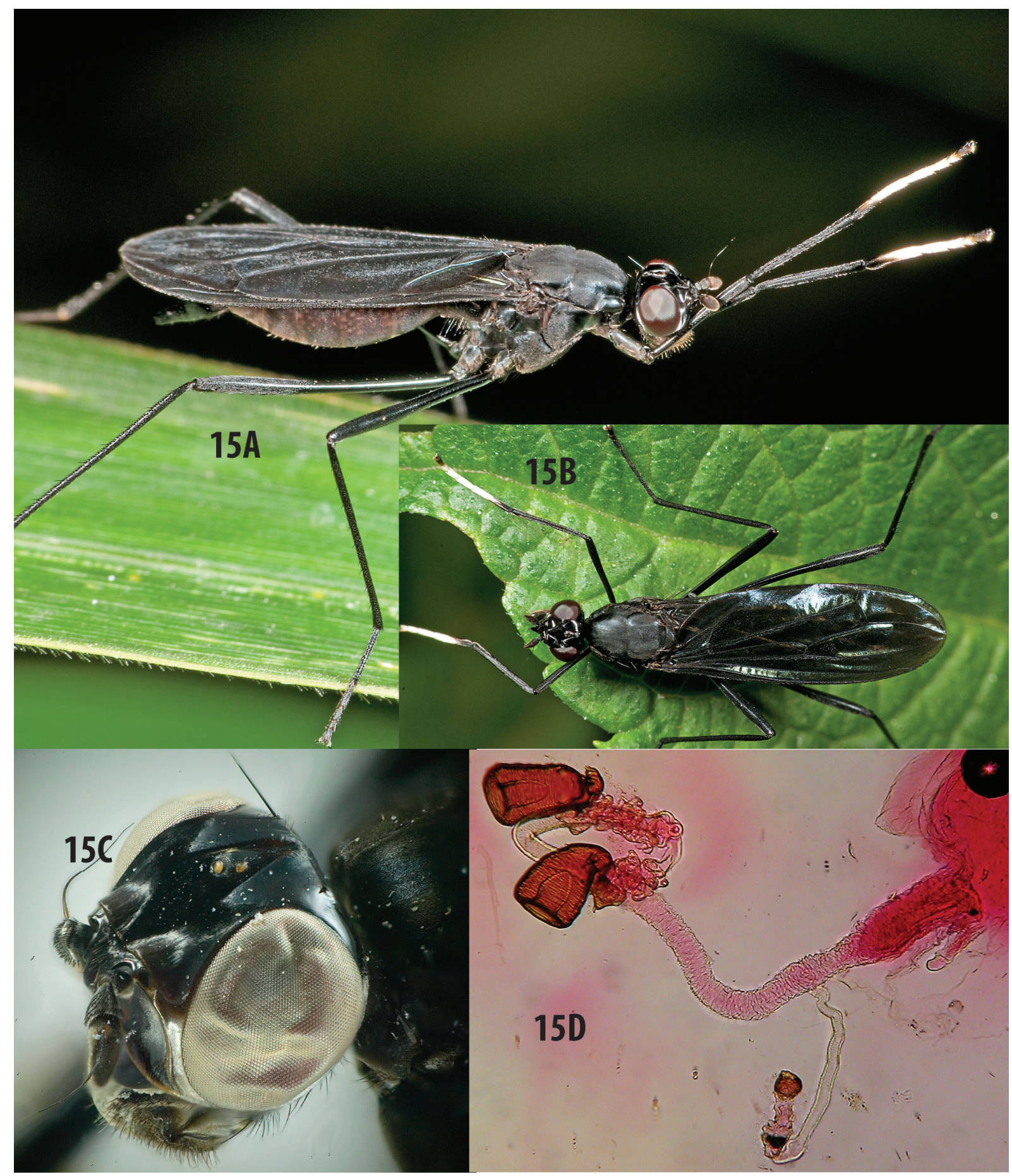

Fig. 15. Mesoconius pasachoa sp. nov. A-B. Holotype prior to capture, ${ }_{+}$, QCAZ. C. Head. D. Spermathecae and associated structures. 
AвDomen. Abdominal segment 1 and base of segment 2 petiolate; length of $1+2$ double that of tergite 3. Bursa smooth, with a distal part forming a common spermathecal duct; ventral receptacle distinct and finger-like, with a smooth rounded apical part; single spermatheca small, tuberculate, on a short duct arising laterally near apex of common duct (extension of bursa); paired spermathecae with a very long, broad duct divided into two parts: basal $4 / 5$ broader, more membranous and accordian-like, distal $1 / 5$ narrow and smooth, splitting into strongly convoluted stems leading to each spermatheca. Paired spermathecae large and elongate, almost cylindrical, slightly expanded and invaginated apically.

\section{Remarks}

Although known only from a single female from a mountain reserve near Quito, this species is distinctive both for its almost entirely black pigmentation and the details of the spermathecal complex.

Mesoconius rufipleuron sp. nov. urn:lsid:zoobank.org:act:F3F5DC0C-BB03-4530-969D-E8141A748C07

Fig. 16

\section{Etymology}

The specific name refers to the strikingly reddish-pink abdominal pleuron.

\section{Material examined}

\section{Holotype}

ECUADOR • O; Pichincha, Bellavista Cloud Forest Reserve; 0001'13" S, 7840'30" W; 2200 m a.s.1.; 9-13 May 2009; S.A. Marshall leg.; QCAZ.

\section{Paratype}

ECUADOR - 1 क; Pichincha, Mindo, trail to Bellavista Reserve; 0003'29" S, 7846'06" W; 1 May 2011; S.A. Marshall leg.; DEBU304-17 sequenced for CO1; DEBU.

Description (female only)

LENGTH. $16 \mathrm{~mm}$.

Colour. Head dark reddish brown to black, except as follows: parafacial, postgena and most of gena silvery microtrichose. Legs mostly reddish, fore tibia and distal part of fore femur black, fore tarsomeres bright yellow, except for black basal part of tarsomere 1. Femora reddish with a faint orange band near mid length. Wing uniformly brownish-yellow infuscated, without clear spots or bands. Metapleuron and abdominal T1-2 orange, T 3-5 pale, abdominal pleuron pink basally, fading to white distally; oviscape orange basally, black distally.

HEAD. Epicephalon and paracephalon very finely striate, microtrichose; frontal vitta matt black, sharply tapered posterior to ocelli, broad anterior to ocelli with an inconspicuous anteromedial point, widely separated from anterior margin of frons; inner vertical bristle strong, with four-five setulae near base. One strong fronto-orbital bristle at level of anterior ocellus, at junction of orbital plate and epicephalon. Lunule bare; upper face broadly raised, white microtrichosity of lower face extending dorsally as a parallel-sided band almost to lunule, subantennal areas shiny.

THORAX. Cervical sclerite with a vertical groove separating a large microtrichose subquadrate posterior portion from a small, shiny anterior portion. Notum finely and densely microtrichose, acrostichal and dorsocentral setulae minute and indistinct, in loose rows; acrostichal row on a faint linear microtrichose strip. Postpronotal lobe dull, densely microtrichose, with several scattered small, pale setae, anterior 
margin bare, shiny and almost vertical, posterior margin microtrichose and sloped. Dorsocentral bristle absent. Scutellum with a reddish median strip, four small discal setulae and long, closely spaced black apical bristles (longer than scutellum). Katatergite very prominent, with a long, nipple-like microtrichose pointed process. Notopleuron with two widely spaced black bristles. Vertical row of katepisternal bristles golden. All coxae with golden anteroventral setae. Postscutellum with a central bare band. Mid and hind femora mostly bare and shiny proximal to yellow band, darker, setulose and slightly swollen distally.

ABDomen. Abdominal segment 1 and base of segment 2 petiolate; length of $1+2$ slightly more than double that of tergite 3. T1 setose, with preapical long, thin lateral setae, T2 almost bare. Oviscape bare except

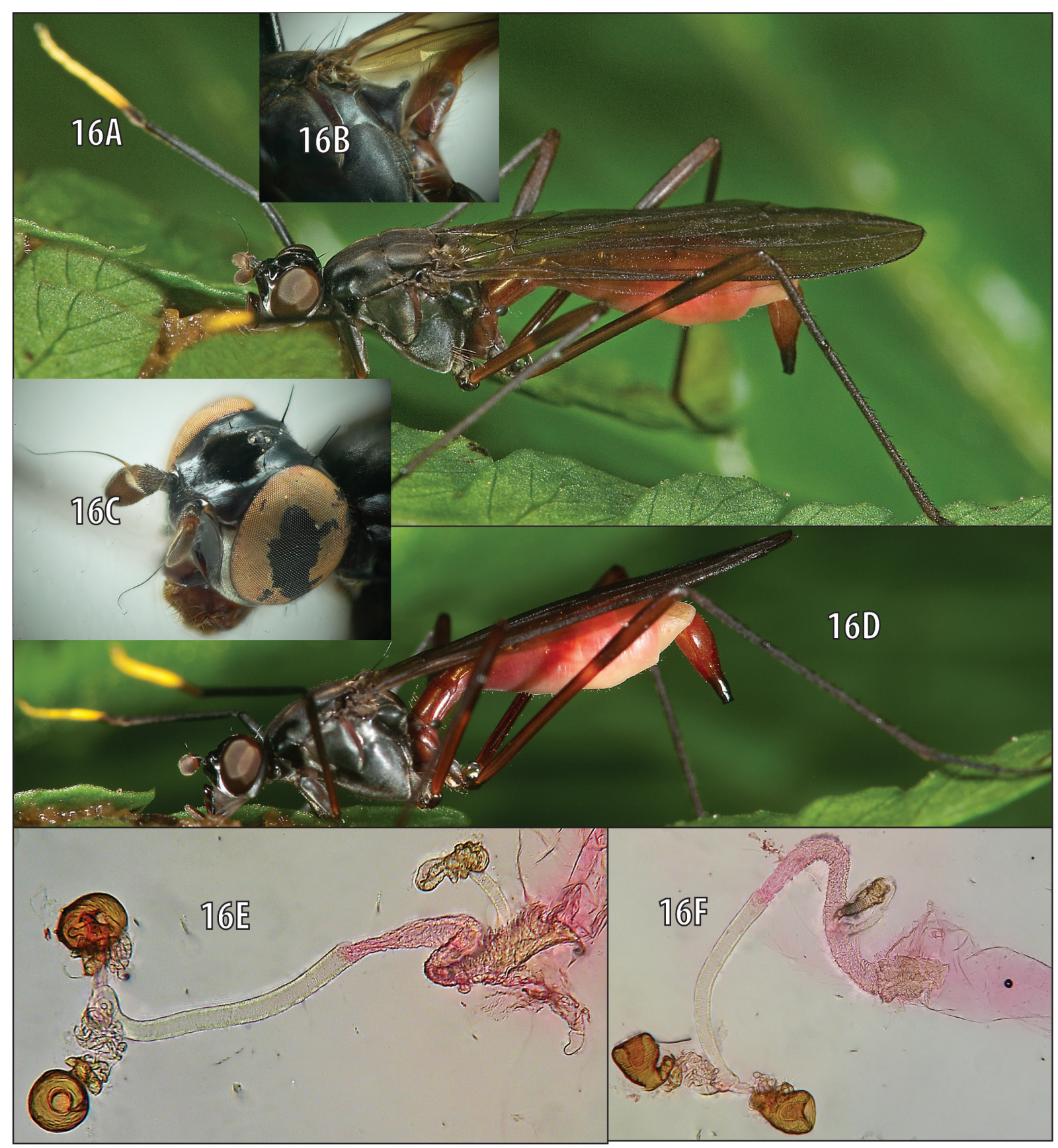

Fig. 16. Mesoconius rufipleuron sp. nov. A, D. Living $\rho \odot$ in nature. B. Pleuron, to show katatergite. C. Head of paratype. E-F. Spermathecae and associated structures, lateral and dorsal views. 
for scattered setulae; microtrichose laterally; dorsal and apical parts shiny. Bursa conspicuously rugose, ventral receptacle with a differentiated tapered and bent apical part, common spermathecal duct grading evenly into paired spermathecal duct. Single spermatheca small, tuberculate, on a very short duct arising lateraly from base of common duct. Paired duct divided into distinct parts, basal third membraneous and amorphous, distal $2 / 3$ cylindrical and weakly striate, branching into strongly convoluted short ducts that run to distally invaginated, striate, cup-shaped spermathecae.

\section{Remarks}

Although this species is known from only two females, the unique colour pattern of the mostly pink to red abdomen and the bright yellow distal fore tarsomeres are diagnostic.

Mesoconius rufithorax Enderlein, 1922

Fig. 17

Mesoconius rufithorax Enderlein, 1922: 178.

\section{Material examined}

Lectotype (here designated, Fig. 17A-B)

PERU • P; Cusco, Callanga, Piñipiñi Valley; 1500 m a.s.l.; O. Garlepp leg.; MNBG.

\section{Paralectotypes}

PERU • 2 Q $O$; same collecting data as for holotype; MNBG.

Enderlein also lists a specimen from Songo, Bolivia in HMNH (not examined).

\section{Other material}

BOLIVIA • 4 우웅 Coroico; 1200 m a.s.1.; "Coll. Fasel”; BMNH.

\section{Redescription (females only)}

LENGTH. 17-18 mm.

Colour. Head mostly black or almost black anterior to ocelli, orange behind ocelli, clypeus, membranous lower face and palpus yellow; parafacial, gena part of postocciput silver-microtrichose. Cervical sclerite entirely orange and subshining. Thorax and syntergites 1-2 orange, femora orange and almost bare basally, black and microtrichose distally, fore and hind tarsi white, except for a black ventrobasal part of fore tarsomere 1. Wing mostly uniformly lightly infuscated, with an indistinct preapical clear area. Abdomen black distally, abdominal pleuron mostly pale, but at least in females with prominent black vertical bands on P2-4, tapered ventrally from tergites, P5 mostly black.

HEAD. Epicephalon and paracephalon shiny, very finely striate; frontal vitta depressed, sharply tapered posterior to ocelli, broad and diffuse anterior to ocelli, with an inconspicuous anteromedial point, widely separated from anterior margin of frons. Inner vertical bristle strong, with four-five setulae near base. One weak fronto-orbital bristle inserted below level of anterior ocellus. Upper face broadly raised. Clypeus bare anteriorly, setulose laterally.

THORAX. Cervical sclerite with a vertical groove separating a large, subquadrate microtrichose posterior portion from a small, bare anterior portion. Notum finely and densely microtrichose, acrostichal and dorsocentral setulae in indistinct rows, scattered setulae also present anterolaterally. Postpronotal lobe sparsely microtrichose, with several scattered small pale setae; posterior half with a central longitudinal ridge, anterior half rounded. Dorsocentral bristle longer than length of scutellum. Scutellum with four 
small discal setulae and long, closely spaced black apical bristles (longer than scutellum). Katatergite prominent but rounded, without a nipple-like apex. Notopleuron with two widely spaced black bristles. Vertical row of katepisternal bristles golden. All coxae with golden anteroventral setae.

ABDOMEN. Abdominal segment 1 and base of segment 2 petiolate; length of $1+2$ slightly more than double that of tergite 3 . T1 setose, with preapical long, thin lateral setae.

Female ABDOMEN (based on BMNH non-type specimens). Oviscape bare except for scattered setulae. Bursa small, suboval, finely wrinkled; ventral receptacle small and inconspicuous, like a small, distally bent finger. Single and paired spermathecal ducts similar in width, length and texture, both arising from a broad extension of the bursa. Single spermatheca cylindrical, distinguishable from duct only by its heavier sclerotization; paired duct uniformly smooth, slightly expanded distally before branching into short, slightly convoluted ducts leading to almost spherical, striate spermathecae.

\section{Remarks}

The combination of an anteriorly darkened head, distally black femora and three bold pleural black stripes distinguish this species from the many other mostly orange species of Mesoconius.

Mesoconius suzukii sp. nov.

urn:lsid:zoobank.org:act:5928413F-78D5-4E5B-AF94-C0B6240BE716

Figs 18-19

\section{Etymology}

The specific name was chosen in part as a patronym for the Canadian popular science writer and broadcaster David Suzuki and in part because the sexual dimorphism in wing pigmentation is

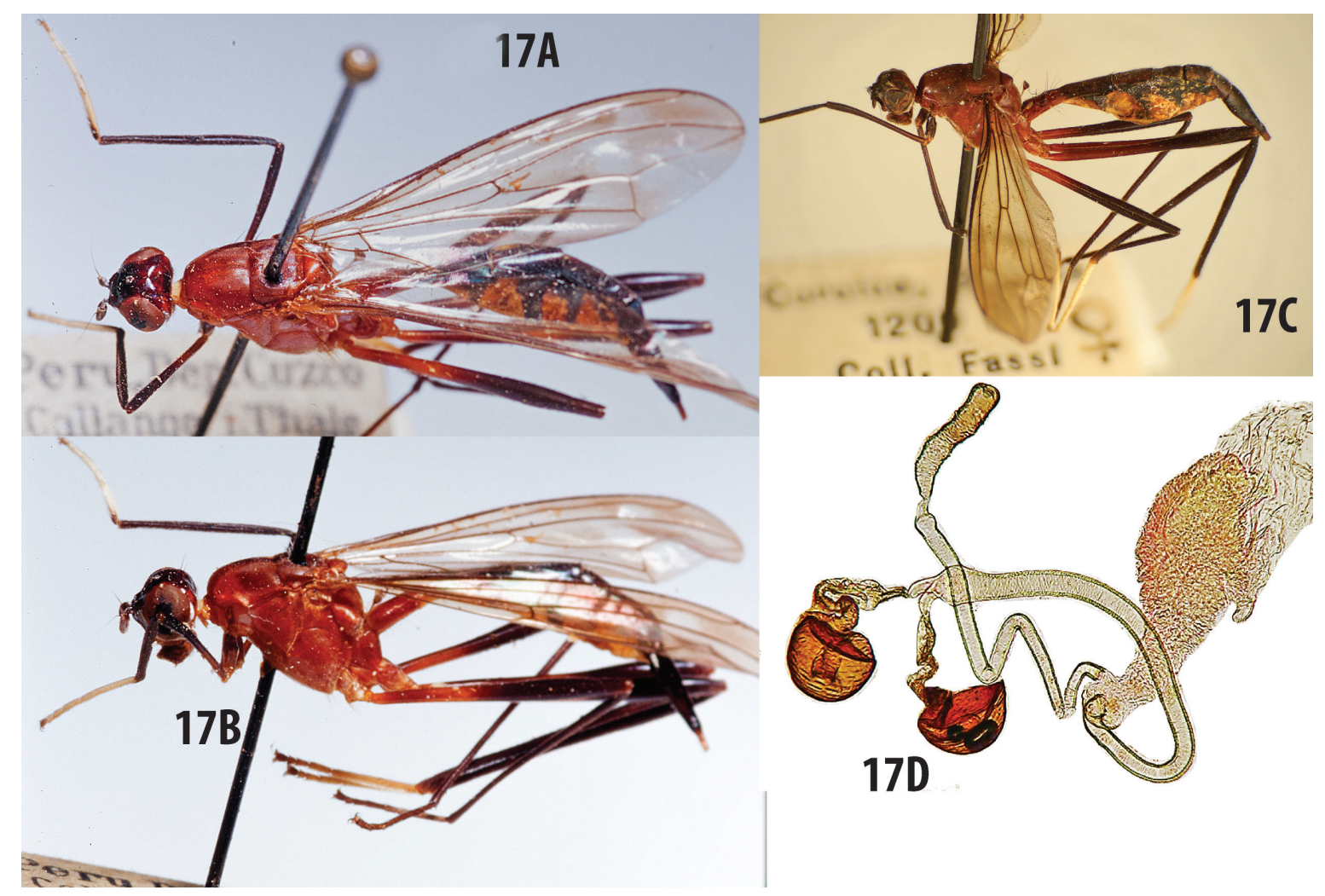

Fig. 17. Mesoconius rufithorax Enderlein, 1922. A-B. Lectotype, + , MNBG, Peru. C. + , Bolivia. D. Spermathecae and associated structures, lateral view, Bolivia. 
coincidentally similar to that of the well-known Drosophila suzukii (Matsamura, 1931), the Spotted Wing Drosophila.

\section{Material examined}

\section{Holotype}

COLOMBIA - O’; Magdalena, PNN Santa Marta, San Lorenzo; $10^{\circ} 48^{\prime}$ N, 7339’ W; 2200 m a.s.1.; 27 Feb.-14 Mar. 2001; J. Cantillo leg.; Malaise trap; IAVH.

\section{Paratypes}

COLOMBIA • 1 क; El Libano, Magdalena Department; 1829 m a.s.1.; Apr. [around 1900?]; Herbert Huntingdon Smith leg. [?]; CMNH • 1 o; El Libano, Magdalena Department; 1829 m a.s.l.; May [around 1900?]; Herbert Huntingdon Smith leg. [?]; CMNH • 2 qo ; Magdalena, PNN Santa Marta, San Lorenzo; $10^{\circ} 48^{\prime} 40^{\prime \prime}$ N, 7339'32" W; 2200 m a.s.1.; 11-25 May 2000; I. Uribe leg.; DEBUA306-17

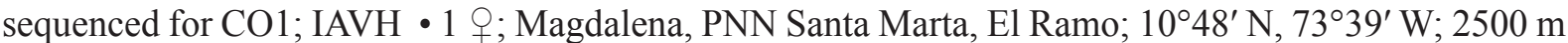
a.s.1.; 15-31 Jul. 2000; J. Cantillo leg.; IAVH 1 ภ , 2 o $\circ$; Magdalena, PNN Santa Marta, San Lorenzo; $10^{\circ} 48^{\prime}$ N, 7339' W; 2200 m a.s.1.; 14-31 Mar. 2001; J. Cantillo and D. Rubi leg.; Malaise trap; IAVH.

\section{Other material}

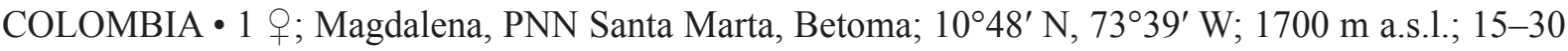
Aug. 2001; J. Cantillo leg.; Malaise trap; CO1 sequence DEBUA302-17; IAVH.

\section{Description}

LENGTH. 15-16 mm.

Colour. Head mostly orange-yellow, except for sharply contrasting black frontal vitta, shiny brown lunule, upper face and scape, and very pale yellow gena, postgena and parafacial; pedicel and first flagellomere brown and heavily setulose, first aristomere white. Thorax pale yellow to white laterally, dorsally orange-yellow with strong brown stripes laterally and a weak medial brown vitta. Fore coxa and base of fore femur white, grading to yellow and then to black distally, fore tibia black, tarsus white. Mid and hind femora yellow, except for a basal brown longitudinal streak and an incomplete brown band just beyond middle. Hind tibia pale brown, tarsomere 1 pale on basal $3 / 4$, black distally. Wing of females uniformly lightly infuscated, in males with a dark and discrete apical black spot. Abdomen pale, sclerites brown to yellow, except for black posterolateral corners of T2; membranes white.

HEAD. Epicephalon and paracephalon shiny and smooth; frontal vitta sharply delineated and tapered to an elongate, narrow, depressed point posterior to ocelli, broad anterior to ocelli, with lateral extensions and anteromedial point separated from anterior margin of frons. Ocellar triangle elevated and prominent, densely setulose; ocelli conspicuous. Inner vertical bristle strong, with four-five setulae near base. Two fronto-orbital bristles: an indistinct lower bristle inserted below level of anterior ocellus and a very small upper bristle well above level of posterior ocelli. Upper face prominent. Subantennal area shiny dark brown. Clypeus bare anteriorly, setulose laterally.

THORAX. Cervical sclerite with a vertical groove separating a large, convex microtrichose posterior portion from a small, bare anterior portion. Notum mostly finely and densely covered with black microtrichia, dorsocentral vittae bare; dorsocentral setulae weak but in a distinct row, acrostichal setulae apparently absent. Postpronotal lobe sparsely microtrichose, with several scattered small, pale setulae; posterior and anterior faces flat. Dorsocentral bristle black, subequal to scutellar length. Scutellum with long, closely spaced black apical bristles (longer than scutellum). Katatergite strongly convex but not conical, without a nipple-like apex. Notopleuron with two widely spaced black bristles. Vertical row 


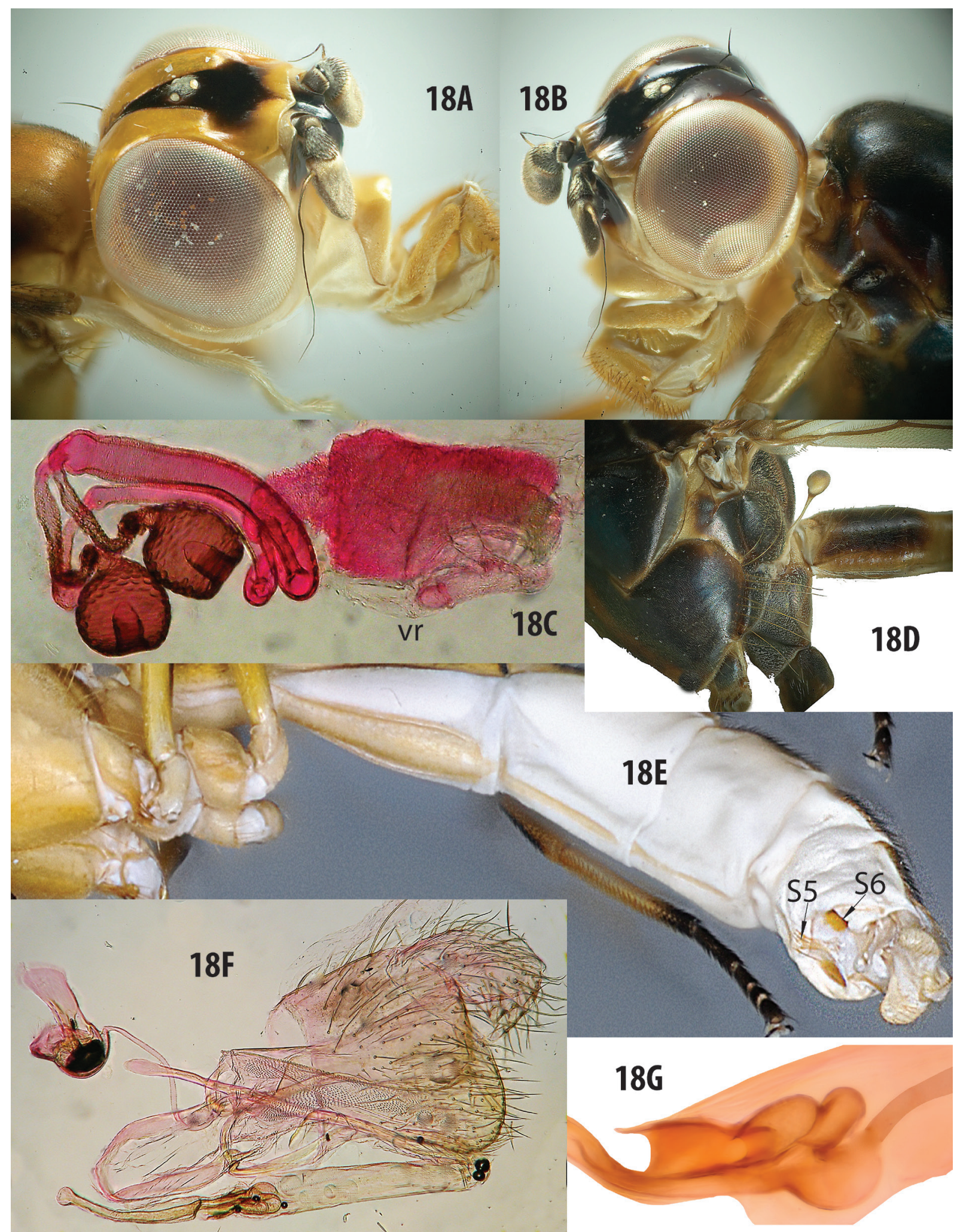

Fig. 18. Mesoconius suzukii sp. nov. A. Typical head. B. Dark head. C. Spermathecae and associated structures. D. Mesopleuron and base of abdomen. E. Abdomen, $\partial$, ventral view. F. Male terminalia, left lateral view. G. Phallic bulb. Abbreviation: vr = ventral receptacle. 
of katepisternal bristles weak, pale. All coxae with golden anteroventral setae. Tarsomere 1 of all legs elongate and slightly swollen, longer than remaining tarsomeres combined.

ABDomen. Abdominal segment 1 petiolate; length of $\mathrm{T} 1+2$ double that of $\mathrm{T} 3$. $\mathrm{T} 1$ setose, with preapical long, thin lateral setae; constricted area between $\mathrm{T} 1$ and $\mathrm{T} 2$ bare.

Female ABDomen. Oviscape shiny, with scattered setulae. Bursa large, conspicuously rugose, suboval; ventral receptacle prominent and on a large base arising from basal part of bursa; spermathecal ducts with a broad common common duct at distal margin of bursa. Paired spermathecal duct thick, basal half smooth-walled, distal half ringed with weak striae. Single spermathecal duct arising laterally before

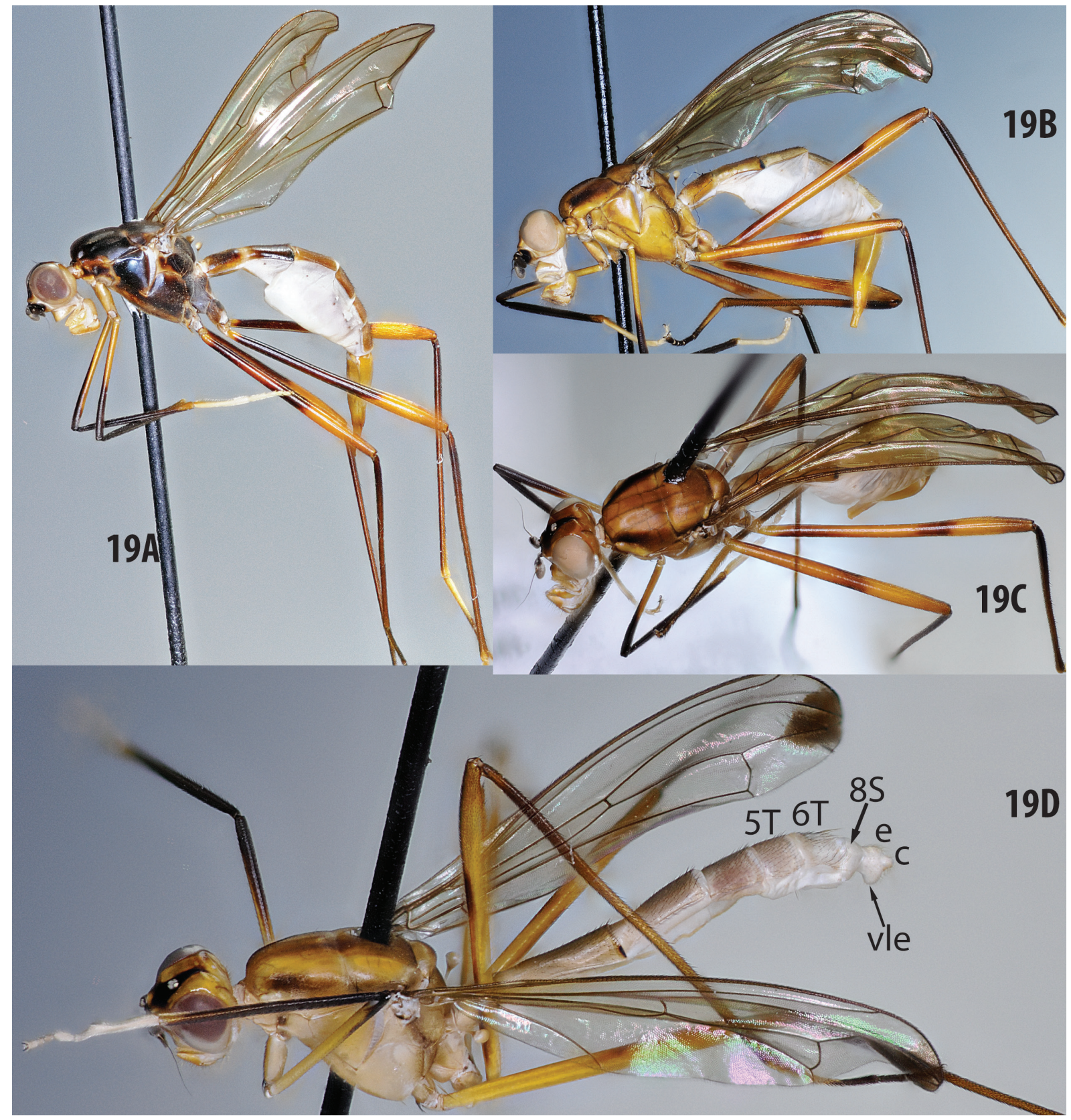

Fig. 19. Mesoconius suzukii sp. nov. A-C. $\odot \propto$ (B and $\mathrm{C}$ are paratypes, IAVH). D. Holotype, $\widehat{\partial}$, IAVH. Abbreviations: $\mathrm{c}=$ cercus; $\mathrm{e}=$ epandrium; $\mathrm{vle}=$ ventral lobe of epandrium. 
apex of common duct, almost as long as half width of paired duct; single spermatheca very small. Stems of paired spermathecae elongate, without swellings or protruberances, but with a spiculose or scaly surface. Spermathecae large, dense and suboval, with distinct oblong punctations; apex deeply invaginate.

Male abdomen. Segments 3-6 thin, parallel-sided; S5 reduced but with a tuft of about ten long golden setae along posterior margin of segment. Sternite 6 divided medially into two small shiny plates, separated by setose membrane. Synsternite 7-8 sparsely microtrichose, shiny, contrasting with dull, microtrichose preceding sclerites and microtrichose epandrium; S7 with narrow, pale ventral part, including a process extending under right plate of S6; S8 white and entirely bare, as long as epandrium. Epandrium very small, white and uniformly setose, constricted basally and greatly expanded distally, with posteroventral corners produced into broad processes as large as remainder of epandrium. Cercus very large, almost round. Hypandrium forming a short loop anteriorly. Basiphallus small, barely extending beyond base of distiphallus. Basal part of distiphallus broad and parallel-sided, phallic bulb large and elongate; distal part of distiphallus half as long as basal part (including phallic bulb), of uniform width except for expanded apex. Ejaculatory apodeme greatly reduced, slightly smaller than broad sperm pump.

\section{Variation}

One female specimen is not included as a paratype although its CO1 sequence (DEBUA302-17) is identical to that of typical specimens. It differs from typical specimens in having a dark brown thorax, darker legs and darker pigmentation on the head, as well as T1 and T2. Internal structures seem identical.

\section{Remarks}

This is a very unusual and distinctive species, easily recognized by the male wing pigmentation and characterized by the greatly reduced male terminalia, with a small but broad white epandrium. Mesoconius suzukii sp. nov. is treated as part of the M. eques group for diagnostic purposes because of the absence of postocellar bristles, but it was recovered outside the M. eques group on the CO1 tree (Fig. 50) and it lacks most of the defining characters of the group.

\section{Mesoconius infestus group}

\section{Diagnosis}

Members of the Mesoconius infestus group are relatively robust micropezids diagnosed by the combination of a strong katatergal swelling with a nipple-like apex, the absence of outer vertical bristles and the presence of postocellar bristles (missing in two apparently aberrant specimens of one species). The large and strongly twisted anterior part of the hypandrium (Fig. 25F) is unique and an extremely distinctive synapomorphy for the group.

\section{Description}

HEAD. Two fronto-orbital bristles, lower small, upper large and inserted on epicephalon near level of upper ocelli. Subantennal concavity entirely shiny. Fore tarsus entirely white or yellow, mid femur usually with a single black band; hind femur with one or two black bands (absent in M. fulvus Enderlein, 1922); hind tarsomere 1 (or 1 and 2) usually pale.

Thorax. Prosternum microtrichose, but usually without distinct socketed setulae (setulae present in M. triunfo sp. nov.). Scutum densely microtrichose, with rows of small acrostichal and dorsocentral setulae and sometimes with weak patterns of silvery pruinosity; pruinosity usually including a broad presutural dorsocentral vitta, a narrow postsutural dorsocentral vitta and a broad postsutural lateral vitta (absent or indistinct on orange species). Dorsocentral bristle strong, slightly longer than scutellum. Notopleuron with two widely spaced bristles. Scutellum with a pair of long apical bristles (longer than 
scutellum) and usually with a pair of marginal setulae in addition to a few discal setulae. Vertical row of katepisternal bristles yellow. All coxae with anteroventral golden setae. Wing infuscated, with a discal pale band divided into diffuse spots below $\mathrm{R}_{2+3}$ and $\mathrm{R}_{4+5}$; clear spots can be difficult to discern in species with relatively light infuscation.

MaLe ABdomen. Sternites 5 and 6 reduced, sclerotization of genital pouch thus derived from linear ventral part of S7. Sternite 8 large, usually deflexed and often contrasting with smaller epandrium. Basiphallus very small, frame-like, not extending beyond base of distiphallus. Basal distiphallus broad and short, distally expanding to envelop a phallic bulb characterized by a perforated saddle-like dorsal sclerite and a ventral part from which a long, whip-like distal distiphallus distally integrated with a very broad and characteristically twisted anterior hypandrial margin.

Female abdomen. Spermathecal complex with a relatively short single spermathecal duct and a long, broad, double spermathecal duct either arising independently from a truncate bursa apex or from a short, broad common duct (extension of the bursa apex). Double duct (common duct of paired spermathecae) divided into distinct basal and distal parts that differ in width and texture; stems of paired spermathecae simple or swollen, without convolutions or branches found in M. eques group.

\section{Remarks}

This group appears to be monophyletic on the basis of the characteristic male terminalia, especially the unusual twisted hypandrium with the whip-like distal distiphallus normally enveloped by the broad anterior hypandrial margin, the very large S8 and possibly the sclerotized pocket in the right side of male segment 7. Furthermore, species of the M. infestus group sequenced for CO1 (M. acca sp. nov., $M$. notacca sp. nov., $M$. nigricephala sp. nov., $M$. infestus) cluster together on a single branch on the maximum likelihood tree (Fig. 50). The $M$. infestus group includes a few distinctive and easily recognized orange species (M. nigricephala sp. nov., M. fulvus, M. ujhelyianus Enderlein, 1922 and M. garleppi Enderlein, 1922), but other members of the group are dark-bodied and closely resemble $M$. infestus.

\section{Distribution}

As is typical for Mesoconius, species in the M. infestus group generally have restricted high elevation ranges. Most occur in the Andes from Bolivia to Colombia, but one species (M. triunfo sp. nov.) occurs in southern Mexico, and several species (M. bicolor Marshall, 2015, M. hemithorax Frey, 1927, M. dianthus Marshall, 2015 and M. zadbi Marshall, 2015) occur in Central America.

Mesoconius acca sp. nov. urn:1sid:zoobank.org:act:63EA4FD8-711C-4848-9EAE-D16008F66BC3

Figs 20-21

\section{Etymology}

The species name is derived from the acronym for the Asociación para la Conservación de la Cuenca Amazónica (ACCA) because most of the type specimens are from the ACCA field station at Wayqecha. This is also a welcome opportunity to honour an organization that has done so much to protect Peruvian biodiversity and to facilitate documentation of that biodiversity while training the next generation of Amazonian conservationists.

\section{Material examined}

\section{Holotype}

PERU - ${ }^{\top}$; Cusco, Wayqecha Biological Station, $9 \mathrm{~km} \mathrm{NE}$ of Challabamba; $13^{\circ} 10^{\prime} 20^{\prime \prime} \mathrm{S}, 71^{\circ} 35^{\prime} 00^{\prime \prime} \mathrm{W}$; 2600-2700 m a.s.1.; 1-6 Dec. 2011; S.A. Marshall leg.; MUSM. 


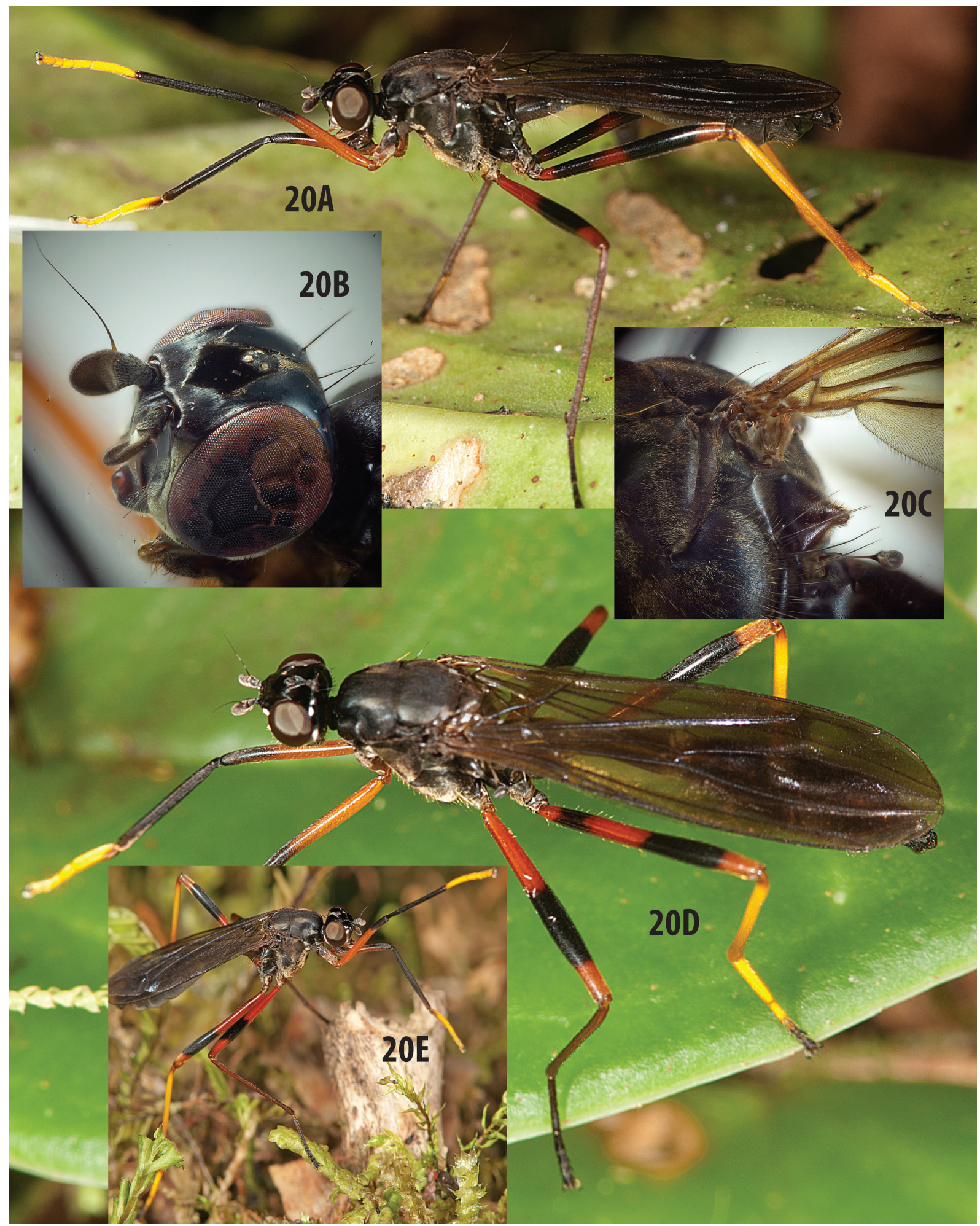

Fig. 20. Mesoconius acca sp. nov., external appearance. A, D-E. Living $\widehat{\partial} \widehat{\partial}$, Wayqecha Biological Station, Peru. B. Head. C. Part of pleuron to show swollen katatergite. 
Paratypes

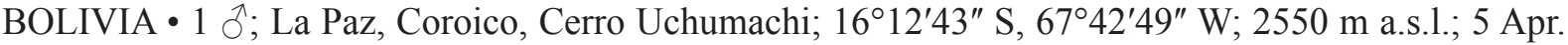
2001; S.A. Marshall leg.; cloud forest; MYCRO456 sequenced for CO1; CBFC.

PERU • 4 §̂े, 1 क; same collecting data as for holotype; DEBU • 1 q; Piches and Perené River valleys; 610-915 m a.s.l.; Soc. Geog. de Lima leg.; one hind leg on body, one hind leg in vial, no other legs; ANSP • 1 q; Charape River; 14 Nov. [probably 1909-14]; C.H.T. Townsend leg.; USNM.
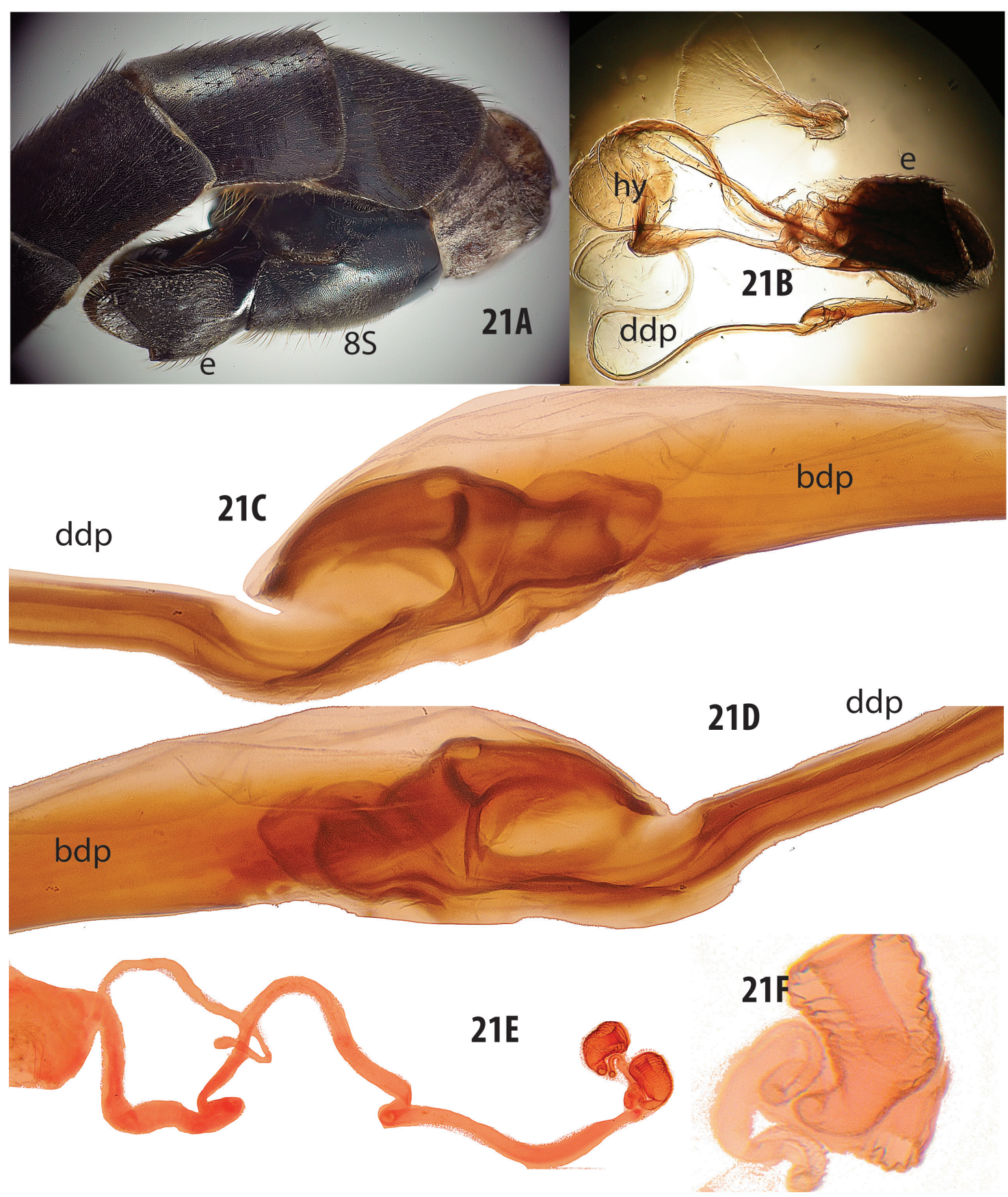

Fig. 21. Mesoconius acca sp. nov., internal characters, Peru. A. Abdomen, Õ. B. Male terminalia. C-D. Phallic bulb and adjacent parts of distiphallus, left (C) and right (D) views. E-F. Spermatheca and associated structures. Abbreviations: $\mathrm{bdp}=$ basal distiphallus; $\mathrm{ddp}=$ distal distiphallus; $\mathrm{e}=$ epandrium; hy $=$ hypandrium. 


\section{Description}

LeNGTH. $20 \mathrm{~mm}$.

CoLour. Head black to dark brown, except for silvery gena, parafacial and middle of face, yellow palpus, narrow anterior strip on T3, yellow fore tarsus, yellow hind tarsomeres 1-2 and variable red or yellow parts on coxae, femora and tibiae. Frontal vitta velvety black, subantennal areas shiny brown. Wing strongly infuscated, with large and distinct clear areas in cell $\mathrm{r}_{2+3}$, cell $\mathrm{r}_{4+5}$, and distal to crossvein dm-cu. Oviscape dark brown basally, black distally.

HEAD. Epicephalon and paracephalon finely striate, subshining, slightly more shiny than orbits; frontal vitta posteriorly tapered to a broad, densely golden-microtrichose patch extending to inner vertical bristles; broad and broadly tapered anteriorly, not reaching frons margin. Antennae separated by width of antennal socket, upper face strongly and broadly carinate; parafacials, lower face flat and microtrichose. Clypeus shiny medially, laterally microtrichose.

Thorax. Cervical sclerite with a vertical groove separating a microtrichose, subquadrate posterior portion from a small, bare anterior portion. Fore tibia broad, sulcate on outer face. Postpronotal lobe microtrichose, with some scattered small setulae, anterior margin forming a vertical, shiny face.

Abdomen. Abdominal segment 1 petiolate; length of $1+2$ double that of tergite 3.

Female ABDOMEN. Bursa small and weakly differentiated, ventral receptacle not noted; spermathecal ducts arising independently from truncate apex of bursa; common duct of paired spermathecae long and broad, divided into distinct parts, including a long, rugose basal part and a narrow, smoother distal part. Paired spermathecae large, tapered to base and ringed by deep transverse striae; each on a separate long stem that is slightly swollen on basal half and deeply sinuate on distal half. Single spermatheca elongate, no wider than duct; duct very short, about $0.3 \times$ length of paired duct, with a short constricted area at base.

Male abdomen. Sternites 5 and 6 lightly sclerotized, small. Sternite 7 dark, with a broad anterior apodeme and an expanded, bare, spatulate right apex. Sternite 8 black, anterior margin shiny, otherwise dull, microtrichose. Epandrium with prominent, setose posteroventral angles, cercus large and distinct. Postgonites small and divergent (directed laterally), with four small apical setae. Basal part of distiphallus broadly tubular, gradually expanding to a very large phallic bulb forming a distinctive broad hood over base of distal part of distiphallus. Ejaculatory apodeme slightly larger than epandrium.

\section{Remarks}

Mesoconius acca sp. nov. is similar to M. infestus and thus part of a diverse species complex of similarly robust flies with bright orange and black legs, heavily infuscated wings with diffuse distal clear spots and a dark brown to black face. Leg and abdominal colours vary widely within these species. $M$. acca sp. nov. is distinguished from M. infestus by its mostly microtrichose black male S8 (in contrast to the bare and shiny S8 that characterizes $M$. infestus), the swollen and extensively pigmented mid femur, and its significantly larger size. As in many other species of Mesoconius, M. acca sp. nov. varies widely in leg colour, most often with a single-banded mid femur and a double-banded hind femur.

Mesoconius albimanus Enderlein, 1922

Fig. $22 \mathrm{H}$

Mesoconius albimanus Enderlein, 1922: 180.

Diagnosis (type females only)

Length $18 \mathrm{~mm}$. General colour dark brown to black. Epicephalon and paracephalon shiny blue-black, palpus yellow and lower face pale. Thorax with extensive red areas covering ventral part of posterior 
half and extending to first tergite and the bases of mid and hind femora. Notum as illustrated for M. albipedis sp. nov., with faint silver longitudinal bands interrupted by a brown patch postsuturally. Fore and hind tarsi almost entirely white, with some dark ventral setulae at base of first fore tarsomere and slight darkening of distal tarsomeres. Oviscape shiny black, orange at tip. Neither of the types has been dissected, so the spermathecal complex has not been observed.

\section{Material examined}

Lectotype (designated here)

PERU • +; Cusco, Callanga, Piñipiñi Valley; 1500 m a.s.1.; 1900; O. Garlepp leg.; MNBG.

\section{Paralectotype}

PERU • P; same collecting data as for lectotype; MNBG.

Enderlein indicated in his description that one of the types is a male, but the Enderlein collection in MNBG includes only two "types", both good female specimens (examined and photographed in 2002). They differ slightly in the extent of the reddish area at the base of the mid and hind femora, and the degree to which the first tergite is red. The specimen illustrated here, in which almost the entire T1 is red, is designated as lectotype.

\section{Remarks}

The type specimens of M. albimanus have a black fore femur in contrast with the mostly red fore femur of the similar Colombian species M. albipedis sp. nov., and they have more extensive red pigmentation of the lower thoracic pleuron (including the katepisternum) and abdominal base compared to M. albipedis sp. nov. Despite these differences, $M$. albimanus and M. albipedis sp. nov. are very similar and need to be reconsidered once fresh material of M. albimanus is obtained. The internal genitalia of M. albimanus have not been examined, but the oviscape of the type is relatively bare and shiny, in contrast to the distinctly setulose oviscape of M. albipedis sp. nov. The two known specimens of M. albimanus also differ from $M$. albipedis sp. nov. in having a clearly visible abdominal pleuron, with distinct black triangular bands tapering down from the lateral margins of tergites 3, 4 and 5 . The pleuron is not visible on the available specimens of $M$. albipedis sp. nov.

Mesoconius albipedis sp. nov.

urn:1sid:zoobank.org:act:B83A4AC4-D7FC-4699-A4F8-52F40C7AFF80

Fig. $22 \mathrm{~A}-\mathrm{G}$

\section{Etymology}

The specific name is from the Latin for 'white' and 'foot', referring to the mostly white tarsi of this species. The name is deliberately similar to that of the closely related M. albitarsus.

\section{Material examined}

\section{Holotype}

COLOMBIA • ㅇ; San Antonio; 2000 m a.s.l.; 16 Feb. 1908; C.T. Trechmann bequest; B.M. 1965 5249; $\mathrm{BMNH}$.

\section{Paratypes}

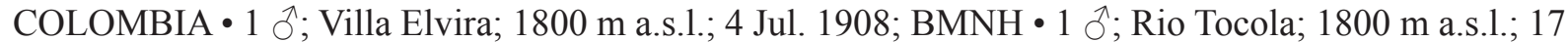
May 1908; C.T. Trechmann bequest; B.M. 1965 5249; BMNH.

\section{Description}

LENGTH. $19 \mathrm{~mm}$. 


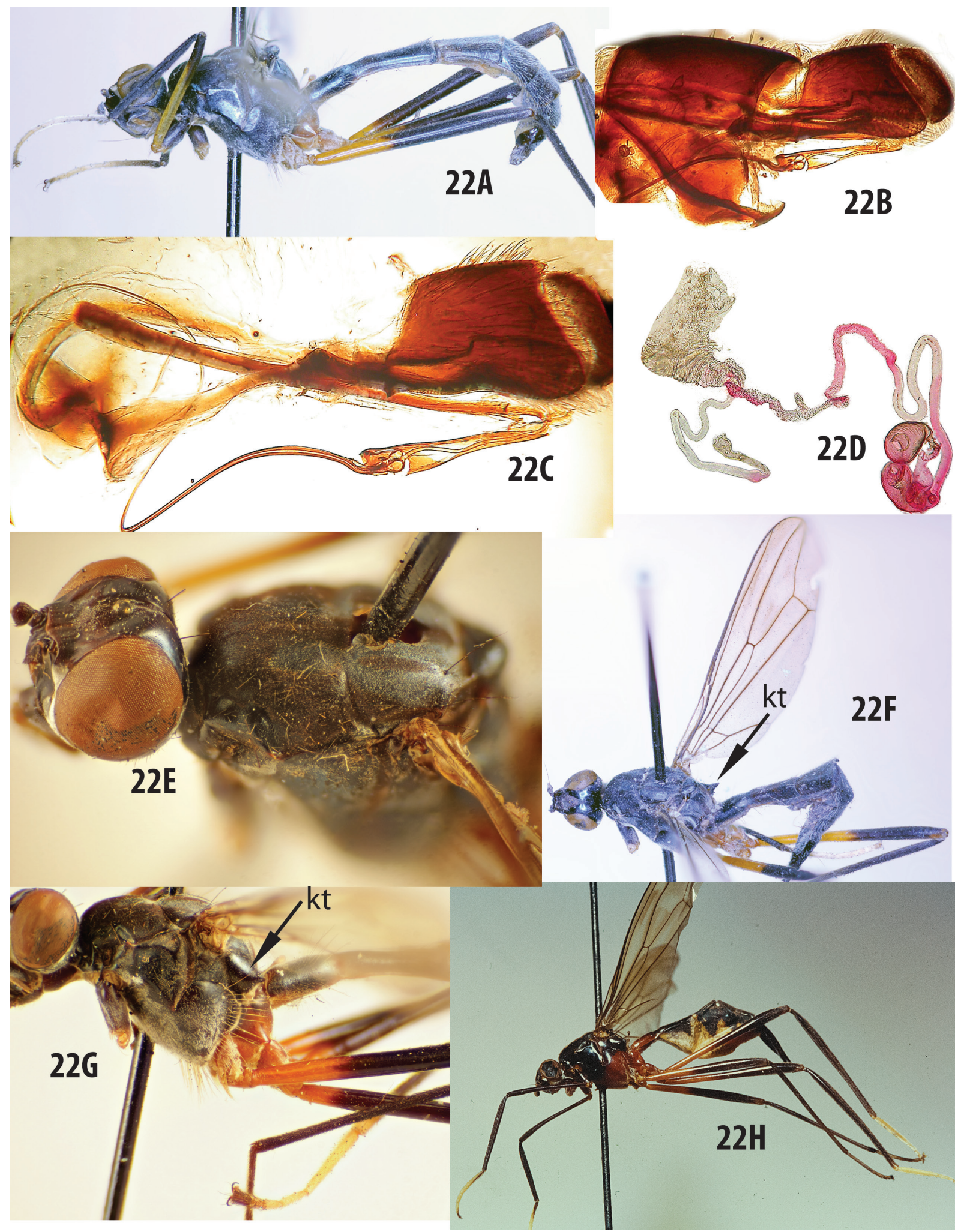

Fig. 22. A-G. Mesoconius albipedis sp. nov. A. Paratype, ふึ, BMNH. B. Male terminalia, including segments 6-8. C. Male terminalia, excluding segments 6-8. D. Spermatheca and associated structures. E. Head and thorax, dorsolateral view. F. Holotype,,$+ \mathrm{BMNH}$, dorsolateral view. G. Holotype, $q$, lateral view. - H. Mesoconius albimanus Enderlein, 1992, lectotype, + , MNBG. Abbreviation: kt = katatergite. 
CoLour. Black to reddish brown, except for silvery gena and parafacial, yellow palpus, mostly white to yellow fore tarsomeres (tarsomere 1 white dorsally and dark ventrally, tarsomere 2 white, tarsomeres 3-4 yellow, tarsomere 5 dark), white hind tarsomeres $1-4$, reddish mid and hind coxa, along with the adjacent femoral bases, and orange-red ventral parts of the metapleuron. Frontal vitta velvety black. Wing strongly infuscated at least anterodistally, with large but diffuse clear areas in cell $r_{2+3}$ and cell $r_{4+5}$. Oviscape dark brown to black, with some orange at apex.

HEAD. Epicephalon and paracephalon finely striate, subshining, slightly shinier than orbits; frontal vitta posteriorly sharply tapered to a very narrow microtrichose groove, ending before level of inner vertical bristles; broadly rounded in front of ocelli, half of frontal width, widely separated from anterior margin of frons. Upper face broadly raised, with a narrow and prominent carina at middle.

THORAX. Cervical sclerite with a vertical groove separating a posteriorly microtrichose, dark, subquadrate posterior portion from a small, bare, pale anterior portion. Notum with a broad silvery microtrichose longitudinal vitta on each side, postsutural part of silver vitta broad, with a central dark vitta. Postpronotal lobe shiny, very sparsely microtrichose, with some scattered small pale setae, anterior margin gently sloped, posterior apex longitudinally carinate.

AвDomen. Abdominal segment 1 and at least basal half of segment 2 petiolate (all of segment 2 petiolate in male); length of $1+2$ slightly more than double that of tergite 3 .

Female abdomen. Oviscape with basal $2 / 3$ setulose, but less microtrichose than other tergites, distally shiny. Bursa with deep transverse striae, taperered to a short common duct branching into short, single duct and a long, paired duct divided into distinct parts, including a long rugose basal part that abruptly transforms into a slightly narrower, relatively smooth (indistinctly striate) distal part. Paired spermathecae expanded distally, surface with transverse striae, each spermatheca on a separate narrow stem, with a large ovate swelling just beyond basal quarter. Single spermatheca slightly enlarged, on a long stem separated from main part of duct by a constriction.

MALE ABDOMEN. Sternites 5 and 6 lightly sclerotized, small; S7 dark, with a broad anterior apodeme and an expanded, bare, spatulate right apex; S7 and S8 bare and shiny, contrasting with dull, microtrichose T16 ; S8 $1.5 \times$ length of epandrium. Epandrium small, microtrichose, with prominent, setose posteroventral angles, cercus large and distinct. Basal part of distiphallus broadly tubular, narrow basally but distally expanding to a large phallic bulb forming a distinctive broad hood over base of distal part of distiphallus. Ejaculatory apodeme narrow and elongate, slightly longer than epandrium.

\section{Remarks}

Mesoconius albipedis sp. nov. resembles the Peruvian species M. albimanus, known only from two females collected in the infamous Piñipiñi Valley. Mesoconius albimanus differs in having an orange to red katepisternum and tergite one, and in having an entirely black fore femur.

Mesoconius flavipes Enderlein, 1922

Fig. $23 \mathrm{~A}-\mathrm{B}$

Mesoconius flavipes Enderlein, 1922: 178.

Mesoconius flaviceps - Steyskal 1968: 9 (lapsus).

Diagnosis (based on holotype photo and notes)

Length $17 \mathrm{~mm}$. Most of head, thorax and abdomen black to dark brown; clypeus bright yellow. Ocellar triangle elevated. Legs yellow, except for black-brown basal $4 / 5$ of fore tibia and darkened distal tarsomeres on at least hind leg. Wing strongly infuscated on distal half, with large clear areas in cell 
$\mathrm{r}_{2+3}$ and cell $\mathrm{r}_{4+5}$. Head chaetotaxy unclear, one inner vertical bristle remaining. Katatergite swollen and strongly tuberculate. Abdominal segment 1 petiolate. Terminalia with S8 directed at right angles to preabdomen (typical of $M$. infestus group), twice as large as epandrium, shiny black. Epandrium reddish brown, subquadrate.

\section{Material examined}

\section{Holotype}

COLOMBIA • $\widehat{\jmath}$; v. Nolcken leg.; MNBG.

The collector was presumably J.H. Wilhelm Baron (von) Nolcken, who collected in the mountains of Colombia 1870-71 (Horn \& Kahle 1936).

\section{Remarks}

Mesoconius flavipes has previously been diagnosed on the basis of its uniformly orange hind femur. The only specimen available is the holotype, which is impossible to confidently place in a species group. It has the general habitus of an $M$. infestus group species, including the strongly deflected male terminalia, so it is tentatively included with that group here.

Mesoconius fulvus Enderlein, 1922

Fig. 23C

Mesoconius fulvus Enderlein, 1922: 177.

Diagnosis (based on holotype only)

Length about $16 \mathrm{~mm}$. Colour almost entirely bright orange, except as follows: frontal vitta forming a brown triangle with a diffuse anterior margin just in front of anterior ocellus; frons from there forward yellow. Fore tarsus and apex of fore tibia yellow, balance of fore tarsus and an apical dorsal patch on fore femur black. Hind tarsus brown with dark setulae, ventral surface of first tarsomere paler. Wing lightly but evenly yellowish infuscated. Abdominal segments 1-3 petiolate. Sternite 8 more shiny and more sclerotized than preceeding sclerites, much larger than epandrium. Posterolateral corners of T2 and T3 black.

\section{Material examined}

\section{Holotype}

ECUADOR • đ̇; Tungurahua Province, Santa Inéz; R. Haensch leg.; MNBG.

According to Dupérré (2014), R. Haensch was an insect vendor who lived in Berlin and collected specimens from Ecuador. Santa Inéz is at an altitude of $1250 \mathrm{~m}$ a.s.1. Haensch also collected the holotype of Mesoconius aeripennis Enderlein, 1922 (= M. eques Schiner, 1868), at Baños, Ecuador.

\section{Remarks}

Mesoconius fulvus seems to be closely related to the sympatric M. ujhelyianus Enderlein, 1922, from which it differs in the absence of black bands on the mid and hind tibia.

\section{Mesoconius garleppi Enderlein, 1922}

\section{Fig. 23D-F}

Mesoconius garleppi Enderlein, 1922: 177.

Diagnosis (based on holotype only)

Length. $15 \mathrm{~mm}$. Orange, except as follows: frontal vitta black, triangular and sharply demarcated with a straight anterior margin; face, lower frons and ocellar tubercle and fore tarsus yellow; fore and hind femora with dark but weakly demarcated broad middle bands; mid tarsus, distal tarsomeres of hind tarsus, T4, side of S7 and top of epandrium black. Postocellar bristles strong, closely spaced and far 


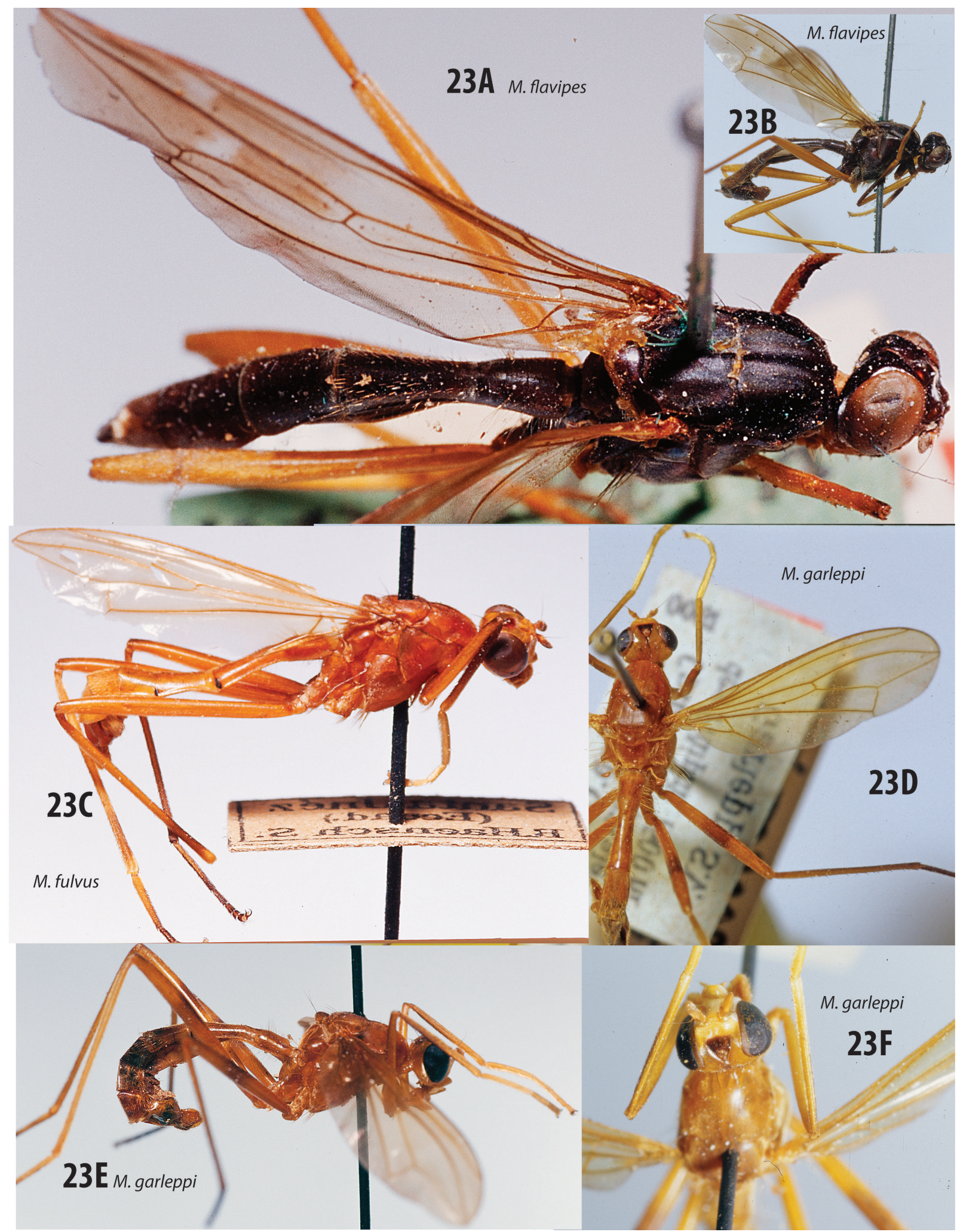

Fig. 23. A-B. Mesoconius flavipes Enderlein, 1922, holotype, §̂, MNBG. - C. M. fulvus Enderlein, 1922, holotype, ð̂, MNBG. - D-F. M. garleppi Enderlein, 1922, holotype, đ̃, MNBG. 
behind level of inner vertical bristles. Male abdominal segment 1 and base of segment 2 petiolate. Sternite 8 twice as large as epandrium, at least laterally dark and shiny, in contrast to dull T6 and epandrium, sparsely setulose.

\section{Material examined}

\section{Holotype}

PERU • ${ }^{\lambda}$; Cusco Department, Callanga, Piñipiñi Valley; 1800 m a.s.1.; O. Garlepp leg.; MNBG.

\section{Remarks}

The Peruvian type locality of M. garleppi, "Callanga, Piñipiñi Valley", is the type locality for several species. Gade (1999) discussed the valley and gave an altitude of about $1500 \mathrm{~m}$ a.s.1., while discussing the confusion over the place name "Callanga". According to Peruvian entomologist Julio Rivera (pers. comm.) the 'correct' Callanga is in Cusco Province at coordinates $12^{\circ} 50^{\prime} 16.80^{\prime \prime} \mathrm{S}, 71^{\circ} 48^{\prime} 28.20^{\prime \prime} \mathrm{W}$. Several species are known only from older type material at that locality, so it would be very useful to have new specimens from the area. The collector is listed as Otto Garlepp, but Papavero (1973) did not mention the highlands of Peru among the localities at which Otto Garlepp collected. Otto Garlepp's brother, Gustav Garlepp, is known to have collected at the "High Ucayali River, Peru". Piñipiñi specimens also appear in the type series of Mesoconius infestus, M. obtusiconus Enderlein, 1922, M. albimanus, and M. rufithorax, as well as in those of many species of other micropezid genera. Almost all of these are rare species, known only from one or a few low-quality specimens. In most cases, the Piñipiñi localities are cited as " $1500 \mathrm{~m}$ high, 1900", and most are attributed to O. Garlepp, although Papavero's (1973) summary of the Garlepp brothers' travels in South America does not place either of them in Peru in 1900.

Tanypoda garleppi Enderlein, 1922, until recently treated as belonging to Zelatractodes, is here treated as a secondary junior homonym of Mesoconius garleppi; it is redescribed below as M. ottoi nom. nov. in the M. nono group.

\section{Mesoconius infestus Enderlein, 1922}

Figs 24-25

Mesoconius infestus Enderlein, 1922: 179.

Mesoconius enderleini Frey, 1927: 72. syn. nov.

\section{Material examined}

Lectotype of $M$. infestus (here designated)

PERU • O’; Cusco, Callanga, Piñipiñi Valley; 1500 m a.s.l.; 1900; O. Garlepp leg.; MNBG.

Paralectotypes of $M$. infestus

PERU $\bullet 2$ 우; same collecting data as for holotype; MNBG.

Enderlein also lists a specimen of M. infestus from Songo, Bolivia in the HMNH (not examined).

Holotype of M. enderleini

COLOMBIA • + ; Aguatal; ZMUH.

Paratype of M. enderleini

COLOMBIA • + ; San Antonio; ZMUH.

\section{Other material}

BOLIVIA - 1 §’; La Paz, Cumbre Alto Beni, 28 km E of Caranavi; $15^{\circ} 40^{\prime} 31^{\prime \prime} \mathrm{S}, 67^{\circ} 29^{\prime} 21^{\prime \prime} \mathrm{W}$; 1400 $m$ a.s.1.; 14 Apr. 2001; S.A. Marshall leg.; cloud forest; MYCRO065-15 sequenced for CO1; DEBU • 1 Јै, 1 क; Coroico; 1200 m a.s.1.; "Coll. Fassl”; "C.T. Trechman bequest to BMNH1964-549”; BMNH. 
COLOMBIA - 1 ㅇ; "Qu. Filandia - Granja Experimental Bengala - U. del Quindio"; 0441'10" N, 75³7'2" W; 2020 m a.s.1.; 13-16 Nov. 2009; Grupo Entomologia leg.; MYCRO0335 sequenced for CO1; CEUA 68655 - 1 ô; Pereira, SFF Otun-Quimbaya; $2890 \mathrm{~m}$ a.s.1.; 8 May 2001; Bosque nativo; mounted on sewing needle, 3 legs missing; CEUA • 1 \&; Rio Tocola, "W. Colombia"; 10 Jun. 2008; BMNH $\bullet 1$ '; same collecting data as for preceding but 20 May 1908; "Fassl 1-12"; BMNH • 1 ○;

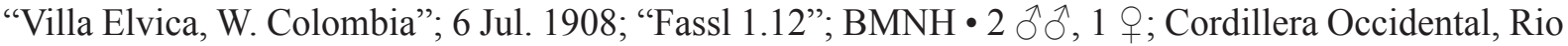
Aguacatal; 2000 m a.s.1.; "Coll. Fassl"; "C.T. Trechman bequest to BMNH1964-549"; BMNH.

ECUADOR • 1 §ิ, 1 क; Napo, Baeza; 2000 m a.s.1.; 1-10 Mar. 1979; S.A. Marshall leg.; DEBU • 1 ठै; Napo, Baeza; 2000 m a.s.1.; 1 Mar. 1979; S.A. Marshall leg.; MYCRO-066-15 sequenced for CO1; DEBU • 1 ơ $^{\top}$; Napo, SierrAzul Reserve, 14 km W of Cosanga; $00^{\circ} 41^{\prime}$ S, $77^{\circ} 56^{\prime}$ W; 10 Oct. 2002; S.A.

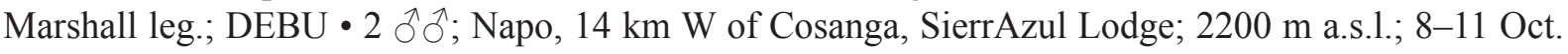
2002; S.M. Paiero leg.; dung on leaf; MYCRO332-18 sequenced for CO1; DEBU.

\section{Redescription}

Based on dissected specimens from Baeza, Ecuador; variation noted below.

LENGTH. 15-16 mm.

CoLour. Mostly black, except as follows: head with silvery gena and parafacial; palpus brown on distal half; T5, T6 and terminalia of male orange, oviscape orange except at tip; fore tarsus and hind tarsomere 1 white to yellow, trochanters orange; fore femur orange on basal half, mid femur orange with broad distal black band, hind femur with basal and distal black bands; hind tibia of female black, hind tibia of male yellow-orange on basal half. Wing strongly infuscated on distal half, with large clear areas in cell $\mathrm{r}_{2+3}$, cell $\mathrm{r}_{4+5}$, and distal to crossvein dm-cu. Oviscape orange with a dark tip. Epandrium dull orange.

HEAD. Epicephalon and paracephalon shiny but finely striate, lower frons microtrichose. Frontal vitta posteriorly tapered and ending at postocellar bristles; broad and sharply tapered anteriorly, not reaching frons margin. Antennae separated by width of antennal socket, upper face strongly carinate. Clypeus shiny medially, laterally microtrichose. Lower back of head densely setulose.

THORAX. Cervical sclerite with a vertical groove separating a mostly microtrichose, subquadrate posterior portion from a small bare anterior portion. Fore tibia broad, flattened, sulcate on outer face. Notum with three silvery vittae anterior to suture; postpronotal lobe microtrichose with some scattered small setulae, anterior margin forming an almost vertical, shiny face.

Abdomen. Abdominal segments 1-3 petiolate on male, segment one petiolate in female. Length of T1+2 double that of tergite 3 .

Female abdomen. Bursa broad and rugose; ventral receptacle large, with a distinct, nipple-like apical part; spermatheca with a short, broad, striate common duct before splitting into ducts leading to paired and single spermathecae. Paired spermathecae large striate, cup-shaped, each on a separate narrow and convoluted duct, deeply invaginated apically; common duct of paired spermathecae long and broad, divided into distinct parts, including wrinkled basal half that abruptly expands into a darker striate distal half. Single spermatheca elongate, narrow basally and expanded distally, only slightly wider than duct; single duct less than half as long as paired duct and wrinkled, weak basal section very short.

Male abdomen. Sternites 5 and 6 lightly sclerotized, unmodified. Sternite 7 sinuate, with a broad anterior apodeme and an expanded, bare, spatulate right apex; S8 bare, shiny orange. Epandrium with prominent, setose posteroventral angles, cercus large and distinct. Hypandrium with a very broad, twisted anterior plate with distiphallus apex coiled into its right side. Basal part of distiphallus broadly tubular, gradually 


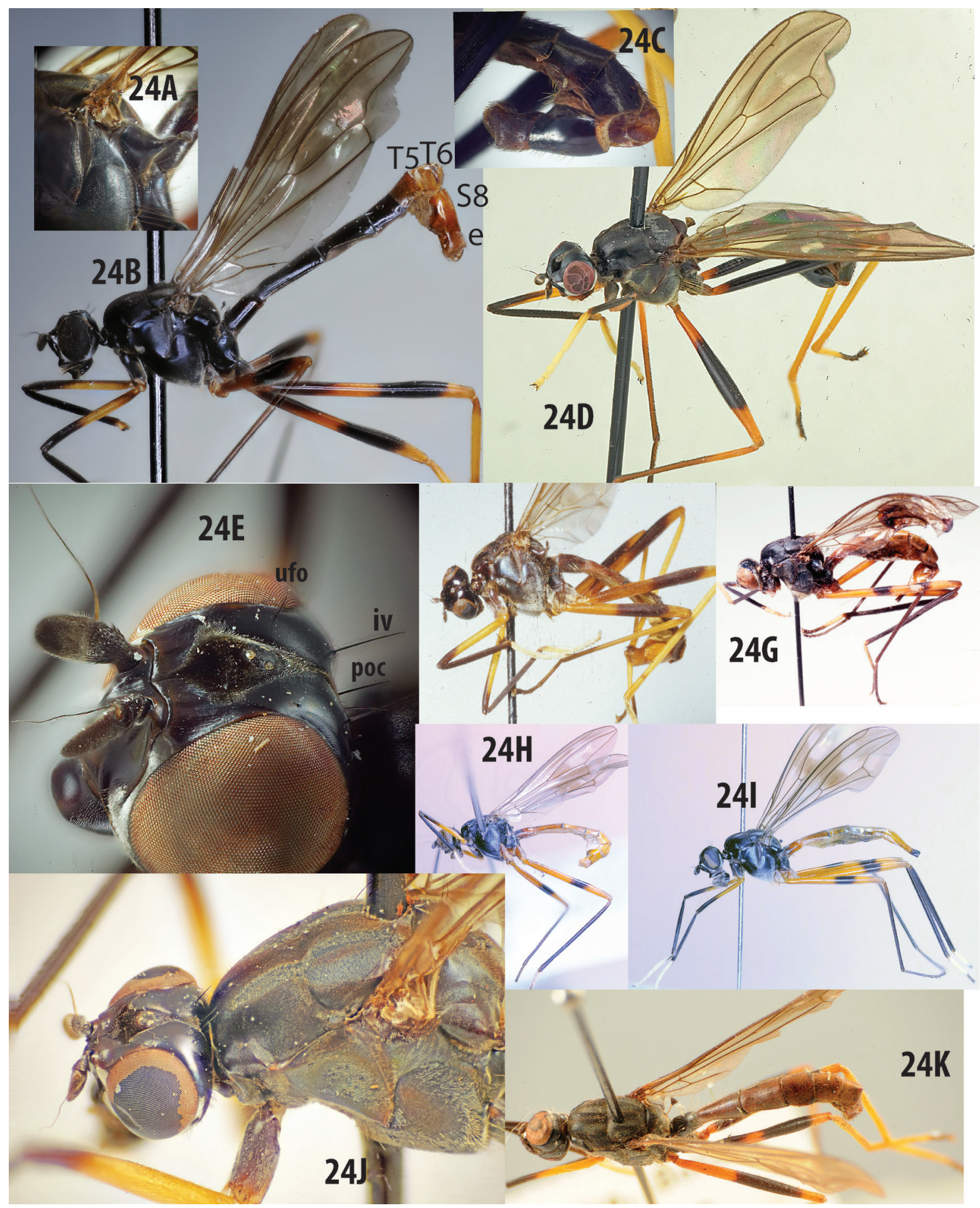

Fig. 24. Mesoconius infestus Enderlein, 1922 (species complex), external characters and colour variation. A. Thorax and base of abdomen, $\hat{\jmath}$, showing prominent katatergite. B. $\hat{\jmath}$, DEBU, Baeza, Ecuador. C-D. 1 , DEBU, SierrAzul Lodge, Eucador. E. Head, specimen from SierrAzul. F. Lectotype, § , MNBG, Piñipiñi Valley, Peru. G. Holotype of M. enderleini Frey, 1927 (junior synonym of M. infestus), $q$, ZMUH, Colombia. H. $\hat{\jmath}$, specimen from Colombia. I. + , specimen from Colombia. J. Head and thorax, specimen from Bolivia. K. Habitus, + , BMNH, oviscape removed, specimen from Bolivia. Abbreviations: $\mathrm{e}=$ epandrium; iv $=$ inner vertical bristle; poc $=$ postocellar bristle; $u$ fo $=$ upper fronto-orbital. 


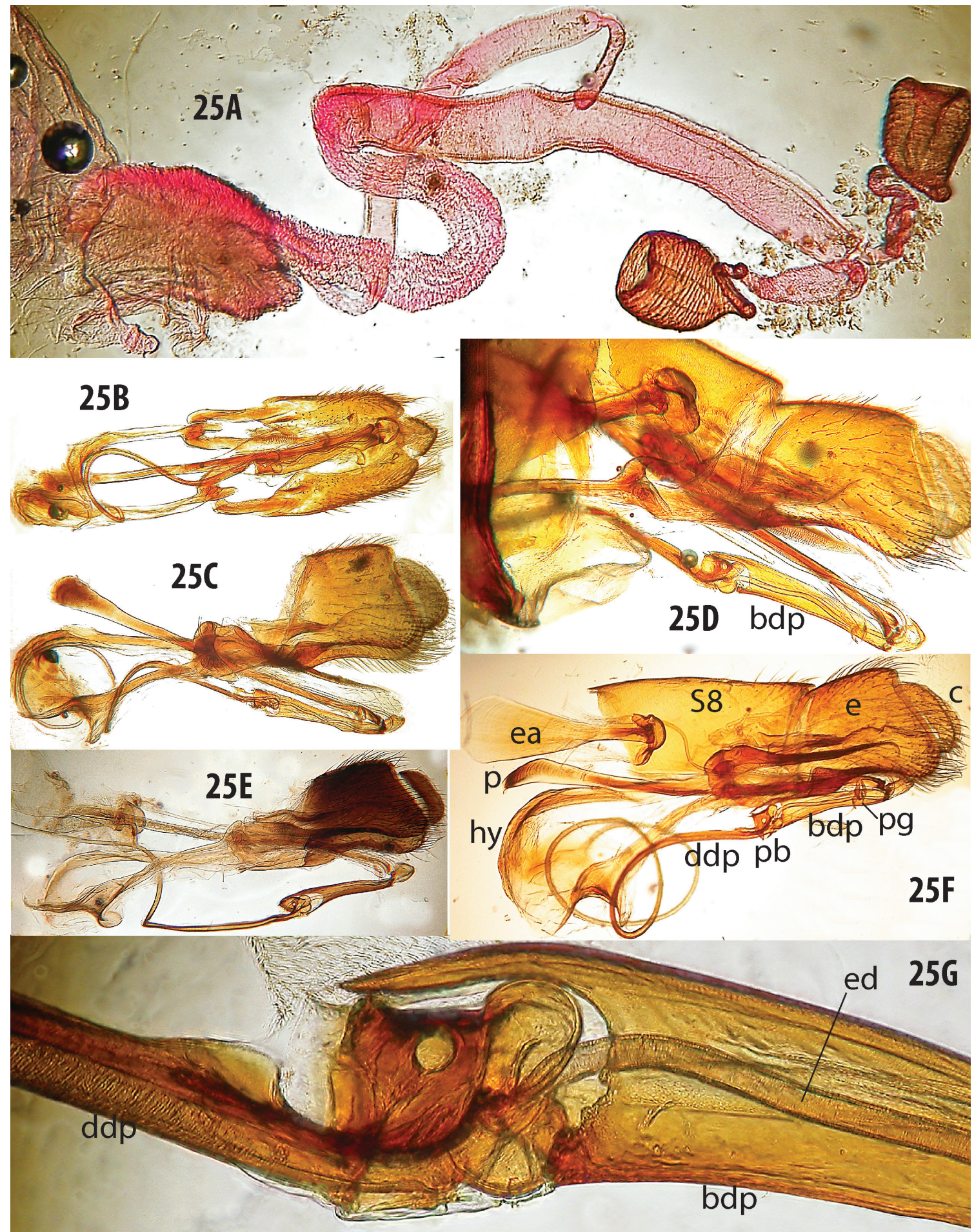

Fig. 25. Mesoconius infestus Enderlein, 1922 (species complex), internal characters. A. Spermatheca and associated structures, specimen from Bolivia. B-C. Epandrium, hypandrium and associated structures, dorsal and lateral views, specimen from Colombia. D. $\widehat{\jmath}$, apex of abdomen, specimen from Bolivia. E. Epandrium and associated structures, specimen from SierrAzul, Ecuador, DEBU. F. Male terminalia, including S8, specimen from Baeza, Ecuador, DEBU. G. Detail of basal distiphallus and phallic bulb, specimen from Ecuador, DEBU. Abbreviations: $\mathrm{bdp}=$ basal distiphallus; $\mathrm{c}=$ cercus; $\mathrm{ddp}=$ distal distiphallus; $\mathrm{e}=$ epandrium; ea = ejaculatory apodeme; ed = ejaculatory duct; hy = hypandrium; $\mathrm{p}=$ phallapodeme; $\mathrm{pb}=$ phallic bulb; $\mathrm{pg}=$ postgonite. 
expanding to form a distinctive dorsal hood over a broad phallic bulb with two broad, basal condyle-like loops, distal part of phalic bulb broadly cylindrical with a circular perforation. Ejaculatory apodeme elongate but narrow, longer than epandrium.

\section{Variation}

The Bolivian specimens differ from the other specimens in having T1 black and the abdomen otherwise entirely reddish, with no contrast in colour between T5 and the terminalia. Some of the Ecuadorian specimens (SierrAzul) have an entirely black abdomen, including the terminalia; one of these specimens was sequenced for $\mathrm{CO} 1$ and had almost the same sequence as an Ecuadorian specimen with red terminalia (Baeza). These species also seem to differ widely in size (the specimens from SierrAzul are much smaller), but the number of specimens available is inadequate to clarify whether this is a real difference or a sampling artifact. The Colombian specimens, corresponding to the type of M. enderleini, are characterized by a combination of a narrow femoral band, a black hind tibia and an orange abdomen. They are also larger larger than the Ecuadorian specimens.

\section{Remarks}

Mesoconius infestus is characterized by a strong katatergal process with an elongate apex, mostly dark wings with the discal pale band divided into diffuse spots below $\mathrm{R}_{2+3}$ and $\mathrm{R}_{4+5}$, fore tarsus entirely white or yellow, face black, mid tibia with one black band, hind femur with one or two black bands, and S8 bare and shiny. The species as recognized here is highly variable in colour and includes two previously described species (M. infestus and M. enderleini) as well as distinctive colour forms from Ecuador and Bolivia. All of these differently coloured specimens form a single cluster on a CO1 tree, with the Bolivian and Ecuadorian specimens separated by a specimen that matches the type of $M$. enderleini. The clade treated here as M. infestus is either a species complex including M. enderleini, M. infestus and two-three undescribed species, or a single variable species. It is tentatively treated as a single species pending examination of more material, despite the extensive variation.

\section{Mesoconius nigricephala sp. nov. urn:Isid:zoobank.org:act:B8C1945B-451B-4BE0-B5B2-9DDDA57B9F52}

Fig. 26

\section{Etymology}

The specific name refers to the dark head that contrasts with the mostly orange body of this distinctive species.

\section{Material examined}

\section{Holotype}

COLOMBIA • ${ }^{\wedge}$; Nariño, La Planada Nature Reserve, Parcela Permanente; $01^{\circ} 15^{\prime}$ N, $78^{\circ} 15^{\prime} \mathrm{W} ; 1885 \mathrm{~m}$ a.s.1.; 2-16 Mar. 2001; G. Oliva leg.; Malaise trap; IAVH.

\section{Paratypes}

COLOMBIA $・ 1$; same collecting data as for holotype; IAVH $\bullet 2$ o $q$; same collecting data as for holotype but 16 Mar.-2 Apr. 2001; IAVH • 1 क; Nariño, La Planada Nature Reserve, Via Hondon; $01^{\circ} 15^{\prime} \mathrm{N}, 78^{\circ} 15^{\prime} \mathrm{W}$; 1930 m a.s.1.; 16 Jun.-2 Jul. 2000; G. Oliva leg.; IAVH.

ECUADOR - 1 q (photograph); Pichincha, Maquipucuna Biological Reserve; 007'34" N, 78³7'57" W; 1200 m a.s.1.; 27 Apr. 2002; M Buck leg.; photographed by S. Marshall; DEBU.

\section{Other material}

COLOMBIA • 1 O; Cordillera Occidental, Monte Socorro; 3800 m a.s.1.; “Coll. Fassl”; BMNH. 
ECUADOR - 1 क; Pichincha, 7 km SE of Nanagalito, trout farm; 1500 m a.s.1.; 27 Oct. 1999; S.A. Marshall leg.; MYCRO451-18 sequenced for CO1; DEBU • 1 क; Pichincha, Maquipucuna Biological Reserve; $00^{\circ} 7^{\prime} 34^{\prime \prime}$ N, 78 37'57" W; 1200 m a.s.1.; 26-28 Apr. 2002; S.A. Marshall leg.; MYCRO063-15 sequenced for CO1; DEBU.

\section{Description}

LENGTH. 14-15 mm.

CoLour. Head black to dark brown, except for silvery parafacial, distally yellow palpus, pale lower face and reddish brown patches flanking facial carina; thorax orange except for variable black areas of prothorax, postpronotal lobe and areas above and below postpronotal lobe; fore leg with coxa and basal half of femur pale orange, distal half of femur and tibia black, tarsus white; mid and hind femora orange, except for dark anteromedial patches and dark apex, mid tibia and tarsus brown, hind tarsomeres 1-3 pale. Wing very lightly infuscated, with indistinct clear area anterior to crossvein dm-cu. Abdominal tergites orange, except for dark posterolateral patches on T2 (distinct), T3 and T4 (indistinct), pleuron of female pale on pinned specimens, some specimens with orange pigmentation on dorsal third of segments three-five (indistinct on most specimens); oviscape light orange basally, darker distally.

HEAD. Epicephalon and paracephalon smooth and shiny, lower half of frons dull; frontal vitta posteriorly narrow and extending to back of head as a very narrow groove, broad and broadly tapered anteriorly, not reaching frons margin. Postocellar bristles normally strong, closely spaced and far behind level of inner verticals (postocellars absent on two Ecuadorian specimens and shifted posteriorly on other Ecuadorian specimen). Frons separated from antennal socket, antennae separated by width of antennal socket, upper face weakly carinate; lower face flat and microtrichose. Clypeus angled anteriorly, meeting face at an angle of about $100^{\circ}$, shiny medially, laterally microtrichose. Postocciput with sparse small setulae.

Thorax. Cervical sclerite small, unmodified, entirely microtrichose. Postpronotal lobe microtrichose with some scattered small setulae, anterior margin forming a vertical, shiny face.

Abdomen. Abdominal segment 1 petiolate; length of $1+2$ double that of tergite 3 .

Female ABDomen. Bursa broad and rugose; ventral receptacle with a distinct, parallel-sided apical part; spermatheca with a long, striate common duct before splitting into ducts leading to paired and single spermathecae. Paired spermathecae large and elongate, each on a separate narrow duct with a large ovate swelling just beyond basal quarter; common duct of paired spermathecae long and indistinctly striate. Single spermatheca small, elongate; duct with a short constricted area at base of spermatheca; duct slightly shorter and narrower than paired duct.

Male abdomen. Sternites 5 and 6 lightly sclerotized, unmodified. Sternite 7 dark, with a broad anterior apodeme and an expanded, bare, spatulate right apex. Sternite 8 very large, twice as large as epandrium, bare except for setulose posterior quarter. Epandrium small; cercus very small, cercus and posteroventral corner of epandrium setose, anteroventral corner of epandrium forming a broad, parallel-sided lobe articulating with hypandrium. Hypandrium with a very broad, twisted anterior plate with distiphallus apex coiled into its right side. Basal part of distiphallus broadly tubular, gradually expanding to a cuplike apex surrounding a large, two-chambered phallic bulb, upper chamber saddle-like. Ejaculatory apodeme larger than epandrium.

\section{Variation}

Two non-type specimens from Ecuador apparently lack postocellar bristles. The presence or absence of postocellar bristles is a relatively constant character in Mesoconius, so this is unusual variation and these specimens would not have been considered to be the same species in the absence of dissections 


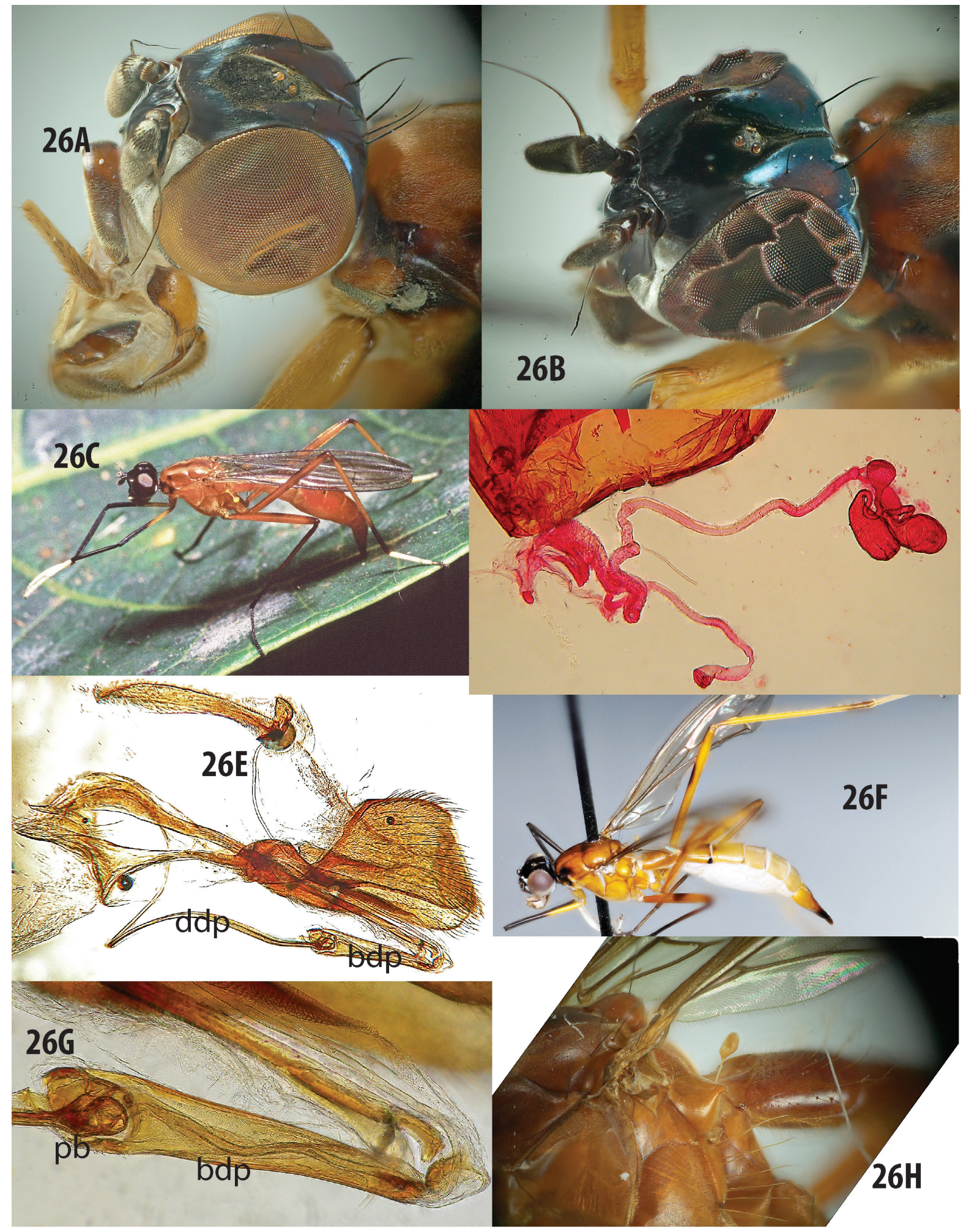

Fig. 26. Mesoconius nigricephala sp. nov. A. Head, $q$ from Colombia. B. Head, specimen from Ecuador (postocellar bristles missing). C. Paratype prior to capture, + , Ecuador (inner vertical and postocellar bristles visible). D. Spermatheca and associated structures, specimen from Colombia. E. Male terminalia, lateral view, specimen from Colombia. F. + , specimen from Colombia. G. Basal part of phallus. H. Thorax and base of abdomen, $q$, showing prominent katatergite. Abbreviations: $b d p=$ basal distiphallus; $\mathrm{dd} p=$ distal distiphallus; $\mathrm{pb}=$ phallic bulb. 
showing every detail of the spermathecal complex to be identical to those of the type. There is also some variation in the extent of pigmentation of the postnotum but, unlike the postocellar bristles, this is normal intraspecific variation.

\section{Remarks}

Despite the unusual variation in postocellar bristles, this species is easily recognized by a large number of consistent characters, including general thoracic and head pigmentation, the isolated dark patches on the mid and hind femora, the narrow, pale palpus and the characteristically modified postnotum, with a bare, vertical anterior face. Female internal characters are consistent (Colombian and Ecuadorian specimens, with and without postocellars, were dissected), but only one male specimen is known. Although it is very differently coloured, $M$. nigricephala $\mathrm{sp}$. nov. shares several synapomorphies with the rest of the M. infestus group, including the two-part ducts of the paired spermathecae, the distally expanded basal phallic section with a hood-like lobe over the phallic bulb, the whip-like phallus incorporated with the broadly twisted anterior hypandrial margin and the very large S8.

\section{Mesoconius notacca sp. nov. urn:1sid:zoobank.org:act:BDFBF472-A111-4E98-AB68-F4CBC4267A80}

Fig. 27

\section{Etymology}

The species name is a noun in apposition coined as a reminder that this species was initially misidentified as the similar and sympatric M. acca sp. nov., from which it is distinguished by its white fore tarsus and mostly black hind femur, as well as features of the distinctive spermathecal complex and the partially shiny male S8.

\section{Material examined}

\section{Holotype}

PERU • $\lambda^{\prime}$; Cusco, Wayqecha Biological Station, $9 \mathrm{~km} \mathrm{NE}$ of Challabamba; $13^{\circ} 10^{\prime} 20^{\prime \prime} \mathrm{S}, 71^{\circ} 35^{\prime} 00^{\prime \prime} \mathrm{W}$; 2600-2700 m a.s.1.; 1-6 Dec. 2011; S.A. Marshall leg.; MYCRO 457-18; MUSM.

\section{Paratype}

PERU • 1 क; same collecting data as for holotype; MYCRO062-15 sequenced for CO1; DEBU.

\section{Description (female only)}

LENGTH. $16 \mathrm{~mm}$.

CoLour. Head black to dark brown, except for silvery gena, parafacial and middle of face and apically yellow palpus. Thorax mostly black, but katatergite orange distally and ventrally. Fore tarsus white. Mid and hind femora black, except for orange apex. Mid tibia black, except for orange base, hind tibia orange, except for darker apical fifth. Hind tarsus with tarsomere 1 pale yellow with pale setae, tarsomeres 2 and 3 pale with dark setae, tarsomeres 4 and 5 darker. Wing strongly infuscated, with small and indistinct clear areas in cell $\mathrm{r}_{2+3}$, cell $\mathrm{r}_{4+5}$ and distal to crossvein dm-cu. Oviscape dark brown to black.

HEAD. Epicephalon and paracephalon finely striate, subshining, slightly shinier than orbits; frontal vitta posteriorly tapered and then expanded to form a broad, densely microtrichose patch connecting inner vertical and postocellar bristles, broad and broadly tapered anteriorly, reaching frons margin only as a narrow line. One very small upper fronto-orbital bristle positioned close to eye at level of upper ocelli, one small lower fronto-orbital bristle on microtrichose part of orbital strip. Antennae separated by width of antennal socket, upper face strongly and broadly carinate; subantennal areas shiny brown on dorsal 
half and silvery microtrichose on ventral half; lower face pale, membranous and microtrichose. Clypeus shiny and sparsely microtrichose medially, laterally densely microtrichose. Lower back of head densely setulose.

Thorax. Cervical sclerite with a vertical groove separating a microtrichose, convex, subquadrate posterior portion from a small, bare anterior portion. Fore tibia broad, sulcate on outer face. Postpronotal lobe microtrichose, with some scattered small setulae, anterior margin forming a vertical, shiny face.

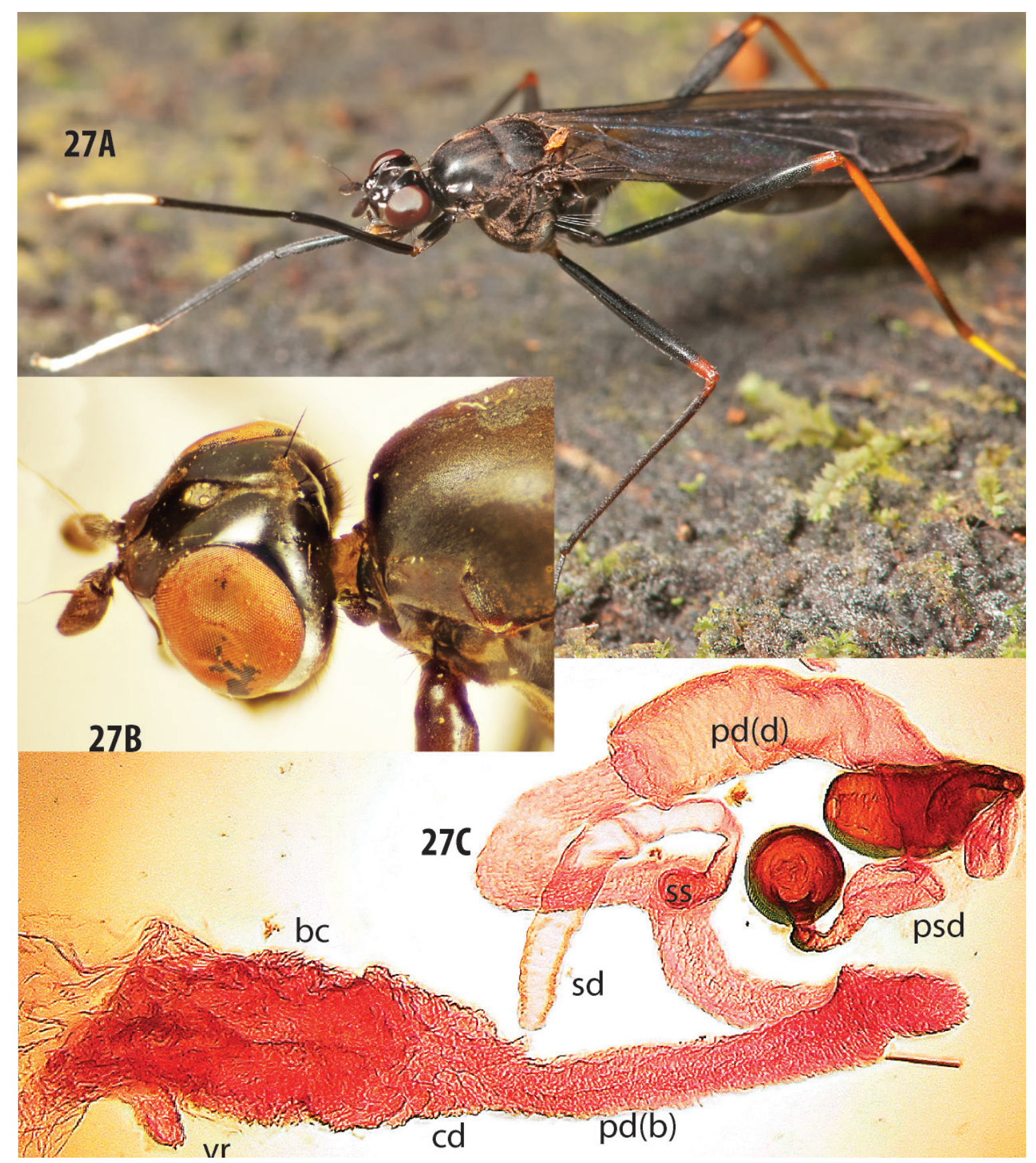

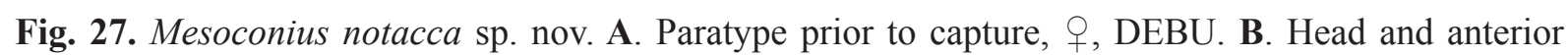
thorax. C. Spermathecae and associated structures. Abbreviations: $b c=$ bursa copulatrix; $c d=c o m m o n$ duct; $\operatorname{pd}(\mathrm{b})=$ paired spermathecal duct (basal); $\mathrm{pd}(\mathrm{d})=$ paired spermathecal duct (distal); psd = paired spermathecal duct; sd = single spermathecal duct; ss = single spermatheca; $\mathrm{vr}$ - ventral receptacle. 
AвDomen. Abdominal segment 1 petiolate; length of $\mathrm{T} 1+2$ double that of tergite 3.

Female abdomen. Bursa elongate, ventral receptacle distinct, near base. Spermathecal ducts arising separately from apex of a short tapered apical part of bursa. Single spermathecal duct constricted at base, then thick, then constricted again at base of a thick stem leading to a vestigial single spermatheca. Paired spermathecal duct with a very long, wrinkled basal part that abruptly expands to a short, broad distal section that branches into stems leading to elongate paired spermathecae; each stem with a central swollen part.

Male ABdomen. Sternites 5 and 6 small and lightly sclerotized, divided medially. Sternite 7 (ventral part of synsternite 7-8) dark, with a broad anterior apodeme and an expanded, bare, spatulate right apex. Sternite 8 black, anterior third shiny, otherwise dull, microtrichose. Epandrium with prominent, setose posteroventral angles, cercus large and distinct. Postgonites small and divergent (directed laterally), with two small apical setae. Basal part of distiphallus broadly tubular, gradually expanding to a very large phallic bulb forming a broad hood over base of distal part of distiphallus. Ejaculatory apodeme slightly larger than epandrium.

\section{Mesoconius triunfo sp. nov. urn:1sid:zoobank.org:act:07C84F8E-C311-400C-B6BE-2DDC966D6B5D}

Fig. 28

\section{Etymology}

The species name refers to the El Triunfo Biosphere Reserve, which protects the unique high elevation cloud forests in which this species lives.

\section{Material examined}

Holotype

MEXICO • ${ }^{\top}$; Chiapas, El Triunfo, $49 \mathrm{~km} \mathrm{~S}$ of Yaltenango; $2000 \mathrm{~m}$ a.s.1.; 13-15 May 1985; A. Freidberg leg.; USNM.

\section{Paratypes}

MEXICO 1 ô, 3 우; same collecting data as for holotype; MYCRO064-15 sequenced for CO1; TAUI.

\section{Description}

LENGTH. 13-16 mm.

CoLour. Burnt orange with narrow black vittae on notum; lunule, lower frons, epicephalon and corners of tergites darkened; mid and hind femora orange, with a black distomedian ring; distal part of fore femur and fore tibia black; fore tarsomeres and tarsomeres 1 and 2 of hind leg white, distal hind tarsomeres black. Antenna brown, with basal fifth of first flagellomere yellow to orange; parafacial silvery, palpus and clypeus yellow. Frontal vitta velvety black. Wing strongly infuscated, with clear areas in cell $r_{2+3}$, cell $\mathrm{r}_{4+5}$ and distal to crossvein dm-cu.

HEAD. Epicephalon and paracephalon smooth and shiny, lower half of frons dull; frontal vitta posteriorly narrow but expanded into a microtrichose patch at level of postocellar bristles, broad and broadly tapered anteriorly, narrowly separated from frons margin. Antennae separated by width of antennal socket, upper face weakly carinate, lower face flat and microtrichose. Clypeus shiny medially, laterally microtrichose. Postocciput with sparse small setulae. 
Thorax. Cervical sclerite small, unmodified, entirely microtrichose. Postpronotal lobe microtrichose with some scattered pale setulae, anterior margin vertical and bare on upper quarter.

Abdomen. Abdominal segment 1-3 petiolate (segment 4 also somewhat petiolate in male), length of $\mathrm{T} 1+2$ double that of $\mathrm{T} 3$.

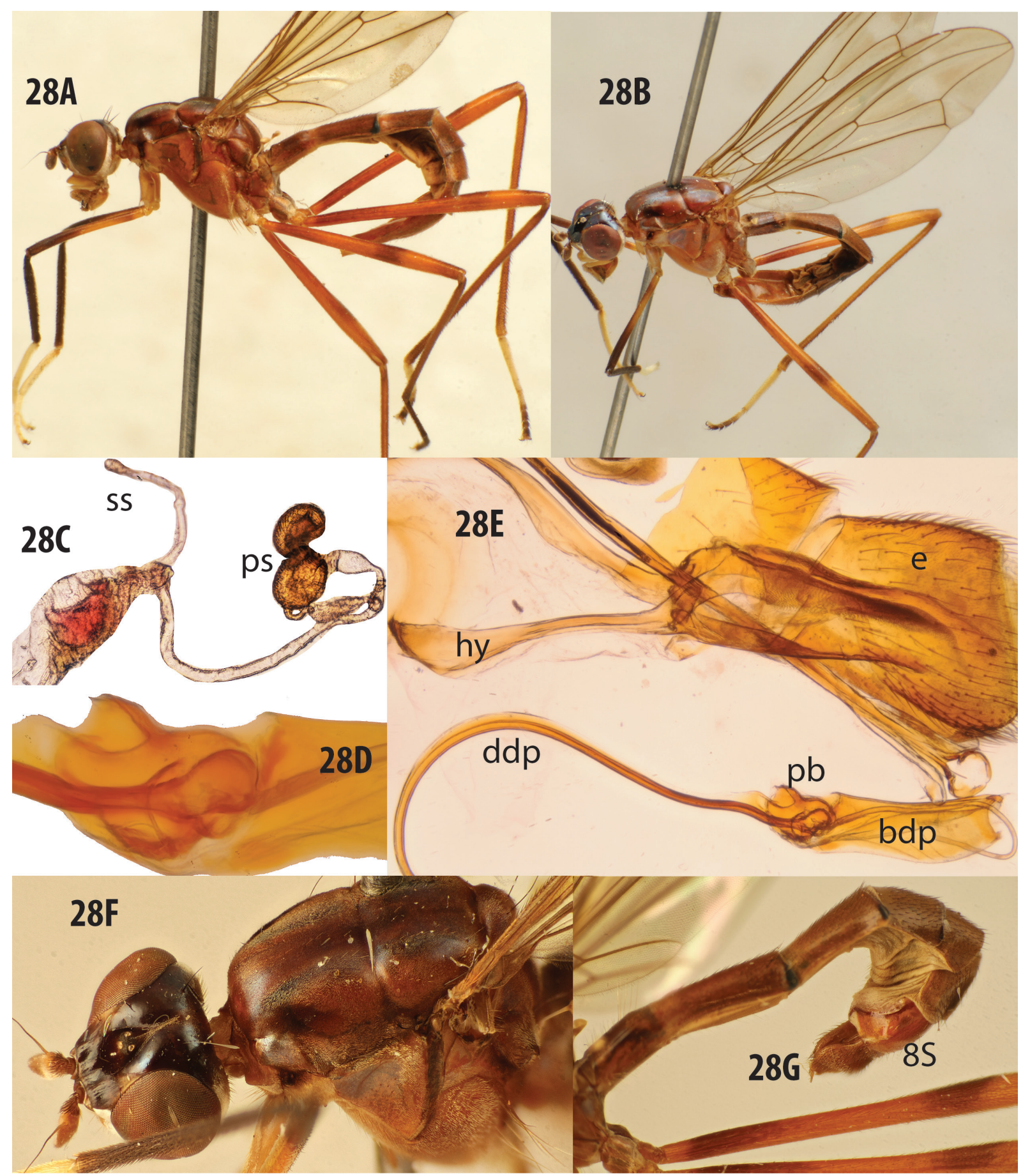

Fig. 28. Mesoconius triunfo sp. nov. A-B. Paratypes, $q \uparrow$, TAUI. C. Spermathecae and associated structures. D. Phallic bulb. E. Male terminalia, left lateral view. F. Head and thorax, $\overbrace{}^{\lambda}$. G. Abdomen, $\partial^{\lambda}$. Abbreviations: $\mathrm{bdp}=$ basal distiphallus; $\mathrm{ddp}=$ distal distiphallus; $\mathrm{e}=$ epandrium; hy = hypandrium; $\mathrm{pb}=$ phallic bulb; ps = paired spermathecae; ss = single spermatheca. 
Female ABDomen. Ventral receptacle not observed; bursa small, terminating in a short, broad, striate common duct that splits into ducts leading to paired and single spermathecae. Paired spermathecae large, kidney-shaped and distally invaginate, distinctly striate, each on a separate narrow stem with a large ovate swelling near base; common duct of paired spermathecae long and indistinctly striate in basal half, smooth distally. Single spermatheca vestigial, barely differentiated from short duct.

Male abdomen. Sternites 5 and 6 greatly reduced, lightly sclerotized and very narrow, S6 slightly broadened at anterior margin. Sternite 7 narrow ventrally, but with an expanded, spatulate right apex. Sternite 8 shiny, longer than epandrium, with scattered setulae. Epandrium and cercus small, cercus and posteroventral corner of epandrium setose, anteroventral corner of epandrium forming a parallel-sided lobe articulating with hypandrium. Hypandrium with a very broad, twisted anterior plate. Postgonites small, broad and divergent, with small preapical setae. Basal basiphallus short and broad, about 3 times as long as broad and ending in a cup-like apex that extends over a large two-chambered phallic bulb, with lower chamber a simple globe and upper chamber saddle-like. Ejaculatory apodeme longer but narrower than epandrium.

\section{Remarks}

The most closely related species seems to be the Costa Rican species M. dianthus Marshall, 2015, from which $M$. triunfo sp. nov. can be distinguished by its dark head and more extensive dark markings on the notum, as well as by characters of the male genitalia (differently shaped basal distiphallus and phallic bulb) and female spermathecal complex (features of the paired duct).

Mesoconius ujhelyianus Enderlein, 1922

Fig. 29

Mesoconius ujhelyianus Enderlein, 1922: 177.

\section{Material examined}

\section{Holotype}

COLOMBIA • ○’; Sierra San Lorenzo; Ujhelyi leg.; MNBG.

\section{Other material}

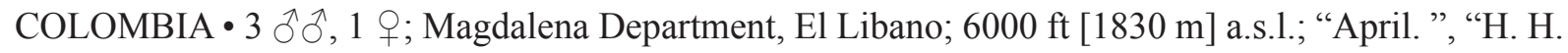
Smith accession number 1740"; CMNH.

ECUADOR • 1 ð̊; Santa Inez; "Mesoconius Garleppi Enderl.”, "purchased from H. Rolle 1904-117”; no legs and right wing torn; BMNH. See also notes about Santa Inez under M. fulvus.

\section{Description}

Based on CMNH specimens from Colombia.

LENGTH. $16 \mathrm{~mm}$.

Colour. Orange, except for brown to black upper part of frontal vitta and apex of fore femur, fore tibia except apex, broad middle band on fore and hind femora, mid tarsus, apical four tarsomeres of hind leg and posterolateral corners of T2 and T3. Epicephalon and paracephalon shiny and indistinctly striate, lower half of frons dull; frontal vitta velvety dark brown to black posteriorly, fading to a convex orange anterior portion that does not reach anterior margin of frons. Antenna orange, but base of first flagellomere and base of arista distinctly paler than rest of antenna. Gena, parafacial, and lower outer corner of face silvery microtrichose; subantennal areas shiny brown. Clypeus shiny yellow medially, 
laterally microtrichose. Palpus pale orange-yellow. Wing yellowish infuscated, with indistinct clear area anterior to crossvein $\mathrm{dm}-\mathrm{cu}$.

HEAD. Postocellar bristles strong, closely spaced and far behind level of inner vertical bristles. Frontal vitta convex, posteriorly forming a narrow microtrichose strip that expands to a microtrichose area extending to inner vertical bristle. Antennae separated by width of antennal socket; upper face weakly carinate; lower face flat and microtrichose. Postocciput with sparse small setulae.

THORAX. Cervical sclerite mostly microtrichose, but with a small, distinctly separate, anterior bare part. Postpronotal lobe microtrichose, with some scattered small setulae, anterior margin forming a vertical, shiny face.

AbDomen. Abdominal segments 1-3 petiolate; length of T1+2 $2.5 \times$ length of tergite 3 .

FEMALE ABDOMEN. Bursa broad and rugose; ventral receptacle small; single and common spermathecal ducts arising separately. Paired spermathecae large and elongate, each on a separate narrow duct with a large ovate swelling just beyond basal quarter; common duct of paired spermathecae long and distinctly striate over basal $2 / 3$, then abruptly tapered to a smooth distal part. Single spermatheca small and elongate, single duct much shorter and narrower than paired duct, with a short constricted area at base of spermatheca.

Male ABdomen. S5 and S6 lightly sclerotized, unmodified. S7 dark, with a broad anterior apodeme and an expanded bare spatulate right apex; S8 very large, twice as large as epandrium, shiny in contrast

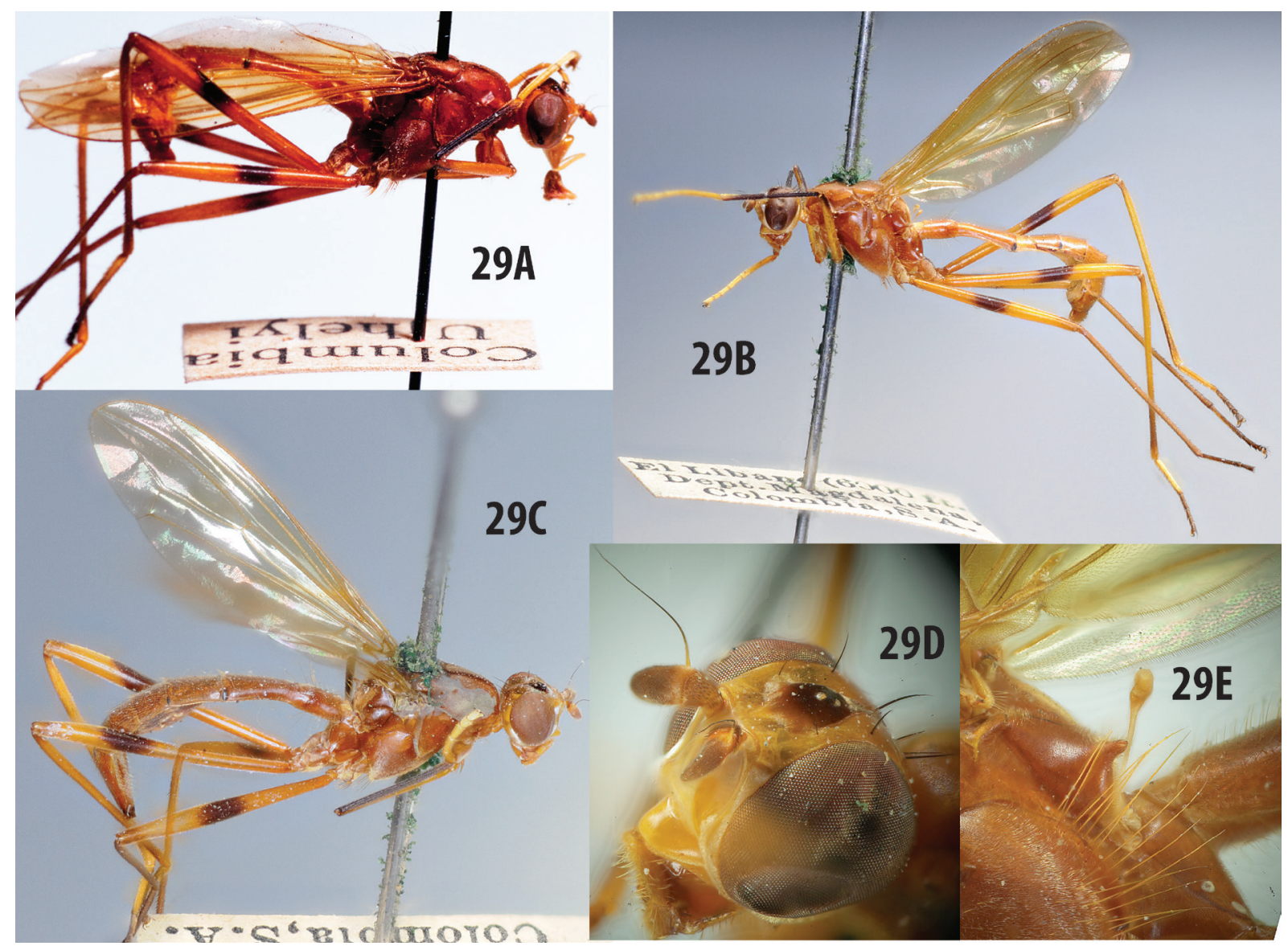

Fig. 29. Mesoconius ujhelyianus Enderlein, 1922. A. Holotype, §, MNBG. B. § (CMNH). C. $q$ $(\mathrm{CMNH})$. D. Head, ㅇ. E. Katatergite, q. 
to dull T6 and epandrium, sparsely setulose. Epandrium small, with a very prominent broad, setose posteroventral lobe. Cercus large, paralleling posteroventral epandrial lobe. Basal part of distiphallus broadly tubular, gradually expanding to a cup-like apex, with a long dorsal part subtended by a separate perforated saddle-like sclerite over part of strongly swollen bulb portion of ejaculatory duct. Ejaculatory apodeme larger than epandrium.

\section{Remarks}

This is one of the few species of Mesoconius for which it was possible to confidently match Enderlein's types with non-type specimens. The four specimens from CMNH used in the above description seem to match the type in almost every detail and were collected from the same part of Colombia. The species was named after its collector, Joseph Ujhelyi (1879-1933), an entomologist of the Hungarian National Museum who made a collecting trip to Columbia in 1912.

Mesoconius ujhelyianus (from Colombia) and M. garleppi (from Peru) are the only orange species of Mesoconius with medially banded mid and hind femora, an anteriorly pale frontal vitta and a strongly projecting katatergite. The original descriptions of both species appeared on the same page, distinguished primarily by the differently coloured fore tibia (entirely pale in $M$. garleppi). These superficially similar species also differ markedly in the shape of the frontal vitta (sharply triangular in M. garleppi).

\section{Mesoconius nono group}

The Mesoconius nono group, diagnosed by the presence of outer vertical bristles and the absence of a conspicuously swollen katatergite, includes 11 South American species (M. aurantium sp. nov., M. bipleuron sp. nov., $M$. garyi sp. nov., M. hoffmansi, $M$. nono sp. nov., $M$. ottoi nom. nov., $M$. reinai sp. nov., M scurrus, M. uchumachi sp. nov., M. wytkoskyi sp. nov. and M. zorro sp. nov.) and one Central American species (M. nigrihumeralis Marshall, 2015) (Fig. 30). Both diagnostic characters are plesiomorphic, and the presence or absence of the outer vertical bristle can be difficult to assess on older type specimens. Furthermore, most species are known from inadequate material, rendering it impossible to assess and compare phylogenetically informative characters of the male and female terminalia. Nine out of the 12 species are known from one sex only and only seven species are known from males; of these only five, including the Central American M. nigrihumeralis, could be examined for male genitalic characters (two species are known only from older holotype males and could not be dissected). The species for which male terminalia were examined have a truncate or vestigial distal distiphallus, markedly unlike the elongate distiphallus of other species groups. They also have a broad, scoop-like hypandrium unlike the twisted hypandrium of the infestus group or the narrow, ribbon-like hypandrium of the M. eques group. Five species in this group were sequenced for $\mathrm{CO} 1$ and are shown on three widely separated branches of the resulting maximum likelihood tree (Fig. 50).

Mesoconius aurantium sp. nov.

urn:1sid:zoobank.org:act:238AAAF3-3136-4822-BAC7-F0B51316C7B3

Fig. 31

\section{Material examined}

Holotype

PERU • + ; Cusco, Wayqecha Biological Station, 9 km NE of Challabamba; $13^{\circ} 11^{\prime} 18^{\prime \prime} \mathrm{S}, 71^{\circ} 35^{\prime} 06^{\prime \prime} \mathrm{W}$; 3100 m a.s.1.; 7-8-Dec. 2011; S.A. Marshall leg.; MUSM.

\section{Etymology}

The name, from the Latin noun for 'orange', refers to the generally orange colour of this species. 


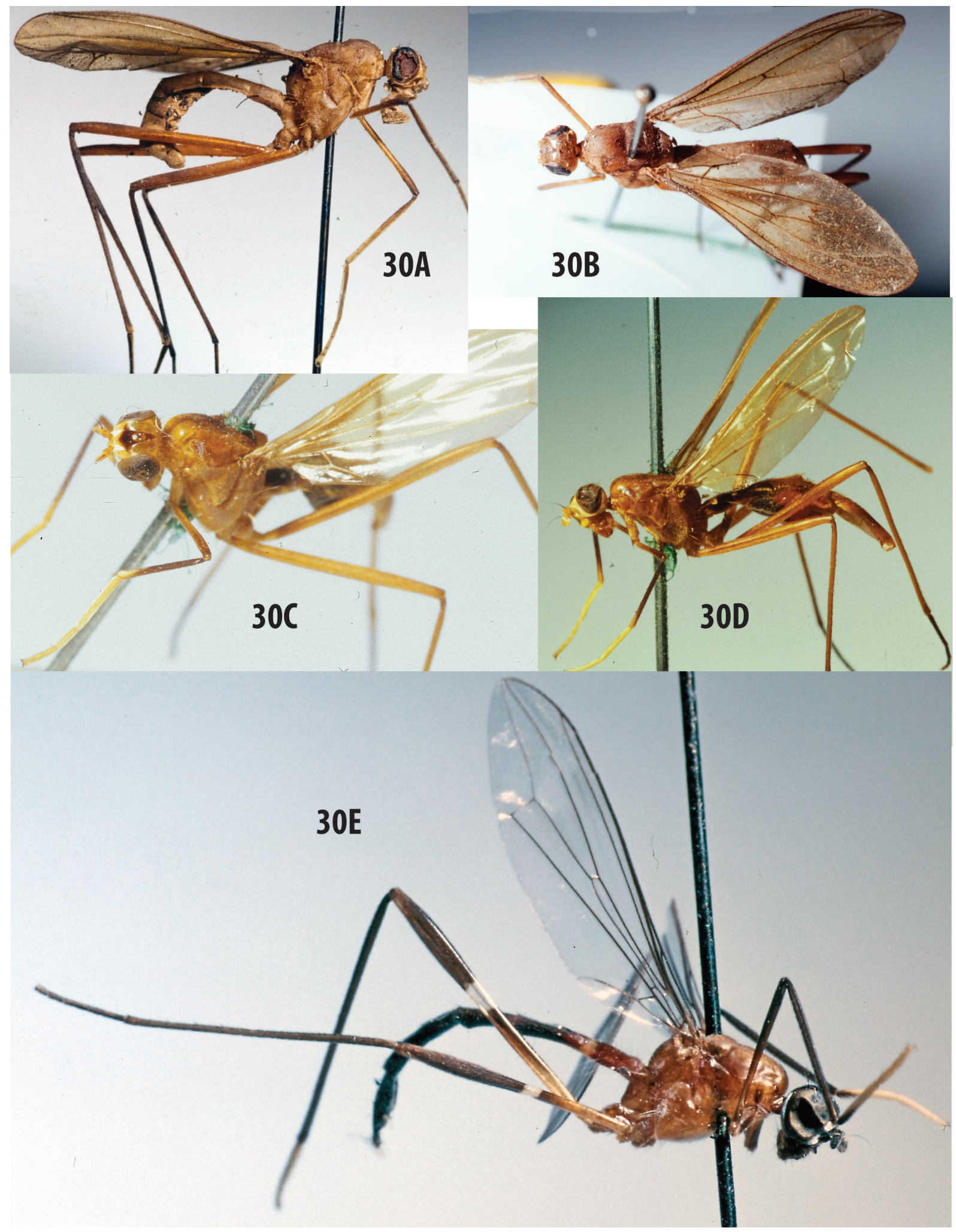

Fig. 30. Species of the Mesoconius nono group known only from original type specimens. A-B. Mesoconius hoffmannsi (Enderlein, 1922), holotype (Peru), ô, MNBG. C-D. Mesoconius ottoi nom. nov. (replacement name for Tanypoda garleppi Enderlein, 1922), lectotype (Bolivia), , MNBG. E. Mesoconius scurrus (Hennig, 1935), holotype (Bolivia), §̂, SMTD. 


\section{Description}

LENGTH. $18 \mathrm{~mm}$.

Colour. Mostly bright orange, except as follows: lower frons dark; face pale, parafacial, gena and postgena silvery microtrichose, except for a shiny gap on posterior part of gena; palpus yellow. Postpronotal lobe, tegula and subalar sclerite dark brown to black, sharply contrasting with orange notum and pleuron. Fore femur black at apex; fore tibia all black; fore tarsus white, with tarsomere 1 black ventrally on basal half. Mid tarsus and apex of mid tibia brown with black setulae, thus appearing black. Hind tarsus with tarsomere 1 with black setulae only at apex, tarsomeres 2-5 all appearing as black due to black setulae. Wing entirely yellowish, without clear bands. Abdominal pleuron discoloured on unique type, but apparently dark dorsally, pale ventrally.

HEAD. Epicephalon minutely striate, shiny, with scattered minute setulae posteriorly. Frontal vitta fusiform, indistinct, narrow but almost parallel-sided behind ocelli, broader in front but still relatively narrow, $0.4 \times$ as wide as frons at widest point. Lower frons bare, broadly depressed at middle. Postocellar

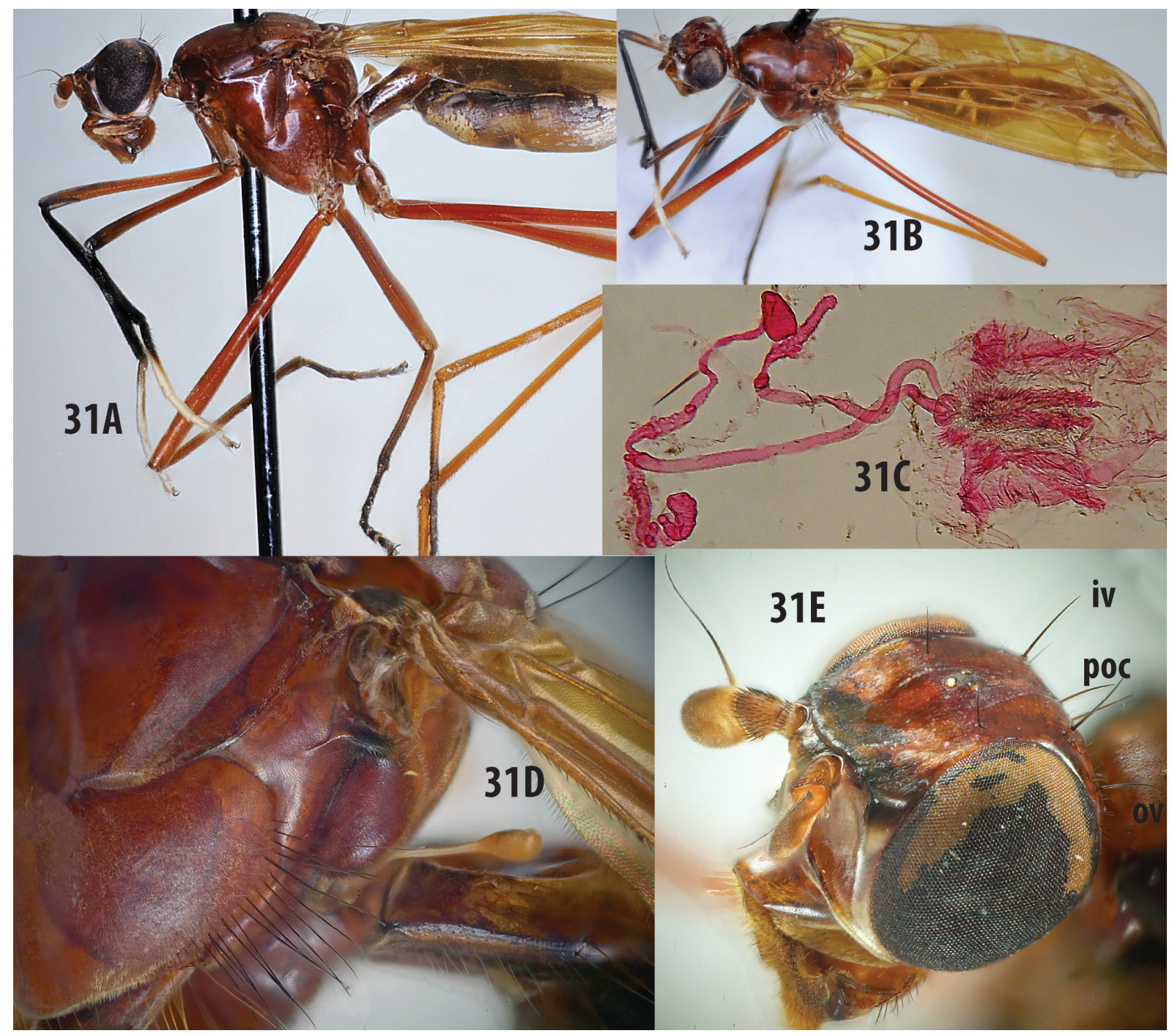

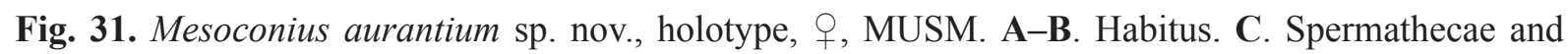
associated structures. D. Pleuron and abdominal base. E. Head. Abbreviations: iv = inner vertical bristle; $\mathrm{ov}=$ outer vertical bristle; poc $=$ postocellar bristle . 
bristles closely spaced and slightly divergent, inner vertical and outer vertical bristles well developed, with scattered setulae anterior to base of inner vertical; upper fronto-orbital bristle very large, inserted at level of upper ocellus; lower fronto-orbital minute or absent.

THORAX. Scutum densely golden microtrichose, laterally black microtrichose. Acrostichal setulae minute, but forming a row; dorsocentral setulae minute, in a row. Thoracic pleuron mostly bare, katepisternum with long white microtrichia and scattered white setulae. Cervical sclerite elongate, shiny dorsally with an incomplete vertical groove separating a large mostly dull posterior section from a minute, constricted and bare anterior portion. Postpronotal lobe unusually wide, dull, with white microtrichia on anterior and posterior faces. Posterior notopleural bristle much stronger than anterior one, on a distinct swelling. Dorsocentral bristle longer than scutellum. Scutellum sparsely microtrichose, shiny; apical bristles strong, almost erect. Vertical row of katepisternal bristles black. Katatergite slightly swollen, without median process, evenly convex and microtrichose; subalar swelling (posterodorsal corner of anepimeron) black, prominent. Fore coxa with black anteroventral setae, mid and hind coxae with an anteroventral tuft of long, golden setae.

ABDOMEN. Strongly petiolate, T1+2 $1.2 \times$ as long as T3, basally narrow, with a strong constriction between T1 and T2, apically as wide as base of T3, T1 with a preapical ring of golden setae.

Female abdomen. Bursa small, broad, with an inconspicuous ventral receptacle. Single and double spermathecal ducts arising from apex of a very short (shorter than wide) common duct; both ducts smooth and of similar diameter, paired duct slightly longer, with pipe-shaped distally swollen spermathecae on exceptionally long stems (stems $2 / 3$ as long as duct before split); spermathecae similar, unusually elongate, narrow, parallel-sided and of similar diameter to the duct.

\section{Remarks}

Mesoconius aurantium sp. nov. differs from all congeners in having an orange (not black or dark brown) frontal vitta. Additionally, it stands out for its black subalar sclerite and postpronotal lobe, which contrast with the otherwise orange body.

\section{Mesoconius bipleuron sp. nov. urn:1sid:zoobank.org:act:A2CC6797-7A50-428B-8A74-0B90D08C5AC5}

Fig. 32

\section{Etymology}

The specific name refers to the bicoloured pleuron.

\section{Material examined}

\section{Holotype}

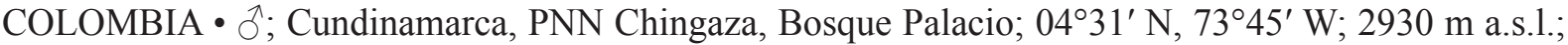
10-24 Nov. 2000; E. Raigoso leg.; IAVH.

\section{Paratypes}

COLOMBIA $\bullet 1$; same collecting data as for holotype; IAVH $\bullet 1$; same locality as for holotype; 5-17 Jan. 2001; L. Cifuentes leg.; IAVH • 1 q; same collecting data as for holotype; 17 Jan.-5 Feb. 2001; E. Niño leg.; IAVH • 1 क; same collecting data as for holotype; 4-16 Feb. 2001; E. Niño leg.; IAVH • 1 क; same collecting data as for holotype; 20 Dec. 2000-5 Jan. 2001; E. Niño leg.; IAVH • 1 ; same collecting data as for holotype; 6-21 Jul. 2000; E. Raigoso leg.; IAVH • 1 क; Boyacá, SFF Iguaque, Cerro Pan de Azucar; $05^{\circ} 25^{\prime} \mathrm{N}, 7^{\circ} 27^{\prime} \mathrm{W}$; 3300 m a.s.1.; 22 Aug.-12 Sep. 2001; P. Reina leg.; Malaise trap; IAVH • 1 क; Boyacá, SFF Iguaque, La Planada; $05^{\circ} 25^{\prime} \mathrm{N}, 73^{\circ} 27^{\prime} \mathrm{W} ; 2850 \mathrm{~m}$ a.s.l.; 13 Nov.-4 Dec. 2000; P. Reina leg.; MYCRO071-15 sequenced for CO1; DEBU. 


\section{Description}

\section{LENGTH. $15 \mathrm{~mm}$.}

Colour. Head black dorsally; face, clypeus and antenna brown; palpus orange; parafacials and gena silvery. Frontal vitta mostly velvety black. Thorax mixed orange and black, pleuron mostly black ventrally, microtrichose except shiny black middle of katepisternum; mostly shiny orange dorsally, orange part often extending ventrad through katepisternum, posterior margin of anepisternum microtrichose; scutum orange and bare laterally, middle of scutum with a broad microtrichose longitudinal band on a dark background; scutellum orange medially, brown laterally. Fore femur orange on basal half, black on distal half, tibia black, tarsomere 1 white dorsally, black ventrally, distal tarsomeres black (tarsomere 2 sometimes white basally). Mid and hind femora variable in colour, entirely reddish brown, brown with strong basal and middle black bands, or brown with partial basal and middle black bands. Mid and hind tibia brown, tarsus black. Wing uniformly lightly infuscated, with only a faint indication of a clearer discal band. Abdomen of female with orange tergites and oviscape, pleuron white, posterolateral corners of T2 black. Abdomen of male with tergites brown, except for pale T2-3; pleura 2 and 3 with black setulose patches.

HEAD. Epicephalon and paracephalon indistinctly striate, with dense white microtrichosity anteriorly and posteriorly, shiny in between. Frontal vitta slightly raised, very broad in front of ocelli, black part broadly rounded behind, but with a microtrichose tapered posterior extension; anterior part of vitta with velvety black part tapered and widely separated from anterior margin of frons, but vitta reaching anterior margin as a differentiated, parallel-sided, depressed strip (obvious or inconspicuous depending on the light). Lower frons dull, indistinctly microtrichose. Palpus relatively narrow, slightly curved upward and tapered towards apex. Postocellar bristles closely spaced and slightly divergent, inner and outer vertical bristles well developed; upper fronto-orbital large, inserted in shiny part of epicephalon, lower frontoorbital minute or absent.

THorax. Scutum densely microtrichose dorsally, forming colour patterns described above; dorsocentral setulae minute, forming a sparse row; acrostichal setulae indistinct. Cervical sclerite subquadrate, with a vertical groove separating a large microtrichose posterior section from a bare anterior portion; central part of posterior portion of females with a large oval patch of dense microtrichia. Prosternum unusually bare and shiny, narrow and tapered anteriorly (unlike all congeners). Postpronotal lobe sparsely microtrichose, without setulae, area above postpronotal lobe with several long, fine, curved setulae. Dorsocentral bristle subequal to scutellar length. Scutellum with minute discal setulae and one pair of apical bristles (slightly longer than scutellum). Vertical row of katepisternal bristles golden. Katatergite evenly convex and microtrichose, without a conspicuous swelling or point. All coxae with an anteroventral tuft of long black setae.

ABDOMEN. Indistinctly petiolate, with a distinct constriction between T1 and T2; length of T1+2 $1.3 \times$ that of T3; width of T1, posterior margin of T2 and anterior margin of T3 similar; posterior margin of T3 conspicuously broader.

Female ABDomen. Oviscape relatively broad and short, subequal to T4-6. Bursa large, irregular; ventral receptacle extremely large, with a distinct head. Paired and single spermathecal ducts arising independently from bursa, single duct slightly thinner and shorter, with an elongate and tuberculate spermatheca (distally evaginated on dissected material). Paired spermathecal duct parallel-sided and uniformly textured, constricted at apex into two very short, narrow stems, each leading to an elongate oval, tuberculate spermatheca. 
MALE ABdomEn. Sternite 5 very small and pale, tapered anteriorly; S6 large, broad, setulose, setose and brown; S7 bare and narrow; right side of segment 7 with a small sclerite surrounding spiracle, pleuron not invaginated. Sternite 8 subequal to epandrium, partially fused with broad ventral lobe of S7 on left side, shiny anterodorsally in contrast to microtrichose anterior sclerites, micosetulose posteriorly and anteriorly. Epandrium setulose, long-setose posterodorsally. Ejaculatory apodeme small, smaller than epandrium; hypandrium with a scoop-like anterior margin; basal part of distiphallus long, mostly broadly sclerotized and parallel-sided, but distally upcurved, with sclerotized part strongly tapered; phallic bulb small and inconspicuous; phallus beyond phallic bulb very short, pale, with a clubbed apex.

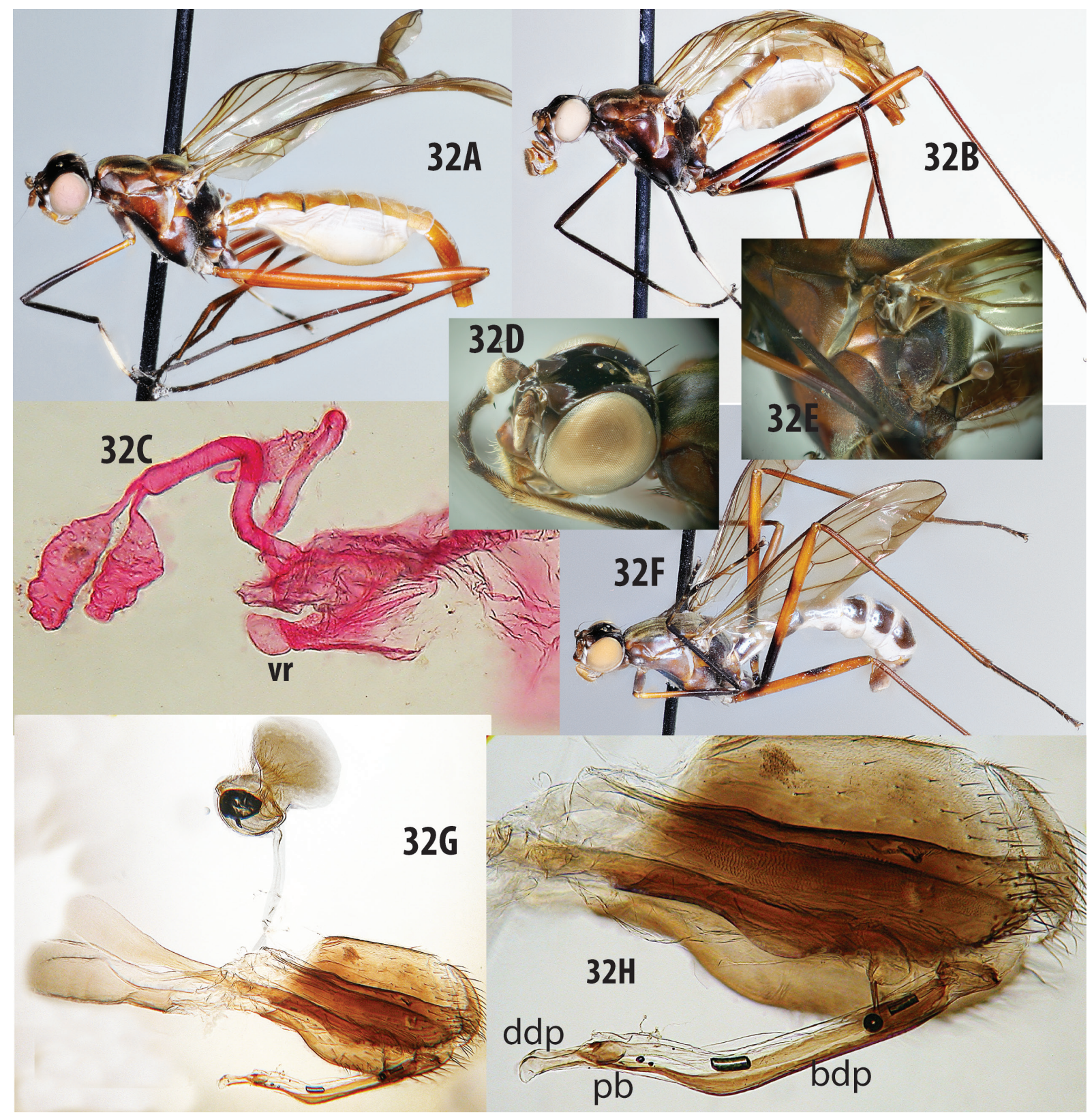

Fig. 32. Mesoconius bipleuron sp. nov. A. $q$ with unmarked tibiae. B. Typical $q$. C. Spermathecae and associated structures. D. Head, holotype, $\hat{\jmath}$, IAVH. E. Pleuron and abdominal base, holotype. F. Holotype, ${ }^{\lambda}$. G-H. Male terminalia. Abbreviations: bdp = basal distiphallus; ddp = distal distiphallus; $\mathrm{pb}=$ phallic bulb; $\mathrm{vr}=$ ventral receptacle. 


\section{Remarks}

Mesoconius bipleuron sp. nov. is externally distinctive for its bicoloured pleuron and internally highly distinctive for the truncate distal distiphallus in the male and the enlarged sperm storage structures (spermathecae, ventral receptacle) in the female.

Mesoconius garyi sp. nov.

urn:1sid:zoobank.org:act:1CAC3CDC-AFB9-4C95-AB4B-DE8037300D90

Fig. 33

\section{Etymology}

The species name is a patronym, honoring University of Guelph entomologist Gary Umphrey.

\section{Material examined}

\section{Holotype}

PERU • P; Cusco, Wayqecha Biological Station, $9 \mathrm{~km} \mathrm{NE}$ of Challabamba; $13^{\circ} 10^{\prime} 20^{\prime \prime} \mathrm{S}, 71^{\circ} 35^{\prime} 00^{\prime \prime} \mathrm{W}$; 2600-2700 m a.s.1.; 1-6 Dec. 2011; S.A. Marshall leg.; MUSM.

\section{Paratypes}

PERU $\bullet 1$ O , 3 क $O$; same collecting data as for holotype; one of each sex in alcohol; MYCRO116-15 and MYCRO337-18 sequenced for CO1; DEBU.

\section{Description}

LENGTH. $16 \mathrm{~mm}$.

CoLour. Mostly bright orange, except as follows: frontal vitta velvety black, except for partially orange ocellar triangle, contrasting with pale lower frons; vitta characteristically shaped with anterior portion broadly tapered and reaching or almost reaching frontal margin, posterior portion elongate triangular; broadest part of vitta continuous with a narrow transverse black band almost meeting eye. Face pale, parafacial, gena and postgena silvery microtrichose. Postpronotal lobe often yellow, but females usually with postpronotal lobe dark brown, sharply contrasting with orange notum and pleuron (postpronotal lobe relatively pale on holotype female). Fore tibia black with apex narrowly orange, fore tarsus bright yellow; hind and mid tarsi brown. Hind femur with a broad black band just beyond base. Wing entirely yellowish, without clear bands. Abdominal pleuron yellow, with orange areas on upper half of segments 4 and 5 (entire pleuron discoloured on pinned specimens).

HEAD. Epicephalon smooth and shiny, with scattered minute setulae and inconspicuous microtrichosity posteriorly; paracephalon minutely black setulose, slightly elevated above epicephalon. Frontal vitta only slightly elevated, narrow, at widest $0.4 \times$ as wide as frons. Lower frons bare, depressed at middle. Palpus narrow, slightly tapered to a rounded apex. Postocellar bristles closely spaced and slightly divergent, inner vertical and outer vertical bristles well developed, with scattered setulae anterior to base of inner vertical; upper fronto-orbital bristle distinct, inserted at level of upper ocellus; lower frontoorbital minute or absent.

Thorax. Scutum inconspicuously but evenly microtrichose, acrostichal setulae minute but forming a row; dorsocentral setulae long and in a distinct row above postpronotal lobe, otherwise minute. Cervical sclerite subquadrate, with a vertical groove separating a large microtrichose posterior section from a minute, constricted and bare anterior portion. Postpronotal lobe unusually wide, sparsely microtrichose and very sparsely setulose. Dorsocentral bristle short, inconspicuous, barely larger than dorsocentral setulae. Scutellum microtrichose but without macrosetae, apical bristles absent. Vertical row of 


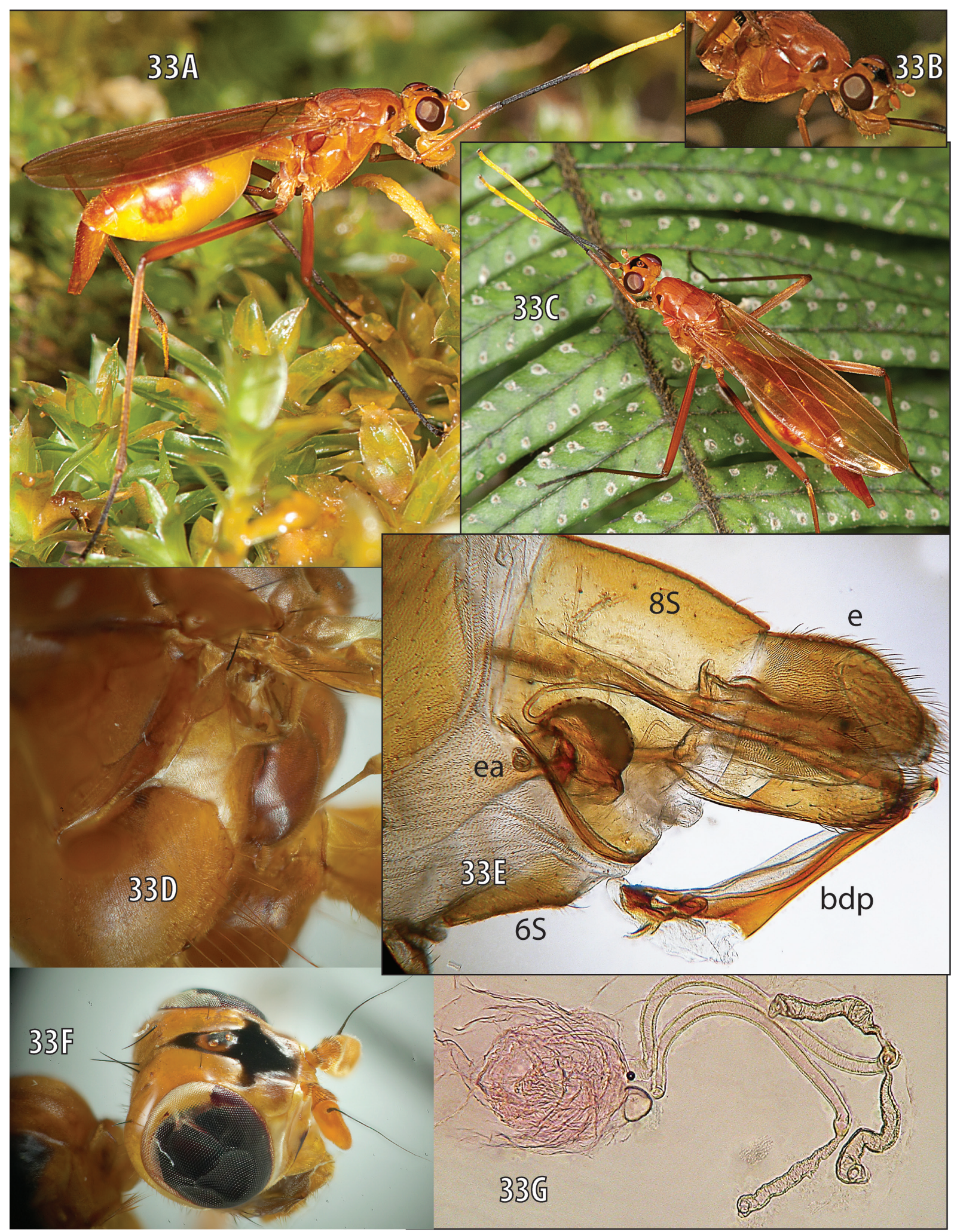

Fig. 33. Mesoconius garyi sp. nov. A-C. Paratypes prior to capture, $q q$, DEBU. D. Pleuron and base of abdomen. E. Male terminalia. F. Head. G. Spermathecae and associated structures. Abbreviations: bdp $=$ basal distiphallus; $\mathrm{e}=$ epandrium; ea $=$ ejaculatory apodeme. 
katepisternal bristles golden. Katatergite not swollen, without median process, evenly convex and microtrichose. Fore coxa with black anteroventral setae, mid and hind coxae with an anteroventral tuft of long golden setae.

ABDomen. Strongly petiolate, $\mathrm{T} 1+2$ twice as long as $\mathrm{T} 3$, basally narrow, with a strong constriction between $\mathrm{T} 1$ and $\mathrm{T} 2$, apically as wide as base of $\mathrm{T} 3$.

FEMALE ABDOMEn. Bursa small, not strongly differentiated, with a short but very broad ventral receptacle. Single and double spermathecal ducts arising independently from bursa, both ducts smooth and of similar diameter and length; paired and single spermathecae similar, unusually elongate; paired spermathecae somewhat larger and more twisted.

Male AbDomen. Sternite 5 small and narrow, S6 large, wide, slightly wider posteriorly and weakly posteromedially notched. Ventral part of S7 narrow, without sclerotization on right side. Sternite 8 twice as large as epandrium, bare in contrast with setulose epandrium. Epandrium saddle-shaped, long-setose posterodorsally; cercus greatly reduced, inconspicuous. Sperm pump unusually robust and ejaculatory apodeme larger than epandrium; hypandrium with a symmetrical, broad, scoop-like anterior margin. Basal part of distiphallus narrow but heavily sclerotized over basal $2 / 3$, then greatly expanded to a characteristically shaped apex with anterodorsally directed arms partly enclosing a large phallic bulb; distal distiphallus apparently represented only by a very short preapical ventral process.

\section{Remarks}

The loss of scutellar bristles, confirmed in all type specimens and on photographs of living flies, is very unusual and makes this species easy to recognize. The elongate triangular shape and dark pigmentation of the frontal vitta is similar in M. garyi sp. nov. and M. ottoi nom. nov., but the anterior part of the frons of the latter species is pale and separates the frontal vitta from the anterior margin of the frons.

Mesoconius hoffmannsi (Enderlein, 1922) comb. nov.

Fig. 30A-B

Tanypoda hoffmannsi Enderlein, 1922: 202.

Aristobata hoffmannsi-Hennig 1935: 31.

Zelatractodes hoffmannsi - Steyskal 1968: 20.

\section{Diagnosis}

Unique type male dirty yellow except for uniformly brown mid and hind tibiae and tarsi, paler fore tibia and tarsus, slightly darkened distal/preapical thirds of all femora, and black ocellar triangle surrounding orange ocelli. Frontal vitta matt yellow-orange, orbits subshining. Wing uniformly yellowish infuscated, without clear areas. Inner vertical, outer vertical and postocellar bristles present; fronto-orbital bristles not noted on type. Abdominal segments one and two petiolate. Sternite 8 matt yellow and slightly larger than subquadrate epandrium. Length about $16 \mathrm{~mm}$.

\section{Material examined}

Holotype

PERU • Ĉं; Cushi Libertad; 1800 m a.s.1.; Aug. 1903; Hoffmanns leg.; MNBG.

\section{Remarks}

The type male is unusually dull and matt yellow-orange, but it is also very dirty and the matt appearance may be the result of problems with moulds. The species is distinguished from other species of Mesoconius without a strongly swollen katatergite by the absence of any distinguishing colour such as femoral 
bands, pigmented tarsi or notal pigmentation. The head chaetotaxy is damaged, but notes on the type taken in Berlin in 2001 record the presence of outer vertical bristles, thus putting this species in the M. nono group.

Mesoconius nono sp. nov. urn:1sid:zoobank.org:act:772D3B1E-23B7-4221-AC4D-4C57AB9A5195

Fig. 34

\section{Etymology}

The species name is a noun in apposition partially inspired by the name of a town near the type locality, and partially reflecting my response to the confounding variation in leg colour.

\section{Material examined}

\section{Holotype}

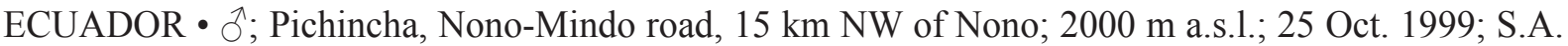
Marshall leg.; on log; QCAZ.

\section{Paratypes}

ECUADOR・ 9 ふふ; same collecting data as for holotype; MYCRO072-15 sequenced for CO1; DEBU - 1 đ; Pichincha, $11.7 \mathrm{~km}$ SE of Tandayapa, road to Nono, near stream; 28 Oct. 1999; S.A. Marshall leg.; litter/wood; DEBU • 1 ơ; Pichincha, Bellavista Reserve; 2200 m a.s.l.; 28 Oct. 1999; S.A. Marshall leg.; DEBU.

\section{Description (males only)}

LENGTH. $14 \mathrm{~mm}$.

CoLour. Mostly black; anterior margin of clypeus brownish, palpus black; parafacials, gena and lower face strongly silvery microtrichose. Fore femur variable in colour, usually black with a small basal orange band, but sometimes entirely orange ventrally; fore tarsomere 1 yellow to orange; mid and hind femora entirely bright orange in holotype and most other specimens, but sometimes all or partially black, mid and hind tibiae black to orange, densely covered with black setulae; mid and hind tarsomeres mostly black, tarsomere 1 variably reddish brown. Silver pollinosity of scutum broken by a broad median brown vitta and narrow lateral brown vittae. Wing lightly infuscated on basal $2 / 3$, darkly infuscated on distal third, except for apical margin, thus with a large, diffuse, dark subapical band.

HEAD. Epicephalon and paracephalon mostly shiny but rugose, epicephala separated by a narrow, microtrichose medial groove; orbits rugose and shiny; frontal vitta microtrichose, tapered to dorsal and ventral points, width of frontal vitta half of frontal width. Postocellar bristles closely spaced and strongly divergent, inner and outer vertical bristles well developed and inserted in microtrichose areas; upper fronto-orbital inserted at level of ocelli; one large lower frontal orbital bristle (doubled on left side on one of type specimens only). Frons contiguous with antennal socket, antennae separated by width of antennal socket, face weakly carinate; subantennal areas shiny, middle of face flat and microtrichose. Clypeus directed anteriorly, meeting face at an angle of about $100^{\circ}$, shiny medially, laterally microtrichose. Postocciput with uniformly small setulae.

THORAX. Notum, including postnotum, dull, microtrichose; scutum, prescutum and postscutum strongly differentiated. Dorsocentral bristle very short and inconspicuous, about half as long as scutellum. Scutellum with minute discal setulae and one pair of long apical bristles (longer than scutellum). Katatergite prominent, swollen, but without median process. Postpronotal lobe dull, with fine bristles along outer margin only; notopleuron with two widely spaced bristles. Propleuron with four ventro- 


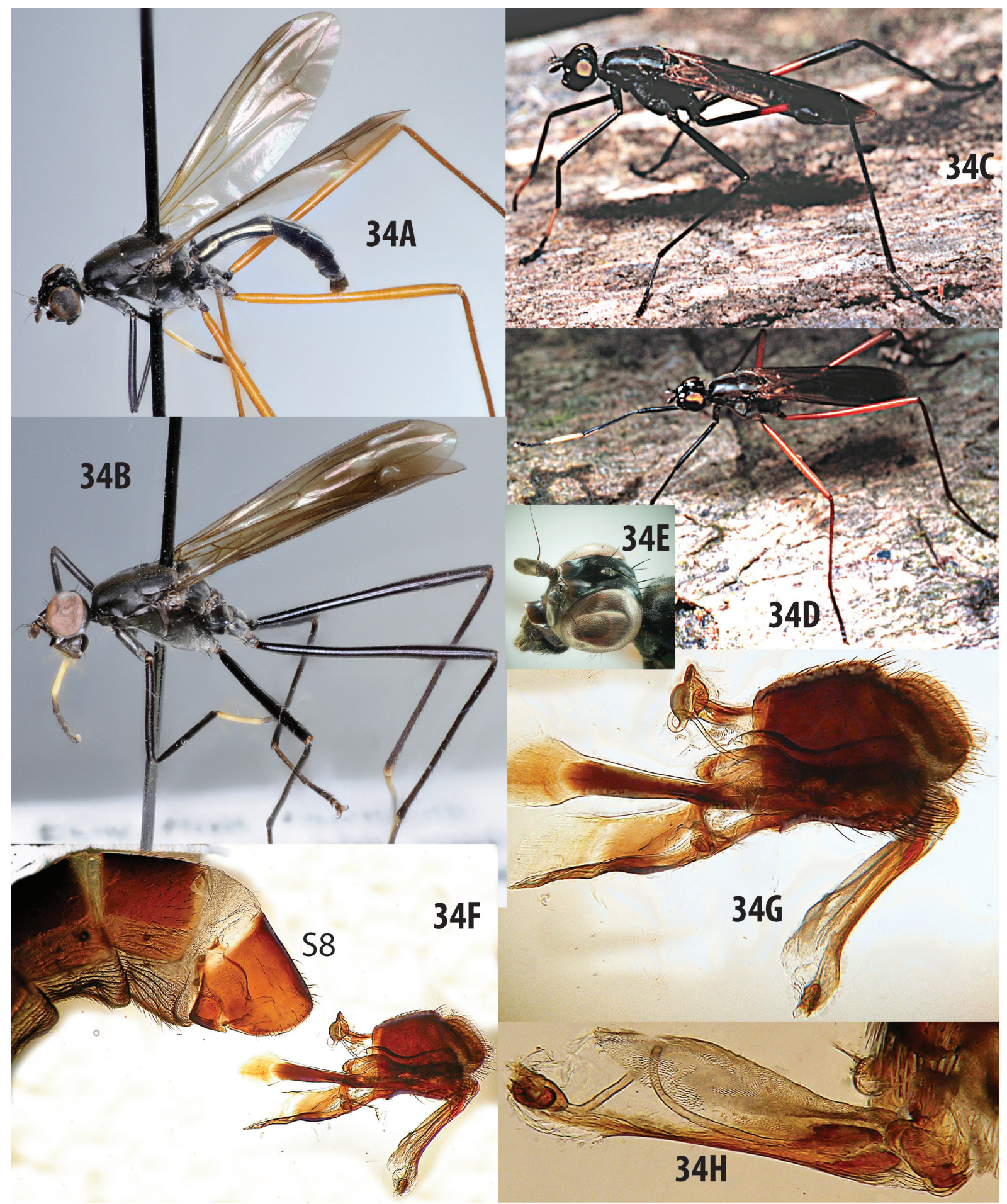

Fig. 34. Mesoconius nono sp. nov., $\hat{\partial} \hat{\jmath}$. A. Holotype, QCAZ. B. Atypical black specimen. C. Another colour form from the type locality. D. Typical form from the type locality. E. Head, holotype. F. Male terminalia and apex of abdomen. G. Male terminalia. H. Phallus, showing broad basal distiphallus with twisted ejaculatory duct terminating in phallic bulb. 
lateral setae. Vertical row of katepisternal bristles brown, other katepisternal bristles (including long ventral bristles) pale. All coxae with an anteroventral tuft of black setae. Postmetacoxal area partly black, but not sclerotized.

ABDomen. At least abdominal segments 1-2 petiolate, T3-4 also narrow; length of $\mathrm{T} 1+2$ double that of T3. Sternites 1-5 very narrow, S5 and S6 unmodified, almost linear, pale. Sternite 7 with a dark ventral and left lateral linear band; S7 fused broadly with large, unmodified S8. Epandrium with short anteroventral arms ( $1 / 5$ of epandrial length); ventral part of epandrium strongly incurved, with prominent ventral lobes at anterior and posterior margin of incurved areas. Hypandrium looped, with a broad, horizontal, scoop-like anterior margin. Pregonites finely setulose, inconspicuous, without prominent ventral lobes. Ejaculatory apodeme and phallapodeme large, with broad posterior parts; central body of sperm pump with finely spinulose surface. Basiphallus small, frame-like; basal part of distiphallus unusually broad, sclerotized dorsally and spinulose-membranous ventrally; broad apex encircling distal bulb, distiphallus ending at distal bulb.

\section{Variation}

One specimen taken with the type series (see Fig. 34B) has entirely black mid and hind legs, but is otherwise identical to other paratypes. Another fly, photographed at the type locality but not collected, had the apex of its hind femur red and the base black.

\section{Remarks}

Most of the type series was taken on a log serving as a makeshift bridge across a small stream along the Nono-Mindo road, Ecuador. Two females of Mesoconius auristrigatus Enderlein, 1922 (a species in the M. eques group) were found on the same log at the same time as the type series of ten male Mesoconius nono sp. nov.

\section{Mesoconius ottoi Marshall nom. nov.}

Fig. 30C-D

Tanypoda garleppi Enderlein, 1922: 201 (preoccupied by Mesoconius garleppi Enderlein 1922: 177).

Aristobata garleppi-Hennig 1935: 31.

Zelatractodes garleppi-Steyskal 1968: 20.

\section{Etymology}

The species name replaces the preoccupied patronym, which was based on the collector's surname, with one based on the collector's first name.

\section{Material examined}

Lectotype of Tanypoda garleppi Enderlein, 1922 (here designated) BOLIVIA • + ; Garlepp leg.; MNBG.

\section{Paralectotype}

COLOMBIA • +; "n. Granada”; v. Nolcken leg.; MNBG.

The paralectotype collector was presumably J.H. Wilhelm Baron (von) Nolcken, who collected in the mountains of Colombia 1870-71 (Horn \& Kahle 1936). The lectotype collector, Otto Garlepp, collected in Bolivia 1893-97, but the type label reads only "Bolivia Garlepp s.v. ", so a precise locality is not available.

\section{Redescription}

Based on lectotype female of Tanypoda garleppi Enderlein, 1922. 
LENGTH. $13 \mathrm{~mm}$.

CoLour. Mostly bright orange, except as follows: frontal vitta velvety black, except for partially orange ocellar triangle, contrasting with pale frons; face, parafacial, gena and postgena pale yellow-white. Fore tibia black with apex narrowly yellow, fore tarsus bright yellow; hind and mid tarsi brown. Hind femur with a broad, indistinct black band just beyond base.

HEAD. Frontal vitta characteristically shaped, with anterior portion broadly tapered and widely separated from very pale frontal margin (continuous with anterior margin in the similar M. garyi sp. nov.), posterior portion elongate triangular; broadest part of vitta continuous with a narrow transverse black band almost meeting eye.

Thorax. Scutellum with long, thin apical bristles. Vertical row of katepisternal bristles golden. Katatergite not swollen, without median process, evenly convex and microtrichose. Wing entirely yellowish, without clear bands.

AвDomen. Strongly petiolate, $\mathrm{T} 1+2$ darker than and twice as long as T3, basally narrow, with a strong constriction between $\mathrm{T} 1$ and $\mathrm{T} 2$, apically as wide as base of T3.

\section{Remarks}

Enderlein (1922) named two similar orange species, both collected by Otto Garlepp, as ' $g a r l e p p i$ ', one in the genus Tanypoda and one in the genus Mesoconius. Tanypoda garleppi was later moved to Aristobata by Hennig (1935) and then treated as Zelatractodes by Steyskal (1968). Now that Zelatractodes and Mesoconius are regarded as subjective synonyms, the species described as Tanypoda garleppi (until recently treated as $Z$. garleppi) is a subjective junior homonym and is renamed $M$. ottoi here. The general habitus and the shape and colour of the frontal vitta suggest a relationship to $M$. garyi sp. nov., which differs in lacking scutellar bristles, having a dark anterolateral thoracic patch and having a dark frontal vitta that reaches the anterior margin of the frons.

Mesoconius reinai sp. nov. urn:1sid:zoobank.org:act:D5DF4A7B-3B74-4CA7-B690-629B754652E5

Fig. 35

\section{Etymology}

Mesoconius reinai is named after P. Reina, who ran the Colombian Malaise traps that collected several of the new species described here.

\section{Material examined}

\section{Holotype}

COLOMBIA • P; Boyacá, SFF Iguaque; $05^{\circ} 25^{\prime} \mathrm{N}, 7^{\circ} 37^{\prime} \mathrm{W} ; 2820$ m a.s.1.; 1-19 Apr. 2000; P. Reina leg.; Malaise trap; DEBU308-17 sequenced for CO1; IAVH.

Description (female holotype only)

LENGTH. $14 \mathrm{~mm}$.

CoLour. Mostly metallic blue-black, palpus distally yellowish-brown, margin of clypeus brown. Legs and abdominal tergites 3-7 brown, except for white fore tarsomeres 1-3, yellow-brown fore tarsomeres 4-5 and ventral base of tarsomere 1, white hind femoral base and white medial bands on mid and 
hind femora. Notum, including postnotum, microtrichose, with two broad longitudinal dorsocentral microtrichose silvery vittae. Wing entirely black.

HEAD. Epicephalon striate-rugose, paracephalon shiny and smooth. Frontal vitta diamond-shaped, black, tapered to dorsal, lateral and ventral points, extending across entire frons. Postocellar bristles closely spaced and cruciate, inner and outer vertical bristles strong; upper fronto-orbital inserted at level of ocelli; one large lower frontal orbital bristle inserted well below border of epicephalon. Frons contiguous with antennal socket, antennae separated by width of antennal socket, upper face broadly raised; parafacials, gena and lower face strongly microtrichose, subantennal areas shiny, middle of face flat and microtrichose. Clypeus directed anteriorly, meeting face at an angle of about $100^{\circ}$, shiny medially, laterally microtrichose. Postocciput with uniformly small setulae.

Thorax. Dorsocentral and scutellar bristles broken on unique type. Katatergite slightly swollen, but without median process. Postpronotal lobe uniformly microtrichose, except for anterior bare margin, with a few scattered fine setae. Cervical sclerite with a small anterior lobe divided into an anterior bare part and a posterior microtrichose part by a vertical carina, and with a large microtrichose and strongly convex posterior lobe. Vertical row of katepisternal bristles brown, other katepisternal bristles pale yellow. All coxae with an anteroventral row of black setae.

ABDomen. Abdominal segment one and base of segment 2 petiolate, $\mathrm{T} 1+2$ twice as long as T3. Bursa subquadrate, with a distinct and distally differentiated ventral receptacle at base; bursa distally-dorsally

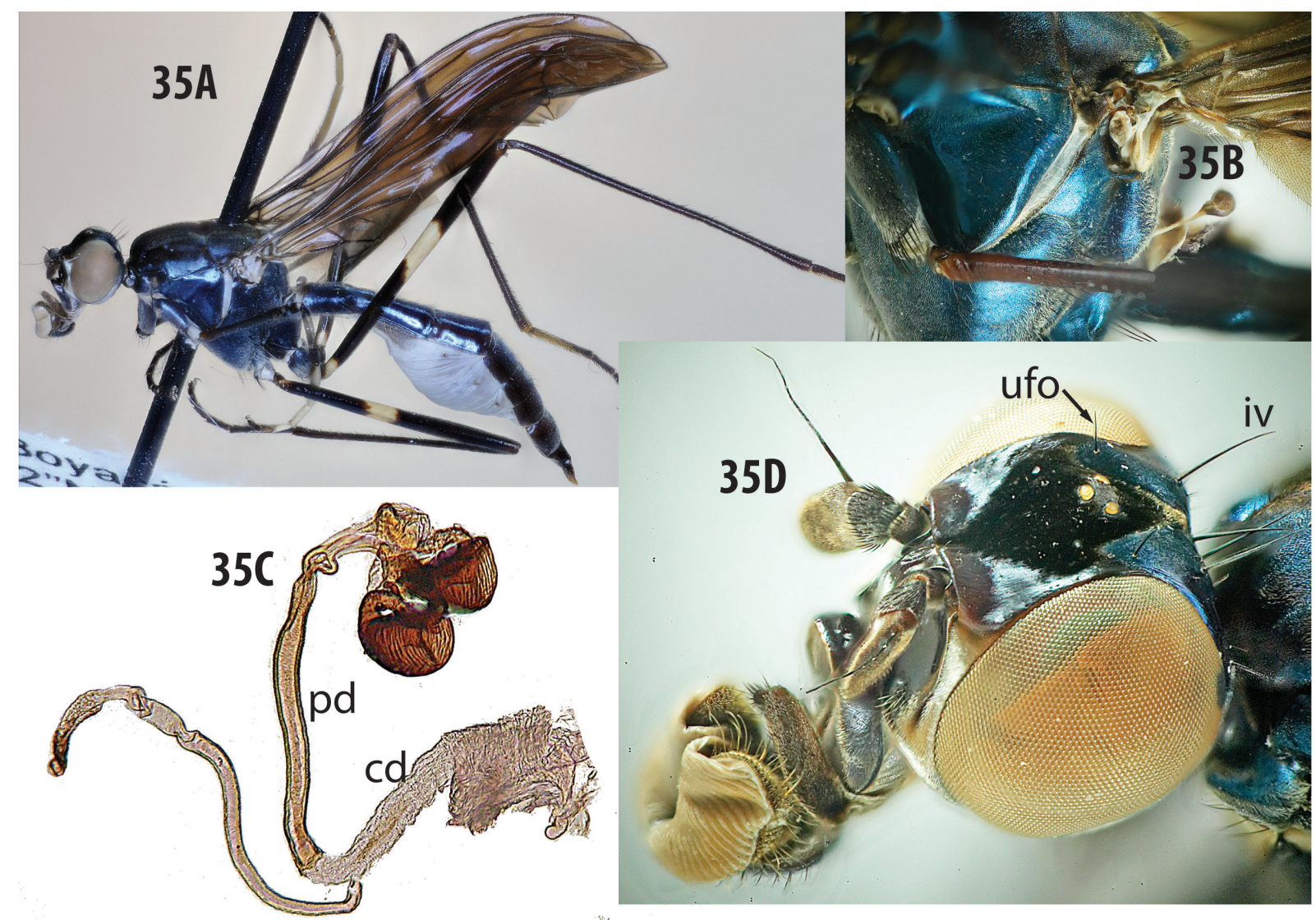

Fig. 35. Mesoconius reinai sp. nov., holotype, $q$, IAVH. A. Lateral view. B. Pleuron, showing slightly swollen katatergite. C. Spermathecae and associated structures. D. Head. Abbreviations: $c d=c o m m o n$ spermathecal duct; iv = inner vertical bristle; $\mathrm{pd}$ = paired spermathecal duct; ufo = upper fronto-orbital. 
extended into a long common spermathecal duct, single duct arising from side of common duct near apex, paired duct arising from apex. Paired duct relatively dark and sclerotized, short, uniform in width, weakly striate, branching into two distally convoluted stems, each leading to a large, ringed, pipe-like spermatheca. Single spermatheca elongate, similar to duct but separated from duct by a constriction.

Mesoconius scurrus (Hennig, 1935) comb. nov.

Fig. 30E

Aristobata scurra Hennig, 1935: 32; 1934: pl 2, fig. 7 (nomen nudum).

Zelatractodes scurrus - Steyskal 1968: 20.

Diagnosis (male holotype)

Length about $14 \mathrm{~mm}$. Thorax and first abdominal tergite bright orange, contrasting with dark brown head and reddish brown abdominal tergites 3-7. Frontal vitta flat and depressed, velvety black excluding raised and densely white microtrichose ocellar triangle; epicephalon shiny brown; lower frons and parafrontals shiny brown, margin sinuate, separated from antennae by antennal shelf. Parafacial silvery, sharply demarcated from brown face. Subantennal pits and upper face shiny brown, upper face carinate, lower face pale and membranous; clypeus shiny brown; palpus narrow, orange. Fore femur and fore tibia brown, fore tarsus white except for black area under basal half of tarsomere 1. Mid and hind femora orange basally; otherwise brown with a contrasting, straight-edged white median band; mid tarsus black; at least tarsomeres 1 and 4 of hind leg white (tarsomere 5 missing). Katatergite not prominent, but obviously collapsed on both sides. Wing almost clear, indistinctly infuscated, with diffuse clear area in distal third. Abdomen red at base (T1 and part of T2), with a pale band between T1 and T2; other segments brown dorsally, venter and epandrium not visible; T1-2 strongly petiolate.

\section{Material examined}

Holotype

BOLIVIA • đ’; Mapiri, Lorenzopata; 30 Apr. 1903; SMTD.

\section{Remarks}

Although the head bristles are obscured on the holotype, Hennig's figure clearly shows postocellar, inner vertical and outer vertical bristles (Hennig 1934). Otherwise M. scurrus seems to be similar to M. versicolorus (Enderlein, 1922), from which Hennig differentiated it on the basis of the relatively pale hind femoral base, the red abdominal tergite one and subtle differences in the colour of the hind basitarsus. Of these characters, only the colour of the hind femur distinguishes the only known specimen of M. scurrus from M. versicolorus. Both species remain known from inadequate material and their status will need clarification once new specimens are obtained.

Mesoconius uchumachi sp. nov.

urn:1sid:zoobank.org:act:C743B2B6-AE9F-4739-8E48-FD64B6083EA5

Fig. 36

\section{Etymology}

The name of this species is a noun in apposition inspired by the name of the type locality, Cerro Uchumachi. 


\section{Material examined}

\section{Holotype}

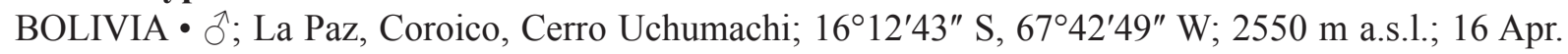
2001; S.A. Marshall leg.; cloud forest; CBFC.

Description (male holotype only)

LENGTH. $13 \mathrm{~mm}$.

CoLour. Mostly orange, but most of head including frons and upper face dark chestnut brown, parafacials and gena silvery white, palpus and clypeus yellow-orange. Fore femur bicoloured, basal half orange

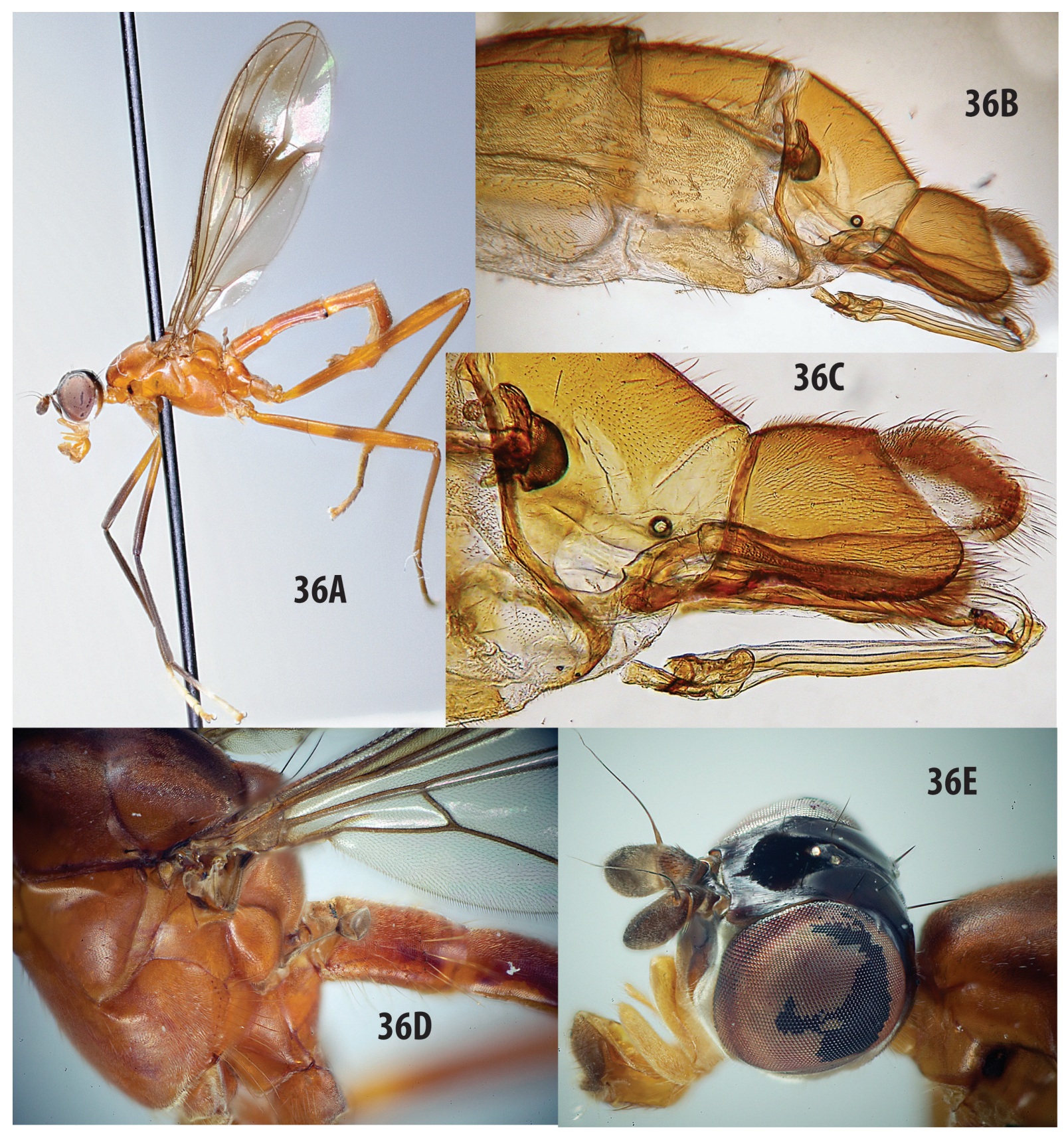

Fig. 36. Mesoconius uchumachi sp. nov., holotype, ô, CBFC. A. Entire specimen. B-C. Abdominal apex. D. Thorax and base of abdomen. E. Head and anterior part of thorax. 
and distal half dark brown. Fore tibia dark brown, fore tarsus white, with basal half of tarsomere 1 brown and tarsomere 5 yellowish. Mid and hind femora with indistinct alternating orange and yellowish brown bands, mid and hind tibia and tarsomeres yellowish brown. Thorax orange, except for sharply contrasting black-fringed anterior spiracle. Wing mostly clear, with a broad and distinct discal band and indistinct basal and distal infuscated patches.

HEAD. Entire frons striate, epicephalon and paracephalon weakly striate and shiny, frontal vitta weakly differentiated and not elevated, with anterior margin broad and posterior margin sharply tapered to a point behind ocelli. Postocellar bristles closely spaced and divergent, inner and outer vertical bristles well developed, with a few setulae around their bases; upper fronto-orbital inserted at level of ocelli, lower frontal orbital bristle inserted at point of overlap between epicephalon and orbital strip. Antennae separated by $0.3 \times$ width of antennal socket, face strongly carinate; parafacials, gena and lower face strongly microtrichose, subantennal areas shiny on mesal half only, middle of face flat and microtrichose. Clypeus directed anteriorly, meeting face at an angle of about $100^{\circ}$, shiny medially, laterally microtrichose. Postocciput with uniformly small setulae.

THORAX. Cervical sclerite with a small, depressed anterior part and a larger, convex and setulose posterior part. Prosternum microtrichose and with fine setulae. Postpronotal lobe microtrichose, with scattered setulae on lower half. Dorsocentral bristle about half as long as scutellum. Scutellum with minute discal setulae and one pair of long apical bristles (longer than scutellum). Katatergite weakly swollen, without nipple-like process. Vertical row of katepisternal bristles yellow. All coxae with an anteroventral tuft of yellow setae.

Male abdomen. Abdominal segments $1+2$ and basal half of segment 3 petiolate, length of $1+2$ double that of tergite 3. Sternite 5 small, pale; S6 broad and somewhat Y-shaped posteriorly. Sternite 7 with a narrow ventral and left lateral linear band; S7 fused broadly with large, unmodified S8. Epandrium with short anteroventral arms (1/5 of epandrial length); ventral part of epandrium strongly incurved in posterior quarter. Hypandrium short, with a broad, scoop-like anterior loop. Ejaculatory apodeme similar in size to epandrium; central body of sperm pump broad, helmet-like. Basiphallus small, frame-like; basal part of distiphallus unusually broad, parallel-sided, sclerotized dorsally (lower side in repose) and spinulose-membranous ventrally; phallic bulb large, elongate; distal distiphallus very short, shorter than phallic bulb.

\section{Remarks}

Mesoconius uchumachi sp. nov. is easily distinguished from related species by its combination of an entirely orange thorax and a clear wing with a distinct discal band.

Mesoconius woytkowskii sp. nov. urn:lsid:zoobank.org:act:57CF9E41-E79E-4F9E-9DE6-BA94A0DFABF1

Fig. 37

Zelatractodes filipes - Albuquerque 1986: 204, fig. 143.

\section{Etymology}

This species is named after the collector, Felix Woytkowski, a professional insect collector in Peru from 1929 to 1964 and the author of Peru, Moja Ziemia Nieobiecana (Peru, my Unpromised Land), the English translation of which was published by the Smithsonian Institution in 1978.

\section{Material examined}

Holotype

PERU • +; Cusco, Santa Isabel, River Cosnipata; 2 Dec. 1951; Woytkowski leg.; rain forest; CNCI. 


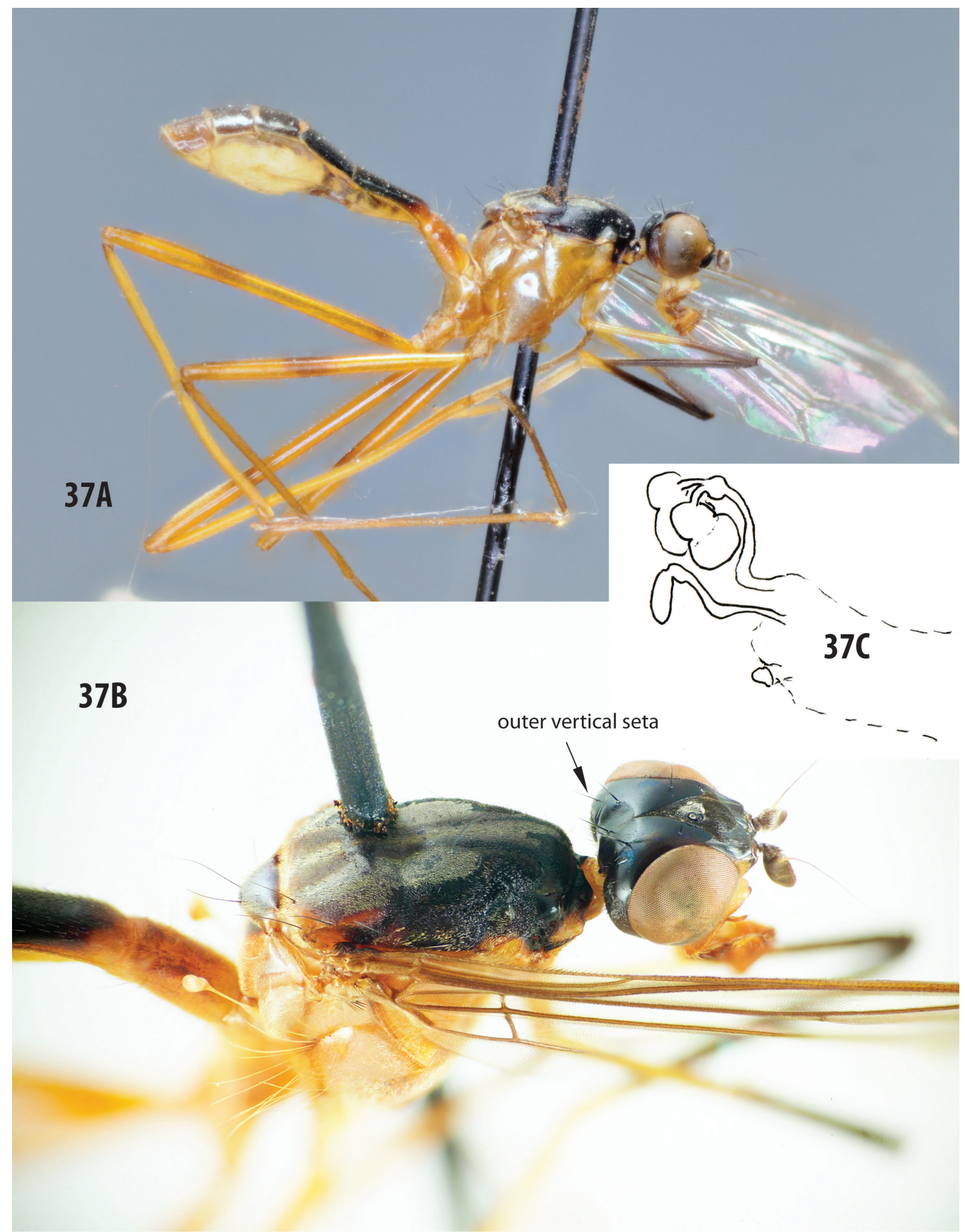

Fig. 37. Mesoconius woytkowskii sp. nov., holotype, + , CNCI. A-B. Lateral and dorsolateral views. C. Sketch of spermathecae and associated structures, showing separate origins of single and double spermathecal ducts (based on illustration in Albuquerque 1986). 
Description (female holotype only)

LENGTH. $15 \mathrm{~mm}$.

CoLour. Head black to dark brown, except as follows: clypeus, lower face, gena, parafacials and palpus yellow; first flagellomere brown and antennal base reddish-brown. Pleuron bright yellow to orange, except for dark area surrounding anterior spiracle and lower margin of proepisternum; cervical sclerite bright yellow. Notum black, with three silvery vittae and a small orange postalar strip. Legs orange, except for black distal part of fore femur, black basal part of fore tibia and yellow fore tibial apex and tarsomeres. Wing uniformly clear. Abdominal T1 and base of T2 orange, abdomen otherwise dark, pleuron with a dark dorsal margin and a vertical black band at junction of P2 and P3.

HEAD. Epicephalon and paracephalon shiny, indistinctly striate. Frontal vitta dull and rugose, distinctly raised, very broad in front of ocelli, sharply tapered posteriorly and ending at about midpoint between ocelli and postocellars; anterior part of vitta narrowly tapered almost to anterior margin of frons. Lower frons bare, shiny, but longitudinally rugose or ridged. Postocellar bristles closely spaced and slightly divergent, inner and outer vertical bristles well developed; upper fronto-orbital large, inserted in shiny part of epicephalon, lower fronto-orbital large, inserted in microtrichose area below extension of epicephalon.

THORAX. Scutum densely microtrichose dorsally, forming colour patterns described above; dorsocentral setulae minute, forming a sparse row; acrostichal setulae indistinct. Cervical sclerite subquadrate, with a vertical groove separating a large densely microtrichose posterior section from a bare anterior portion. Postpronotal lobe mostly sparsely microtrichose, with few setulae, bare on anterior half, posterior margin sloped and densely white microtrichose. Dorsocentral bristle subequal to scutellar length. Scutellum with minute discal setulae and one pair of apical bristles (slightly longer than scutellum). Vertical row of katepisternal bristles golden. Katatergite evenly convex and microtrichose, without a conspicuous swelling or point. All coxae with an anteroventral tuft of long yellow bristles.

AвDomen. Segment one distinctly petiolate, $\mathrm{T} 1+2$ elongate, about twice as long as T3.

Female ABDOMEn. Oviscape lost, but the following is inferred from Albuquerque (1986): bursa small with a small ventral receptacle; paired and single spermathecal ducts arising independently from bursa, single duct slightly thinner and shorter, with an elongate but vestigial spermatheca; paired spermathecal duct constricted at apex into two very short, narrow stems, each leading to an acorn-shaped spermatheca.

\section{Remarks}

The specimen designated here as the holotype had previously been sent from CNCI to L. Albuquerque (a doctoral student in Brazil at that time), who labeled it as Zelatractodes filipes. This was certainly a misidentification, because Mesoconius woytkowskii sp. nov. differs from M. filipes in having banded femora and sharply contrasting dark dorsal and lateral parts of the thorax. The specimen was returned to CNCI without an oviscape, but it is a safe assumption that the drawing of the female terminalia of 'Zelatractodes filipes' in Albuquerque (1986) was made from this specimen. The description of the female terminalia above was formulated based on that drawing.

I would not normally describe a species based on a single damaged female, but since this distinctive species has already been illustrated under an incorrect name, it seems worthwhile to clarify the status of the specimen. 


\section{Mesoconius zorro sp. nov. urn:1sid:zoobank.org:act:1B6B615F-E09E-4300-B0A5-7FB5E01A75CD}

Figs $38-39$

\section{Etymology}

The species name is an arbitrary collection of letters to be treated as a noun in apposition.

\section{Material examined}

\section{Holotype}

PERU • ${ }^{\top}$; Cusco, Wayqecha Biological Station; 2800 m a.s.1.; 14-15 May 2007; Kits and Marshall leg.; cloud forest, leaf litter, dung pans; MUSM.

\section{Paratypes}

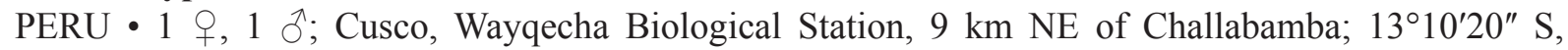
71 ${ }^{\circ} 35^{\prime} 00^{\prime \prime} \mathrm{W} ; 2600-2700 \mathrm{~m}$ a.s.1.; 1-6 Dec. 2011; S.A. Marshall leg.; MYCRO117-15 and MYCRO315-17 sequenced for CO1; in 1 vial; DEBU $\bullet 1$; ; same locality as preceding; 13-15 May 2007; S.A. Marshall leg.; DEBU • 1 क; same locality as preceding but $2800 \mathrm{~m}$ a.s.1.; 13-15 May 2007; J.H. Kits leg.; MYCRO173-15 sequenced for CO1; DEBU • 1 o; same locality as preceding but $3100 \mathrm{~m}$ a.s.1.; 7-8 Dec. 2011; S.A. Marshall leg.; DEBU.

\section{Description}

LENGTH. 11-13 mm.

CoLour. Mostly orange, except as follows: frontal vitta velvety black, lower frons entirely shiny black; area around base of inner vertical bristle also black, contrasting with pale frons and antennal socket; anterior spiracle black. Frontal vitta with anterior portion tapered to a point almost reaching frontal margin, posterior portion small, elevated. Face pale; parafacial, gena and postgena silvery microtrichose. Postpronotal lobe unmodified, concolorous with scutum. Distal half of fore femur, fore tibia and most of tarsomere 1 black, fore tarsomeres 2-4 white in females but yellow in males, tarsomere 5 dark. Hind and mid tarsi brown. Mid femur with a broad black band just beyond base and a narrower band just beyond middle; hind femur similar, but basal band weaker. Wing entirely yellowish, without clear bands. Abdominal pleuron pink to orange.

HEAD. Epicephalon striate and shiny, with scattered minute setulae and inconspicuous microtrichosity posteriorly; paracephalon minutely black setulose, slightly elevated above epicephalon. Frontal vitta only slightly elevated, at widest $0.6 \times$ as wide as frons. Lower frons bare, depressed at middle. Postocellar bristles closely spaced and parallel, inner vertical and outer vertical bristles well developed, with scattered setulae anterior to base of inner vertical; upper fronto-orbital bristle very large, inserted at or above level of upper ocellus; lower fronto-orbital bristle inserted where epicephalon and orbital strip overlap, orbital strip with one or more setulae near lower fronto-orbital bristle.

THorax. Scutum inconspicuously but evenly microtrichose; acrostichal and dorsocentral setulae small, but in distinct rows. Cervical sclerite subquadrate, with a vertical groove separating a convex microtrichose posterior section from a minute, constricted and bare anterior portion; females with sensillar patch covering most of posterior portion. Postpronotal lobe pinkish, sparsely microtrichose throughout and sparsely but distinctly setulose on posterior half. Two notopleural bristles, posterior large and anterior very small. Dorsocentral bristle small, about half as long as scutellum. Scutellum microtrichose and with one pair of small discal setulae, apical bristles well developed. Vertical row of katepisternal bristles golden. Katatergite slightly swollen, without median process, evenly convex and microtrichose. All coxae with an anteroventral tuft of long golden setae.

ABdomen. Segments 1-2 petiolate, $\mathrm{T} 1+2$ twice as long as T3. 


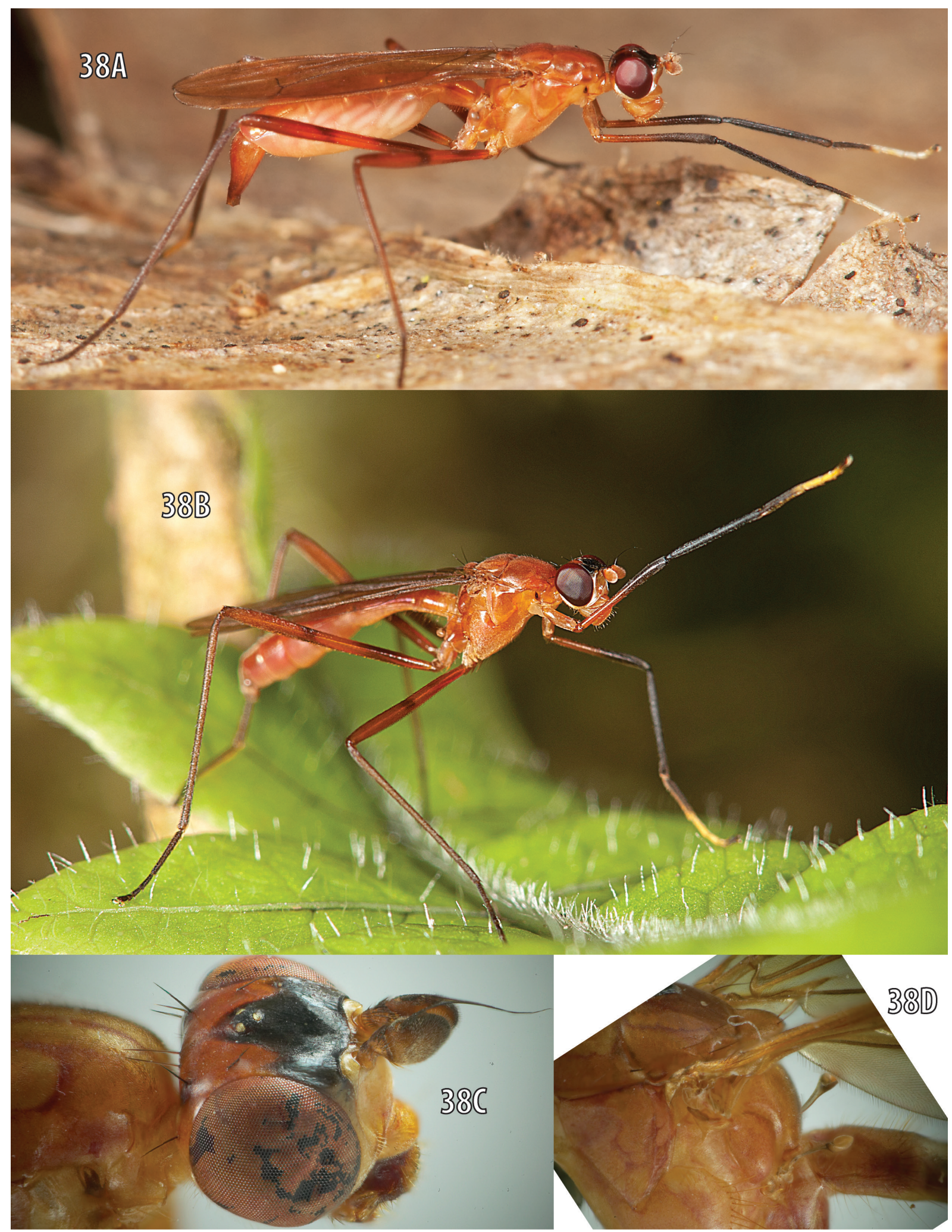

Fig. 38. Mesoconius zorro sp. nov., external characters. A. Paratype prior to capture, $\uparrow$, DEBU. B. $\overbrace{}^{\Uparrow}$ prior to capture. C. Head. D. Posterior thorax and base of abdomen. 


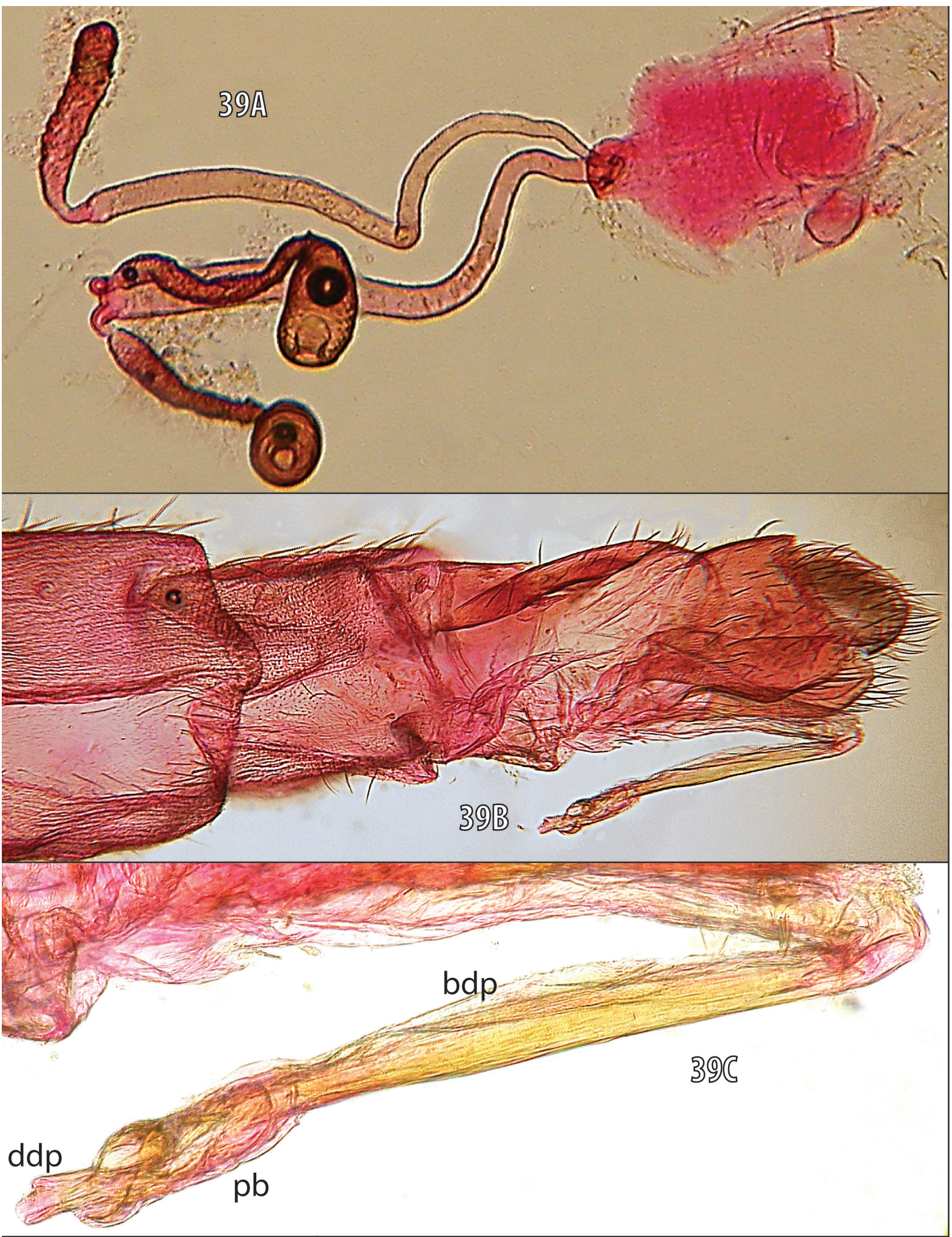

Fig. 39. Mesoconius zorro sp. nov., internal characters. A. Spermathecae and associated structures. B. Male abdomen, left side. C. Phallus. Abbreviations: $b d p=$ basal distiphallus; $d d p=$ distal distiphallus; $\mathrm{pb}=$ phallic bulb. 
Female abdomen. Bursa small, not strongly differentiated, with a short, broad ventral receptacle. Single and double spermathecal ducts arising independently from a short swelling at apex of bursa, both ducts smooth and of similar diameter and length; paired spermathecae large and on long, thick stems; single spermatheca elongate and narrow.

Male ABDomen. Sternites 5 and 6 elongate, well developed and widened posteriorly; S5 pale and setulose, S6 shiny. Ventral part of S7 narrow; S8 twice as large as epandrium, bare and shiny in contrast with setulose epandrium. Epandrium saddle-shaped, lobate and densely setose posterodorsally; cercus large and conspicuous. Ejaculatory apodeme large, subequal in size to epandrium, with a broad sperm pump; hypandrium short, with broad, scoop-like anterior margin. Basal part of distiphallus narrow, but heavily sclerotized over basal $2 / 3$, then expanded to an elongate phallic bulb; distal distiphallus greatly reduced, extending as a very short cylindrical tube beyond phallic bulb.

\section{Remarks}

Mesoconius zorro sp. nov. is one of the most distinctive species in the genus, characterized by its inky black lower frons and frontal vitta, its extremely truncated distal distiphallus and its elongate basal distiphallus. It is thus far known only from collections at Wayqecha Biological Station in Peru in 2007 and 2011.

\section{Mesoconius oblitus group}

\section{Diagnosis}

Outer vertical bristle absent, katatergite not strongly swollen. Upper frontal orbital bristle present or absent. Wing evenly infuscated brown or black, with a discal clear area or with clear spots. Male and female genitalia, where known, highly diverse, with nothing to suggest that this is a natural group.

\section{Remarks}

Like the M. nono group, the M. oblitus group is a heterogeneous assemblage of species that would have previously been treated as Zelatractodes. Most species in this group are known only from older types, and information on male genitalia is available for only three species out of 16 . The group is shown as paraphyletic on the CO1 tree (Fig. 50), which includes one undescribed species, as well as eight of the 16 named species in the group. The undescribed species is known only from a single damaged female specimen from southern Ecuador.

Mesoconius afurcatus (Hennig, 1935) comb. nov.

Fig. 40A

Aristobata afurcata Hennig, 1935: 33.

Zelatractodes afurcatus - Steyskal 1968: 19.

\section{Diagnosis}

Length about $15 \mathrm{~mm}$. Head, thorax and abdominal tergites black to dark brown, pleura with bluish sheen. Frontal vitta tapered posteriorly, broad anteriorly and reaching anterior margin of frons. Postocellar and inner vertical bristles present, outer vertical bristle not visible on type and presumably absent. Upper fronto-orbital bristle large. Fore femur yellow-brown at base, dark and slightly swollen distally, fore tibia black, fore tarsus missing from type, but yellow according to original description. Mid femur almost entirely yellow brown, slightly darker on apical third. Hind femur yellow-brown on basal $2 / 3$ and brown on distal third, with a distinct white band separating yellowish and brown sections; hind tarsomeres 1 and 2 white, distal tarsomeres brown. Katatergite moderately swollen, rounded, without 


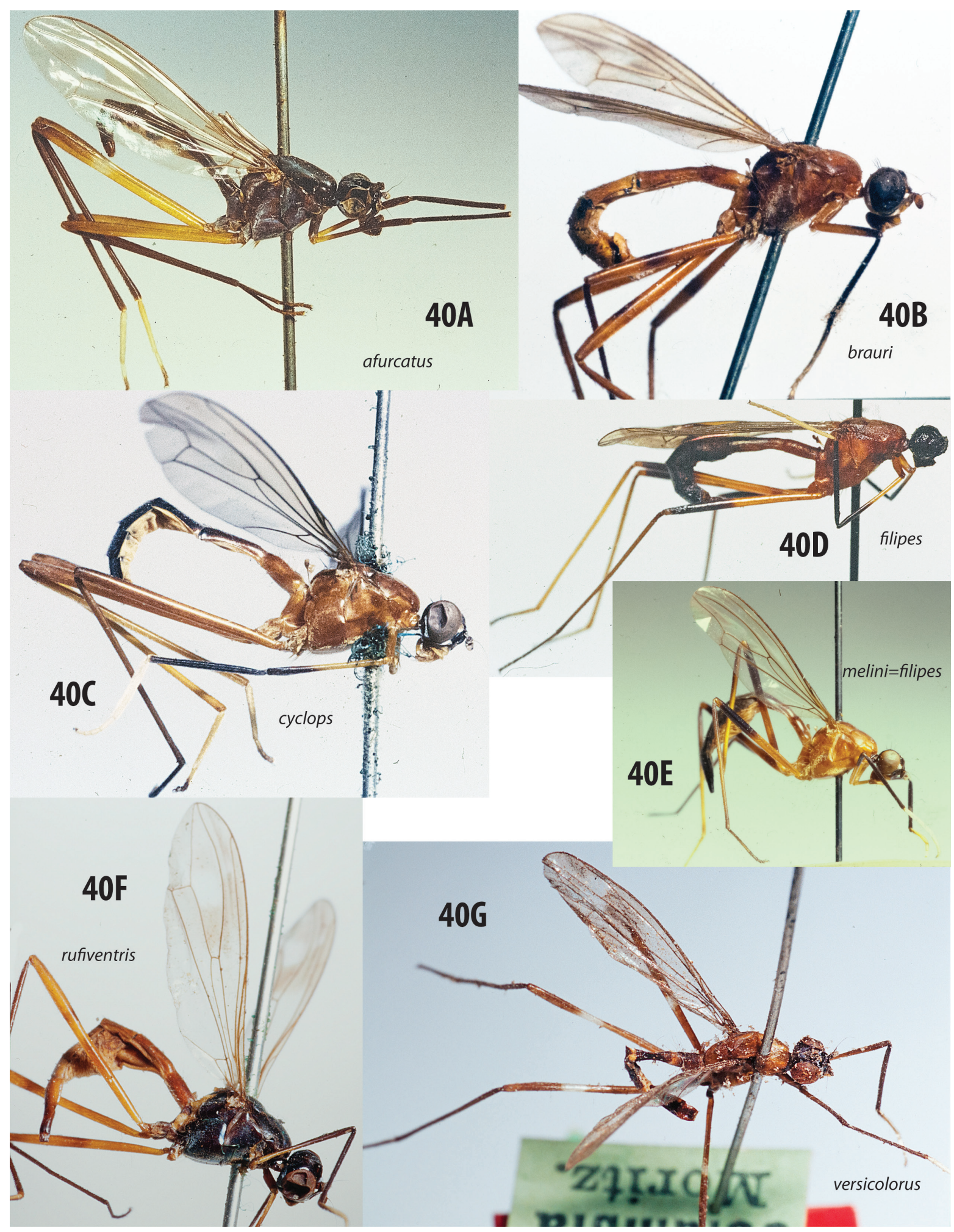

Fig. 40. Mesoconius oblitus group species known only from original type specimens. A. Mesoconius afurcatus (Hennig, 1935), holotype, đ̂, MLUH, Venezuela. B. M. braueri (Hennig, 1935), paratype, §, NHMW, Venezuela. C. M. cyclops (Hennig, 1935), holotype, đ̂, SMTCk, Bolivia. D. M. filipes Enderlein, 1922, holotype, ㅇ, MNBG, Peru. E. Aristobata melini Frey, 1927 (junior synonym of $M$. filipes), syntype, ZMUH, Peru. F. M. rufiventris (Enderlein, 1922), holotype, ㅇ, MNBG, Colombia. G. M. versicolorus (Enderlein, 1922), holotype,, , MNBG, Colombia. 
apical process. Wing lightly infuscated, except for a weak, clear patch in $\mathrm{r}_{4+5}$ at level of dm-cu and two less distinct clear patches distally. Abdominal segments 1-2 petiolate.

\section{Material examined}

\section{Holotype}

VENEZUELA • ${ }^{\Uparrow}$; Merida; V. Röder leg.; MLUH.

\section{Remarks}

I have seen no material other than the unique type (Fig. 40A), but the largely yellow-brown mid femur combined with the white-ringed hind femur seem to adequately diagnose the species. The original description adds nothing that is not visible in a photograph of the type other than the colour of the fore tarsomeres (Hennig 1935), which are missing from the type.

Mesoconius apa sp. nov.

urn:lsid:zoobank.org:act:F4CA1A6D-DE00-45D8-A950-40DDBFC5C242

Fig. $41 \mathrm{~A}-\mathrm{B}$

\section{Etymology}

The species name ' $a p a$ ' is a noun in apposition inspired by the type locality.

\section{Material examined}

\section{Holotype}

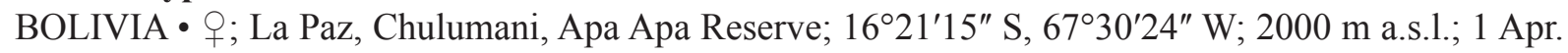
2001; S.A. Marshall leg.; DEBUA300-17 sequenced for CO1; CBFC.

Description (female holotype only)

LENGTH. $17 \mathrm{~mm}$.

CoLour. Shiny blue-black, except as follows: first flagellomere and mid tarsomere 1 brown; frontal vitta velvety black; fore tarsomeres 1-2 and hind tarsomeres 1-3 white; hind femur with narrow red distomedian band; pleuron, parafacial and subantennal pit silvery. Wing membrane evenly and lightly infuscated, except for a large central clear area in cell $\mathrm{r}_{4+5}$ and a small pale spot in $\mathrm{r}_{2+3}$. Abdominal T1 with reddish posterolateral margin; pleural membrane black; oviscape silvery microtrichose dorsally, shiny laterally.

HEAD. Epicephalon and paracephalon smooth and shiny; frontal vitta velvety black, posteriorly narrow and parallel-sided, anteriorly rounded and widely separated from anterior margin of frons. Outer vertical bristle absent, inner vertical bristle strong, postocellar bristle strong, only slightly posterior to inner vertical bristle, area between bristles setulose and microtrichose. Fronto-orbital bristles large, upper bristles inserted at level of upper ocelli. Antennae separated by $1.5 \times$ width of antennal socket, upper face broadly carinate, with broadly raised middle and flat lower face sparsely microtrichose, inner half of subantennal area shiny, outer half and parafacial heavily microtrichose. Clypeus bare medially and microtrichose laterally.

Thorax. Cervical sclerite with a small, shiny, depressed anterior part divided by a carina and a large, elevated, setulose posterior portion. Prosternum microtrichose with a few setulae. Notum microtrichose, with rows of small acrostichal and dorsocentral setulae; postpronotal lobe microtrichose, with some scattered small setulae, anterior face shiny and almost vertical, posterior face microtrichose and almost horizontal. Dorsocentral bristle short (subequal to scutellum). Scutellum with four small discal setulae 
and very long apical bristles (much longer than scutellum). Katatergite rounded and indistinctly convex. Notopleuron with two widely spaced bristles. Vertical row of katepisternal bristles black. Coxae with anteroventral black setae.

AbDomen. $\mathrm{T} 1+2$ forming a narrow petiole 3 times as long as $\mathrm{T} 3$.

Mesoconius apicalis sp. nov.

urn:lsid:zoobank.org:act:87837FA9-7934-45C0-B03B-F5F836A48ACF

Fig. $41 \mathrm{C}-\mathrm{E}$

\section{Etymology}

Mesoconius apicalis is named to reflect the orange apices of the mid and hind femora, one of the characters distinguishing this species from the closely related M. gelbifacies $\mathrm{sp}$. nov.

\section{Material examined}

Holotype

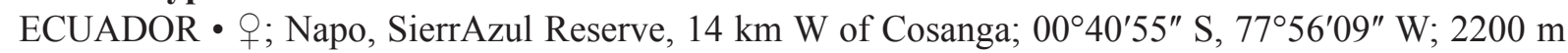
a.s.1.; 8-11 May 2002; S.A. Marshall leg.; DEBUA301-17 sequenced for CO1; QCAZ.

\section{Paratype}

ECUADOR • 1 q; same collecting data as for holotype; DEBUA303-17 sequenced for CO1; DEBU.

\section{Description (females only)}

LENGTH. $16 \mathrm{~mm}$.

CoLour. Dark brown with yellow face, lunule and palpus; antenna reddish brown; frontal vitta velvety black; gena and parafacial strip silvery microtrichose. Fore tarsus and hind tarsomere 1 white; mid and hind femora with a narrow orange base followed by equal length black bands separated by a reddish band of same length; oviscape orange. Wing membrane evenly and lightly infuscated, except for three small, equal, distal clear spots. Abdominal tergites, especially syntergite, reddish.

HEAD. Epicephalon and paracephalon finely striate, slightly more shiny than orbits; frontal vitta velvety black, posteriorly sharply tapered (narrowed to a point), anteriorly reaching anterior margin of frons as a broad band. Outer vertical bristle absent, inner vertical bristle strong, postocellar bristle strong, only slightly behind inner vertical bristle. Fronto-orbital bristles large, upper bristle inserted at level of upper ocelli. Antennae separated by $1.5 \times$ width of antennal socket, upper face broad with an indistinct central carina; lower face flat and microtrichose. Clypeus shiny medially and laterally, microtrichose at posterior corners only.

Thorax. Cervical sclerite with a small, shiny, depressed anterior part divided by a carina and a large, elevated, setulose posterior portion. Prosternum microtrichose and with fine setulae along margin. Notum microtrichose, with rows of small acrostichal and dorsocentral setulae; postpronotal lobe microtrichose, with some scattered small setulae on posterior half only, anteromedial corner shiny, anterior face partially shiny and almost vertical, posterior face microtrichose and almost horizontal. Dorsocentral bristle short (subequal to scutellum). Scutellum with two small discal setulae and long apical bristles (longer than scutellum). Katatergite not prominent, but distinctly convex. Vertical row of katepisternal bristles golden. Coxae with anteroventral golden setae.

AвDomen. Abdominal segment 1 and basal third of segment 2 petiolate, syntergite $1+2$ twice as long as tergite 3. Bursa small, ventral receptacle inconspicuous. Common part of spermathecal duct as long 
as bursa, splitting into similar single and paired ducts, single duct half as long and half as wide. Paired duct uniformly weakly striate until split, then tapered to a bulb-like swelling at mid point; each paired spermatheca striate and broadly oval. Single spermatheca much reduced but distinct, with an irregular surface.

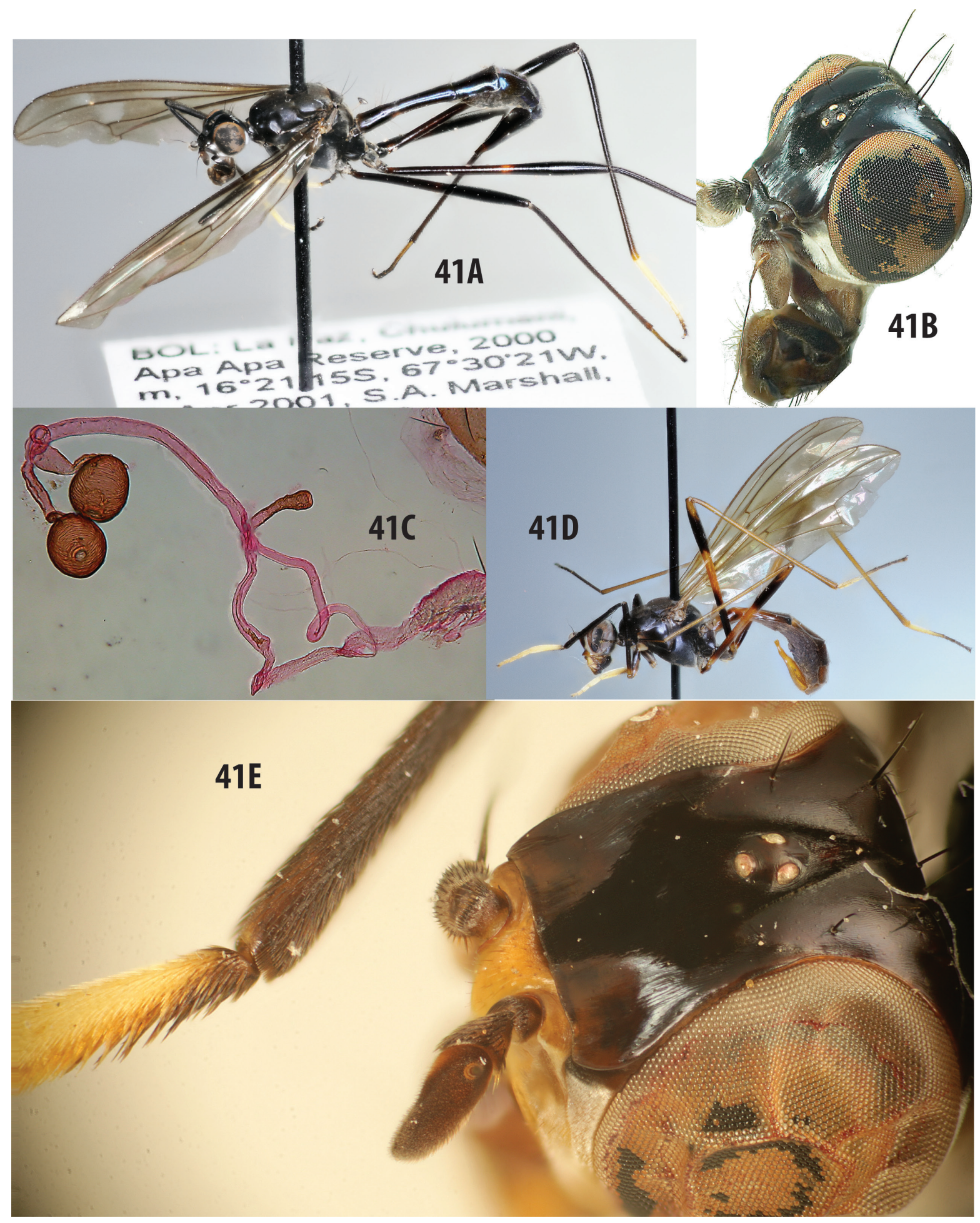

Fig. 41. A-B. Mesoconius apa sp. nov., holotype,, , CBFC. A. Habitus. B. Head. - C-E. M. apicalis sp. nov., holotype,, , QCAZ. C. Spermathecae and associated structures. D. Habitus. E. Head and apex of fore tibia. 


\section{Remarks}

This species is similar to M. gelbifacies sp. nov., from which it differs in having the postocellar portion of the frontal vitta tapered to a narrow point, the oviscape orange, the parafacial pale and setulose, upper fronto-orbital bristles present, and the mid and hind femora ending in a broad orange apical band. These species appear on the same branch of a CO1 maximum likelihood tree, but they are deeply divergent (Fig. 50).

\section{Mesoconius braueri (Hennig) comb. nov.}

Fig. 40B

Aristobata braueri Hennig, 1935: 31, 1934: pl. 2, fig. 5 (nomen nudum).

Zelatractodes braueri - Steyskal 1968: 20.

\section{Diagnosis}

Length about $14 \mathrm{~mm}$. Colour entirely dull orange, with the following exceptions: head shiny yellow, with frontal vitta velvet black; fore tarsomere 1 black basally and dorsally, tarsus otherwise white, except for some ventral black pigmentation on tarsomere 2; fore femur black distally, fore tibia entirely black; mid femur with a broad and complete band at middle, hind femur with an incomplete black band beyond middle. Head with ocellar tubercle distinctly elevated; inner vertical and postocellar bristles present, outer verticals absent. Wing membrane evenly and lightly infuscated, except for a large central clear area in cell $r_{4+5}$ continuous with a small pale spot in $r_{2+3}$. Abdominal segments 1-2 petiolate, segment 3 somewhat petiolate.

\section{Material examined}

Holotype

VENEZUELA • +; "Venezuela"; SMTD.

Paratypes

VENEZUELA • 1 +, 1 $\overbrace{}^{\Uparrow}$; same collecting data as for holotype; NHMW.

\section{Remarks}

Mesoconius braueri is distinguished from other orange species of Mesoconius lacking a prominent katatergite (M. garyi sp. nov., M. ottoi nom. nov. and M. hoffmannsi) by its black mid-femoral rings.

\section{Mesoconius cyclops (Hennig) comb. nov.}

Fig. 40C

Aristobata cyclops Hennig, 1935: 30; 1934: pl. 2, fig. 4 (nomen nudum). Aristobata cyclops var. hemichrysus Hennig, 1935: 31.

Zelatractodes cyclops - Steyskal 1968: 20.

\section{Diagnosis}

Length about $14 \mathrm{~mm}$. Head black. Frontal vitta velvety black; paracephalon and epicephalon shiny black; lower frons and orbital strips shiny brown, frons with anterior margin sinuate. Upper and lower parts of parafacial silvery, sharply demarcated from brown contiguous parts of frons. Subantennal pits and upper face shiny brown, upper face carinate, lower face pale and membranous; clypeus shiny 
orange; palpus relatively narrow, orange. Thorax orange. Distal half of fore femur and all of fore tibia black, fore tarsus white. Mid and hind femora orange in holotype (female paratype with a very weak basal ring), tibiae orange-yellow; mid tarsus black; tarsomeres 1 and 2 of hind leg orange-yellow. Wing clear, without pattern or pigmented areas. Abdomen red at base (T1 and part of T2), otherwise blueblack dorsally in male, matt black in female; abdomen pale yellow ventrally, epandrium orange-yellow, oviscape black. Female abdominal pleuron apparently with black pigmentation near junctions of some tergites. Ovipositor black. Male with S8 shiny black in contrast with dull orange epandrium; visible pleuron cream-yellow. Frontal vitta rounded and convex; postocellar bristles closely spaced and slightly divergent, inserted in microtrichose areas, inner vertical bristle well-developed; outer vertical bristle absent; one small lower frontal and one large upper orbital bristle. Abdominal segment 1 petiolate, segment 2 somewhat petiolate in male holotype but not in female paratype. Male abdomen with S6 long and y-shaped; S8 bare.

\section{Material examined}

Holotype

BOLIVIA • つ’; Mapiri, Sarampioni; 700 m a.s.1.; Jan. 1903; missing front and middle left legs; SMTD.

Paratype

BOLIVIA • ; San Carlos; 800 m a.s.l.; 2 Jan. 1903; SMTD.

\section{Syntypes of Aristobata cyclops var. hemichrysus}

BOLIVIA • 1 ठ̊; Mapiri, San Carlos; 13 Jan. 1903; SMTD • 1 q; Yungas de Coroico; 1000 m a.s.1.; 13 Jan. 1907; SMTD.

\section{Remarks}

The shiny black head and bicoloured abdomen of this otherwise mostly orange species seem to be distinctive, but it remains known only from the types. Hennig (1935) split the type series of four specimens into two varieties, with a male and female in the nominate variety and a male and female with more extensively pigmented mid and hind femora treated as Aristobata cyclops var. hemichrysis. Hennig (1934) illustrated the head of Mesoconius cyclops, as Aristobata cyclops, without an outer vertical bristle, but mentions the possession of an outer vertical bristle as a character in his diagnosis of Aristobata. I cannot see the outer vertical on the types. Hennig (1935) considered this species to be close to A. melini Frey, 1927 (= M. filipes Enderlein, 1922), which differs in having a black prothorax.

Mesoconius filipes (Enderlein, 1922)

Fig. 40D-E

Zelatractodes filipes Enderlein, 1922: 169.

Aristobata melini Frey, 1927: 69. syn. nov.

Zelatractodes filipes - Hennig 1935: 38. — Steyskal 1968: 20.

\section{Diagnosis}

Length $13 \mathrm{~mm}$. Head and prothorax black; mesothorax orange-brown; palpus orange. Mid and hind femora orange on basal $2 / 3$, black on distal $1 / 3$. Fore tarsus white-yellow, except for pale brown apex; hind tarsus with tarsomere 1 white-yellow, except apex, other tarsomeres black. Abdomen orange basally, metallic blue-black distally. Frontal vitta slightly raised. Dorsocentral bristle small (shorter than scutellum) but distinct. Wing very lightly infuscated, with no apparent pattern. Abdominal segments 1-2 strongly petiolate; $\mathrm{T} 1+2$ slightly more than twice as long as $\mathrm{T} 2$. 


\section{Material examined}

Holotype of Zelatractodes filipes

PERU • क; Pozuzo; 800 m a.s.1.; May 1903; S.B. Hoffmanns leg.; MNBG.

\section{Syntypes of Aristobata melini}

PERU・2 우, 2 ठ̊; Eastern Andes, Roque; 1925; Douglas Melin leg.; ZMUH.

\section{Other material}

ECUADOR $-1 \delta$ (photograph only); Eastern Andes, near Loreto, Narupayacu Biological Station; $00^{\circ} 43^{\prime} 30^{\prime \prime} \mathrm{S}, 77^{\circ} 46^{\prime} 2.8^{\prime \prime} \mathrm{W} ; 1138 \mathrm{~m}$ a.s.1.; 10 May 2019.

\section{Remarks}

Mesoconius filipes is based on a single type specimen that S.B. Hoffmanns collected in Peru at the unusually low (for Mesoconius) altitude of $800 \mathrm{~m}$. The specimen is in poor condition, greasy and with no antennae, but the colours seem distinctive and the same as those of Aristobata melini. The type locality of Aristobata melini, also in Peru, is similar to that of Mesoconius filipes and at the same altitude $(800 \mathrm{~m})$.

Note added in proof: The male photographed in Equador (subsequent to the acceptance of this paper) was collected, but remains at Yanayacu Biological Station. It has not been available for detailed study due to delays in obtaining the permits necessary for transport and export of the specimen.

\section{Mesoconius gelbifacies sp. nov. urn:1sid:zoobank.org:act:2348A024-0CCA-4039-8599-879B5EF98D87}

Fig. $42 \mathrm{~A}-\mathrm{C}$

\section{Etymology}

This species is named for its bright yellow face, a feature also found in the closely related M. apicalis sp. nov.

\section{Material examined}

\section{Holotype}

ECUADOR • O ; Napo, Baeza; 2000 m a.s.l.; 1 Mar. 1979; S.A. Marshall leg.; MYCRO0338-18 sequenced for CO1; QCAZ.

Description (female holotype only)

\section{LENGTH. $15 \mathrm{~mm}$.}

CoLour. Dark brown to black, with white-yellow face and yellow clypeus, gena, palpus, fore and hind tarsus, and hind tibia; mid and hind femora with a broad orange middle band. Frontal vitta velvety black; parafacial, gena and vibrissal angle black; abdominal T1+2 reddish-black; antenna reddish, except for brown dorsal surface of first flagellomere. Wing membrane evenly and lightly infuscated, except for a large, indistinct central clear area in cell $\mathrm{r}_{4+5}$. Oviscape microtrichose on basal half, distally shiny black, with a brownish tip.

HEAD. Epicephalon and paracephalon smooth and shiny, orbital strips striate and shiny; frontal vitta posteriorly broad and gradually narrowed to back of head, broadly meeting anterior margin of frons and laterally linked to eyes by angled black bands. Outer vertical bristle absent, inner vertical bristle strong, postocellar bristles strong, close and far back on the back of the head, separated from inner vertical bristles by approximately the length of a bristle. One small lower fronto-orbital bristle, upper frontoorbital bristle absent. 
THORAX. Cervical sclerite with a vertical ridge separating a partially bulbous, microtrichose, dark posterior portion from a small, pale, flat, depressed, bare anterior portion; posterior portion flat along anterior and dorsal margins. Prosternum microtrichose, with some small setulae. Notum microtrichose, with rows of

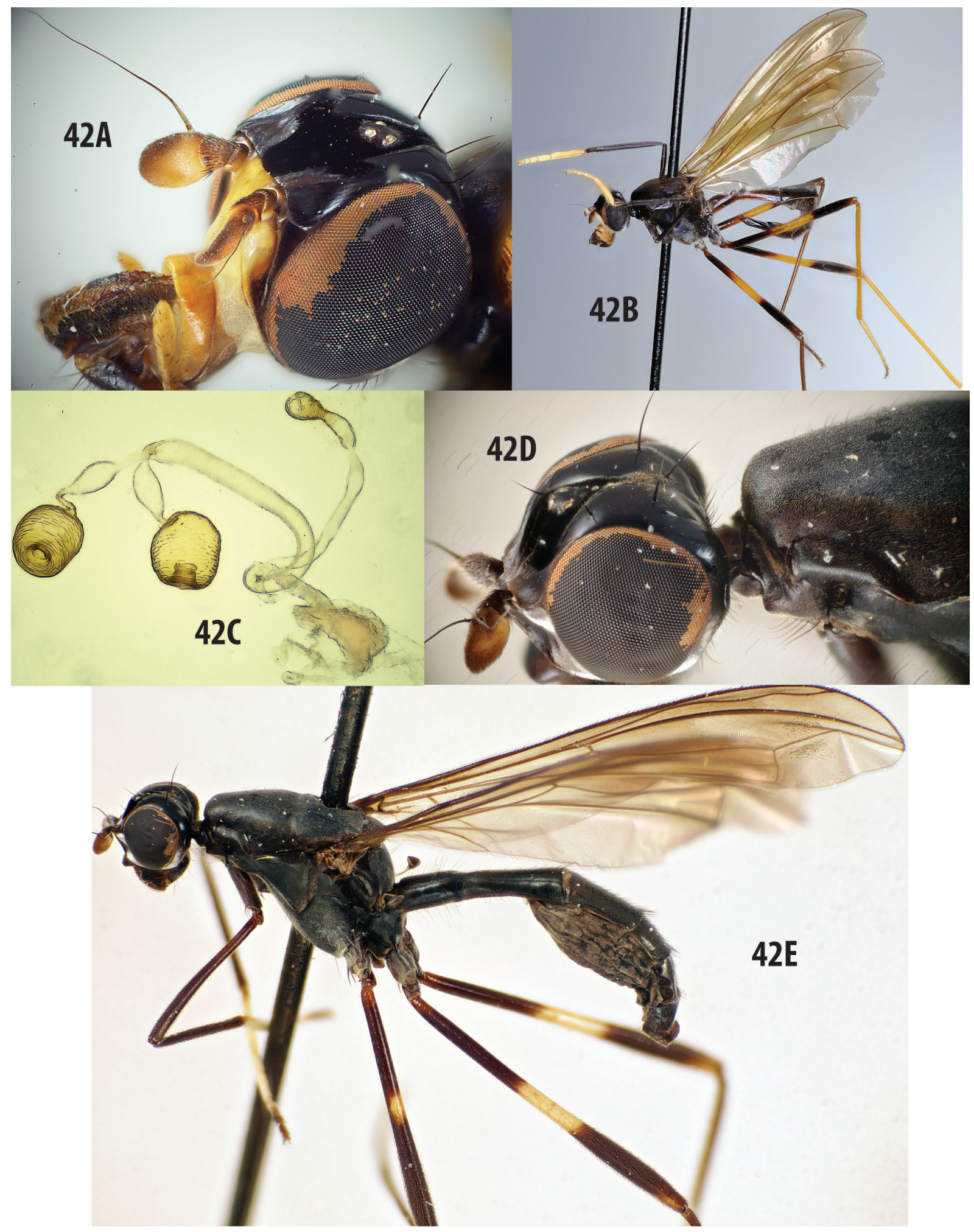

Fig. 42. A-C. Mesoconius gelbifacies sp. nov. A-B. Holotype, ${ }_{+}$, QCAZ. C. Spermathecae and associated structures. - D-E. M. keili sp. nov., holotype,, , QCAZ, oviscape missing. 
small acrostichal and dorsocentral setulae and scattered setulae above postpronotal lobe; postpronotal lobe microtrichose, with some scattered small setulae, anterior face shiny and almost vertical, posterior face sloped and microtrichose, except for a carinate extension on ventral corner. Dorsocentral bristle slightly longer than scutellum. Scutellum with four small discal setulae and long apical bristles (longer than scutellum). Katatergite not prominent, rounded and indistinctly convex. Vertical row of katepisternal bristles yellow. Fore coxae with anteroventral brown setae, other coxae with anteroventral golden setae.

Abdomen. T1 and T2 forming petiole; T1 $22 \times$ length of T3.

Female abdomen. Bursa short, rugose; ventral receptacle slender and extending far beyond bursa. Common part of spermathecal duct as long as bursa, single duct arising from side of common duct at midpoint, constricted at base and at start of stem, leading to elongate, clubbed single spermatheca. Paired duct uniformly smooth or indistinctly striate, slightly expanded before apex, where it splits into the paired spermathecal stems, each of which has a large swelling and bends at right angles before reaching short, oval, reticulate-surfaced paired spermathecae.

\section{Remarks}

This species is similar to M. apicalis sp. nov., from which it differs in having the postocellar portion of the frontal vitta broad and not pointed, the parafacial and oviscape black, upper fronto-orbital bristles absent, the epicephalon smooth, and the mid and hind femora black almost to the apex. These species appear on the same branch of a CO1 tree, but they are deeply divergent (Fig. 50).

Mesoconius keili sp. nov.

urn:lsid:zoobank.org:act:1A0AD255-0E49-41F8-82AD-56BF3F005715

Fig. 42D-E

\section{Etymology}

This species is named after Dr. Clifford Keil of the Pontificia Universidad Católica del Ecuador, in recognition of his efforts to expedite taxonomic work on Ecuador's insects.

\section{Material examined}

Holotype

ECUADOR - 9 ; Napo, $4.2 \mathrm{~km} \mathrm{~S}$ of Cosanga, pipeline trail; $2150 \mathrm{~m}$ a.s.l.; 7 Nov. 1999; S.A. Marshall leg.; MYCRO109-15 sequenced for CO1; QCAZ.

Description (female holotype only)

LENGTH. $12 \mathrm{~mm}$.

Colour. Black to dark brown, with the following exceptions: parafacial, vibrissa and gena silvery microtrichose; clypeus shiny brown; fore tarsomeres 1, 2 and basal half of 3 white, 4 and 5 brown. Mid and hind femora with white distomedian bands, narrow on mid femur and broad on hind femur, apices reddish. Wing membrane lightly infuscated, except for a large, central clear area in cell $\mathrm{r}_{4+5}$, pigmentation light along posterior margin.

HEAD. Epicephalon and paracephalon shiny and indistictly striate; frontal vitta elevated, posteriorly sharply tapered and ending in a patch of setulae anterior to postocellar bristles, anteriorly broad and ending well above frons. Outer vertical bristle absent, inner vertical bristle strong, postocellar bristle strong (one missing on holotype). Fronto-orbital bristles large, upper fronto-orbital bristle inserted 
above level of ocelli, lower fronto-orbital inserted in patch of microtrichia at epicephalon-orbital plate junction. Antennae separated by width of antennal socket, upper face broadly carinate, lower face flat and microtrichose. Clypeus shiny medially and laterally.

Thorax. Cervical sclerite with a vertical groove separating a bulbous, microtrichose, posterior portion from a smaller, flat, bare anterior portion. Prosternum microtrichose and sparsely setulose. Notum microtrichose, with rows of small acrostichal and dorsocentral setulae; postpronotal lobe microtrichose, with some scattered small setulae, anterior face almost vertical, shiny; posterior surface sloped, microtrichose except for a carinate ventral extension. Dorsocentral bristle slightly longer than scutellum. Scutellum with two small discal setulae and long apical bristles slighlty longer than scutellum. Katatergite not prominent, rounded and indistinctly convex. Vertical row of katepisternal bristles black. Coxae with anteroventral black setae.

Abdomen. Abdominal segments 1 and 2 petiolate; length of $1+22.2 \times$ that of tergite 3 . Oviscape of unique type missing.

\section{Remarks}

This distinctive species was collected at the same time and place as a female of $M$. eques Enderlein, 1922 and a female of M. cosanga sp. nov. All three flies were found on the surface of an oil pipeline.

Mesoconius lobopoda sp. nov. urn:1sid:zoobank.org:act:F039A155-9663-4D78-ACF7-61C5B0D124A1

Fig. 43

\section{Etymology}

The specific name refers to the lobopod-like outgrowths of male abdominal segments 4 and 5 .

\section{Material examined}

\section{Holotype}

COLOMBIA • ^’; Cordillera Occidental, Rio Aguacatal; 2000 m a.s.l.; 1908 [?]; Fassl leg.; BMNH.

\section{Paratypes}

COLOMBIA $\bullet 1$; same collecting data as for holotype; BMNH $\bullet 1$; ; Cordillera Occidental, Rio Aguacatal; 1800 m a.s.l.; Fassl leg.; BMNH • 1 क; S. Antonio; 2000 m a.s.1.; 16 Feb. 1908; Fassl leg.; BMNH.

All types are part of the C.T. Trechmann bequest to the BMNH (1964-549) and are part of a significant collection of high altitude Colombian micropezids, including several other rarely collected species of Mesoconius.

\section{Description}

LENGTH. $17-18 \mathrm{~mm}$.

CoLour. Abdomen orange-brown, except for black posterolateral corners of T3 and T4 and orange S8epandrium; thorax mostly black to dark brown, apex of scutellum reddish. Head strikingly bicoloured, upper half black, lower half yellow, except for silvery parafacial and postocular strips, palpus yellowish. Fore femur brown, except reddish apex. Fore tibia of male brown, strongly flattened and sulcate over basal 3/4, distally inflated; female tibia unmodified. Fore tarsomere 1 of male flat and greatly expanded, brown on outer surface and brilliantly white on inner surface, black setulose ventrally; female fore tarsomere 1 swollen, white, not flattened; tarsomeres 2-5 white, except for black setulose ventral edges. 


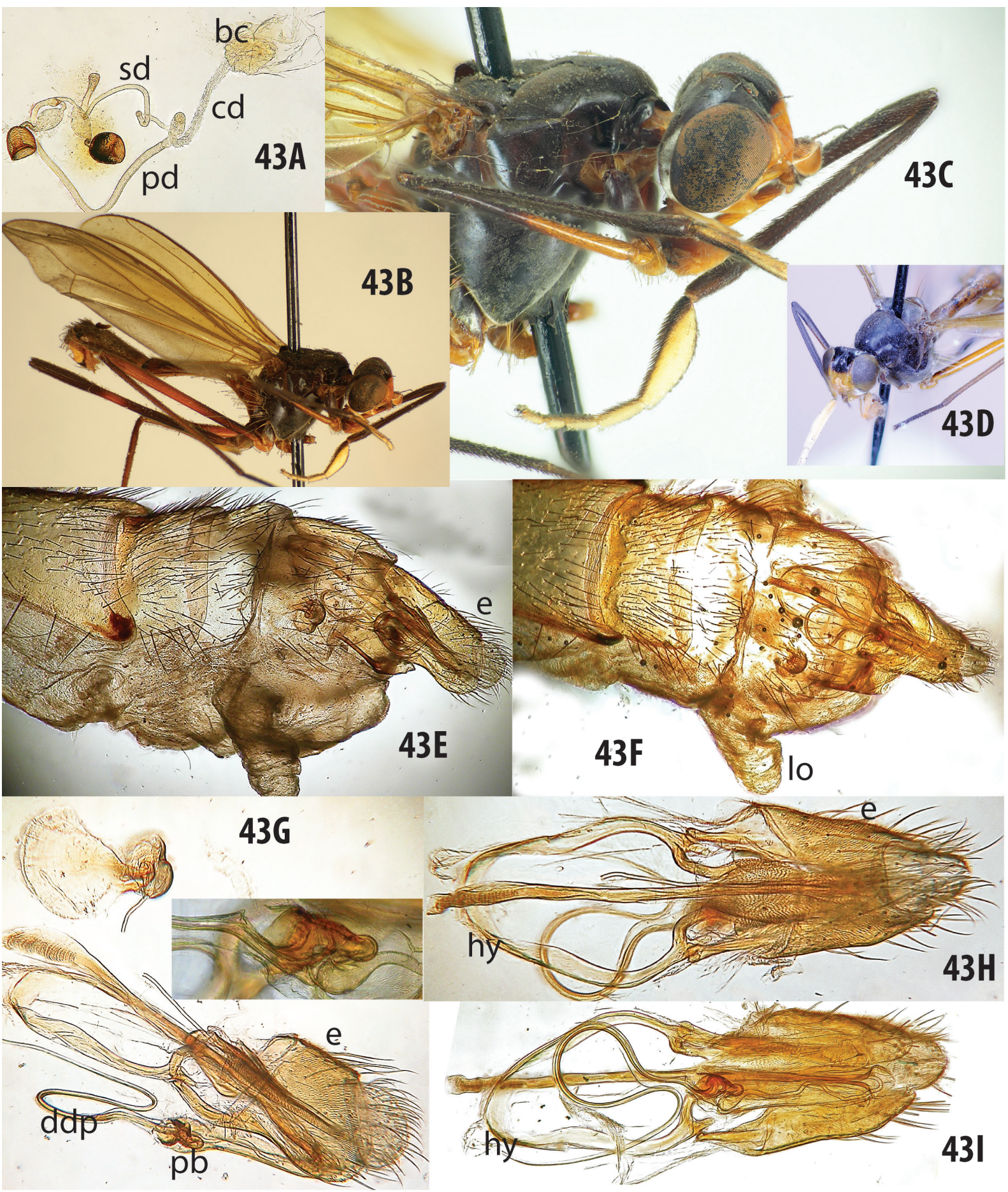

Fig. 43. Mesoconius lobopoda sp. nov. A. Spermathecae and associated structures. B-D. Holotype,

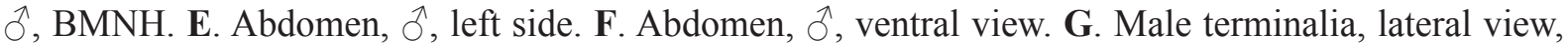
with phallic bulb enlarged in inset. H. Male terminalia, dorsal view. I. Male terminalia, ventral view. Abbreviations: $\mathrm{bc}=$ bursa copulatrix; $\mathrm{cd}=$ common spermathecal duct; $\mathrm{ddp}=$ distal distiphallus; $\mathrm{e}=$ epandrium; hy = hypandrium; lo = 'lobopod' pleural lobe of segment 5; $\mathrm{pb}=$ phallic bulb; $\mathrm{pd}=$ paired spermathecal duct; $\mathrm{sd}=$ single spermathecal duct. 
Mid femur brown basally and distally orange-brown; mid tibia and tarsus brown; hind femur mostly brown basally and distally with some reddish ventral areas and a reddish ring near middle. Hind tarsus brown, except for white basal $3 / 4$ of tarsomere 1 . Wing evenly and heavily yellow-brown infuscated. Abdominal pleuron pigmentation obscured on all types.

HEAD. Epicephalon, paracephalon and upper half of frontal vitta shiny dark brown, sharply contrasting with orange lower frons; lower part of frontal vitta and interfrontal strip vertically microstriate, identical in colour to smooth orange orbital strips. Outer vertical bristle absent, inner vertical bristle strong, postocellar bristle strong. Two strong fronto-orbital bristles. Antennae separated by width of antennal socket, lunule and facial carina bare, upper face strongly and broadly carinate; lower face flat and microtrichose. Clypeus shiny medially, posterolaterally microtrichose. Occipital setae sparse, postgena densely setulose.

THorax. Cervical sclerite with a vertical groove separating a brown, microtrichose, subquadrate, indented posterior portion from a small, bare, reddish anterior portion. Prosternum microtrichose and sparsely setulose. Notum microtrichose, with sparse, indistinct rows of small acrostichal and dorsocentral setulae; postpronotal lobe sparsely microtrichose, with some scattered small setulae. Scutellum with two small discal setulae and long apical bristles (longer than scutellum). Katatergite rounded, not prominent, sparsely setulose. Notopleuron with two widely spaced bristles (holotype with an extra anterior notopleural on one side). Vertical row of katepisternal bristles yellow. Coxae with anteroventral golden setae.

АвDomen. Abdominal segments 1-3 strongly petiolate, length of $\mathrm{T} 1+2$ double that of $\mathrm{T} 3$.

FemAlE ABDOMEN. Abdominal sclerites, including oviscape, reddish brown. Bursa broad and short, ventral receptacle small but distinct, basal (undivided) part of spermathecal duct long (as long as single duct), broad, pale and wrinkled; single spermatheca small, slightly broader than duct; paired spermathecal duct double the diameter of paired duct and longer and striate throughout. Paired spermathecae elongate cupshaped, distinctly striate, tapered basally, ducts beyond split with a large, elongate, oval swelling and a distal section with a single S-bend putting spermatheca at right angle to duct.

Male abdomen. Segments 5-6 with two large cylindrical, membranous lobes at anterior margin of pleuron 6 and four smaller ventral membranous lobes; sternites $4-6$ apparently unsclerotized. Synsternite 7-8 simple, S8 orange, similar in size to epandrium. Epandrium with broad, long-setose posteroventral margins, cercus large and distinct. Hypandrium elongate, anterior plate narrow, strap-like. Basiphallus very small, frame-like; not extending beyond base of distiphallus. Basal part of distiphallus broadly tubular, more or less parallel-sided basal to very large phallic bulb, which forms a distinctive distal dorsal notch at origin of distal part of distiphallus; distal part of distiphallus tapered and whip-like, apex broken on only dissected male. Ejaculatory apodeme broad, half size of epandrium.

\section{Remarks}

This is one of the most distinctive species of Mesoconius, because of the frontal colour and distinctive male structures. The sharply bicoloured frons, with the red-yellow lower frons and black upper frons, is diagnostic. The very broad first tarsomere on the fore leg is highly distinctive, especially on males, and the remarkable lobopod-like outgrowths of the male abdominal segments four and five are unlike anything else known in the Micropezidae.

Mesoconius nigra sp. nov.

urn:1sid:zoobank.org:act:B032E41E-1F0A-490A-9907-10E7B8847C50

Fig. 44

\section{Etymology}

Mesoconius nigra is named for its almost entirely black body and darkly pigmented wings. 


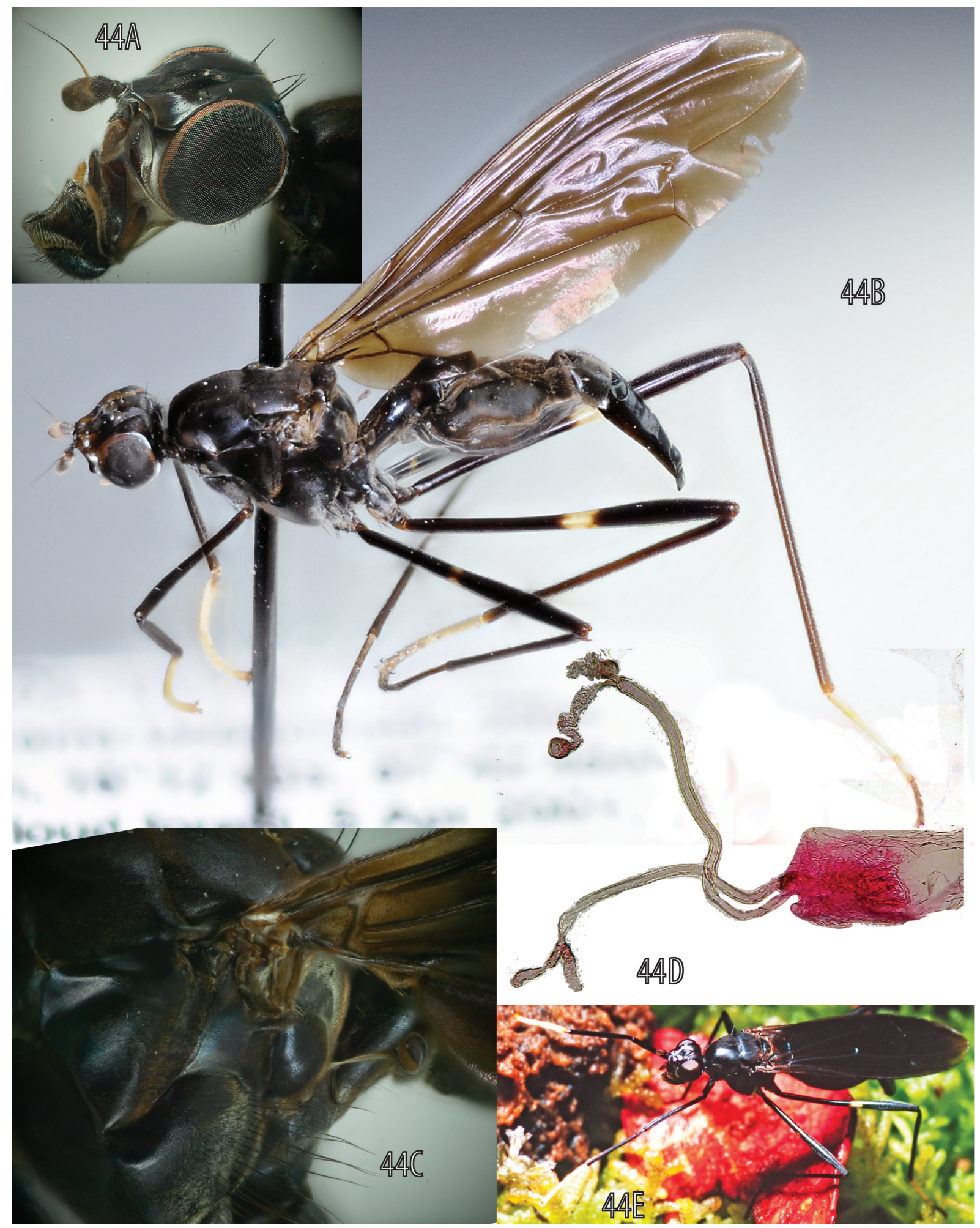

Fig. 44. Mesoconius nigra sp. nov. A. Head, dorsolateral view. B. Holotype, $q$, CBFC. C. Posterior part of thorax, lateral view. D. Spermathecae and associated structures. E. Living 9. 


\section{Material examined}

\section{Holotype}

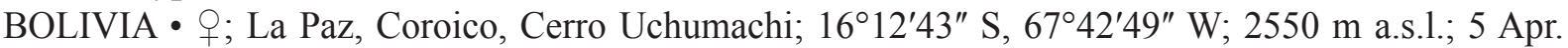
2001; S.A. Marshall leg.; cloud forest; CBFC.

\section{Paratypes}

BOLIVIA • 2 + $\odot$; same collecting data as for holotype; MYCRO070-15 sequenced for CO1; DEBU.

\section{Description (females only)}

LENGTH. $16-17 \mathrm{~mm}$.

Colour. Mostly brown to black, fore tarsus white, hind tarsus white basally and darkened distally, palpus pale orange. Frontal vitta velvety black. Hind femur with a broad white band just beyond middle; mid femur with a narrow band. Wing uniformly black. Abdominal pleuron dark.

HEAD. Epicephalon and paracephalon smooth and shiny. Frontal vitta narrow, only slightly raised, narrow and indistinct behind ocelli, where it expands to a microtrichose patch between postocellar bristles; anteriorly tapered to near anterior margin of frons. Postocellar bristles and inner vertical bristles well developed. Upper fronto-orbital absent, lower fronto-orbital large, inserted at point of overlap between orbital plate and epicephalon.

THORAX. Scutum inconspicuously microtrichose; dorsocentral and acrostichal setulae very small. Cervical sclerite oblong, with a small, depressed anterior portion divided by a vertical carina; posterior portion elevated, but with surface bare and flat-topped or slightly depressed at middle. Prosternum microtrichose and strongly setose. Postpronotal lobe sparsely microtrichose and very sparsely setulose, anterior surface vertical and shiny along dorsal margin, posterior surface sloped and microtrichose, except for ventral carina. Dorsocentral bristle slightly longer than scutellum. Scutellum with minute discal setulae and one pair of long apical bristles (longer than scutellum). Vertical row of katepisternal bristles golden. Katatergite not swollen, without median process, evenly convex and microtrichose. All coxae with an anteroventral tuft of long black setae.

ABDomen. Abdominal segment 1 petiolate on basal half only, T2 short and expanded posteriorly. T3-5 narrow and depressed relative to T2 and T6. Pleuron greatly expanded on segments 3-5. Bursa small, subquadrate, with a small distal ventral receptacle, spermathecal ducts arising separately from apex of bursa. Both ducts lead to pairs of spermathecae, with one duct and one pair of spermathecae slightly larger than the other duct and spermathecae. The smaller spermathecae are narrow and long, on short stems, the larger spermathecae are short and on longer, convoluted stems.

\section{Remarks}

Mesoconius nigra sp. nov. is similar to, and obviously closely related to, M. quadritheca sp. nov. from Peru. These species share the four spermathecae, limited constriction at the abdominal base, narrowed T3-5, and similar colour and general habitus, but M. nigra sp. nov. differs from M. quadritheca sp. nov. in having well-developed vertical and postocellar bristles. Mesoconius ruficrus sp. nov. from Peru is also very similar, but differs in colour. All three species share a setose prosternum.

Mesoconius oblitus (Hennig, 1935) comb. nov.

Figs 45-46

Aristobata oblita Hennig, 1935: 32.

Zelatractodes oblitus - Steyskal 1968: 20. 


\section{Material examined}

\section{Holotype}

VENEZUELA • ○; "Venezuela, 486, TYPUS"; dirty, missing right fore leg and left antenna; SMTD.

Paratypes (not examined)

VENEZUELA • 2 \% 9 ; Merida; MLUH.

\section{Other material}

VENEZUELA •1 O’; Lara, PN Yacambú; 6-8 Apr. 1981; A.S. Menke and L. Hollenberg leg.; USNM • 1 q; Merida, Rio Albarregas; 2200 m a.s.1.; 24 Apr. 1988; S.A. Marshall leg.; cloud forest; DEBU A30517 sequenced for CO1; DEBU.

COLOMBIA • 1 क; Huila, PNN Cueva de los Guácharos Cabaña Cedros; 01 ${ }^{\circ} 37^{\prime}$ N, $76^{\circ} 06^{\prime}$ W; 1950 m a.s.1.; 21 Dec. 2001-5 Jan. 2002; C. Cortes leg.; Malaise trap; MYCRO334-18 sequenced for CO1; IAVH.

\section{Redescription}

LeNGTH. $15-17 \mathrm{~mm}$.

CoLour. Mostly brown to black, head darker, fore femur yellow basally, fore tarsus white, hind tarsus white basally and darkened distally (dirty and dark on type). Hind femur brightly banded but variable, yellow-brown at base, then black, then white band, then black, then yellow-brown at apex; mid femur similarly coloured on type but non-type specimens with a more orange mid femur (Fig. 45B). Scutum with a continuous, broad, parallel-sided, silvery longitudinal strip on each side of a central dark strip. Wing membrane lightly infuscated, except for a large central clear area in cell $\mathrm{r}_{4+5}$. Abdominal pleuron pale.

HEAD. Epicephalon and paracephalon indistinctly striate, epicephalon with dense white microtrichosity. Frontal vitta conspicuously raised, with ocellar triangle on a distinct peak at centre of a prominent dome $0.6 \times$ as wide as frons, vitta sharply constricted behind ocelli, forming a short microtrichose trough not reaching postocellar bristles; vitta widely separated from anterior margin of frons. Lower frons and parafacials densely covered with white setulae. Palpus not clearly visible on type but very narrow, brown on other material. Postocellar bristles very closely spaced and slightly divergent, inner vertical bristle well developed. Two fronto-orbital bristles, widely separated, upper fronto-orbital bristle very large, inserted on epicephalon well above level of ocellar tubercle, lower fronto-orbital minute.

Thorax. Scutum densely microtrichose, with silver microtrichia forming two broad, longitudinal vittae separated by a gold strip of similar width; dorsocentral setulae forming a sparse row in silver vitta; acrostichal setulae forming a distinct row in central gold strip. Prosternum microtrichose and setulose. Cervical sclerite subquadrate, with a vertical groove separating a large microtrichose posterior section from a bare anterior portion. Postpronotal lobe sparsely microtrichose and very sparsely setulose. Dorsocentral bristle slightly longer than scutellum. Scutellum with minute discal setulae and one pair of long apical bristles (longer than scutellum). Vertical row of katepisternal bristles golden. Katatergite not swollen, without median process, evenly convex and microtrichose. All coxae with an anteroventral tuft of long golden setae.

AвDOMEn (based on non-type Venezuelan material). Segments 1-2 petiolate, narrow and twice as long as T3. 


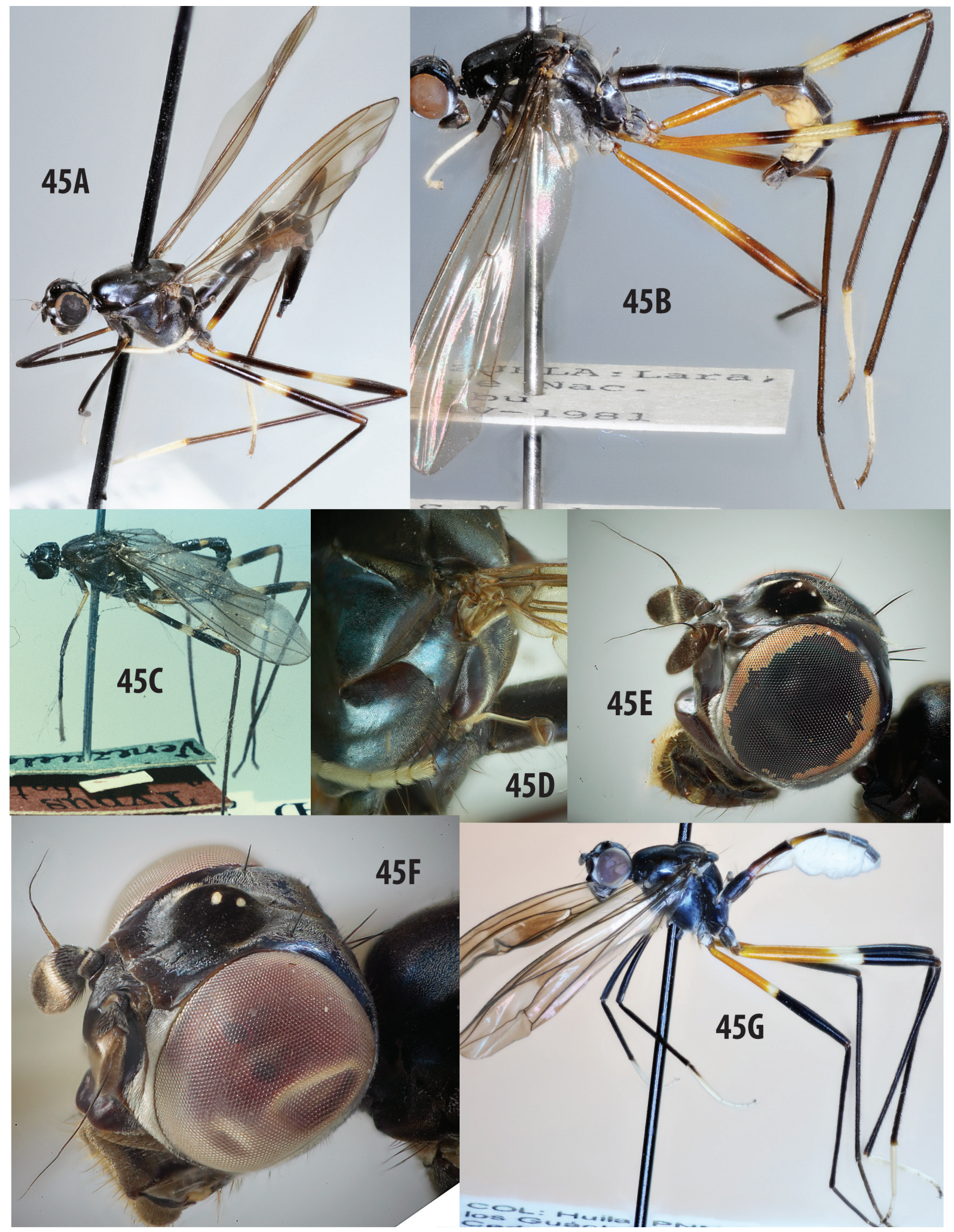

Fig. 45. Mesoconius oblitus (Hennig, 1935), external characters. A. Typical + , DEBU, Venezuela. B. Colour variant, $\hat{\jmath}$, USNM, Venezuela. C. Holotype, $\widehat{\partial}$, SMTD. D. Posterior part of thorax, lateral view. E. Head, + , DEBU, specimen from Venezuela. F. Head, + , IAVH, specimen from Colombia. G. Colour variant, + , IAVH, oviscape removed, specimen from Colombia. 
Female ABDOMEn. Bursa with a small subquadrate body with a small ventral receptacle, distally extending as a broad common spermathecal duct. Single spermathecal duct arising just before apex of common spermathecal duct, uniformly smooth and parallel-sided until a constriction just before basally swollen and distally tapered single spermatheca. Paired spermathecal duct arising at apex of common duct, entirely smooth and uniform from apex of striated common duct to constriction before splitting into paired spermathecae and their stems. Paired spermathecae elongate-oval, not distinctly striate, stems narrow, distal section with an S-bend.

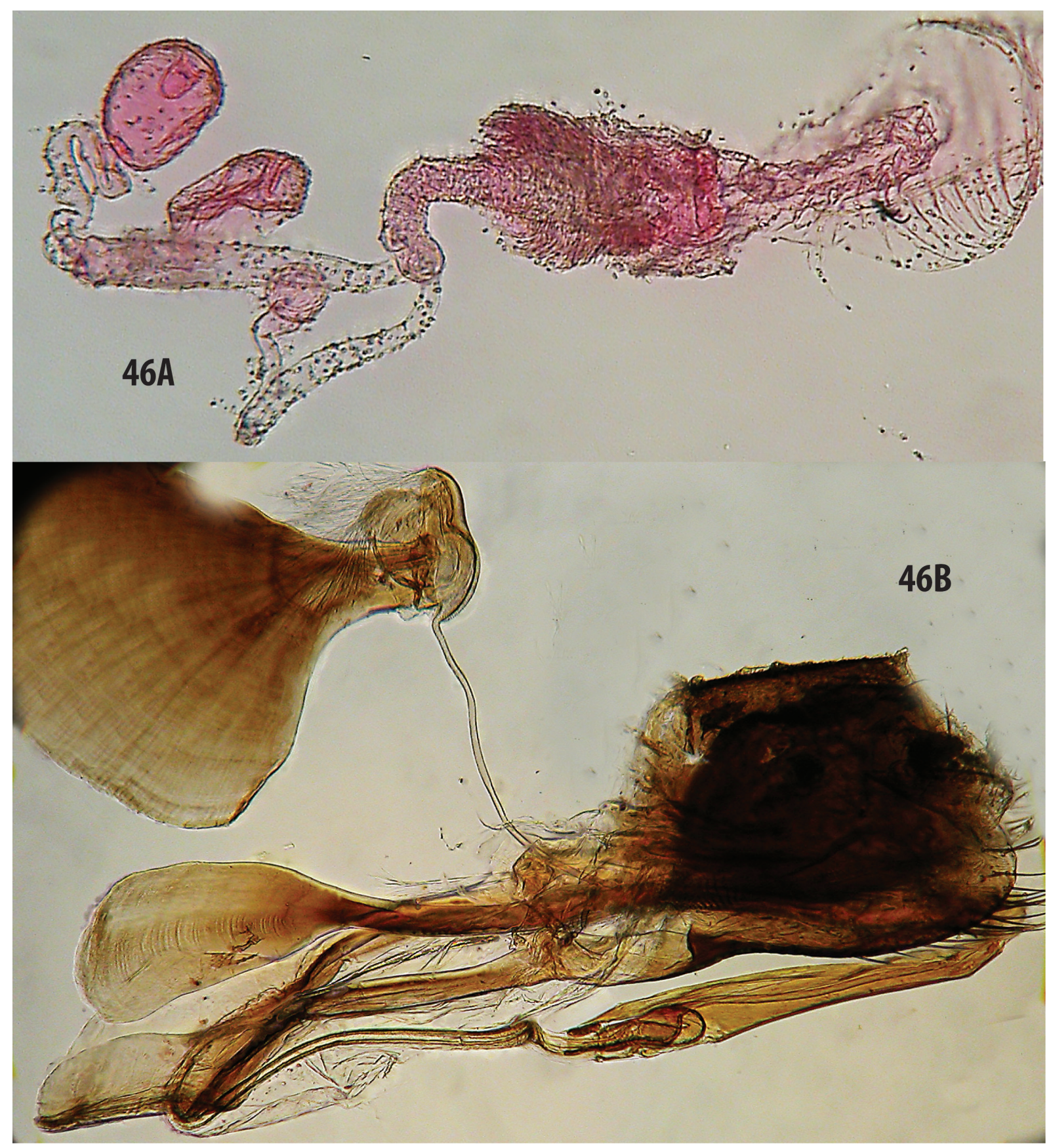

Fig. 46. Mesoconius oblitus (Hennig, 1935), internal characters. A. Spermathecae and associated structures, specimen from Colombia. B. Male terminalia, left lateral view, specimen from Venezuela. 
Male abdomen. Preabdominal sternites greatly reduced, but S4-6 present as distinct, elongate and very narrow sclerites. Sternite 8 subequal to epandrium, setulose except for bare posterior margin, partially fused with broad ventral lobe of S7 on left side, separate from a large lateral, normally invaginated sclerite on right side. Epandrium setulose, long-setose posterodorsally. Ejaculatory apodeme larger than epandrium; hypandrium with a long, scoop-like anterior margin, basal part of distiphallus broad, distally extending hood-like over a large phallic bulb; distal distiphallus slender and curved into flat, symmetrical, scoop-like anterior part of hypandrium.

\section{Remarks}

The specimens here treated as Mesoconius oblitus share many distinctive characters, including the unique and diagnostic prominent frontal tubercle, the characteristic bicoloured and white-banded femora, the microtrichosity of the epicephalon, the characteristically vittate scutum and the narrow brown palpus. This leaves little doubt that they are at least closely related, but the variation in other characters is hard to assess with so few specimens. The non-type male from Venezuela and the female from Colombia, for example, have much more orange on the femora than the type, and the Colombian specimen lacks the dark area proximal to the white femoral band. More specimens are needed to distinguish intraspecific variation from interspecific variation and to ascertain whether the material examined here represents one species or a group of related species. Sequence (barcode) data group the Colombian female with the Venezuelan female, but with a deep split between them.

The combination of a long distal distiphallus and a long, scoop-like anterior hypandrium is unusual and not found in other groups.

Mesoconius quadritheca sp. nov.

urn:1sid:zoobank.org:act:2494B1F0-9AFC-4177-901E-9A044662A2AB

Fig. 47

\section{Etymology}

The species name refers to the unusual complement of four spermathecae.

\section{Material examined}

\section{Holotype}

PERU • 9 ; Cusco, Wayqecha Biological Station, $9 \mathrm{~km} \mathrm{NE}$ of Challabamba; $13^{\circ} 10^{\prime} 20^{\prime \prime} \mathrm{S}, 71^{\circ} 35^{\prime} 00^{\prime \prime} \mathrm{W}$; 2600-2700 m a.s.1.; 1-6 Dec. 2011; S.A. Marshall leg.; MUSM.

\section{Paratype}

PERU • 1 9; same collecting data as for holotype; MYCRO069-15 sequenced for CO1; DEBU.

\section{Other material}

PERU • 2 $q$; same collecting data as for holotype; in alcohol; DEBU.

Description (females only)

LENGTH. $17 \mathrm{~mm}$.

CoLour. Mostly black, fore tarsus white, except for ventral base of tarsomere 1, hind tarsus white basally and darkened distally, palpus yellowish apically. Mid and hind femora with a broad white band just beyond middle. Wing uniformly black. Abdominal pleuron dark.

HEAD. Epicephalon and paracephalon finely striate, shiny. Frontal vitta narrow and only slightly raised, anteriorly tapered to near anterior margin of frons, narrow and indistinct behind ocelli, where it expands 


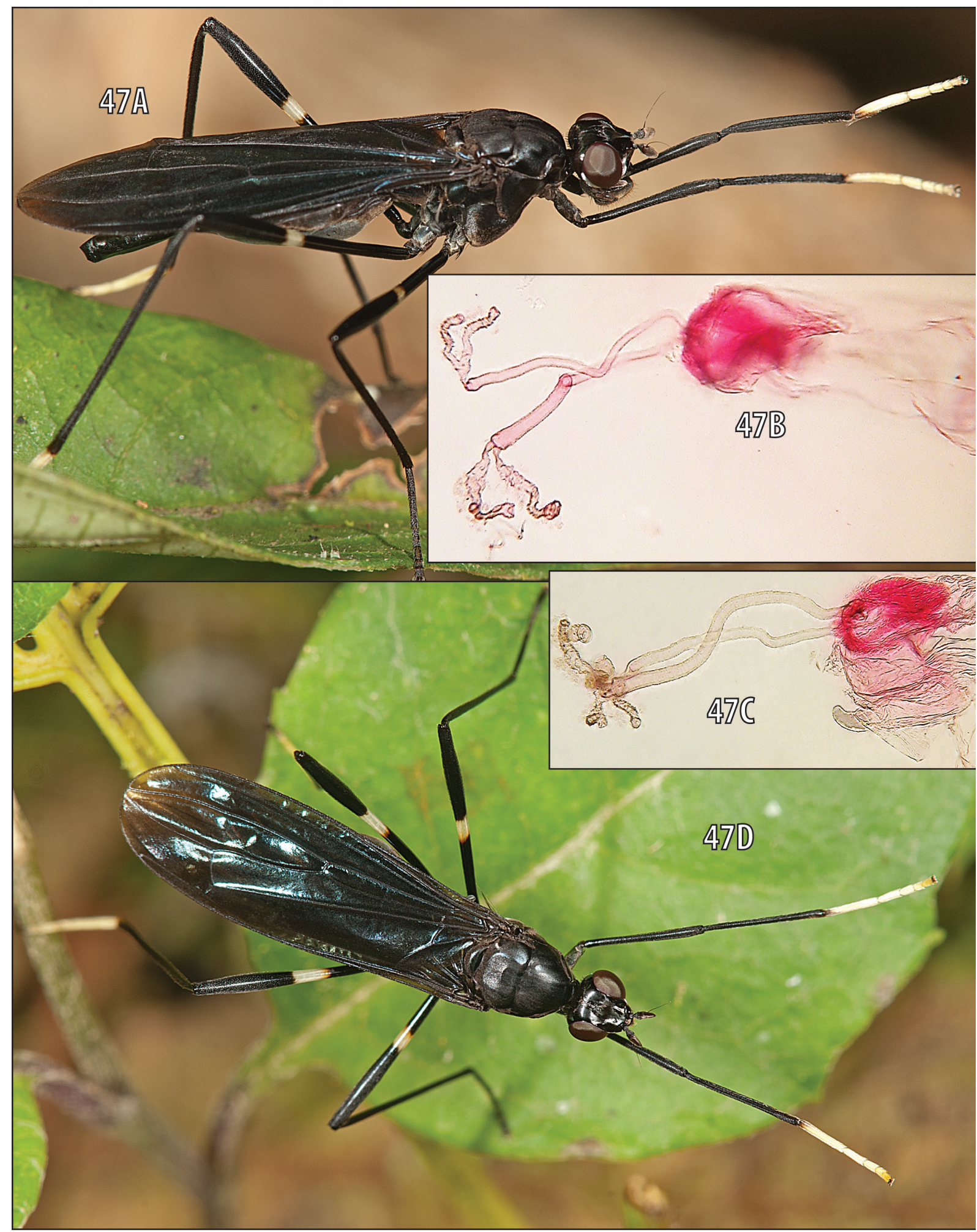

Fig. 47. Mesoconius quadritheca sp. nov. A, D. Living $q$. . B-C. Spermatheca and associated structures, dorsal and lateral views. 
to a microtrichose patch between very small postocellar bristles. Postocellar bristle small, inner vertical bristle minute and barely distinguishable from surrounding setulae. Fronto-orbital bristles absent.

THORAX. Scutum inconspicuously microtrichose, setulae inconspicuous, except for a densely setulose patch on each side of anterior margin. Cervical sclerite oblong, with a small, depressed anterior portion; posterior portion elevated, with a large, whitish oval patch (probably a dense field of sensillae). Prosternum microtrichose and conspicuously setulose. Postpronotal lobe almost bare, very sparsely microtrichose and very sparsely setulose, anterior surface vertical and shiny along dorsal margin, posterior surface almost vertical and microtrichose, except for ventral carina. Dorsocentral and scutellar bristles absent. Vertical row of katepisternal bristles black. Katatergite weakly swollen, without median process, evenly convex and microtrichose. All coxae with an anteroventral tuft of long black setae.

AвDomen. Abdominal segment 1 petiolate on basal half only, T2 short and expanded posteriorly. T3-5 narrow and depressed relative to T2 and T6. Pleuron greatly expanded on segments 3-5, micosetulose on dorsal third. Bursa with a small subquadrate body with a small and distal ventral receptacle, both spermathecal ducts arising separately from apex of bursa. Both ducts lead to paired spermathecae, with one duct and one pair of spermathecae slightly larger than the other. The smaller spermathecae are narrow and long, on short stems; the larger spermathecae are short, on longer convoluted stems.

\section{Remarks}

The equal length spermathecal ducts, four spermathecae, reduced head bristles, and relatively nonpetiolate abdominal base (only the basal part of segment one is narrowed) of this species are atypical for Mesoconius, as is the extended lower frons that covers part of the antennal socket. The general habitus, combined with a short oviscape, heavily pigmented wings and large size, are typical of the genus, but male specimens are needed to confirm this placement. Sequence data suggest that M. quadritheca sp. nov. belongs firmly in the genus, close to M. nigra sp. nov. (Bolivia) and M. ruficrus sp. nov. (Peru). Mesoconius quadritheca sp. nov. is similar to, and obviously closely related to, $M$. nigra sp. nov. from Bolivia. These species share the very unusual possession of four spermathecae, limited constriction at the abdominal base, narrowed T3-5, setose prosternum, and similar colour and general habitus, but M. nigra sp. nov. differs from $M$. quadritheca sp. nov. in having well-developed vertical and postocellar bristles (present but minute in M. quadritheca sp. nov.). Mesoconius ruficrus sp. nov. seems to be closely related, but has only three spermathecae.

Mesoconius rex sp. nov. urn:Isid:zoobank.org:act:EBF11F77-E8B9-4155-AFDD-4416FC14607D

Fig. 48

\section{Etymology}

The specific name of this unique male, superficially similar to Mesoconius reinai sp. nov., known only from a single female, is from the Latin for 'king'.

\section{Material examined}

Holotype

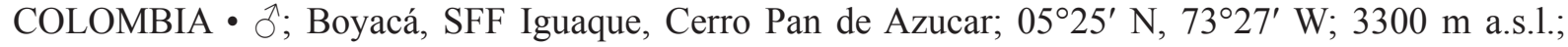
27 Mar.-16 Apr. 2000; Malaise trap; M1517; P. Reina leg.; IAVH.

Description (male only)

LENGTH. $14 \mathrm{~mm}$. 


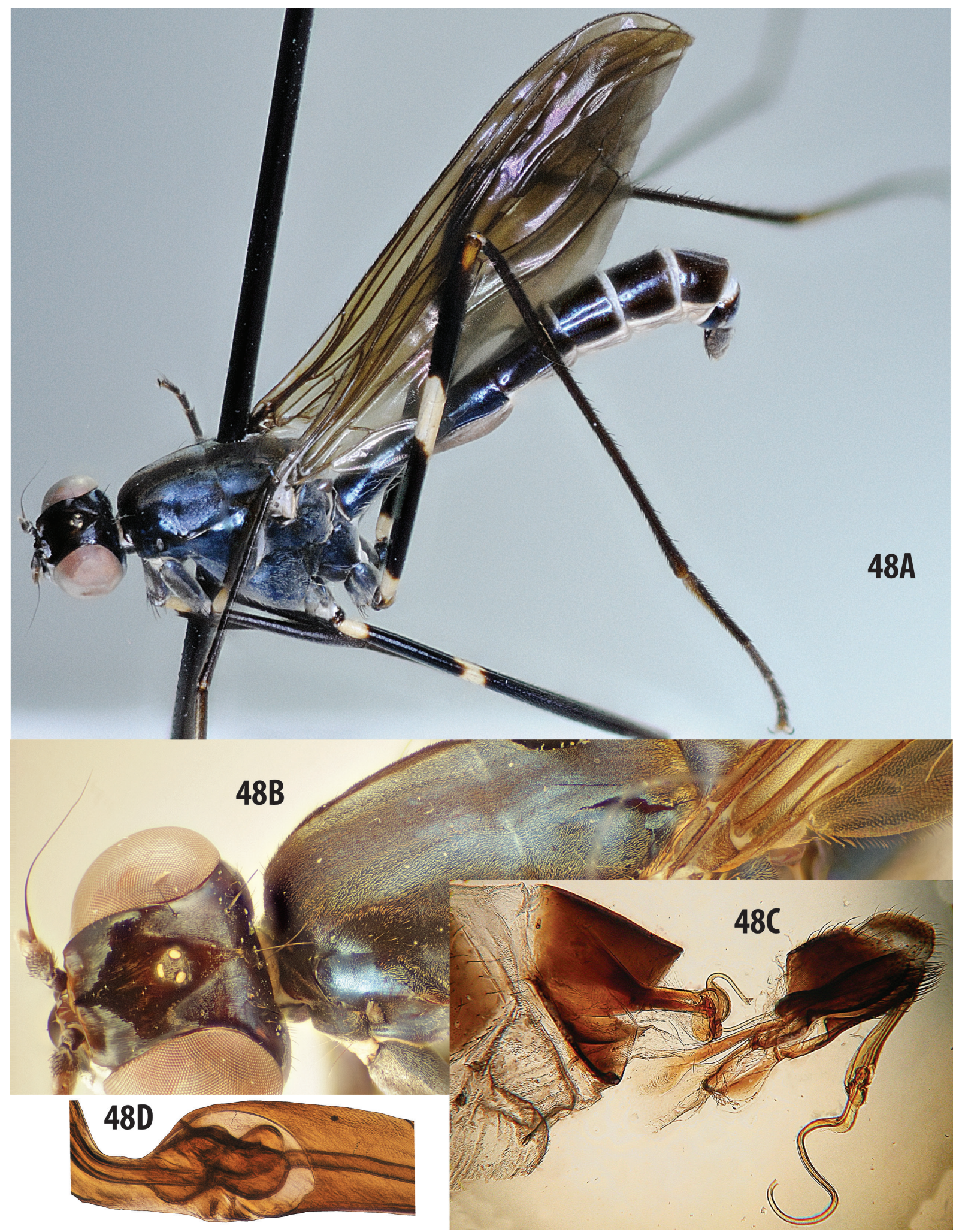

Fig. 48. Mesoconius rex sp. nov., holotype, $\widehat{\jmath}$, IAVH. A. Habitus, dorsolateral view. B. Head and thorax, dorsolateral view. C. Apex of abdomen, with terminalia detatched (phallus teased out, ejaculatory duct broken). D. Phallic bulb. 
CoLour. Mostly shiny blue-black to brown; all femora white at base, mid and hind femora with a white band just beyond middle, with band on mid femur much wider; apex of mid and (more distinctly) hind femora yellowish-brown. First flagellomere yellow-brown; notum with broad, silvery dorsocentral vittae. Wing uniformly black. Abdominal segment 1 blue-black; T3-5 black; pleuron white.

HEAD. Epicephalon and paracephalon distinctly striate, dull. Frontal vitta velvety brown and broad, centrally depressed, more or less diamond-shaped, with anterior point reaching front of frons and lateral points with extensions broadly reaching eye. Postocellar bristles and inner vertical bristles well developed, postocellars very close to one another. Upper fronto-orbital strong, above level of upper ocelli, lower fronto-orbital minute or absent.

Thorax. Scutum conspicuously microtrichose; dorsocentral and acrostichal setulae very small; dorsocentral microtrichose strips broad, expanding postsuturally. Cervical sclerite with a shiny anterior portion divided from a setulose posterior portion by a vertical carina. Postpronotal lobe sparsely microtrichose, sparsely setulose on posterior half, anterior surface vertical and shiny along dorsal margin, posterior surface sloped and microtrichose, except for a strong ventral carina. Dorsocentral bristle strong, distinctly longer than scutellum. Scutellum with one pair of discal setulae and one pair of long apical bristles (longer than scutellum). Vertical row of katepisternal bristles dark brown. Katatergite moderately swollen, without median process, evenly convex and microtrichose. All coxae with an anteroventral tuft of long, golden-brown setae.

Abdomen. T1+2 2.8 $\times$ T3. S5 and S6 reduced, linear. S8 shiny and much larger than microtrichose epandrium. Cercus large, subquadrate. Hypandrium relatively short (similar in length to anteroventral epandrial arms), anterior margin broad, scoop-like and symmetrical. Basal basiphallus broad, distally expanding to an excavated apex holding a broad phallic bulb; distal distiphallus apparently wiry, narrow, flanged at base, but otherwise parallel-sided, forming an 'S' shape.

\section{Remarks}

Although this species is only known from a single male, it is distinctive for several features, including the sinuate distal distiphallus and mostly metallic blue-black body.

Mesoconius ruficrus sp. nov. urn:1sid:zoobank.org:act:16125162-2840-41C0-9A13-EA78074DC451

Fig. 49A-E

\section{Etymology}

The specific name refers to the mostly red mid and hind legs of this species.

\section{Material examined}

\section{Holotype}

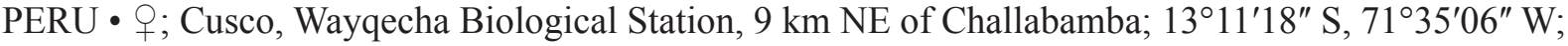
3100 m a.s.1.; 7-8 Dec. 2011; S.A. Marshall leg.; DEBU307-17 sequenced for CO1; MUSM.

Description (female holotype only)

LENGTH. $17 \mathrm{~mm}$.

Colour. Head mostly black; clypeus and palpus orange; face and antenna reddish brown, area between and below postocellar bristles orange. Cervical sclerite yellow. Thorax mostly dark reddish brown, scutellum and supra-alar area orange, anterior part of scutum with two short, faint reddish longitudinal 
fasciae and a similar central strip just anterior to scutellum; pleural suture reddish. Hind and mid legs orange, except for black distal hind tarsomeres and black mid tarsomeres; fore leg dark reddish brown, except for orange basal half of femur and yellow tarsomeres (base of tarsomere 1 black). Wing broad, uniformly tinted reddish-orange. Abdomen mostly orange, including upper half of pleuron and entire oviscape.

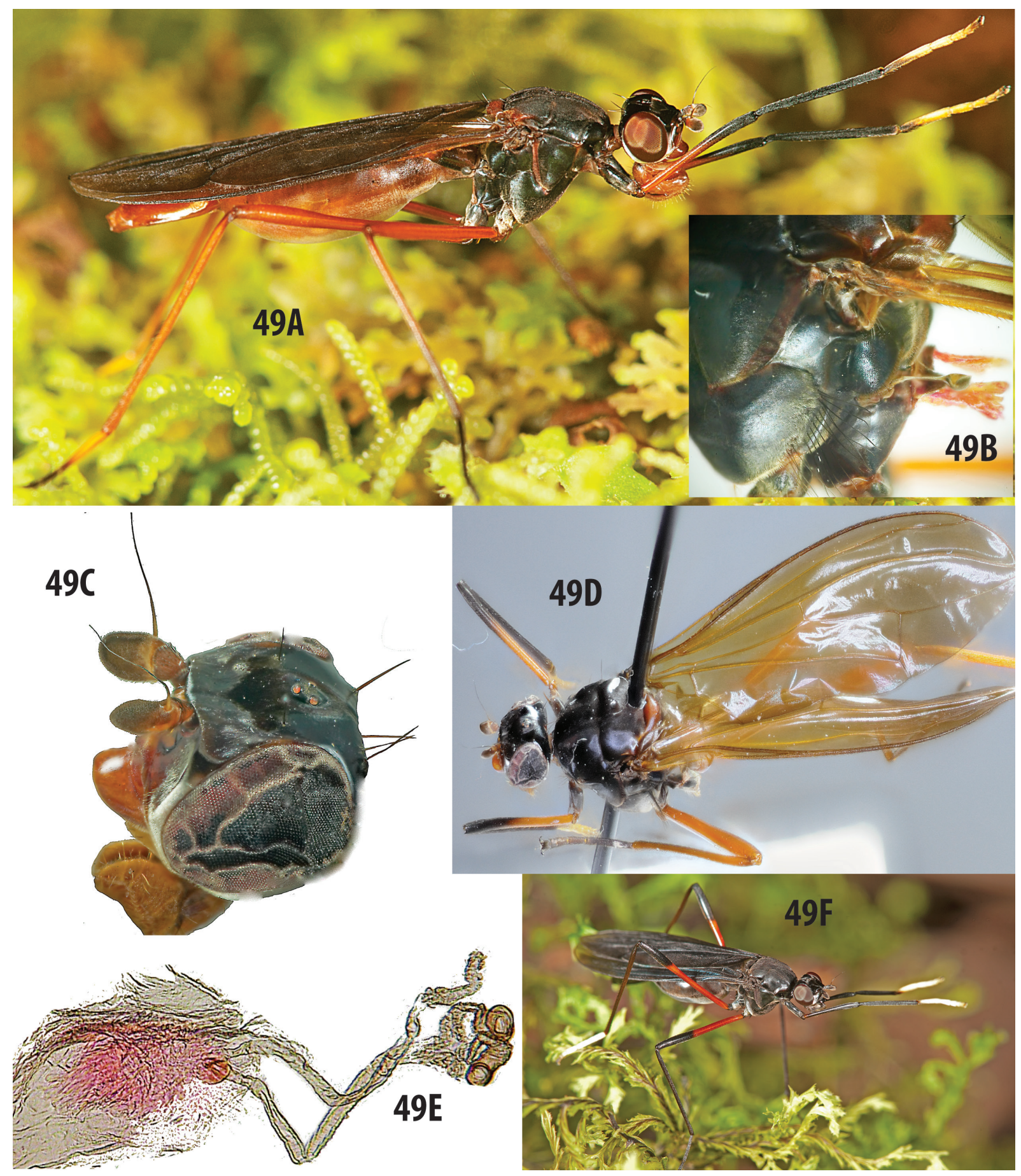

Fig. 49. A-E. Mesoconius ruficrus sp. nov. A. Living . . B. Posterior part of thorax, lateral view. C. Head. D. Holotype, + , MUSM, dorsal view showing wing. E. Spermathecae and associated structures. - F. Undescribed species of Mesoconius Enderlein, 1922 from Wayqecha Biological Station, Peru. 
HEAD. Epicephalon and paracephalon shiny, weakly striate. Frontal vitta broad and short, only slightly raised, indistinct behind ocelli, where it splits a microtrichose patch between postocellar bristles. Frontal vitta extending as a very narrow strip to anterior margin of frons. Postocellar bristles and inner vertical bristles well developed. With only a single well-developed fronto-orbital, inserted just above point of overlap between orbital plate and epicephalon.

THORAX. Scutum inconspicuously microtrichose; dorsocentral and acrostichal setulae very small. Cervical sclerite oblong, with a small, depressed anterior portion divided by a vertical carina; posterior portion elevated and conspicuously depressed at middle. Prosternum microtrichose and conspicuously setulose. Postpronotal lobe sparsely microtrichose, anterior surface with a small, shiny patch; posterior surface sloped and microtrichose, except for ventral carina. Dorsocentral bristle slightly longer than scutellum. Scutellum with minute discal setulae and one pair of long apical bristles (longer than scutellum). Vertical row of katepisternal bristles mostly black, bottom few golden. Katatergite not swollen, without median process, evenly convex and microtrichose. All coxae with an anteroventral tuft of long, golden bristles.

ABDomen. Abdominal segment 1 short and petiolate on basal half only, $\mathrm{T} 2$ short and expanded posteriorly, with a dark anteromedial spot. T3-5 slightly narrower than T2. Pleuron densely microtrichose on dorsal third, greatly expanded on segments 3-5. Bursa small, with a small and distal ventral receptacle, spermathecal ducts similar in length and width, arising separately from apex of bursa. Single spermatheca elongate, but not distinctly thickened; paired spermathecae bent, widened and pipe-shaped.

\section{Remarks}

Mesoconius ruficrus sp. nov. is similar to the sympatric M. quadritheca sp. nov. and to the Bolivian species $M$. nigra sp. nov. These species share the limited constriction at the abdominal base, but $M$. ruficrus sp. nov. has red legs, in marked contrast to the black legs of the other two species. An apparent undescribed fourth species in this group, characterized by basally red and distally black femora, a bicoloured pleuron (black dorsally and pale ventrally) and broad black wings is known only from a photograph of a female (Fig. 49F), taken at the same time and place where the holotype of M. ruficrus sp. nov. was collected.

Mesoconius rufiventris (Enderlein, 1922) comb. nov.

Fig. 40F

Tanypoda rufiventris Enderlein, 1922: 204.

Aristobata rufiventris - Hennig 1935: 32.

Zelatractodes rufiventris - Steyskal 1968: 20.

\section{Material examined}

\section{Holotype}

COLOMBIA • + ; v. Nolcken leg.; MNBG.

The collector was presumably J.H. Wilhelm Baron (von) Nolcken, who collected in the mountains of Colombia in 1870-71. Papavero (1973) provides a summary of Baron von Nolcken's travels in Colombia, naming several collecting localities of which three are recorded as above $1500 \mathrm{~m}$ : Ubaque $(1950 \mathrm{~m})$, Cuequeta $(2200 \mathrm{~m})$ and Hato $(1500 \mathrm{~m})$. Enderlein indicated that the von Nolcken material came from the H. Loew collection.

\section{Diagnosis}

Based on unique female holotype. 
LeNGTH. About $14 \mathrm{~mm}$.

CoLour. Mesothorax and head dark shiny brown, metathorax reddish yellow. Mid and hind femora yellowish, except for pale brown distomedian ring; mid and hind tibiae brown; fore tarsus white, except for tarsomere 1, which is darkened with a dense patch of black ventrobasal setulae. Abdomen yellowishbrown, except for dark oviscape tip.

HEAD. Outer vertical bristle absent, inner vertical bristle strong, postocellar bristles parallel and very close together; fronto-orbital bristles not visible on type. Frontal vitta strongly convex, prominent and cone-like, velvety in contrast to shiny epicephalon and delineated by a silvery margin.

Thorax. Hind femur slightly swollen and setulose on distal half. Wing mostly clear on basal half and otherwise very lightly infuscated, with a circular clear patch just distal to indistinct, but broad discal band.

AвDomen. Abdominal segment 1 petiolate.

\section{Remarks}

The prominent frontal vitta, contrastingly coloured anterior and posterior halves of the body, basal vestiture of the fore tarsus and mostly clear wings combine to render this a recognizable species, although it is only known from the holotype female.

Mesoconius versicolorus (Enderlein, 1922) comb. nov.

Fig. 40G

Tanypoda versicolora Enderlein, 1922: 203.

Aristobata versicolora - Hennig 1935: 32.

Zelatractodes versicolorus - Steyskal 1968: 20.

Material examined

Holotype

COLOMBIA • + ; Moritz leg.; MNBG.

\section{Diagnosis}

Based on unique female holotype.

LENGTH. $14 \mathrm{~mm}$.

CoLour. Head brown to black, fore tarsus white, thorax orange, except for mostly black pronotum and anterior margin of postpronotal lobe, hind femur with a broad white band just beyond middle, mid femur with a narrow white band, mid and hind femora with pale brown apices. Wing of type very dirty, but lightly pigmented and apparently with a weak discal band and a weakly pigmented apex. Abdomen dark, with pale margins.

HEAD. Epicephalon and paracephalon smooth and shiny, with no trace of striae. Frontal vitta parallelsided and depressed behind ocelli, oblong and only slightly raised anteriorly, not reaching anterior margin of frons. Postocellar and inner vertical bristles well developed. Upper fronto-orbital on epicephalon near level of upper ocelli, lower fronto-orbital inserted in microtrichose area below point of overlap between orbital plate and epicephalon. 
THORAX. Scutum inconspicuously microtrichose; acrostichal setulae very small. Cervical sclerite oblong, with a small, depressed orange anterior portion and a larger, subquadrate, dark, microtrichose posterior part. Prosternum microtrichose, but without distinct setulae. Postpronotal lobe shiny, sparsely microtrichose and with a few black setulae along lower margin, anterior surface vertical and shiny along dorsal margin, posterior surface sloped and microtrichose. Dorsocentral bristle thin, subequal in length to scutellum. Scutellum with one pair of discal setulae and one pair of long, golden apical bristles (longer than scutellum). Vertical row of katepisternal bristles golden. Katatergite slightly swollen, without median process, evenly convex and microtrichose. All coxae with an anteroventral tuft of long golden setae.

Abdomen. Abdominal segment 1 petiolate, $\mathrm{T} 1+22.2 \times$ as long as $\mathrm{T} 3$.

\section{Remarks}

I could find no information on the collector (Moritz) and therefore cannot suggest a more precise type locality than "Colombia". The abdomen of the holotype is very shrivelled, but seems to have dark tergites with pale posterior margins. The very prominent frontal vitta, with a strongly convex area bearing the ocelli, is similar to that of M. oblitus, which has a dark thorax and different femoral banding. See also Remarks under M. scurrus.

\section{Discussion}

Mesoconius, as defined here, is one of the most distinctive clades in the Micropezidae and is strongly supported by both molecular and morphological data. Males are easily recognized by the unusual loss of the genital fork, and both sexes usually have a distinctive habitus, with a strongly petiolate abdomen (reduced in one small but well-defined cluster made up of M. ruficrus sp. nov., M. quadritheca sp. nov. and M. nigra sp. nov.).

About half the species in this genus have the distinctively swollen katatergite that was previously used as a defining character of Mesoconius s. str. These former Mesoconius species fall into two well-defined clades, here recognized as the $M$. infestus and $M$. eques species groups. The rest of the genus, loosely equivalent to the former genus Zelatractodes, is here organized into two weakly supported groups (the M. nono and M. oblitus groups) based on the presence or absence of outer vertical bristles. More specimens, especially more male specimens, are needed to clarify the limits and relationships of these groups. Over half of the species in the genus, and nine out of twelve species in the $M$. nono group, remain known only from one sex; 17 South American species of Mesoconius are known only from females.

Sequence data for the barcode region of $\mathrm{CO} 1$ were acquired primarily to test species concepts, but the 45 sequenced specimens clustered more or less congruently with the major lineages previously recognized on the basis of morphology. The M. infestus group, distinctive for a number of conspicuous and unequivocally polarized apomorphic characters of the male genitalia, appears as a single branch on the maximum likelihood tree (Fig. 50), as do all of the members of the M. eques group other than M. suzukii sp. nov. However, M. suzukii sp. nov. is an unusual and highly autapomorphic species lacking the strongly developed katatergite characteristic of the rest of the $M$. eques group. Neither the M. nono group nor the $M$. oblitus group is recovered on the maximum likelihood tree, but the best-defined clade within the M. oblitus group (including M. ruficrus sp. nov., M. quadritheca sp. nov. and M. nigra sp. nov.) is recovered as a single branch. Some of the taxa treated here as single species include allopatric populations reflected in deep splits on the $\mathrm{CO} 1$ tree, for example the Colombian and Venezuelan populations treated as M. oblitus, and the Bolivian, Colombian and Ecuadorian populations of M. infestus. These probably represent complexes of closely related species, but further material is required to sort them out. Until such material is available it is pragmatic to treat such clearly monophyletic clusters under single names. 
The distribution and taxonomic status of the species and species complexes of Mesoconius warrant further study, in part because of the apparent restriction of many species to narrow high elevation ranges. The fragility of the fragmented high elevation habitats of the neotropics is well known and of increasing concern. Climate change has been described as creating an "escalator to extinction" for birds on a Peruvian mountain (Freeman et al. 2018), and species of Mesoconius are conspicuously on that same 'escalator' as their high elevation habitats are presumably shifting higher as temperatures warm, with nowhere further to shift once the mountaintops are reached. Few taxa lend themselves to documentation of high elevation faunal change as well as the large, colourful and narrowly endemic species of Mesoconius.

Several species of Mesoconius were originally described from historically important collecting localities, and some were described simply from "Colombia" or "Venezuela". Many previously described species remain known only from century-old type specimens collected at localities now inaccessible or significantly altered. For example, five of the 12 species of Mesoconius named by Enderlein (1922)

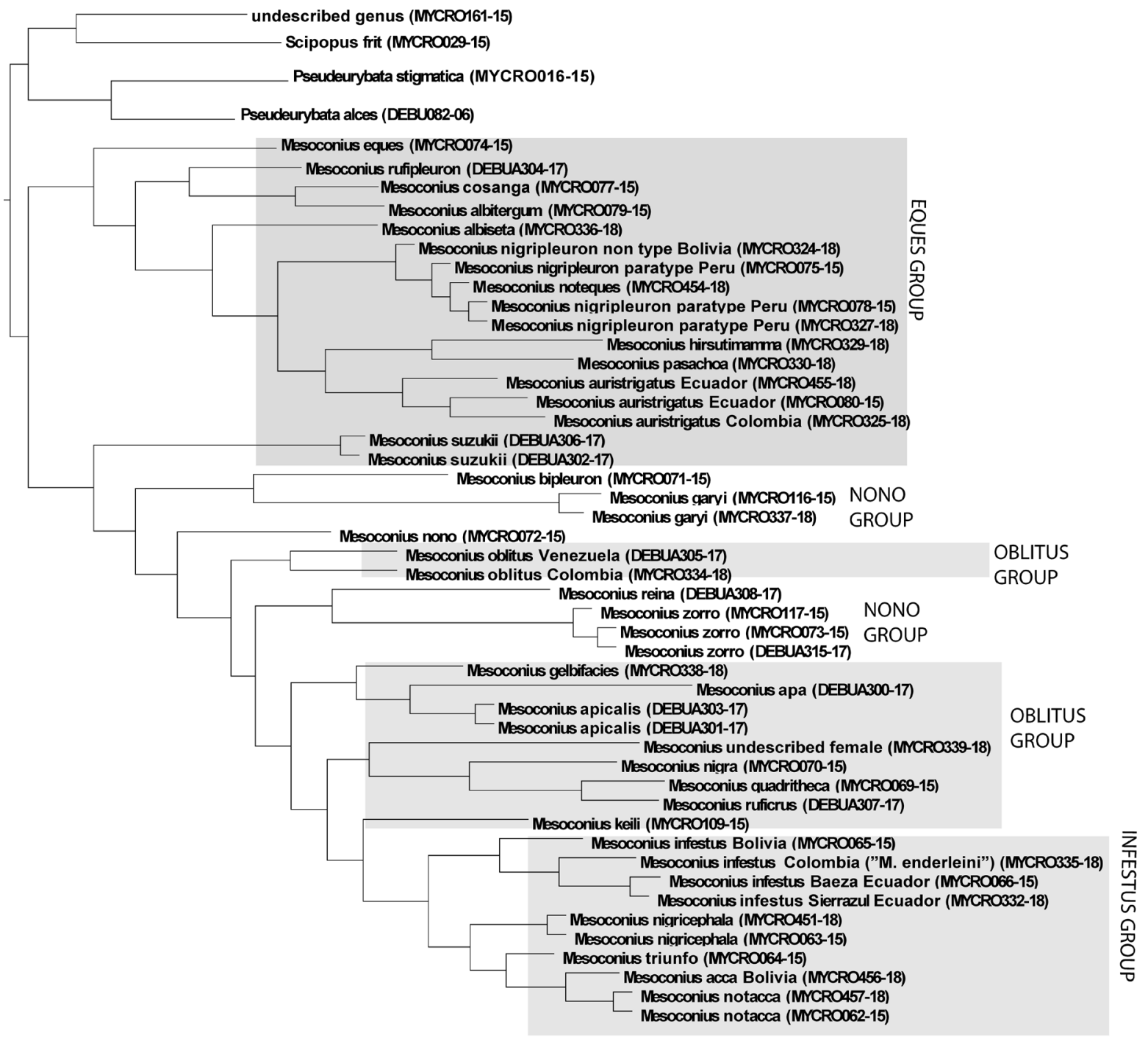

Fig. 50. Maximum likelihood tree from $\mathrm{CO} 1$ barcodes. Sequences were aligned using BOLD (amino acid based HMM) and then manually corrected. Maximum likelihood analysis was performed in RAxML (ver. 8.2) using GTR-G with 100 replicates. 
were described from a single Peruvian locality, "Callanga, im Tale des PiniPini” (Piñipiñi Valley, Cusco Province). All five of these species represent taxonomic problems, and at least two of them remain known only from the types (the others have been tentatively associated with recent material). About a quarter of the specimens used for this study are from only three localities sampled for a few days each in 1999, 2007, 2009 and 2011: Wayqecha Biological Station in Peru and two private 'ecolodges' (Bellavista and SierrAzul) in Ecuador. Most of the remaining material came from other collections by the author or from a Malaise trap survey done by the Humboldt Institute in Colombia in 2000-2001. The inordinate impact of these few collection events on our understanding of this diverse genus underscores the value of a few cloud forest reserves, illustrates the critical importance of specialized collecting and indicates that many more species of Mesoconius remain to be discovered.

\section{Acknowledgments}

In addition to the curators of the collections listed in the materials and methods, I would like to thank the following individuals and organizations for making this work possible. It would have been impossible to gain an understanding of the genus without the rich recent collections from Peru, Ecuador and Bolivia. The Peruvian collections were made possible by access to the incredible habitats of Wayqecha Biological Station. I thank ACCA (Asociación para la Conservación de la Cuenca Amazónica) for hosting me at Wayqecha in 2016, and Allen Norrbom for arranging appropriate permits for our fly collecting during that visit, as well as providing me with specimens from his subsequent trips to Peru. The several Ecuadorian collections were made thanks to help with permits and other arrangements by Giovanni Onore and Clifford Keil at the Pontificia Universidad Católica del Ecuador and facilitated by access to the rich forests of the Bellavista Cloud Forest Reserve. Most of the Bolivian specimens are from a 2001 expedition organized by Stephen Gaimari. The most significant recent collections of Mesoconius other than my own are those from Colombia made available to me by Michael Sharkey and Brian Brown. I thank Mike and Brian for sending this material, and I thank the Humboldt Institute for allowing me to study the Micropezidae from those collections for the decade or so that it took to revise this difficult genus. Amnon Friedberg kindly sent me his collection of Mexican Micropezidae, including the unexpected new species of Mesoconius described herein. Steven Paiero assisted in many ways, Valerie Levesque-Beaudin helped with arranging CO1 sequencing, Michael Balke offered advice on interpreting the sequence data and Ken Stead funded some of the sequencing. Most of this work was supported through the NSERC discovery grant program.

\section{References}

Albuquerque L. 1986. Sistemática dos Taeniapterinae da Região Neotropical. Doctoral Thesis, Universidad Federal do Paraná.

Dupérré N. 2014. Demystifying three species of Ctenidae (Arachnida: Araneae) described by Embrik Strand. Part I, Ecuador. Zootaxa 3784: 67-73. https://doi.org/10.11646/zootaxa.3784.1.3

Eberhard W. 2005. Threading a needle with reinforced thread: intromission in Ceratitis capitata (Diptera, Tephritidae). Canadian Entomologist 137: 174-181. https://doi.org/10.4039/n04-077

Enderlein G. 1922. Klassifikation der Micropeziden. Archiv für Naturgeschichte A 88 (5): 140-229. Available from https://biodiversitylibrary.org/page/45506103 [accessed 23 Jul. 2019].

Freeman B.G., Scholer M.N., Ruiz-Gutierrez V. \& Fitzpatrick J.W. 2018. Climate change causes upslope shifts and mountaintop extirpations in a tropical bird community. Proceedings of the National Academy of Sciences 115 (47): 11982-11987. https://doi.org/10.1073/pnas.1804224115

Frey R. 1927. Zur Systematik der Diptera Haplostomata. III. Fam. Micropezidae. Notulae Entomologicae 7: $65-76$. 
Gade D.W. 1999. Nature and Culture in the Andes. University of Wisconsin Press, Madison, WI.

Hennig W. 1934. Revision der Tyliden (Dipt., Acalypt.). I. Teil: Die Taeniapterinae Amerikas [continued]. Stettiner Entomologische Zeitung 95: 65-108, 294-330.

Hennig W. 1935. Revision der Tyliden (Dipt., Acalypt.). I. Teil: Die Taeniapterinae Amerikas [conclusion]. Stettiner Entomologische Zeitung 96: 27-67.

Horn W. \& Kahle I. 1936. Über entomologische Sammlungen (ein Beitrag zur Geschichte der EntomoMuseologie. Entomologische Beihefte aus Berlin-Dahlem 3: 161-296.

Marshall S.A. 2011. A review of the genus Hoplocheiloma Cresson (Diptera: Micropezidae). Zootaxa 2806: 1-23. https://doi.org/10.11646/zootaxa.2806.1.1

Marshall S.A. 2015. Mesoconius Enderlein (Diptera, Micropezidae, Taeniapterinae) of Central America. Zootaxa 3914 (5): 525-540. https://doi.org/10.11646/zootaxa.3914.5.2

Papavero N. 1973. Essays on the History of Neotropical Dipterology. Volume 2. Museu de Zoologica, Universidade de São Paulo.

Schiner J.R. 1868. Diptera. In: von Wüllerstorf-Urbair B. (ed.) Reise der österreichischen Fregatte Novara um die Erde in den Jahren 1857, 1858, 1859 unter den Befehlen des Commodore B. von Wüllerstorf-Urbair. Zoologischer Theil. Vol. 2. Abt. I. Karl Gerold \& Sons, Vienna. Available from https://biodiversitylibrary.org/page/1221403 [accessed 17 Jul. 2019].

Steyskal G.C. 1968. Family Micropezidae. In: A Catalog of the Diptera of the Americas South of the United States 48: 1-33. Departamento de Zoologia, Secretaria da Agricultura, São Paulo. Available from https://biodiversitylibrary.org/page/50660619 [accessed 17 Jul. 2019].

Woytkowski F. 1974. Peru, My Unpromised Land. Translated in 1978 for the Smithsonian Institution and National Science Foundation. [Original title: Peru, Moja Ziemia Nieobiecana; published by Zaktad Narodowy, Wrocław, Poland.]

Manuscript received: 22 December 2018

Manuscript accepted: 17 June 2019

Published on: 5 September 2019

Topic editor: Rudy Jocqué

Desk editor: Danny Eibye-Jacobsen

Printed versions of all papers are also deposited in the libraries of the institutes that are members of the EJT consortium: Muséum national d'Histoire naturelle, Paris, France; Meise Botanic Garden, Belgium; Royal Museum for Central Africa, Tervuren, Belgium; Royal Belgian Institute of Natural Sciences, Brussels, Belgium; Natural History Museum of Denmark, Copenhagen, Denmark; Naturalis Biodiversity Center, Leiden, the Netherlands; Museo Nacional de Ciencias Naturales-CSIC, Madrid, Spain; Real Jardín Botánico de Madrid CSIC, Spain; Zoological Research Museum Alexander Koenig, Bonn, Germany; National Museum, Prague, Czech Republic. 